\title{
Diaspora mobilisation in a conflict setting
}

Citation for published version (APA):

Ragab, N. J. (2020). Diaspora mobilisation in a conflict setting: The emergence and trajectories of Syrian Diaspora Mobilisation in Germany. [Doctoral Thesis, Maastricht University]. Boekenplan. https://doi.org/10.26481/dis.20200424nr

Document status and date:

Published: 01/01/2020

DOI:

10.26481/dis.20200424nr

Document Version:

Publisher's PDF, also known as Version of record

\section{Please check the document version of this publication:}

- A submitted manuscript is the version of the article upon submission and before peer-review. There can be important differences between the submitted version and the official published version of record.

People interested in the research are advised to contact the author for the final version of the publication, or visit the DOI to the publisher's website.

- The final author version and the galley proof are versions of the publication after peer review.

- The final published version features the final layout of the paper including the volume, issue and page numbers.

Link to publication

\footnotetext{
General rights rights.

- You may freely distribute the URL identifying the publication in the public portal. please follow below link for the End User Agreement:

www.umlib.nl/taverne-license

Take down policy

If you believe that this document breaches copyright please contact us at:

repository@maastrichtuniversity.nl

providing details and we will investigate your claim.
}

Copyright and moral rights for the publications made accessible in the public portal are retained by the authors and/or other copyright owners and it is a condition of accessing publications that users recognise and abide by the legal requirements associated with these

- Users may download and print one copy of any publication from the public portal for the purpose of private study or research.

- You may not further distribute the material or use it for any profit-making activity or commercial gain

If the publication is distributed under the terms of Article $25 \mathrm{fa}$ of the Dutch Copyright Act, indicated by the "Taverne" license above, 
DIASPORA MOBILISATION IN A CONFLICT SETTING:

THE EMERGENCE AND TRAJECTORIES OF SYRIAN DIASPORA MOBILISATION IN GERMANY 
(C) 2020 Nora Jasmin Ragab

ISBN 9789086665075

Publisher: Boekenplan, Maastricht

www.boekenplan.nl

Cover page: Optix Design, Andreas Braun \& Tanja Penner

All rights reserved. No part of this publication may be reproduced, stored in a retrieval system, or transmitted in any form, or by any means, electronic, mechanical, photocopying, recording or otherwise, without the prior permission in writing, from the author. 
DIASPORA MOBILISATION IN A CONFLICT SETTING: THE EMERGENCE AND TRAJECTORIES OF SYRIAN DIASPORA MOBILISATION IN GERMANY

\section{DISSERTATION}

to obtain the degree of Doctor at Maastricht University, on the authority of Rector Magnificus,

Prof. Dr. Rianne Letschert, to be defended in public on

Friday, 24 April 2020, at 10.00 hours

By

Nora Jasmin Ragab 



\section{Supervisors:}

Prof. Dr. Khalid Koser

Prof. Dr. Melissa Siegel

Assessment Committee:

Prof. Dr. Ronald Skeldon (Chair)

Dr. Maria Koinova (Warwick University)

Prof. Dr. Arjen Leerkes

Dr. Ilse van Liempt (Utrecht University) 



\section{Abstract}

The study of the nexus between diasporas and conflict has received rising interest over the last decades, as diaspora groups are increasingly recognised as important agents in the international political arena. Recent research has moved away from an impact-oriented analysis towards the understanding of diaspora mobilisation as a process. Rather an independent variable, diaspora is treated as a dependent variable, allowing researchers to investigate how the process of diaspora mobilisation is influenced by the transnational political opportunity structure, i.e. factors in the destination, origin and transnational context. It is therefore necessary to understand the various configurations in place that shape the nexus between diaspora mobilisation and conflict.

Taking Syrian diaspora mobilisation in Germany as a qualitative case study, this dissertation sheds light on the underlying factors and their intersections that shape the trajectories of the complex process of diaspora mobilisation in conflict settings. The research makes use of inductively developed multi-level analysis to examine the interconnectivity and interaction of different factors at the micro and macro levels and to investigate how these shapes the trajectories of the diaspora mobilisation process (meso-level analysis). As a result, the primary research question guiding the study is: How does the interplay of individual characteristics, group dynamics and the transnational political opportunity structure shape the trajectories of Syrian diaspora mobilisation in Germany?

The central argument of this dissertation is that diaspora mobilisation in conflict settings should be understood as a dynamic process in which structures and diaspora agents co-construct each other. Acknowledging the agency of diaspora actors, the study explores how diaspora political entrepreneurs individually and collectively negotiate the transnational political opportunity structures present in the mobilisation process. While transnational repression historically prevented bottom-up diaspora mobilisation, the Syrian revolution gave birth to a vibrant civil society both at home and abroad that challenged the prevailing authoritarian system. As the conflict escalated, diaspora groups filled the void to support local NGOs inside Syria in the absence of formal institutions of humanitarian assistance. Even though conflict lines were reproduced in the diaspora space, diaspora political entrepreneurs engaged in acts of solidarity and promoted common spaces for empowerment to overcome divides. With increasing displacement to Germany, diaspora actors provided a safe place of community and belonging to those forcibly displaced by the conflict. Hence, diaspora actors showed considerable agency in shaping the transnational political reality, by transforming political spaces both in the contexts of origin and destination. 


\section{Acknowledgements}

The path towards finalising this dissertation has been extremely adventurous, an exciting journey, which has been both tremendously challenging and highly rewarding. A time where I was confronted with many uncertainties, but also with a space to grow on a lot of accomplishment. The completion of this dissertation is thanks in a large part to the precious people, who accompanied me on this way. I am happy for the opportunity to thank them all for their endless patience, encouragement, and support.

I would like to start with thanking my supervisors Prof. Dr. Khalid Koser and Prof. Dr. Melissa Siegel for their valuable support, encouragement, patience and constructive critiques throughout the duration of this PhD project. Melissa, I am extremely grateful that you offered me the opportunity to start my academic path as a team member of the migration group and for your encouragement to embark on this exciting PhD journey. Your profound confidence in me as a researcher from the very beginning, the opportunities to engage in various research projects, as well as your advice and assistance in keeping my progress on schedule, not only encouraged me to believe in my abilities but also enabled me to gain enriching experiences in various contexts. Dear Khalid, thank you very much for allowing me to freely develop my research and for taking the time to supervise my research despite the long distance. Your encouraging feedback and always motivating words, as well as your professional guidance offered me the emotional support much needed during this challenging journey.

I am grateful to the members of the reading committee Prof. Dr. Ronald Skeldon, Dr. Maria Koinova, Prof. Dr. Arjen Leerkes and Dr. Ilse van Liempt, for your valuable, critical and highly constructive comments on the previous draft of this thesis. Your feedback not only allowed me to significantly improve my dissertation, but also motivated me to reflect critically on future research projects. A special thanks to my colleagues and dearest friends Elaine and Eleni for the countless hours we spent discussing my thesis findings and for the endless encouragement along the way. The finalisation of this dissertation would not have been possible without your valuable thoughts, support, guidance and friendship.

This PhD would not exist without all the people who took the time to participated in the interviews of this study. I am grateful for the opportunity to have met you and I am more than thankful that you shared your experience, thoughts, views and knowledge with me on this complex and difficult topic. Your hopes, dreams and tireless engagement were the most valuable sources of inspiration and motivation for my dissertation. 
I would like to extent my gratitude to those, who assisted me during my field work, especially in the process of data collection, the transcription of interviews and other research support. In particular, I would like to thank Laura Rahmeier, not only for the invaluable assistance in transcribing the interviews, but also for sharing with me your thoughts and reflections on the data collected. A special thanks also to Amer Katbeh for your research assistance, valuable feedback and guidance that helped me to contextualise my findings further.

This dissertation makes use of data and insights arising from research commissioned by several external stakeholders, such as Danish Refugee Council, the Centre for International Migration and Development (CIM) and International IDEA. I want to express my gratitude to these actors for not only funding the research on Syrian diaspora mobilisation in Germany, Europe and the region, but also for providing me with opportunities to disseminate the findings of the research at various occasions to a non-scientific audience. Special thanks to Stephanie Deubler, Lina Antara, Mingo Heiduk and Adrien Bori for the valuable feedback on the studies, as well as for the enriching and productive collaboration along the way. I am very much looking forward to our cooperation in the future.

I am glad to be part of the UNU-Merit community and thankful for the inspiring discussions, opportunities for sharing knowledge, as well as the support and guidance of so many colleagues. In particular, I want to thank all the beloved members of the Migration team, especially Ayla, Charlotte, Craig, Elaine, Eleni, Inez, Julia, Jenny, Katharina, Katie, Katrin, Michaela, Mohammad, Nasrat, Ortrun, Soha, Sonja, Talitha, Tamara, Veronika, Zoë and all the others who have been part of this wonderful group over the past years. The guidance and solidarity I received from you was the strongest emotional and intellectual pillar during this journey. I am grateful for the exciting projects we realised together, the adventures during field trips, the inspiring debates and discussions, as well as the many opportunities to learn from all of you. I am very much looking forward to working, learning, and growing with you in the future. Zina, your kind words, inspiring perspectives, and emotional support throughout this process is equally appreciated. I am also happy to be part of the great PhD cohort: Arip, Bruhan, Cho, Davina, Eli, Fernando, Francesca, Hugo, Janyl, Maria, Mario, Nga, Wondi. It was very inspiring and exciting to spend with you the first year of the $\mathrm{PhD}$, with these rich discussions, many learnings and funny nights.

I would like to recognize the valuable assistance and support of the many people of the UNU-merit community, who made this dissertation possible. I very much appreciate the assistance of Susan and Marc, who dealt with the administrative issues always with great patience and flexibility. I would like to thank Herman and 
Mourik Jan for always finding solutions to any technical problem I encountered throughout the research. Robin and Tatiana, thank you very much for your support and guidance, especially during the first year of the $\mathrm{PhD}$ project. A special thanks also to Eveline, not only for your great amount of assistance in dealing with administrative issues, but also for the emotional support you offered during this challenging journey. I am grateful for the advice of Howard and Sueli, which offered me a lot of guidance of how to communicate and disseminate my findings to a broader audience. Sueli, thank you very much for your invaluable assistance at the final stage of my $\mathrm{PhD}$, your feedback, flexibility and encouraging words cannot be underestimated. Ingrid, Ingeborg and Mieke, your assistance with so many things has been greatly appreciated.

I would never have completed this dissertation without the friendship, support and endless encouragement of the many beloved people, who stayed on my side along this journey. I am tremendously fortunate to have so many precious friends in my life, who always showed great patience during this challenging time and were eager to support, motivate and distract me with exciting things. I am extremely grateful to have my friends from childhood, Agata and Helena, who have accompanied me in the best and most challenging times in life. Your friendship means the world to me. Aga, your courage in realising your dreams is a precious inspiration and Helenita, your endless belief in love and the good shows me continuously what counts in life. To all my friends from Cologne, I am happy to have you in my life and very much appreciate the wonderful moments we have spent together, which were the most valuable distractions from my PhD. Esther, I will always remember the endless hours we have spent together, drinking coffee and reflecting on the world and our emotions. Tami, you are not only the best dancing partner but also a supportive friend who always encouraged me to believe in myself. The life during the $\mathrm{PhD}$ would have been extremely boring without the many adventurous trips, funny nights and wonderful encounters with the beloved people from the Kuschelclub, thanks to all of you and especially Aileen, Bobbita, Fabi, Joito, Julian, Kili, L.A., Paul, Tim and Strina. I shared my home with so many beautiful people, to whom I am extremely grateful for the wonderful moments above the roofs of Cologne: Caro, Pennita, Calli, Emiliya, Anni, and Miri, it has been great to live with all of you. Marleeni, my little sister, your lightness and enchanting smile enlighten the world. Anja, not only your emotional support and intellectual guidance but also the rememberable moments we spend together make our friendship so valuable. Papa Gerry, you always filled the house with warmth and love and your perfect breakfast has been highly appreciated.

To my friends from Vienna, I am so grateful that you are part of my life since the beginning of my academic journey. Julia, your warm laugh and optimism makes 
me believe that one can overcome every challenge in life. Lelita, you not only constantly provided me with the best music but also with so much support and enriching discussions. Kristin, your strength and creativity is a great inspiration, and I am so happy for the opportunities to learn from you. A special thanks to my friends from Damascus, Abudhe, Hadi and Yassar, you made me feel at home in this magnificent city. I am grateful for the new and old friends, with whom I start a new adventure in Berlin. Dunja, your perspectives, critical thinking and emotional guidance, not only represents valuable support in life but also enriched my thinking within the process of finalising this dissertation. Hamudi, your critical thoughts, and intellectual support have been a precious inspiration throughout this project, your great sense of humour and energy have eased my life.

I am incredibly fortunate to have such strong women in my life, my aunts Gitti, Momo, Theresia and my cousin Sarah, you not only encouraged, supported and motivated me, but also always have been a great inspiration. Most importantly, to the most precious people in my life, my beloved family, thank you for your endless support and love throughout this entire process. Mamita, thank you so much for teaching me to think critically about the injustices in the world, for your unconditional love and for always believing in me and my capabilities. Issi, without your encouragement I would have never embarked on this journey and I am so grateful that you taught me to aspire exciting challenges in life. Jalili, you are the best brother one could have, thank you so much for believing in me and for celebrating with me every little step of this journey. I dedicate this dissertation to all of you! 


\section{Table of Contents}

ABSTRACT V

ACKNOWLEDGEMENTS VI

LIST OF FIGURES XIV

LIST OF TABLES XIV

LIST OF ACRONYMS XV

CHAPTER 1: INTRODUCTION 1

1.1. Relevance of the study 4

1.2. Research aim and questions 9

1.3. Structure of the study 11

CHAPTER 2: CONCEPTUAL FRAMEWORK: THE PROCESS OF DIASPORA MOBILISATION IN CONFLICT SETTINGS 15

2.1. A note on the conceptualisation of conflicts 17

2.2. Conceptual evolution of the term diaspora: From migration to mobilisation 21

2.2.1. Diasporas as essence and ethno-national groups 22

2.2.2. Diaspora mobilisation as process, project and stance 25

2.3. Meso-level: Three dimensions of the diaspora mobilisation process 27

2.3.1. Construction of diasporic consciousness 27

2.3.2. Organisational framework and mobilising structures 32

2.3.3. Transnational action and practices 34

2.4. Micro-level: Capabilities 40

2.5. Macro-level: Transnational political opportunity structures 42

2.6. Conclusion 50

CHAPTER 3: METHODOLOGY 55

3.1. Case selection 55

3.2. Data collection 56

3.2.1. In-depth interviews 58 
3.2.2. Participant observation 63

3.2.3. Supplementary quantitative data sources 64

3.3. Qualitative data analysis: Thematic analysis 65

3.3.1. Getting familiar with the data 66

3.3.2. The process of coding 67

3.3.3. Categorisation 68

3.3.4. Identification of themes 69

3.4. Practical challenges, opportunities and ethical considerations in doing research in an on-going conflict setting

3.4.1. Practical challenges and opportunities _ 72

3.4.2. Interviews on sensitive topics __ 73

3.4.3. Security risks__ 74

3.4.4. Researchers' responsibility ___ 75

3.5. Reflections on the researcher's positionality _ 76

CHAPTER 4: MAPPING THE ORIGIN COUNTRY CONTEXT___ 79

4.1. The Syrian conflict___ 80

4.1.1. Roots of the conflict _ 80

4.1.2. The Syrian revolution ___ 86

4.1.3. Militarisation and the rise of the armed opposition __ 89

4.1.4. Sectarianisation of the conflict ___ 92

4.1.5. Conclusion - Syria's many questions ___ 95

4.2. Socio-political space of diaspora mobilisation in Syria ___ 97

4.2.1. Socio-political framework of emigration __ 97

4.2.2. Relevant institutions and general diaspora engagement policies __ 99

CHAPTER 5: MAPPING THE DESTINATION COUNTRY CONTEXT___ 103

5.1. Syrian emigration profile _ 104

5.2. Characteristics of Syrian immigrant population in Germany ___ 107

5.3. Socio-political space of diaspora mobilisation in Germany ___ 116

5.3.1. Germany's stance and response to the Syrian conflict ___ 117

5.3.2. Socio-political framework of migration ___ 118

5.3.3. Relevant institutions and general programmes for supporting diaspora groups _ 120

5.3.4. Specific programmes targeting Syrian diaspora groups ___ 121 
CHAPTER 6: FROM REPRESSION TO LIBERATION - THE EMERGENCE OF THE SYRIAN DIASPORA IN GERMANY 125

6.1. The era of Assad - A diaspora silenced 126

6.1.1. Negotiation belonging and dis-belonging 128

6.1.2. Mistrust and fragmented solidarity 131

6.1.3. Transnationalism from above - The co-optation of diasporic mobilising structures

6.2. The Syrian Revolution - Political mobilisation around a new diasporic consciousness

6.2.1. Construction of identity and belonging 135

6.2.2. The emergence of a political consciousness - At home and abroad 137

6.2.3. Transnationalism from below 139

6.3. Conclusion - From transnationalism from above to transnationalism from below 141

\section{CHAPTER 7: DE-CONSTRUCTION AND RE-CONSTRUCTION OF THE} DIASPORIC CONSCIOUSNESS

7.1. From unification to fragmented solidarities 144

7.1.1. Home country influences - The reproduction of conflict dynamics 144

7.1.2. Destination country influences - Quest for resources, power and influence

7.1.3. Searching for a common ground - The desires for unity and solidarity among diaspora actors

7.2. The Process of de-diasporisation - The fall of diaspora structure 154

7.3. Conclusion 158

CHAPTER 8: THE EVOLUTION OF MOBILISING STRUCTURES 161

8.1. Conflict and displacement - Transformation of mobilising structures 162

8.2. A typology of diaspora organisations 167

8.2.1. Humanitarian organisations 168

8.2.2. Revolutionary civil society 171

8.2.3. Integration and cultural associations 174

8.3. Conclusion 176

CHAPTER 9: THE TRANSFORMATION OF DIASPORIC PRACTICES 179

9.1. Conflict escalation and humanitarisation of the diasporic space 180

9.1.1. From activists to aid workers 181 
9.1.2. The humanitarisation of diaspora space - Between reaction and strategic choice 183

9.2. Migrations - The transnationalisation of activism and the re-politicisation of the diasporic space 188

9.2.1. Transnational activism 189

9.2.2. Fostering spaces of civic and political empowerment 193

9.3. Displacement - A Syrian community in the making 197

9.3.1. Fostering the inclusion of newcomers 198

9.3.2. Impossibilities of return, lost homeland and the desire for a stable place of belonging and community 200

9.4. Conclusion 204

CHAPTER 10: CONCLUSION 207

10.1. Summary of the thesis 207

10.2. Contribution to the debate 212

10.3. Policy recommendation 216

10.3.1. Conflict- and context-sensitive approach in engaging with diaspora groups 216

10.3.2. Participatory approach in engaging with diaspora groups 217

10.4. Avenues for future research 218

REFERENCES 221

APPENDIX I: INTERVIEW GUIDE 247

APPENDIX II: TEMPLATE FIELD NOTES 250

APPENDIX III: PARTICIPANT LIST 251

APPENDIX IV: LIST OF SELECTED PARTICIPANT OBSERVATIONS 257 


\section{List of Figures}

Figure 1: Conceptual Framework 17

Figure 2: Diaspora mobilisation process and influencing factors 53

Figure 3: A streamlined codes-to-theory model for qualitative inquiry 66

Figure 4: Thematic map: Transnationalism from above 71

Figure 5: Map of the Syrian Arab Republic 79

Figure 6: Map of the Federal Republic of Germany 103

Figure 7: Syrian citizens in Germany 1970-2018 108

Figure 8: Geographical distribution of Syrian citizens in Germany, December 2018 110

Figure 9: Syrian immigrants in Germany by sex and age group, 2018 111

Figure 10: Age groups of the Syrian population and total population in Germany, 2018112

Figure 11: Educational status of persons with a Syrian migration background, 2018 113

Figure 12: Secondary school qualifications of persons with a Syrian migration background, 2018 113

Figure 13: Labour force categorisation, 2018 114

Figure 14: Income categories, 2018 115

Figure 15: Stock of Syrian diaspora organisations, 1979-June 2019 164

Figure 16: Conceptual framework revised 212

\section{List of Tables}

Table 1: Set of sub questions 11

Table 2: Common features of diasporas 23

Table 3: Extract of Code book 68

Table 4: Top 10 Destination Countries for Syrian Migrants, mid-2019 106

Table 5: Residence Status of Syrian Citizens in Germany, December 2018 109

Table 6: Household characteristics and income situation, 2018 115 


\section{List of Acronyms}

BAMF Bundesamt für Migration und Flüchtlinge

BMI Bundesministeriums des Innern, für Bau und Heimat

BMZ Bundesministerium für wirtschaftliche Zusammenarbeit und Entwicklung

CMI Center for Mediterranean Integration

DSV Deutsch-Syrische Verein zur Förderung der Freiheiten und Menschenrechte

DEMAC Diaspora Emergency Action and Coordination

ERCIC Ethical Review Committee Inner City

FSA Free Syrian Army

GIZ Gesellschaft für Internationale Zusammenarbeit

ICPMPD International Centre for Migration Policy Development

IOM International Organisation for Migration

IRA Irish Republican Army

IS Islamic State

IZA Islamisches Zentrum Aachen

LAC Local Administrative Councils

LCC Local Coordination Committee

LTTE Liberation Tigers of Tamil Eelam

MIT Milli Ishhbarat Teskilati

NC National Coalition for Syrian Revolutionary and Opposition Forces

NCB National Coordination Body for Democratic Change

OCHA United Nations Office for the Coordination of Humanitarian Affairs

PKK Partiya Karkerên Kurdistanê

PLO Palestine Liberation Organisation

PNA Palestinian National Authorities

SNC Syrian National Council

SWN Syrian Women Network

UOSSM Union of Medical Care and Relief Organizations

VDSH Verein Deutsch-Syrischer Hilfsvereine 



\section{Chapter 1: Introduction}

What started in Syria in 2011 as an initial peaceful movement of people demanding freedom, justice and democracy, has escalated into one of the world's most dramatic humanitarian and security crises. At the time of writing, many observers argue that President Assad has effectively won the Syrian war and will most likely remain in power. Yet, resolving the conflicts within the broader Syrian society will be a long-term endeavour, heavily challenged by the fact that the sovereignty of the Syrian government continues to be contested and that the future of Syria's displaced population, which accounts for almost half of the overall population, remains uncertain. Existing studies note that the Syrian uprising encouraged not just a revolutionary movement inside Syria but also externally, within the Syrian diaspora. It sparked collective actions of Syrians residing in diverse geographies to contribute to the transformation in the origin country through political mobilisation, involvement in relief and development (Baeza \& Pinto, 2016; Jörum, 2015; Moss, 2016b; Qayyum, 2011; Ragab, Rahmeier, \& Siegel, 2017; Svoboda \& Pantuliano, 2015; Ulutas, 2011), or the pursue of transitional justice (Stokke \& Wiebelhaus-Brahm, 2019). This research contributes to the literature by providing a deeper understanding of the mechanisms that shaped the trajectories of Syrian diaspora mobilisation in Germany over the course of the Syrian conflict.

Using Syrian diaspora mobilisation in Germany as a case study, this $\mathrm{PhD}$ dissertation aims to shed light on the transnational embeddedness of diaspora mobilisation in conflict-settings. Based on 80 in-depth interviews with Syrian diasporic political entrepreneurs in Germany and participatory observation of selected diaspora activities, this thesis investigates how conflict dynamics in Syria, as well as factors in the destination country, influenced the process of transnational mobilisation of Syrian diaspora groups in Germany. Examining both direct and indirect mechanisms, it analyses how the conflict affected the construction and reconstruction of a diasporic consciousness and shaped diasporic mobilising structures and practices at different points in time. Acknowledging the agency of diaspora actors, the study explores how diaspora political entrepreneurs individually and collectively negotiate the transnational political opportunity structures present in the mobilisation process. The central argument of this dissertation is that diaspora mobilisation should be understood as a process in which structures and diaspora agents co-constitute each other. While political opportunity structures do provide opportunities and constraints in the process of mobilisation, diaspora actors show considerable agency in shaping the transnational political reality, by transforming political spaces both in the contexts of origin and destination. The dissertation, therefore, not only investigates the 
structural conditions of mobilisation, but also sheds light on the diverse contributions of Syrian diaspora actors to the transformation of conflicts in different locations, be they in the country of origin, the places they live in, or within the broader diasporic space.

As such, the dissertation sheds light on both destination and origin country influences and explores in detail the interconnectivities of the transnational social field of Syrian diaspora mobilisation in Germany. Further, the research contributes to an in-depth exploration of the temporal dimension of diaspora mobilisation. Transnational opportunities are seldom fixed and static. Indeed, changes in the structural level of diaspora mobilisation can lead to shifting configurations of power and transform the strategies, spaces and trajectories of diaspora mobilisation (Koinova, 2018). Taking into account the volatility of transnational political opportunities, the dissertation explores show changes in the structural context shape the trajectories of diaspora mobilisation over time.

The findings will show that the initially peaceful uprising that took to the streets in Syria in March 2011 can be perceived as a transformative event that triggered a transnational mobilisation of Syrians in Germany based on a shared diasporic consciousness. While Syria's extra-territorial reach of state power historically prevented any form of political mobilisation in the Syrian diaspora space, the protest movement in Syria broke down the walls of fear and inspired those Syrians abroad, who harboured historical grievances against the regime, to engage in diverse means of collective action. As such a transnational imagined community was constructed, which not only transcended the physical borders of the nation, but was also able to manifest itself based on the dichotomy of 'us' and 'them', 'us' the people and 'them' the members of the Assad regime, giving salience of the Syrian collective identity abroad.

However, many Syrians abroad perceived the revolution in 2011 as a short-lived unifying event. As the conflict escalated, opposing imaginations of the transnational community evolved. Given the relational and interactive process of collective identity formation and consciousness-building, this dissertation seeks to provide a detailed investigation of the re-construction and de-construction processes of the Syrian diaspora consciousness. The findings show how different diaspora actors struggle not only over the definition of a transnational imagined community but also over the representation and legitimation of their voices. The dissertation argues that the socio-political dynamics present in the diaspora mobilisation process are a result of influences from both the origin and destination country contexts. As such, it contributes to the field of diaspora studies, as it explores these dynamics and interactions of diaspora consciousness-building and collective identity formation and their embeddedness in the structural context. 
Given that the diaspora consciousness is not objectively created but a result of boundary work and consciousness-raising by diaspora political entrepreneurs, the dissertation seeks to analyse the evolution of diasporic mobilising structures and the actors engaging in the construction of the imagined community. The findings of this case study indicate that many organisations were established in Germany in response to the needs arising from the Syrian conflict, either to originally support the non-violent movement inside Syria, to alleviate suffering through humanitarian aid as the conflict escalated, or to support Syrians newly arrived in Germany. The dissertation further argues that diaspora structures and the set of actors should not be perceived as fixed and static, but rather as highly dynamic and continuously changing. The findings highlight how the changes of diasporic mobilising structures were not only a result of the more contextual dynamics, but also of displacement of Syrians to Germany. So far, limited attention has been paid to how forced displacement may influence the process of diaspora mobilisation, since most of the research effort has focused on the actors who were already established in the country of destination and their relation to actors engaging in the conflict in the country of origin. The findings of this dissertation show that with the displacement of people, political ideas, projects and initiatives also travel with them, leading to a diversification of mobilising structures.

Despite the growing recognition of the transnational approach, most studies found in the diaspora literature limit their analysis to transnational practices and actions directed towards the homeland. This perspective, however, neglects the fact that diaspora actors can and often do influence political processes both in the country of origin and the country of destination. The dissertation addresses this gap, by shedding light on the various transnational practices of Syrian diaspora actors and how these have contributed to political and societal transformations in Germany and Syria. By doing this, it also emphasises the circularity of political remittances and argues that further research needs to move beyond a uni-directional investigation of transnational transfers. The analysis of the temporal dimension of transnational practices further suggests that changes in the transnational political opportunities may not only change the type of diasporic actions, but also the contextual focus and channels of collective action. In the case of the Syrian diaspora in Germany, as avenues for direct influence on Syria became more restrictive, diaspora political entrepreneurs capitalised on the opportunities of expression and protest in Germany to indirectly influence decision-making towards their cause, or shifted the focus of actions towards influencing the situation in their country of settlement. 


\subsection{Relevance of the study}

The last decades witnessed an increased interest in studying the nexus between diasporas and conflict. While there seems no doubt that "diasporas have increasingly become significant players in the international political arena" (Vertovec, 2005, p. 1) there has been an ongoing debate on the nature and impact of diaspora mobilisation in conflict-settings. Initially, the debate focused on the question whether diasporas could be perceived as peace-wreckers, who exacerbate the dynamics of conflict, or as peace-makers, who contribute to reconciliation and development in the country of origin. When this question was answered, after evidence arose that diaspora mobilisation can have both constructive and destructive consequences on the homeland conflict, the research agenda shifted towards better understanding the dynamics of mobilisation, focusing mainly on finding explanations why diasporas mobilise in violent or moderate ways. Moreover, research increasingly sought to explore and unpack the diverse range of mechanisms to explore how the diaspora is mobilised.

Discussions on the transnational mobilisation of conflict-generated diaspora initially focused on the impact of diaspora mobilisation on conflict dynamics in the origin country. At an early stage, the debates mainly highlighted the negative impact of such engagement, as it was perceived to fuel the conflict through different channels. As long-distance nationalists, it was argued, diaspora groups tend to exacerbate dynamics of conflict, through the provision of financial and political support to different parties involved in conflicts. Emphasising the negative potentials of political involvement, scholars argue that diasporas seek to actively support ethnicist, nationalistic and exclusionary movements from abroad, which are often perceived as more radical than those remaining in the country of origin (Anderson, 1998; Wayland, 2004). What Anderson (1992) calls "longdistance nationalism" often remains without any consequence, for those engaged from a safe distance:

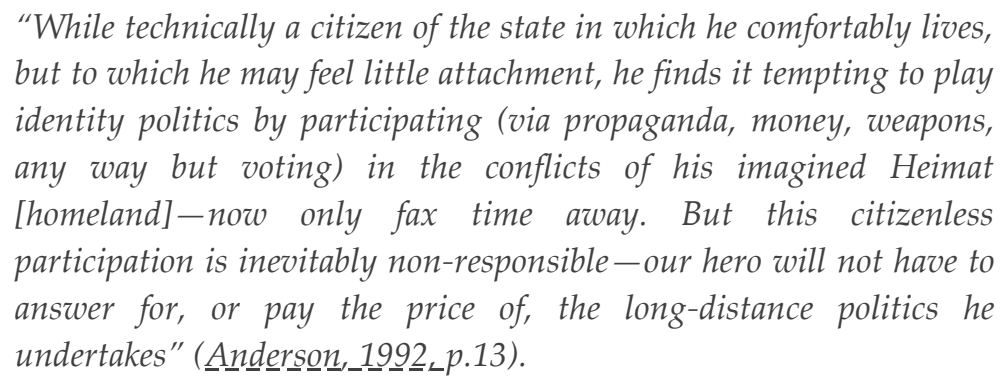

In particular, a study by the World Bank launched a wide-ranging debate over the economic impacts of diaspora mobilisation in conflict settings. By using an 
econometric model, Collier and Hoeffler (2004) concluded that "countries with a large diaspora abroad experience higher conflict risks" (p. 17). According to this study, the risk of renewed conflict is approximately six times higher for the country with the largest diaspora compared to the country with the smallest one. The study argues that diasporas are often powerful actors, who provide financial and political support to parties involved in conflicts. In this regard, an often-cited example relates to the financial contributions by Tamil diaspora groups to support the warfare of the Liberation Tigers of Tamil Eelam (LTTE). The LTTE established a global network of offices that collected voluntary as well as forced financial contributions, with estimates indicating that contributions from the diasporas reached US\$60 million per annum, representing 90 per cent of LTTE's military procurement budget (Fair, 2007). Not just the Tamil Tigers but also the Kurdistan Workers Party (Partiya Karkerên Kurdistanê, PPK), the Irish Republican Army (IRA) as well as Palestinian movements are well-cited examples of successful fundraising in the diaspora (Byman et al., 2001).

At the same time, there was increasing recognition of the peace-building potential of diasporic action and of the constructive role diaspora groups can play through their contributions to peace, stability and development (Bercovitch, 2007; Cochrane et al., 2009; Lyons, 2004; Orjuela, 2008). Diaspora groups may engage in nonviolent action, mobilise for conflict resolution, and promote cross-ethnic dialogue (Orjuela, 2008). Financial contributions of diaspora groups are not necessarily exclusively channelled towards radical fractions of a conflict, but can indeed also provide financial resources for moderate, pro-peace political parties and civil society movements (Bush, 2008). Especially in times of active conflict, where conventional sources of income are not available, individual and collective remittances can enhance the resilience of households in conflict-affected settings by providing support for basic subsistence needs, including food, clothing, and shelter. For instance, a study analysing the effect of remittance on fragile states conducted by Lum et al. (2013) revealed that larger, more geographically concentrated diasporas located in high-income, democratic destination countries have a stabilising effect on fragile origin country communities. A study of Zunzer (2004) revealed that in the case of Sri Lanka the largest share of remittances is sent to families in the poorest region, which represent the most socially disadvantaged group in the country. Next to remittances, diaspora investment in local economies, which is often perceived as being counter-cyclical, might help to generate employment and provide greater economic stability in conflict-affected countries (Nielsen \& Riddle, 2010). Moreover, diaspora groups can also promote alternative and progressive discourses that may evolve in conflicting societies. Hence, political practices of diaspora groups do not have to be destructive in nature, but may also include long-distance voting, membership in political parties, or other forms of 
non-violent resistance such as demonstrations, protests and political campaigns (Østergaard-Nielsen, 2003b).

The contradictory findings of the conflict and diaspora literature sparked the debate whether diasporas act as 'peace-makers or peace-wreckers' in origin countries' conflicts. The book edited by Smith and Stares can be considered as an influential contribution to this topic. Applying a conflict cycle framework (Bercovitch, 2007) and researching the Armenian, Cambodian, Croatian, Jewish, Palestinian and Tamil diaspora cases, the volume edited by Smith and Stares (2007) concludes that:

"diasporas play varied roles in conflict; and different groups and
individuals within the same diaspora may have different approaches,
organisations, interests and objectives within the same conflict. Even
where a diaspora is more united on objectives, it may play a positive
role in peace-making but also may play a negative role in terms of a
contribution to continued conflict" (p.9).

Hence, by now, it is well established that research needs to move beyond the dichotomy of diasporas being either peace-wreckers or peace-makers, by analysing the diverse roles played by diaspora groups in conflicts and the factors shaping transnational mobilisation and collective action. As a result, the research agenda shifted towards providing explanations why diaspora groups mobilise in certain ways to better understand the conditions which favour more radical or more moderate mobilisation.

Using a structuralist approach, Brinkerhoff's (2008) identity mobilisation framework mainly focuses on the drivers of the mobilisation process as well as on the factors that influence its direction (destructive or constructive). While destructive contributions of diasporas refer to violence and criminal acts, constructive actions include the use of non-violence and other activities in consistency with liberal values of human rights. Brinkerhoff argues that the direction of mobilisation is linked to the migrant's identity construction strategy to find a stable place of belonging, which can either by homeland orientated, host country orientated or hybrid. Social marginality or isolation of diaspora groups in the host country runs the risk to promote destructive contributions. By analysing migrant mobilisation in Switzerland and France, Giugni and Passy (2004) argue that differences in the political opportunity structure in the host country influence the strategies, forms and content of mobilisation. If diaspora mobilisation is repressed and confronted with a lack of access to political institution in the destination country, a radicalisation of the movement tends to be more likely. With greater access to the national public space in the destination country, migrants are 
more likely to mobilise around integration related issues, whereas if this space is narrow, they tend to pursue more homeland orientated goals.

Aside from the destination country context, developments and factors in the origin country have been shown to influence the nature of diaspora mobilisation. For instance, comparing diaspora mobilisation of Albanian diaspora groups in the US and the United Kingdom, Koinova (2012b) found that the degree of radicalism was linked to conflict dynamics in the origin country context, with high levels of violence leading to a more radical response of diaspora political entrepreneurs. This effect was further influenced by the links of the Albanian diaspora groups to the secessionist elite in the homeland, and the perceived importance of the respective diaspora group in the sovereignty struggle. In the case of United Statesbased diaspora actors, who were closely linked to the homeland secessionist elite, mobilisation became much more radical once the conflict escalated, when compared to United Kingdom-based actors where this relationship was rather weak.

As such, the nature of diaspora mobilisation (moderate or radical) is influenced by both the political opportunity structure in the destination and origin country context. However, labelling different diaspora groups as either peace-makers or peace-wreckers, or moderate and radical tends to mask the complex realities that exist in a conflict and often carries a normative judgement on the different parties involved. Further, such a judgement relies on several assumptions: 1) that diaspora groups are able to completely control how their contributions are used in the context of origin, 2) that there are no unintended consequences of a actions, and 3) that there is only one (linear) pathway to peace. Many assessments of diasporas as "peace makers or breakers" review the actions, practices and transfers from the sending side in the context of destination without assessing how those contributions are actually play out in the context of origin. In addition, peace can be achieved through different means, both violent and non-violent. It would be difficult to determine if diasporic actions that can accelerate conflict (e.g., the purchase of arms) would actually lead to further violence, would facilitate selfdefence, or would accelerate the pace of conflict and bring earlier stability. Smith (2007) reflects on the findings of Skrbiš analysis of Croatian diaspora mobilisation during times of conflict as follows:

"For outside observers therefore, the Croatian diaspora could have
been seen as a peace-wrecker, because of its fundraising for illegal
arms shipments. For the diaspora, such fundraising meant support for
a final peace, which was 'achievable only through military victory'; it 
was 'interested in victory that would bring peace rather than in peace perse" (p. 12).

Recent research on the diaspora conflict nexus moved away from an impactoriented analysis towards dealing with diaspora mobilisation as a process. Rather than treating diasporas as the independent variable, they are approached as the dependent variable, through which diaspora mobilisation is seen as a consequence

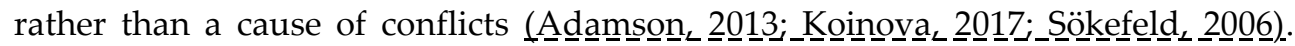
These studies suggest that the process of diaspora mobilisation is influenced by the transnational political opportunity structure which is comprised of factors in the destination, origin and transnational context. These can either provide constraints or opportunities for the mobilisation (Chaudhary \& Moss, 2019; Koinova, 2014a; Smith \& Stares, 2007; Sökefeld, 2006). With a few exceptions (Giugni \& Passy, 2004; Hess \& Korf, 2014; Koopmans, 2004; Baser, 2017; Koinova, 2014b, 2016), the question as to how political opportunities of both contexts interplay and intersect and how these shape the positionality of diaspora actors has been relatively unexplored. This dissertation addresses this gap in the literature by exploring how the conflict dynamics inside Syria, as well as contextual factors present in Germany, influence the process of Syrian diaspora mobilisation simultaneously, and how the diaspora actors negotiate arising opportunities and constraints at the individual and collective level.

In addition, existing research has put the emphasis on the mobilising structures, the organisations and transnational networks through which a diaspora consciousness is mobilised (Adamson, 2013; Sökefeld, 2006; Wayland, 2004). These structures and agents are seldom homogeneous or unified but characterised by a heterogeneous set of actors with diverse and sometimes conflicting interests and aspirations and institutions. Intersecting factors such as class, professional, ethnic, generational or gendered hierarchies may further shape the socio-political dynamic of diaspora mobilisation such as fragmentation, power relations and competition (Baser, 2014; Koinova, 2011; Smith \& Stares, 2007; Van Hear \& Cohen, 2017; Walton, 2014).

It is acknowledged that both conflicts and diaspora mobilisation are not static but dynamic social processes, which are embedded in broader systems and open to external influences (Féron \& Lefort, 2019; Mavroudi, 2007). This calls for an analysis that takes both the contextual and the temporal dimension into account. As such, Kleist (2008) calls for perceiving diasporas as 'becoming' rather than 'being'. However, the temporal dimension of diaspora mobilisation has so far been less explored. Most of the existing research focuses on how conflict dynamics (conflict emergence, continuation, escalation, termination and post-conflict reconstruction) in the homeland shape the transnational practices of diasporas over 
time (Bercovitch, 2007; Koinova, 2012b). Other studies look at the continuity of diaspora mobilisation, by analysing the factors that may sustain or disrupt diaspora mobilisation over time (Koinova, 2016; Van Hear \& Cohen, 2017), or how critical junctures or transformative events can lead to shifting configurations of power and transform the strategies, spaces and trajectories of diaspora mobilisation (Koinova, 2018). To address this gap, this dissertation puts the focus on the temporal dimension of diaspora mobilisation by exploring the trajectories of Syrian diaspora mobilisation over the course of the conflict.

Finally, the transnational perspective, which argues that migrants tend to be embedded in multiple societies at once, puts emphasis on the hybrid and multisited nature of diaspora mobilisation. Migrants, hence, may not only engage in activities related to their homeland but also pursue political and civic participation in the destination context (Horst, 2018; Koopmans, 2004). So far research has relatively unexplored how civic and political participation in host and home country happens simultaneously and how political opportunities of both contexts interplay and intersect and influence the trajectories of such engagement. This dissertation adds to the field in that it explores the diverse range of contributions and actions made by Syrian diaspora actors and how these influences both political processes in the country of destination and the country of origin. In line with Féron and Lefort (2019) it is argued that 'diasporas and conflicts can literally co-construct each other' (p.46), and it is therefore necessary to understand the various configurations in place that shape the nexus between diaspora mobilisation and conflicts both in the origin and destination countries.

\subsection{Research aim and questions}

The main aim of this study is to investigate the processes and mechanisms behind the emergence and trajectories of Syrian diaspora mobilisation in Germany over the course of the Syrian conflict. The research makes use of multi-level analysis to examine the interconnectivity and interaction of different factors at the micro and macro level and how these shape the trajectories of the diaspora mobilisation process (meso-level). Acknowledging the agency of diaspora actors, the study puts emphasis on the process of how diasporas actively negotiate the transnational political opportunity structures at an individual and collective level. Given the above identified lack of research, this study seeks to contribute to the ongoing debate on diaspora mobilisation in three distinct ways.

If the emergence of diasporas is not only a result of migration or boundarycrossing processes, but instead a product of mobilisation through which a transnational imagined community is constructed based on a shared diasporic 
consciousness, it is therefore crucial to explore not only the conditions under which diaspora mobilisation is triggered and unfolds, but also the process of how the collective imagination of the transnational community is discursively constructed. In addition, given that diaspora mobilisation is a dynamic process, in which imaginations of the transnational community, actors and organisational structures, as well as actions and practices change over time, it is crucial to unpack the diverse mechanisms that shape the pathways and trajectories of mobilisation. Hence, by analysing Syrian diaspora mobilisation over the course of the conflict, this study seeks to contribute to the gap in research, as it sheds light on the temporal dimensions of the mobilisation process. As such, it not only looks how Syrian diaspora groups mobilised in a specific juncture but investigates the underlying mechanism and processes in place that shape the diaspora consciousness, mobilising structures and practices over time.

Second, through an in-depth investigation of the macro level of mobilisation, which takes into account changing factors both in the context of destination as well as in the context of origin, the aim is to provide a deeper understanding of the dynamics and intersection of transnational political opportunity structures. Herein, the focus lies on the relational space, in which sending and receiving country dynamics intersect and mutually affect each other, as well as on the strategic choices made by diaspora political entrepreneurs in response to it.

Finally, by analysing Syrian diaspora civil society contributions directed towards both the home and the host countries, the research sheds light on the embeddedness and interconnections of diaspora politics, how sending and receiving country dynamics may intersect and mutually affect each other and how mobility transforms political spaces in several places.

The main question addressed in this research project is:

How does the interplay of individual characteristics, group dynamics and the transnational political opportunity structure shape the trajectories of Syrian diaspora mobilisation in Germany?

In order to answer the overarching research question, the following set of subquestions has been developed: 
Table 1: Set of sub questions

\begin{tabular}{|l|l|}
\hline Dimension & Research questions \\
\hline Emergence & $\begin{array}{l}\text { Which events and developments triggered Syrian transnational } \\
\text { mobilisation based on a shared diasporic consciousness? }\end{array}$ \\
\hline $\begin{array}{l}\text { Diaspora } \\
\text { consciousness }\end{array}$ & $\begin{array}{l}\text { How is the transnational community discursively constructed } \\
\text { and imagined? What are sites of contestations and resistance? } \\
\text { Are there competing imaginations of community proposed? } \\
\text { How did these change over time? } \\
\text { What are the factors that influence a change in the collective } \\
\text { consciousness? }\end{array}$ \\
\hline $\begin{array}{l}\text { Mobilising } \\
\text { structures }\end{array}$ & $\begin{array}{l}\text { What are the different networks, institutions or organisations } \\
\text { that engage in the discursive construction of community and } \\
\text { how do they change over time? } \\
\text { What is their degree of institutionalisation, professionalisation } \\
\text { and formalisation and how has this change over time? } \\
\text { Which factors influenced the trajectories of mobilising } \\
\text { structures? }\end{array}$ \\
\hline $\begin{array}{l}\text { Transnational } \\
\text { practices }\end{array}$ & $\begin{array}{l}\text { What forms of engagement and practices do different groups of } \\
\text { the Syrian diaspora pursue? } \\
\text { How did these change over time? } \\
\text { What are the factors that influence the trajectories of } \\
\text { transnational practices? }\end{array}$ \\
\hline
\end{tabular}

\subsection{Structure of the study}

Chapter 2 presents the analytical framework developed and used to analyse diaspora mobilisation in conflict settings. Given that the nexus of diaspora and conflict depends in part on how key concepts - diaspora and conflict - are understood and operationalised, the first two sections seek to position the research epistemologically, by exploring some conceptual considerations of the terms conflict and diaspora, respectively. Further, the third section outlines the main aspects of the meso process of diaspora mobilisation which can be structured along three dimensions: 
1) discourse of collective identity, which forms the basis for mobilisation based on a shared imagined community,

2) organisational framework and structures, through which the community is constructed and mobilised, and

3) actions and practices through which diaspora groups seek to pursue the achievement of collective goals.

These three dimensions are shaped not only by the transnational opportunity structures at macro level, but also by the individual capabilities, aspirations and desires of those actors, who engage in the construction and mobilisation of the community. The fourth section explores the process of how conflict might lead to the emergence of diaspora mobilisation, by focusing on the micro realm of identity constructions, and the process and politics of belonging through which collective identities become politicised in conflict settings. The last section links the micro realm of interpretations, negotiation of meanings and construction of identities to the macro sphere of contexts, by highlighting the transnational structural embeddedness of human experiences.

Chapter 3 provides an overview of the methodology used in this study, by outlining the case selection, data collection tools and the analytical strategies and method used. The chapter further discusses some practical and ethical considerations and provides some reflections on the researcher's positionality within the fieldwork process.

Given that the process of diaspora mobilisation is shaped by the transnational opportunity structures, the contextual factors of both origin and destination countries, Chapters 4 and 5 are dedicated to the mapping of the origin and destination country contexts, respectively, in order to embed the analysis into the historical and contemporary structures and systems. Chapter 4 discusses the roots and trajectories of the Syrian conflict as well as the state-diaspora relations, by analysing the different contextual factors shaping the process of mobilisation, such as the relevant legal frameworks, the diaspora engagement institutions and strategies, as well as the government discourse towards emigrants. Focusing on the destination country context, Chapter 5 provides a short overview of emigration trends from Syria more generally, before turning to a description of the characteristics of the Syrian immigrant population in Germany. It also explores the socio-political space of diaspora mobilisation in Germany, by taking into account the institutional and discursive dimension of citizenship and incorporation regimes, relevant actors, institutions and policies targeting diasporas, as well as 
programmes and policy that specifically target Syrian diaspora groups in Germany.

Chapter 6, 7, 8 and 9 are devoted to the empirical analysis of this thesis. Chapter 6 explores the events and developments that triggered Syrian transnational mobilisation in Germany based on a shared diasporic consciousness. By focusing on the historical origin of state-diaspora relations, the first section discusses how the Syrian government exercised its control beyond the borders of its territorial jurisdiction through long-distance instruments and policies that repressed any form of transnational political mobilisation of Syrian diaspora groups in Germany prior to the conflict. The second section sheds light on the emergence of Syrian bottom-up diaspora mobilisation in Germany, arguing that the initially peaceful Uprising that took to the streets in Syria in March 2011 can be perceived as a transformative event that triggered collective action of Syrians in Germany based on a shared diasporic consciousness.

After exploring how Syrian diaspora mobilisation was triggered, Chapter 7, Chapter 8 and Chapter 9 seek to examine the evolution and trajectories of diaspora mobilisation. Each of the chapters is dedicated to one of the three dimensions of diaspora mobilisation elaborated in Chapter 2. By examining both direct and indirect mechanisms, the chapters analyse how both political opportunities in the destination and origin country context influence the construction and reconstruction of a diasporic consciousness (Chapter 8) and shape diasporic mobilising structures (Chapter 7) and transnational practices (Chapter 9). In each chapter, an emphasis is also put on the individual and collective process of negotiation to explore how diaspora actors enact their agency in response to the structural constraints and opportunities at different stages of the diaspora mobilisation process.

Chapter 10 presents the conclusion of this study. The chapter summarises the main findings of thesis and the contributions made to the conceptual framework developed in Chapter 2. It then explores the policy implications of the findings and develops recommendations for action characterised by a context-specific and conflict-sensitive approach for involving diaspora actors in policy and decisionmaking processes. Finally, the chapter identifies avenues for further research on Syrian diaspora mobilisation, as well as on the nexus of diaspora mobilisation and conflict in general. 



\section{Chapter 2: Conceptual Framework: The Process of Diaspora Mobilisation in Conflict Settings}

Diaspora mobilisation in conflicts is a multi-causal phenomenon in which causeand-effect relationships are particularly complex, multidimensional and interlinked. On the one hand, critical social and political developments, such as revolutionary or secessionist struggles and other forms of violent conflicts, are often transformative events that shape and influence diaspora consciousness and mobilise members to take action. On the other side, through their transnational practices, diasporas may shape the nature of conflicts in the country of origin, contribute to its exacerbation or promote initiatives for non-violent actions, peacebuilding and reconciliation (Hammond et al., 2011; Hess \& Korf, 2014; Koinova, 2011; Skrbis, 2007). The nexus of diaspora and conflict depends in part on how the key concepts - diaspora and conflict - are understood and operationalised. The first section of this chapter briefly reflects on the conceptualisation of conflict, by focusing on some selected aspects identified as being essential for the understanding of diaspora mobilisation from a more social constructionist perspective. The second section seeks to outline the conceptual evolution of the term diaspora and discusses the prevalent contestations around the different definitions used as well as their core elements.

The central argument of this dissertation is that diaspora mobilisation should be understood as a dynamic process in which structures and diaspora agents coconstitute each other. While structures do provide opportunities and constraints in the process of mobilisation, diaspora actors show considerable agency in shaping the transnational political reality, by individually and collectively negotiating the transnational political opportunity structures present in the mobilisation process. The dissertation, therefore, not only puts emphasis on the structural conditions of mobilisation, but also sheds light on the diverse contributions of diaspora actors to the transformation of conflicts in different locations, be they in the country of origin, the places they live in, or within the broader diasporic space.

Hence, after conceptualising the key concepts under study, the next section outlines the main aspects of the meso process of diaspora mobilisation which can be structured along three dimensions:

1) construction of diasporic consciousness which forms the basis for mobilisation based on a shared imagined community,

2) organisational framework and mobilising structures, through which the community is constructed and mobilised, 
3) the transnational actions and practices through which diaspora groups seek to pursue the achievement of collective goals.

These three dimensions are shaped not only by macro-level transnational opportunity structures and positionalities, but also by the individual capabilities, aspirations and desires of those actors, who engage in the construction and mobilisation of the community.

The fourth section explores how conflict might lead to the emergence of diaspora mobilisation, by focusing on the micro-realm of identity constructions, and the process and politics of belonging through which collective identities become politicised in conflict-settings. It outlines, the transnational dimension of identities, and explores the factors and processes that may construct, deconstruct or reconstruct territorial belonging to the origin place. Beside motivation or desire, the individual's capacity influences the way and form of diaspora engagement. This leads to uneven patterns of transnational engagement, since members of diasporas are facing different social, economic and political circumstances and conditions in the destination country that influence the capacity of individuals to get involved. It is therefore crucial to understand how the intersection of class, professional, ethnic and gendered hierarchies reproduces pre-existing power asymmetries.

The last section links the micro-realm of interpretations, negotiation of meanings and construction of identities to the macro -sphere of contexts, by highlighting the role of transnational political opportunities and the transnational structural embeddedness of human experiences. Here the focus lies on the cultural, social, economic and political factors within both the origin and destination country contexts that shape the nature and process of transnational mobilisation of diasporas. Transnational political opportunities consist in more general origin and destination country factors, such as the respective political systems in place (e.g. absence of a central government, authoritarian regime vs democracy) as well as the relative stability of the country (conflict, post-conflict, economic/political crises, natural disasters). On the other hand, migration specific aspects such as the emigration and immigration regimes that guide the legal and institutional framework (citizenship, voting, civil rights of migrants) as well as policies targeting the immigrant or emigrant population are crucial structural and relational factors that influence the space of diaspora mobilisation. Next to government systems and practices, an analysis of opportunities needs to address the symbolic dimension of state practices towards the diaspora and immigrant or emigrant population more in general in order to understand how the diaspora is discursively and symbolically included in the nation and who is included or excluded from the discourse. 
Thus, the empirical analysis draws on inductively developed multi-level analysis to examine the interconnectivity and interaction of different factors at the microand macro- level and how these shape the trajectories of the diaspora mobilisation process at the meso-level. It has to be emphasised that the model relates to the process of Syrian diaspora mobilisation in Germany linked to the Syrian conflict, which cannot necessarily be generalisable for different conflict-generated diasporas.

\section{Figure 1: Conceptual Framework}
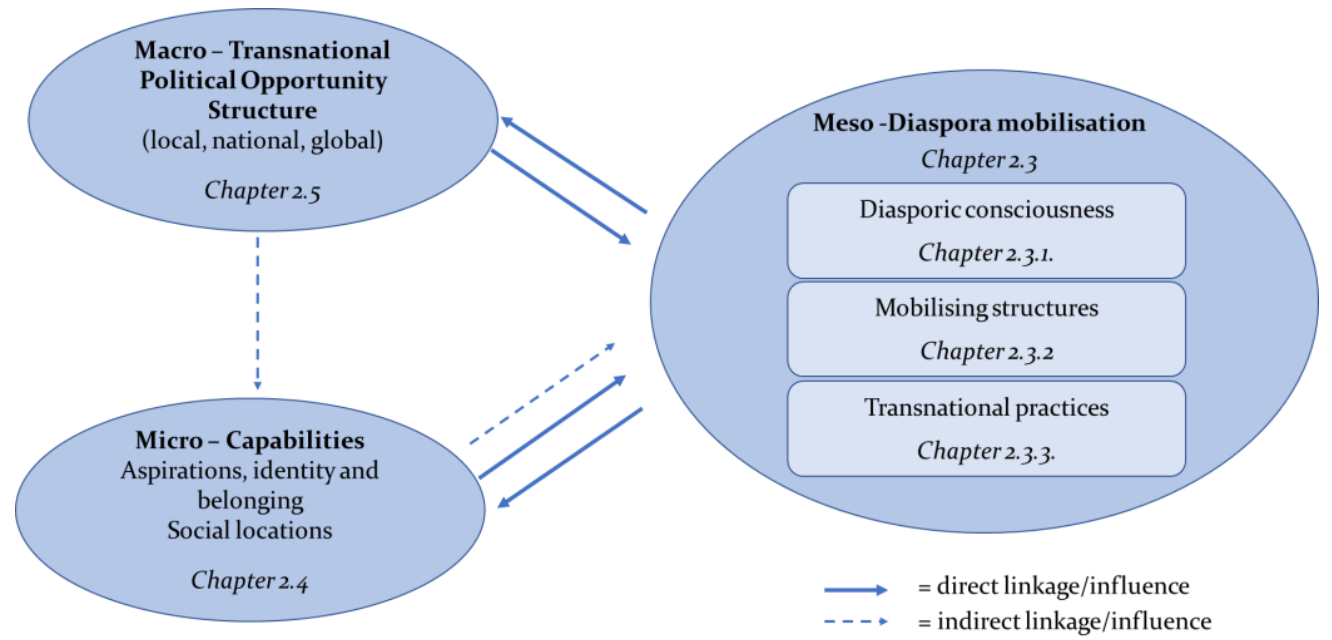

\subsection{A note on the conceptualisation of conflicts}

Given the focus of the dissertation on diaspora mobilisation in conflict-settings, it is essential to better explain how conflict is conceptualised. It would be beyond the scope of this research to discuss the diverse range of definitions and theories explaining the nature, emergence and dynamics of conflicts. Rather the aim is to discuss some selected aspects identified as being essential for the understanding of diaspora mobilisation from a more social constructionist perspective. If conflicts are understood as socially constructed, they only exist because parties involved give them meaning. There is not just one interpretation of reality and its 'truth', and the issues under dispute - who are the adversaries, which party is good and which party is evil - are often heavily contested and involve competing conflict narratives. Conflicts are an integral part of human life and natural elements of societies and therefore should not be understood exclusively as violent or hostile but as the result of an incompatibility between different actors with differing 
interests and positions relating to resources and goals (Kriesberg, 2014). According to Wallensteen (2018) a conflict can be defined as 'a social situation in which a minimum of two actors (parties) strive to acquire at the same moment in time an available set of scarce' (p. 18). Central to most of definitions are three key elements: incompatibilities, actors and actions. The issues under dispute refer not just to incompatibilities related to material resources such as land, money or natural resources, but also to social resources such as power and prestige, or values inherent in religious or political ideologies. In order to manifest themselves, conflicts require actors who try to achieve their goals through a range of actions.

The $20^{\text {th }}$ and $21^{\text {st }}$ centuries are characterised by a rise in intrastate conflicts, with civil wars as the dominant form of organised violence (Pettersson \& Wallensteen, 2015). Contemporary intrastate conflicts or civil wars are often characterised by competition for power and control within territories around religious, ethnic, and cultural identities (Demmers, 2007). From a constructivist perspective to 'ethnic conflict', the explanatory power of identities lies not in an essentialist categorisation of ethnicity, race and nation as given natural groups or entities, but rather on how this essentialisation is used to produce a kind of 'otherness', a powerful tool that helps to mobilise individuals and groups for political power struggles. As Brubaker (2006) argues, rather than treating ethnicity, race and nation as essentialist groups or entities, it might be more fruitful to talk about 'practical categories, cultural idioms, cognitive schemas, discursive frames, organisational routines, institutional forms, political projects and contingent events' (p.38). Similarly, Lake and Rothchild (1998) argue that 'ethnicity is not something that can be decided upon by individuals at will, like other political affiliations, but is embedded within and controlled by the larger society' (p. 6). This also means that conflict analysis should deal with ethnicity as a relational, dynamic, political, social, cultural and psychological process.

Understanding the narrative dimension of conflicts is crucial for conflict transformation, as it helps to investigate the underlying origins of a conflict, the issues under dispute and how these are translated into polarised identity narratives that manifest themselves in intractable conflicts (Funk \& Said, 2004). It is therefore essential to understand the process of identity construction and the politics of narrating belonging and boundaries, within its structural embeddedness and hegemonic forms of power relations. Identities as such do not constitute causes for conflict, but rather provide a basis for its legitimisation, if successfully mobilised. While cultural identities can be resources that leaders draw on for political mobilisation, it is nevertheless important to understand the broader structures of a society, in which violence is rooted (Davis, 2002). 
Socio-economic factors such as inequality in power and wealth distributions, poverty, as well as exclusion and marginalisation are perceived as important drivers of conflicts. According to Relative Deprivation Theory, one of the most influential theories linking grievances to conflict, individuals who feel unjustly deprived of something they desire will experience anger and resentment and seek to improve their situation (Gurr, 2011). Grievance, as a central source of conflict, can be a result of several factors such as political repression, political exclusion, denial of social rights or economic inequality (Kriesberg \& Dayton, 2011). Moreover, research emphasises that perceived injustice is more likely to result in collective action if deprivation is perceived as group based, where inequalities align with cultural, ethnic or religious identities. In particular, multidimensional horizontal inequalities are more likely to lead to violent conflicts. These are present if culturally defined groups experience exclusion and marginalisation in the social, cultural, economic and political realm (Cederman et al., 2013). Yet, it can be also argued that conflicts do not automatically emerge out of social grievances or injustice, but that before grievances can be transformed and expressed, contextual and structural conditions have to be met (Tarrow, 1988).

Scholars therefore highlight the role of political and institutional factors, which refer to the capacity of states and institutions to manage and deal with societal conflicts and the opportunities and constraints faced by political elites to mobilise the mass for their cause. While there is no general agreement on the role of democracy in creating and sustaining peace, Mansfield and Snyder (2007) argue that mature democratic states seem more likely to address conflicts in constructive ways, through democratic inclusion and institutionalised conflict resolution mechanisms. On the other hand, autocracies are often able to repress violence through the use of force and other forms of political oppression. Those countries, which are most prone to the outbreak of violent conflicts, are those in democratic political transitions, due to the breakdown in the legitimacy of political authority. While democratising states provide more space and freedom for political participation and power struggles than autocracies, they often still lack strong political institutions to manage conflicts in constructive ways. In states in democratic transitions, newly emerging political elites may mobilise the mass to challenge the power of the established elite, through the construction of new narratives based on nationalist, ethnic or other popular ideologies. Factors such as uncertainty and collective fears, failure of the social contract, including nepotism, clientelism and corruption, often coming along with social and political transitions can serve as fertile ground for identity politics of elite power struggles.

The concept of grievances as a source of conflict has been highly criticised most prominently by Collier and Hoeffler (2004) in their widely cited study 'Greed and 
grievances in civil wars'. One of their main criticisms is that grievances as such fail to predict the outbreak of violent conflicts, as these are much too widespread to explain the limited cases of large-scale violence. Their main argument, which was also put forward by other scholars such as Kalyvas (2003) who focus on microlevel, individualist interpretations of conflict causes, is that greed based on economic interests and opportunities rather than on political ideologies or grievances is the driving force of conflict. Based on the rational choice theory, scholars argue that parties become involved in conflicts, if the economic benefits of their actions exceed the cost of involvement. Nicholson (1992) questions the basic assumption of rationality as this would presume a strategic decision-making process by informed rational actors. This, however, neglects the dynamic and interactive processes taking place over the course of the conflict, in which goals and perceptions are constantly reshaped. Since conflicts, including their emergence and dynamics, are complex, context-specific and multidimensional, he argues that they cannot be explained by one single economic factor alone, but rather result from the interplay of multiple political, socio-economic and cultural factors.

The emergence of conflicts around identities seems more likely if horizontal inequalities become manifested as perceived group-based injustice, and contextual opportunities arise that provide political actors a space for identity mobilisation and other forms of political struggle. In many conflict settings, the analysis is concerned with the violent actors and their ethnicised, sectarian or nationalist narratives of a conflict, whereas potential alternative and progressive discourse, counter-narratives and non-violent resistance that can evolve in conflict societies are often omitted (Chenoweth \& Cunningham, 2013). According to Luckman, Moncrieffe and Harris (2006) identity politics do not necessarily have to be exclusionary or promote violence, but they can also provide a common peaceful narrative, based on inclusion, empowerment, rights and citizenship. As a result, conflicts can be waged by violent means, but also through acts of non-violent struggles, such as protests, non-cooperation, and intervention without the use of physical violence (Sharp, 2012). For instance, one side can address grievances through non-violent struggles, despite the use of harsh coercion by the other, or different approaches, both destructive and constructive, might be chosen among different actors of the same adversary. In other cases, the same actors may use different forms of waging conflict throughout the conflict trajectory, potentially seeing the need to respond to violence with destructive means during times of conflict escalation, while favouring commitment to non-violent means during conflict resolution. It is therefore important to acknowledge that conflicts are waged by heterogeneous groups of actors, and that, despite often powerful politics of othering and boundary maintenance, each advisory side tend to be characterised by diverse understandings of the issues under dispute and the resolution to the 
conflict. In addition, conflict narratives and perceptions of each actor are not stable, but rather change over time, reinforcing the dynamic trajectory of a conflict (Kriesberg, 2014).

Finally, conflicts are not closed and static systems, but rather embedded in broader historical conflict narratives, sometimes part of geopolitical struggles, and open to external influence. Terms like civil, ethnic, or societal conflicts therefore tend to mask the extent to which these conflicts are the results of historical and present colonial and imperial domination and neglect their embeddedness in broader conflicts and narratives. In addition, research emphasises the 'deterritorialisation' and 'transnationalisation' of conflicts due to transnational ethnic, political and economic links that span actors, events and resources beyond national boundaries (Gleditsch, 2007). As argues Adamson (2016):

"Standard categories, such as 'interstate' and 'intrastate', do not
adequately capture the complex security linkages that exist across
seemingly dispersed locations in a world in which we see the blurring
of 'external' and 'internal' security concerns, accompanied by an
ongoing securitization of new spaces and places of public and social
life" (p. 29).

The transnational perspective highlights the importance of actors that span networks over diverse range of countries and increasingly emphasised the role of diasporas in conflict-settings. In that sense, diaspora groups can be perceived as significant transnational sources for financial and political support for different activities that both support and constrain conflict.

\subsection{Conceptual evolution of the term diaspora: From migration to mobilisation}

Nowadays, the term diaspora has become a catchword in academic, political and media debates and serves as a concept in diverse academic disciplines ranging from history, literature, anthropology, cultural studies and sociology to geography, and more recently to international relations and political science. Due to its multidisciplinary usage, the term diaspora is frequently applied as a synonym for immigrant populations, displaced communities, ethnic minorities or transnational social formations (Brubaker, 2005; Dufoix \& Waldinger, 2008; Vertovec, 2007). The stretching of the concept has resulted in competing definitions that pose a challenge to the analytical power of the term. The following sections, therefore, briefly describe the evolution of the concept of diasporas and discusses the current debate around its core elements. 


\subsubsection{Diasporas as essence and ethno-national groups}

Traditionally, the term diaspora was used to describe the dispersal of the Jewish people from Palestine after Babylonian exile. Central to the notion of diaspora was a catastrophic event that led to forcible displacement, traumatized the group as whole and created a central feeling of victimhood (Sheffer, 2006). Gradually, the term was applied to other groups, such as Armenians, Palestinians and Irish due to their similar experience of forced dispersion, creating a collective memory of trauma and suffering, a myth of an ancestral homeland and strong desire for return. Since the 1980s, the concept of diaspora has been further expanded to incorporate other ethnic/national groups that might not have experienced massive forced displacement yet maintained a collective and idealised memory of their homeland. The term, hence, has started to capture diverse collectivities with varying histories ranging from Cubans in the United States, Turks in Germany and Maghrebis in France to Afghans, Tamils, Sikhs and Kurds. To overcome the analytical challenge resulting from the conceptual stretching, attempts have been made to characterise diasporas by creating groups and categories, such as victim, trade and stateless diasporas, as well as by listing common features of diaspora experiences (Cohen, 2008; Safran, 1991; Sheffer, 2006). Cohen, for instance, elaborated nine common features of diasporas which are illustrated in the following table: 


\section{Table 2: Common features of diasporas}

Dispersal from an original homeland, often traumatically, to two or more foreign regions;

alternatively or additionally, the expansion from a homeland in search of work, in pursuit of trade or to further colonial ambitions;

a collective memory and myth about the homeland, including its location, history, suffering and achievements;

an idealization of the real or imagined ancestral home and a collective commitment to its maintenance, restoration, safety and prosperity, even to its creation;

the frequent development of a return movement to the homeland that gains collective approbation even if many in the group are satisfied with only a vicarious relationship or intermittent visits to the homeland;

a strong ethnic group consciousness sustained over a long time and based on a sense of distinctiveness, a common history, the transmission of a common cultural and religious heritage and the belief in a common fate;

a troubled relationship with host societies, suggesting a lack of acceptance or the possibility that another calamity might befall the group;

a sense of empathy and co-responsibility with co-ethnic members in other countries of settlement even where home has become more vestigial; and

the possibility of a distinctive creative, enriching life in host countries with a tolerance for pluralism.

Source: Cohen (2008), p.17

According to Sheffer (2006) the members of diasporas sustain regular or occasional contacts with their country of origin and with individuals of the same ethnonational background residing in other countries. Even though they might decide to settle permanently in the receiving country, members of diaspora are said to maintain a common identity and therefore show solidarity with other members and the so-called homeland. In addition, diasporas organise themselves in the social, cultural, economic, and political spheres and establish transnational networks that connect the diaspora, the receiving country and the country of origin. Today, the concept of diaspora, therefore, refers to different conceptualisations of migrants (forced and/or voluntary) and focuses on their 
relationship to their country of origin, their country of residence and to other members of their ethnic or origin-country groups (Cohen, 2008). In general, definitions all include the following three common features: 1 ) dispersion (implies movement) 2) boundary-maintenance (group identity), and 3) link with homeland (Brubaker, 2005). The following quote captures these dimensions well, since it defines diasporas as:

\section{"formed by the forcible or voluntary dispersion of people to a number of countries. They constitute a diaspora if they continue to evince a common concern for their 'homeland' (sometimes an imagined homeland) and come to share a common fate with their own people, wherever they happen to be" (Cohen \& Kennedy, 2013, p. 39).}

Diasporas are, therefore, described as social formation that maintain a collective national, cultural or religious identity, with a strong, and often idealised, sense of belonging to a real or imagined homeland and a troubled relationship to the host society, often as a result of experiences of discrimination, marginalisation and exclusion (Cohen, 2008).

Within the constructionist turn, the conceptualisation of diasporas, including its core elements of dispersion, homeland, and identity, has become highly criticised, as it treats diasporas as natural entities, implying a homogeneous dispersed population with historically fixed identity, values and practices (Brubaker, 2005; Vertovec, 2005). Scholars reject ideas of migrants' natural rootedness and belonging to places of origin by recognising identities as fluid, hybrid, multidimensional, personalised complex social constructions, which are shaped not just by ethnicity, religion or nationality, but also by other social locations such as gender, social class, generation and lived experiences (Anthias, 1998; Howard, 2000; Weerakkody, 2006). As migration patterns have changed in the context of globalisation and social transformations, there is also differentiation within an immigrant population of the same origin, due to multiple waves and patterns of migration, involving forced migrants to those seeking labour, education and family unification (Vertovec, 2007). As a result, members of diasporas face different social, economic and political circumstances and conditions in the destination country that, along with different trajectories of displacement, shape identities, political orientations and their capacity of engagement (Al-Ali et al., 2001). The traditional conceptualisations of diasporas, therefore, is perceived to fail to move beyond essentialist understandings of culture, identity and belonging. The imposing of a communal identity based on a homogenising narrative, often precludes an investigation of the processes through which this identity may or may not be constructed as well as who is claiming community for what purpose, and it 
disregards differences, divisions and positionalities that cross-cut communal identities.

\subsubsection{Diaspora mobilisation as process, project and stance}

By arguing that diasporas not merely form as a result of migration, but rather emerge through an active process of mobilisation, new conceptualisations are shifting the focus from transnational communities to transnational practices. As Brubaker (2005) emphasises that:

"rather than speak of a diaspora or the diaspora, as an entity, bounded group, an ethnodemographic or ethnocultural fact, it may be more fruitful, and certainly more precise, to speak of diasporic stances, projects, claims, idioms, practices and so on" ( $p .13)$.

This study uses the definition elaborated on by Adamson and Demetriou (2007) who conceptualise diasporas as:

"a social collectivity that exists across state borders and that has
succeeded over time to (1) sustain a collective national, cultural or
religious identity through a sense of internal cohesion and sustained
ties with a real or imagined homeland and (2) display an ability to
address the collective interests of members of the social collectivity
through a developed internal organisational framework and
transnational links"(p.497).

In line with these new conceptualisations within diaspora literature, the dissertation understands the provided definition from a constructionist perspective. In that sense, diasporas are not natural entities resulting simply out of migration, but instead a product of an active process of transnational mobilisation by diaspora political entrepreneurs, who engage in the construction of 'transnational imagined communities' (Adamson, 2012; Sökefeld, 2006). Understanding diaspora mobilisation as a process puts emphasis on the dynamic, multi-layered and heterogeneous nature of the concept. However, diasporas do not act in a political vacuum, rather their motives, strategies and practices are shaped by contextual factors at the structural level. Central to this approach are the questions of how and why people mobilise for certain collective goals and what are the political opportunities and constraints, providing conditions for transnational mobilisation (Adamson, 2008; Sökefeld, 2006). As Lyons and Mandaville (2010) argue, not every migrant who feels connected to the homeland and shares a common identity with others should be considered as part of a diaspora, but only those who are 'mobilised to engage in homeland political process' (p. 126). 
The process of diaspora mobilisation has been conceptualised in various ways. For instance, focusing on claims-making and practices, Koinova (2016) puts emphasis on the process through which resources for homeland-oriented goals are mobilised. She understands diaspora mobilisation as 'individual and collective actions of identity-based social entrepreneurs who organise and encourage migrants to behave in a concerted way to make homeland-oriented claims, bring about a political objective, or contribute to a cause' (pp. 501-502). Similarly, MüllerFunk (2016) defines diaspora mobilisation as a 'political activity which crosses one or more borders' and 'targets the domestic and foreign policy of that [origin] country' (p. 354). Although most often undertaken by migrants and their descendants from one origin, allegiances may foster the involvement of other groups such as human rights activists, religious groups, or similar movements in other countries. She argues that diaspora mobilisation aims at exerting influence on the homeland's political situation. This influence can be pursued either directly through the establishment of networks and links with political actors, organisations, and institutions in this country, or indirectly by raising awareness and influencing public opinion in the destination countries.

In contrast, Mavroudi (2017) understands mobilisation more broadly, as 'helping' the homeland in material ways. This may include charitable contributions and activities, participation in demonstrations or protests, or advocacy for the political cause in everyday interactions. In a similar vein, the migration and development literature encompass a wider range of diasporic collective action that contributes to development processes in the homeland in material and non-material ways. Besides political involvement, diaspora actors can contribute to peace processes and mechanisms, promote infrastructure development, education and employment, or provide humanitarian or emergency assistance (Brinkerhoff, 2011). Even though these activities do not constitute political action in a narrow sense, diasporic contributions to development have nevertheless political implications and effects, in particular if they help to maintain important government functions such as the provision of education, healthcare, infrastructure and other social and public services (Chaudhary \& Moss, 2019).

The conceptualisations provided, however, limit their definitions to homeland oriented transnational mobilisation, by excluding migrant's political and civic engagement in destination countries. However, as mentioned in the introduction of this study, migrants tend to be embedded in multiple societies at once and may engage in both the origin and destination contexts simultaneously (Horst, 2018; Koopmans, 2004). Hence, this research understands diaspora mobilisation as a process in which collective action and practices can be either homeland-oriented to influence political processes in the country of origin, or hostland-oriented in which 
civic or political practices address the context of destination or hybrid in which these action may intersect and happen simultaneously. In line with Mavroudi (2017), this study also understands the mobilisation as more broadly, as it includes collective practices that do not constitute political action in a narrow sense, but nevertheless influence political processes more indirectly.

\subsection{Meso-level: Three dimensions of the diaspora mobilisation process}

The inductively developed conceptual framework envisions three dimensions of the diaspora mobilisation process: 1) construction of diasporic consciousness (Chapter 2.3.1.), which forms the basis for mobilisation based on a shared imagined community; 2) an organisational framework and mobilising structures (Chapter 2.3.2.), through which the community is constructed and mobilised; and 3) transnational actions and practices (Chapter 2.3.3.) through which diaspora groups seek to pursue the achievement of collective goals. Each of the dimensions are discussed more in detail in the following sections.

\subsubsection{Construction of diasporic consciousness}

Diaspora as well as social movement scholarship sees collective identities as the key feature that creates cohesiveness among members and triggers collective action aiming at social change. As outlined before, the dissertation understands diasporas not as 'natural' entities emerging solely from the process of migration or boundary crossing, but rather as a product of mobilisation through which a transnational imagined community is constructed based on a shared diasporic consciousness. In that sense, it is crucial to explore not only the conditions under which diaspora mobilisation is triggered and unfolds, but also the process of how the collective imagination of the transnational community is discursively constructed. Rather than imposing a communal identity based on a homogenising narrative, a constructionist understanding of diaspora puts emphasis on an investigation of the processes through which this identity may or may not be created and sustained and who is expressing and claiming community for what purpose.

Polletta and Jasper (2001) define collective identity as:

"an individual's cognitive, moral, and emotional connections with a
broader community, category, practice, or institution. It is a
perception of a shared status or relation, which may be imagined
rather than experienced directly, and it is distinct from personal
identities, although it may form part of a personal identity. A 
collective identity may have been first constructed by outsiders (for example, as in the case of "Hispanics" in this country), who may still enforce it, but it depends on some acceptance by those to whom it is applied. Collective identities are expressed in cultural materials names, narratives, symbols, verbal styles, rituals, clothing, and so on - but not all cultural materials express collective identities. Collective identity does not imply the rational calculus for evaluating choices that "interest" does. And unlike ideology, collective identity carries with it positive feelings for other members of the group" (p. 285).

The definition presented highlights the multidimensional nature of collective identities, as it points to the cognitive, moral, emotional and symbolic elements. As such, collective identities can be understood as a shared sense of 'we-ness' - based on shared perceptions and feelings of a common cause, threat, or fate - that defines the group's place in the larger society, and can motivate people to act together generating a 'collective agency' (Snow, 2001). Melucci (2003) points to the processual and interactional nature of identity construction as he sees collective identity as 'an interactive and shared definition produced by several interacting individuals who are concerned with the orientation of their action as well as the field of opportunities and constraints in which their action takes place' (p. 44). Rather than perceiving collective identities as an attribute of social actors, the focus lies on the process of how social actors recognise themselves as a collectivity.

Taylor and Whittier (1992) proposed three analytical tools for understanding the interactional dynamics of collective identity construction, namely 1 ) boundaries 2) consciousness 3) negotiation. Boundaries refer to 'the social, psychological, and physical structures that establish differences between a challenging group and dominant groups' (p. 111). As a central element of the collective identity construction process, boundary work helps to construct the shared sense of 'weness' by defining who is part of the group, and who is included or excluded. Hence, by defining and negotiating the boundaries, the process not only generates a collective self but also a collective other, an 'us' and 'them'. Boundary makers may include categories such as gender, religions, ethnic groups, and nations, yet given that these are not clear-cut, stable, and objectively given, but rather politically and socially constructed and generated by a shared and interactive interpretation of group members, they allow for the existence of an intersectional system of multiple dominations. Although collective identities can be ascribed by others, as dominant groups or institutions often tend to erect social, economic, political and cultural boundaries, they nevertheless have to be 'internalised' by social actors through the construction of meaning in order to become salient and relevant (Castells, 2011). 
While boundaries define the membership to a group, consciousness provides groups with a meaning and awareness about their position in society in relation to selected others and a framework to analyse and define the interests. Hence, according to Taylor and Whittier (1992) consciousness refers to 'the interpretive frameworks that emerge out of a challenging group's struggle to define and realize its interests' (p. 111). In order to make group membership politically relevant and a collective identity salient as in the case of a political or an 'oppositional consciousness' (Morris \& Braine, 2001), the position in society must be perceived as unjust or illegitimate. Consciousness raising is a crucial element in the process of collective identity construction and involves among others mechanisms like talk, narratives, framing processes, emotion work, and interactions with antagonists, in which a shared meaning and interests are produced and negotiated (Hund \& Benford, 2004).

In their social psychological framework on politicised collective identity construction Simon and Klandermans (2001) argue that shared grievances, based on horizontal inequalities in the socio-economic, cultural and political realm can reinforce group consciousness and motivate individuals to engage in collective action. Beside shared grievance, the process of adversarial attributions comprises another important aspect of collective identity politicisation. Adversarial attribution refers to the perception that deprivation is unjustified and that there is an opponent such as an authority or system to blame. Adversarial attribution helps to create a dichotomy of ' $u s^{\prime}$ and 'them', promoting salience of the collective identity. Finally, involvement of society at large refers to the assumption that power struggles are nested in a broader society that provides the context for shared grievances and in which social change is aimed to happen. With the connection of claims to more general issues, such as human rights, and by involving the broader public to seek societal support for the claims, the more specific collective identity becomes part of a more inclusive societal identity.

The last aspect also points to the relational and interactional dimension of collective identity construction, in which shared meanings and claims of a collectivity are produced and negotiated among members of a movement, between the protagonists and the antagonists, as well as in interaction with the broader audience (Hund and Benford 2004). According to Taylor and Whittier negotiation (1992) encompasses 'the symbols and everyday actions subordinate groups use to resist and restructure existing systems of domination' (p. 111). In their view 'the concept of negotiations points to the myriad of ways that activists work to resist negative social definitions and demands the others value and treat oppositional groups differently' (p. 118). Next to resisting structures of power and to the change of symbolic meaning, negotiation also takes place at the inter-group level, in which 
commonalities and differences, as well as ideas of the groups position in society are contested and debated in the process of internal meaning making (Doorn et al., 2013). The process of negotiation is not only embedded in particular sociocultural contexts, but also has a temporal dimension as shared meanings and claims are reproduced and renegotiated in the interaction of different actors over the life course of a social movement. As such, collective identities as a category of practices are not only a driver of mobilisation but are also constantly under construction as collective actions lead to reconfigurations of collective identities. Politicisation of identities is heightened by sequences of transformative events, that lead to shifting configurations of power within a system and gradually changes the group's position in its social environment (van Stekelenburg, 2013). Taylor therefore sees social movements as 'discursive communities held together not only by common action and bonds of solidarity, but by identities, symbols, shared identity discourse, and practices of everyday life that attribute participants' experiences to particular forms of social injustice' (2013).

Collective identity is at the centre of diaspora concepts and seen as the key feature that creates cohesiveness among the members and triggers transnational engagement. Ethnicity, religion and nationality, thus, are often used, both internally and externally, to set the boundaries of different diaspora groups. Initially, boundary maintenance was seen as a central feature of diasporas and was perceived as resulting from an active resistance to assimilation, or as a consequence of the social exclusion and marginalisation that diaspora groups experience in the country of destination (Cohen, 2008; Sheffer, 2006). Boundary maintenance, which can be understood as preserving a distinct identity vis-à-vis the host societies, helps, it is argued, to engender dense social relations and active group solidarity, linking scattered individuals to a distinctive transnational community (Brubaker, 2005). The conventional understandings have been challenged by the literature on transnationalism that replaces the static notion of cultural distinctiveness with the idea of cultural hybridity, which sees boundaries and identities as shifting and fluid and emphasises the interactions, exchange and negotiations taking place across and within culturally-constructed boundaries (Bhabha, 2004; Hall, 2014). The concept of hybridity, however, does not necessarily imply that social, political, symbolic and cultural boundaries diminish, but rather point to the condition of in-betweenness and the complicated entanglements resulting from social inequalities, differences and exclusions. As Ang (2003) argues:

\footnotetext{
"hybridity then is a concept that confronts and problematises boundaries, although it does not erase them. As such, hybridity always implies an unsettling of identities. It is precisely our encounters at the border-where self and other, the local and the
} 
global, Asian and Western meet - that make us realise how riven with potential miscommunication and intercultural conflict these encounters can be. This tells us that hybridity, the very condition of in-betweenness, can never be a question of simple shaking hands, of happy, harmonious merger and fusion. Hybridity is not the solution, but alerts us to the difficulty of living with differences, their ultimately irreducible resistance to complete dissolution" ( $p .8)$.

It is exactly the notion of in-betweenness and multiple belongings, which Clifford (1994) considers as the diaspora consciousness, which he sees as a state of mind and a feeling of being simultaneously 'home and away from home' or 'here' and 'there'. Similarly, for Vertovec (2005) 'belonging to a diaspora entails a consciousness of, or emotional attachment to, commonly claimed origins and cultural attributes associated with them. Such origins and attributes may emphasise ethno-linguistic, regional, religious, national or other features' (p.3). Hence, the notion of consciousness presents one of the central aspects of diasporas, which are characterised by group solidarity, loyalty and co-responsibility connecting scattered individuals grounded on an idea of a shared collective past and future. As Sökefeld (2006) argues, 'there can be no diaspora community without a consciousness of diaspora, in other words without an idea of shared identity, of common belonging to that group' (p. 267), albeit the nature and meanings of the collectivity can (and often tend to) be highly contested among the members. As such the discourse on diaspora consciousness can be seen as a manifestation 'not simply of transnationality and movement, but of political struggles to define the local, as distinctive community, in historical contexts of displacement' (Clifford, 1994, p. 308). This is argued to be particularly relevant in the case of conflict-generated or stateless diasporas, since their experience of dislocation along with their adversarial stance towards their homeland governments seem more likely to create a strong politicised consciousness (Baser \& Swain, 2010; Quinsaat, 2019; Saideman et al., 2011).

In that sense boundaries and a diaspora consciousness are not objectively given, but instead are constantly contested and negotiated and a result of boundary work and consciousness-raising undertaken through organised efforts by diaspora political entrepreneurs who struggle over the definition of the transnational imagined community, and who is included and how excluded (Brubaker, 2017). Adamson (2013) highlights the role of transnational brokerage in the process of diaspora mobilisation, a process which links scattered groups with the conflict networks of the homeland. Diaspora brokers can be powerful actors in connecting diaspora populations in different destination countries with the political space of the homeland. Taking the example of Kurdish diaspora mobilisation, Adamson 
illustrates how exiled intellectuals, activists and militants connected to the National Liberation Front of Kurdistan, the political wing of the PKK, managed to link the already settled Kurdish population in Europe to the political networks and actors of the conflict in Turkey. These diaspora brokers, who were exiled by the military coup in Turkey in the 1980s, played an essential role in the establishment of institutions, as well as in the transnational circulation of both symbolic and material transfers, that promoted a political mobilisation based on a shared Kurdish consciousness.

In the context of diasporas, this also means that boundary work is multi-layered as identities are constructed in a transnational space, given that positions and belongings are negotiated in the context of the country of destination and the country of origin. As a result, identities are not merely transferred from the homeland but also shaped by migrant's encounters in their host society (Orjuela, 2012). While labels such as ethnicity, nationality and religion can serve as strong markers for the mobilisation of collective identity, these also might conceal great differences within diaspora groups.

\subsubsection{Organisational framework and mobilising structures}

If collective identities are understood as socially and politically constructed, there is a need to investigate the mobilising structures and agents, who produce, mobilise, and spread the discourse of the transnational community. The 'agents of diaspora discourse' not only claim to be legitimate representatives of a particular group, but also engage in consciousness-raising and in the politicising process, channel collective action and provide an important basis for mobilising practices of diaspora groups (Sökefeld, 2006).

'Diaspora political entrepreneurs', such as formal or informal leaders of different diaspora groups, are considered as key actors in the mobilisation process, due to their capacity to make claims, mobilise and organise support with respect to the original homeland (Koinova, 2018). Whereas the term diaspora political entrepreneurs refers to individual actors who engage in a claims-making process, mobilising structures can be understood as the set of 'networks of people that are bound to the same issue or formal organisations that are established for the purpose of making particular claims' (Sökefeld, 2006). Bush (2008) defines diaspora organisations as 'complex, formal, informal or semi-formal organisations that articulate and pursue goals that are asserted to be representative of the interests and aspirations of 'the diaspora' as a whole' (p.195). It is important, however, to critically reflect on the role of diaspora organisations who often state to represent the diasporic group as a whole without necessarily having the legitimation to do so, since collective action of diaspora groups often tend to be a result of 
transnational mobilisation activities by a small but often powerful elite (Adamson, 2008; Portes et al., 2007). What Glick Schiller (2013) calls the 'ethnic association fetish', involves the risk of limiting the analysis to the voice of a small but powerful diasporic elite, whose legitimation is potentially highly contested. In addition, the focus on the institutionalised and organised diaspora might conceal transnational mobilisation of diaspora members that goes beyond formal means of engagement.

Hence, diaspora political entrepreneurs mobilise or are mobilised through different structures such as networks, institutions or organisations ranging from hometown associations, religious and cultural clubs and development, humanitarian and human rights organisations to political parties and activists, academic networks and media outlets that engage in the construction of the discourse of community (Kleist, 2015; Sinatti \& Horst, 2015). In some cases, diaspora groups may establish formal political organisations in the destination country linked to political movements in the origin country to mobilise financial, political and ideological support among the emigrant population. For instance, the Liberation Tigers of Tamil Eelam (LTTE) established a global network of offices that collected voluntary as well as forced financial contributions described as a tax to finance the insurgency during the civil war. It was estimated that the diaspora contribution represented around 90 per cent of the LTTE's annual military procurement budget (Fair, 2007). Another prime example is the Kurdish Workers Party (Partiya Karkeren Kurdistan, PKK), which became the backbone of Kurdish diaspora organisations in Europe as well as the main driving force of Kurdish nationalism (Baser, 2017). In the case of Palestine, the Palestine Liberation Organisation (PLO) created a representative worldwide structure and largely operated in centres of the diaspora, which - as a 'government in exile' became the main feature of the Palestinian national project (Bamyeh, 2007). Yet, according to Koinova (2018), the Oslo Accords in 1993 can be considered a critical juncture as it shifted the centre of gravity of the Palestinian struggle from the diaspora to the homeland territory. The creation of the Palestinian National Authority (PNA), responsible for the selfgovernment in the West Bank and Gaza, moved the focus towards the project of state-building and away from the right to return, one of the key concerns of Palestinians in the diaspora.

Importantly, diaspora groups and their sources of network identity should not be considered just along national, ethnic and religious lines, but also based on gender, professional networks and political affiliation. Thus, diaspora groups and their respective institutions are seldom unified and homogeneous; there is a need to understand the different aspirations and institutions of diaspora groups as well as the underlying factors such as class, professional, ethnic and gendered hierarchies 
that create fragmentation, power relations and competition among diaspora groups (Baser, 2014; Koinova, 2011; Walton, 2014). As Bernstein (2008) argues:

"Individuals' identities based on the intersections between, for
example, race, class, gender, and sexual orientation provide sources of
internal differences within movements. Collective identities are not
simply free-floating cultural phenomena but also historically,
materially, and organizationally located. Organizational structure
can serve to exacerbate differences within social movement
organizations or to foster a more cohesive empowering identity" ( $p$.
279).

If diaspora mobilisation is understood as a process, in which a heterogeneous group of diaspora actors engage in the construction of community and political projects, it becomes necessary to explore the internal social, cultural and political dynamics of mobilisation (Sökefeld, 2006). These processes might also influence who is included and excluded from diaspora mobilisation. Ang (2003) advocates for recognising the 'double-edgedness of diasporic identity: it can be the site of both support and oppression, emancipation and confinement, solidarity and division' (p. 3).

Moreover, situating diasporas in the historical context and process of mobilisation, their actors and structures should not be perceived as fixed, but rather as highly dynamic and continuously changing (Mavroudi, 2007). First, there might be changes in the organisational field, as some organisations which were set up at the beginning of mobilisation may no longer be functioning a few years later, and at the same time new agents may enter the field, leading to a high degree of dynamic change and fluctuation within the diaspora organisational structures. Next to the size of the organisational landscape, evolution also can be analysed based on changing degrees of formalisation, institutionalisation and professionalisation of diaspora civil society organisations. For instance, mobilising structures may consist of informal ties and networks at the start of mobilisation, but eventually become highly institutionalised and professionalised over the course of the mobilisation process.

\subsubsection{Transnational action and practices}

Migrants and refugees may influence political processes in the origin country, by engaging in transnational politics and political action both through conventional and unconventional means. Boccagni et al. (2016) define transnational politics as 'an open-ended process encompassing the diffusion of ideas, values, information, and skills via cross-border mobility that includes political content or is used to 
drive forward state-led and/or migrant-driven forms of political engagement'. In countries where legal frameworks such as dual citizenship, voting and representation rights for non-resident citizens are in place, emigrants may engage in formal mechanisms of political participation from afar, by participating in elections, running for an office, funding of political parties or establishing an overseas office. In Somalia, a significant share of leaders of state institutions in 2011 were former migrants; despite being less than 10 per cent of the total Somali population, at least a third of all Somali regional governments (and up to twothirds in some regions) were comprised of diaspora members. These former diaspora members filled roles as heads of state, members of parliament, members of cabinets, and other high-level bureaucrats (Ismail, 2011). A similar scenario occurred in Iraq, where over half of the ministers in Iraqi Kurdistan in 2013 were former diaspora members from Europe or the US (Kadhum, 2014).

Emigrants can shape a country's political agenda, both during and following conflict, through participation in elections. Voting provisions are determined by a state and are largely outside of the diaspora's scope of influence; in some instances, however, diaspora groups have actively lobbied home states for the right to vote in home elections. While unsuccessful in securing the right to vote in general elections, the Nigerian diaspora has petitioned the Nigerian government for extraterritorial voting rights and has used the issue of voting as a key point in testing the government's commitment to diaspora engagement (Binaisa, 2013). Irish diaspora groups have similarly pressured the Irish government since the early-1990s to extend voting rights to citizens residing abroad to no avail, which has been a source of tension between members of the diaspora and the state (Gray, 2013). Other diaspora groups have been more successful in lobbying their home states for political enfranchisements rights. After years of significant pressures from the diaspora, Mexico granted non-resident nationals the right to vote in 2005 (Turcu \& Urbatsch, 2015).

If formal avenues are absent or the origin country's government system does not allow for democratic political participation, emigrants can make use of unconventional political actions such as protests, awareness raising, grassroots mobilisation, lobbying and advocacy work (Chaudhary \& Guarnizo, 2014; Chaudhary \& Moss, 2019; Gabrielli, Gsir, \& Zapata-Barrero, 2017). Diasporas may engage in lobbying the host-country governments to support specific political stances against home-country governments. For instance, both Libyan and Syrian diaspora political entrepreneurs lobbied for militarised intervention by the US government, such as the establishment of a no-fly zone or logistical support for rebel groups to weaken the respective regimes (Moss, 2016a). Diaspora groups have actively pursued trials of home-state perpetrators of crimes abroad under 
universal jurisdiction laws, which enable prosecution for serious violations of human rights outside of the country where such violations occurred when the justice system in the home state is unwilling or unable to do so. The Argentinian, Cambodian, Chilean, and Rwandan diasporas all petitioned and lobbied for their host states, particularly France and Belgium, to arrest and try former members of state regimes accused of human rights abuses, in the host counties (Mey, 2008). In the context of Sweden, politicians with Kurdish backgrounds gave speeches in the parliament to lobby for the implementation of a 'Genocide Bill', which was eventually passed by the Swedish Parliament in March 2010 to recognise the 1915 mass killing of Armenians in Turkey as genocide (Baser, 2013).

In times of active conflict, members of the diaspora might establish formal and informal forums which provide space for dialogue and negotiation (Bercovitch, 2007), offer direct political support for pro-peace actors in the country of origin or participate in advisory councils, negotiation teams and conferences (Bush, 2008). For example, Afghan diaspora groups have taken a decisive role in the Petersberg Talks on a peaceful transition in 2002 in Bonn (Zunzer, 2004). In a review of the role of diasporas in conflict societies, Brinkerhoff (2011) noted that diasporas from countries as diverse as Burundi, Nepal, Somalia, and Sudan all substantially shaped peace negotiations and agendas. Their contributions included identifying, communicating with, and encouraging conflictual parties to engage with international meditators; supporting the implementation of peace agreements, by directly mediating between warring parties; encouraging host-country governments to act as mediators or to support negotiations; advising on the context of the conflict and the relevant actors, and; suggesting features to be included in peace agreements. Political mobilisation can, hence, raise international awareness, promote dialogue, negotiations and reconciliation and contribute to the rehabilitation of political institutions, thus promoting conflict resolution.

Other diaspora groups have targeted the populations of their host countries more generally with information on the conflicts occurring in their countries of origin to encourage humanitarian intervention. Some members of the Colombian diaspora in Canada, as one example, created an NGO to promote awareness about the humanitarian crisis in Colombia and to inspire better-coordinated support for human rights campaigns in Colombia. The NGO (Life and Peace Colombia) also disseminated information on peace-building initiatives and coordinated educational tours of community leaders to Colombia (Riaño-Alcalá \& Goldring, 2014). Both the Kurdish and Sri Lankan diasporas have used protests, such as sitins and hunger strikes, to call attention to the political or humanitarian plights of their communities in their home countries (Baser \& Swain, 2010). Tamil diaspora groups in Switzerland also used forms of mass media, such as a commuter tabloid 
to draw public attention to how Tamils in Sri Lanka were suffering during the last battles of the civil war. The second-generation Tamil diaspora, in particular, used Swiss media outlets and the international/Swiss discourses on human rights to incite intervention while remaining distant from party politics in Sri Lanka (Hess \& Korf, 2014). Hence, political influence can be pursued either directly through the establishment of networks and links with political actors, organisations, and institutions in the country of origin and the cross-border diffusion of material and immaterial political resources, such as money, political tools, values or ideologies, or indirectly by raising awareness and influencing public opinion and political decision-making in the host countries (Müller-Funk, 2016).

Next to engaging in political processes, diaspora groups may engage in collective action that contributes to development processes in the homeland in material and non-material ways. While these contributions do not represent transnational political practices in a narrow sense as they are often framed in more neutral terms, Chaudhary and Moss (2019) highlight that these action nevertheless have political implications and effects on the origin country context, since they often tend to supplement weak government functions. As such, projects promoting civil society, community development, and humanitarian aid can support development, reconstruction and reconciliation and help those affected by the conflict to receive protection. As one example, the Sierra Leone War Trust for Children (SLWT), a project which was established by members of the Sierra Leone diaspora living in the United Kingdom, aimed at improving the well-being of conflict-affected children through collective social activities and to provide intensive trauma management (Bercovitch 2007). Specific sectors within a country, such as education, may also inspire particular investments from diaspora members. One specific example that concretely links diaspora groups to the development of the educational sector relates to the mobilisation of diaspora funding to support school construction in Rwanda. A 2009 conference of the Rwanda Diaspora Global Network in collaboration with the Rwandan Ministry of Foreign Affairs led to the establishment of the 'One Dollar' campaign, which encouraged Rwandans in the diaspora and Rwandans inside the country to contribute to a development fund. This fund was then used to construct student housing for youth who had been orphaned by the genocide (S. Turner, 2013).

Diaspora groups may mobilise financial contributions to provide humanitarian aid

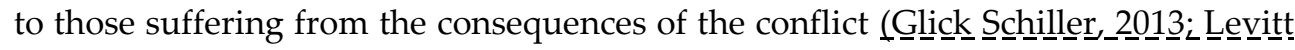

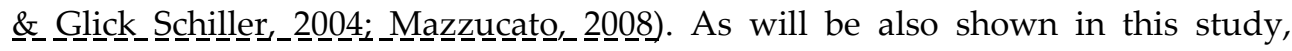
Syrian diaspora groups have not only raised funds for relief efforts for those displaced within and beyond Syria but have also directly facilitated the delivery of assistance. As noted in a 2015 report on the international and local actors who have 
responded to the humanitarian crisis in Syria, the formal humanitarian system chiefly through international aid agencies - has not maintained a physical presence in Syria, a gap that has been filled by local NGOs. Many local NGOs have been created or supported by members of the diaspora, and their presence in local communities affected by the conflict has been essential to ensuring that assistance is provided at local level (Svoboda \& Pantuliano, 2015).

While contributions of diaspora groups to conflict, peace and development in origin countries have been widely explored in various studies, cases and contexts, so far little research has dealt with diaspora transnational practices oriented towards the destination country context. Scholars of transnationalism emphasise that migrants, being connected to several places, commonly engage in exchanges and interactions across borders and are involved in multiple societies at once (Glick Schiller, 2013; Levitt \& Glick Schiller, 2004; Mazzucato, 2008). As a result, diaspora civil society actors also transform political spaces of the host country, by promoting the inclusion of co-nationals, advocating for rights and against discrimination or promoting intercultural dialogue and social cohesion (Però \& Solomos, 2010). Transnational practices of diaspora actors, hence, can be considered not just as a form of civic participation in the country of origin, but as a crucial part and voices of the civil society in the country of settlement (Horst, 2013; Müller-Funk, 2019). Despite the conceptional rise of transnationalism, the nexus between integration, migration and development has not been explored in detail, and the different concepts continue to be discussed and analysed in separate disciplines. Recent studies, however, highlight that engagement in host and origin countries is not a zero-sum game but rather often happens simultaneously (Portes et al., 2008). While some diaspora organisations may have an exclusive origin country focus, others focus on life in the host country, and again others contribute to development in multiple societies at once (Brinkerhoff, 2008).

In recent years, there has been a growing interest in studying the political participation of migrants by examining immigrants' political preferences, electoral practices, collective mobilisation as well as their representation in destination country political processes (Martiniello, 2006; Morales \& Giugni, 2011; Sauer, 2016; Vertovec \& Kraal, 2016; Wüst, 2014, 2016). In general, the literature stresses that migrants' political participation is not only influenced by individual characteristics such as human and social capital, socio-economic status, gender, age, duration of stay or linguistic skills among others, but also by the political and discursive opportunity structures that define the space for conventional political participation such as voting, party membership or the running for election. In their study on Colombian, Dominican and Mexican migrant organisations in the United States, Portes, Escobar and Arana (2008) showed that, next to engagement focusing on 
origin country developments, members of these organisations also practice their American citizenship through voting and frequent engagement in other USfocused civic and political activities.

In addition, Martiniello (2006) acknowledges that political life is not only confined to electoral processes, but that less conventional and non-formal mechanisms, including migrants' participation in consultative bodies, civil society organisations, protests, grassroots initiatives can provide alternative avenues for participation. Migrant and ethnic organisations can serve as bridge-builders between the migrant population and local communities, may raise awareness on the challenges faced by immigrant populations, and are increasingly seen as important actors in decisionmaking processes, hence, fostering representation of migrant interests in the political process (Sauer, 2016). In particular, for those whose political rights are neglected and conventional avenues for political participation are closed, migrantled grassroots mobilisation provide important ways of expressing the challenges immigrant communities face in the destination country and to raise their voice against discrimination, and therefore have a transformative role by contributing to community cohesion, structural integration and social change (Però \& Solomos, 2010). Similarly, Castles (2011) emphasises the role and potential of migrant associations that mobilise successfully at local, national and international levels to bring human rights and the rights of migrants into the debate of human development.

Diaspora organisations may promote the integration of those more recently arrived in the destination country, by facilitating their access to public services, or by offering themselves services that promote integration such as language courses or tutoring (Nijenhuis \& Zoomers, 2015). As cultural brokers, diaspora groups may encourage cultural exchanges and act as a bridge builder that contributes to community cohesion by promoting mutual understanding and intercultural dialogue. On the other hand, politics of othering may reinforce a process of othering and manifest negative stereotypes towards the majority society.

To conclude, engagement and participation in host and origin countries are not a zero-sum game but, in many cases, intersect and tend to happen simultaneously (Guarnizo et al., 2003; Portes, 2015; Portes et al., 2008; Pries \& Sezgin, 2012). Even if political actions have a purely origin country focus, in many cases they take place in the realm of the destination country context, in particular in the case of unconventional political action such as protests, advocacy and grassroots initiatives. As such, Horst (2013) argues that transnational engagements of migrants and refugees should not just be seen as form of civic participation in the 
country of origin, but as a crucial part of the civil society in the country of settlement.

\subsection{Micro-level: Capabilities}

Given that communities are made up of individuals, it is crucial to not only focus on the meso-level processes of mobilisation but also on how individual aspirations, desires and the willingness to become engaged in the diaspora project evolve and change over time. In this regard, Al-Ali, Black and Koser (2001) stress the importance of transnational capabilities, which refer to the willingness and ability of individuals to engage in political, economic, and social transnational activities. Capabilities include not just the more structural factors such as the political opportunities or constraints, which members of diaspora encounter in the transnational field, but also their agency, such as the level of motivation to maintain group solidarity as well as the willingness and desire to re-establish links with the country of origin. As such, capabilities are also shaped by 'the extent to which individuals and communities identify with the social, economic or political processes in their home countries, which is a prerequisite for them to engage in transnational activities' (Al-Ali et al., 2001, p. 581).

A sense of belonging, hence, presents a significant precondition for establishing links with the place of origin and for engaging in transnational practices. The field of transnational studies has engaged in attempts to conceptualise transnational belonging, moving away from essentialist understandings of identity, membership, and belonging towards an analysis that seeks to explore the processual, dynamic and contextual dimensions of social constructions. Rather than seeing belonging as fixed, homogeneous and unidimensional, the emphasis lies on the fluid, hybrid and intersectional nature, meaning that belonging is constantly constructed, deconstructed and reconstructed and influenced by people's social locations in a specific place and moment in time (Anthias, 1998; Antonsich, 2010; Soysal, 2000; Yuval-Davis, 2006; Yuval-Davis et al., 2006). In that sense, identities are not essentialist, natural categories, but can be defined as 'narratives, stories people tell themselves and others about who they are (and who they are not)' (Yuval-Davis, 2006, p. 202). As ongoing stories, identities emerge and develop through a selection of past moments, lived experiences and critical events that locate the self in the present and provide a vision for the future. They cannot be detached from individual beliefs, which form the basis for ethical and political values of what is perceived as right or wrong, and good or bad. The construction of identities is inherently a social process, as human self-interpretations are created in reference to or by others and are embedded in broader social, cultural and historical narratives, in which identity and difference are being shaped and 
negotiated (Davis, 2002; Yuval-Davis, 2006). Despite their dynamic nature, these broader narratives persist over time and serve as a cultural stock of symbols and historical experiences, hence, as a basis for collective identity construction. Narratives give meanings of what the membership to a grouping or collectivity (ethnic, racial, national, cultural, religious) entails, and are always told selectively and in relation with selected 'others' and 'otherness' (Funk \& Said, 2004).

With hybrid and multiple identities and changing borders over time, homeland orientation and relation can be the subject of constant transformation and change. Soysal (2000) criticises that traditional concepts see diasporas as an extension of the nation-state model, implicating that there exists a conformity between territory, culture and identity. Yet, particularly since the post-Second World War era, economic, political and cultural boundaries are shaped and changed constantly, resulting in new claims of membership, belonging and identity. Attachment to the homeland should therefore not be seen as static, but as process in which construction of meaning and interpretations of belonging is shaped by various actors and context. As such, Abramson (2017) argues that there is a need to unpack the process of cultivating attachments to the homeland. Taking the example of diaspora tourism, he explores the discourses, embodied practices, and affective tools involved in the process of homeland-making. Focusing on Taglit-Birthright, a free educational trip to Israel offered to young Jewish adults, he shows how Israeli and North American elites engage strategically in the reproduction of a narrative of dispersion, the demarking of collective group boundaries as well as in the construction of a homeland attachment. As such, diaspora identities are not purely a resource that can be tapped by homeland actors, but rather are constructed, reproduced, and transmitted by different actors across generations and spaces.

In the transnationalism discourse, scholars emphasise that migrants, being connected to several places, commonly engage in exchanges and interactions across borders and are involved in multiple societies at once (Mazzucato, 2008). King (2002) for instance, introduces a much more fluid depiction of concepts of home: 'Even the notions of 'home' and 'away' or 'abroad' have become blurred. Members of transnational communities may feel 'at home' in two or more places (or not feel at home anywhere)' (p.102). While traditional concepts of diasporas often put strong focus on the relations to the real or imagined homeland, the transnational shift allows for an investigation of the multiple embeddedness of members of diasporas and how these shape transnational practices and engagement.

The explanatory power of identities lies, hence, not in an essentialist categorisation of ethnicity, race and nation as given natural groups or entities, but rather in how a 
sense of collective identity emerges and is used in the construction of a diasporic consciousness. This also means that their analysis should deal with the politicisation of ethnic, national (or other collective) identities as a relational, dynamic, political, social, cultural and psychological process. For instance, Demmers (2007) argues that critical developments in the homeland, such as secessionist conflicts or revolutionary struggles, can be considered as transformative events that trigger mobilisation around a shared consciousness, as a collective identity becomes salient (the so-called 'diasporic turn'). There might be a feeling of obligation, guilt and grievance or a desire for power, just as well as an aspiration for social change and transformation that inspires new or renewed interest of members of diasporas to shape the politics of the country of origin (Brinkerhoff, 2011).

Al-Ali et al. (2001) argue that beside motivation or desire, the individual's capacity influences the way and form of diaspora engagement. In particular education, employment and a secure legal status seem to be major factors that promote diaspora engagement since these influence the capacity and ability to get involved (Hammond, 2013; Koser, 2007; Warnecke, 2010). Whereas permanent residence status enables migrants to enjoy similar social, economic and political rights as citizens, asylum seekers, refugees, temporary or undocumented migrants often suffer from restriction or even exclusion of rights, leading to a stratified system of socio-legal entitlement for the migrant population (Ruhs, 2010). As a result, different legal categories of migrants face distinct socio-economic conditions that also influence the capacity of migrants and refugees to become involved in the diasporic mobilisation process (Al-Ali et al., 2001; Martiniello, 2006). This leads to uneven patterns of transnational engagement, since members of diasporas are facing different social, economic and political circumstances and conditions in the destination country that influence the capacity of individuals to get involved. It is therefore crucial to understand how the intersection of class, professional, ethnic and gendered hierarchies reproduces pre-existing power asymmetries.

\subsection{Macro-level: Transnational political opportunity structures}

The political process approach argues that social movements do not automatically emerge out of social grievances or injustice, but that before grievance can be transformed and expressed, contextual and structural conditions have to be met, stressing therefore the importance of political opportunity structures, hence the exogenous factors enabling or constraining mobilisation. Tarrow (1988) defines political opportunity structures as 'consistent - but not necessarily formal or permanent - dimensions of the political environment that provide incentives for collective action by affecting people's expectations for success or failure' (pp. 76- 
77). Traditionally the concept focused on political aspects, by highlighting factors that favour the emergence and success of social movements within a given national context. A shift in political positioning and arrangements, which increases access for marginalised groups for which access has been historically denied, can be perceived as an enabling factor for movement emergence. Moreover, low state strength and divisions within political elites limit the capacity and capability to suppress protest providing the movement room to grow and persist in its actions. International conditions and influential allies within the political elite that support the goals and actors of the movement provide additional strength and favourable conditions for success (Tarrow, 2011). While some emphasise the stable aspects of governmental structures that explain differences in outcomes between movements (e.g. Kitschelt, 1986), others stress the more volatile aspects of political opportunity, such as public policy, public discourse and political alignments (Meyer \& Minkoff, 2003).

The concept of opportunity structures has received much attention in the study of collective action and mobilisation of diaspora groups. Importantly, studies highlight the transnational dimension of opportunities, putting emphasis on both the country of origin and country of destination as well as on the international sphere (Sökefeld, 2006). According to Wayland (2004) people who originate from a closed society and migrate to a more open society 'are able to capitalise on newfound freedoms to publish, organise, and accumulate financial resources to an extent that was impossible in the homeland' (p.417). At the same time, long distance public policies of the country of origin might oppress political movements even in the diaspora (Østergaard-Nielsen, 2003b). Transnational political opportunities structures, therefore refer to opportunities and constraints in the country of destination, the country of origin and the transnational sphere (Sökefeld, 2006). Transnational political opportunity structures thus help to explain why the success of a diaspora groups in homeland conflict often vary over time and place (Wayland, 2004).

Depending on the type of governance of the country of origin's authority, there will be a more open or more restrictive space for transnational political action, with authoritarian origin-country regimes tending to provide fewer avenues for political influences, at least in the case in which the sovereignty of the government is contested by the diaspora political entrepreneurs. In contrast, in origin countries in which a democratic system is in place or which recently experienced a political transition, diaspora actors tend to find more avenues and legitimacy to influence social, political, economic and cultural processes in the origin country from abroad (Chaudhary \& Moss, 2019). Transnational political actions are also influenced by the relative stability of the country of origin, as critical social and political events, 
such as revolutionary struggles, conflicts, economic crises, or natural disasters, can shape and influence diaspora consciousness and mobilise members to take action (Hammond et al., 2011; Hess \& Korf, 2014; Khayati, 2012; Maria Koinova, 2011; Skrbis, 2007). The efficacy of diaspora contribution is also influenced by the availability of local partners as well as practical, security and financial challenges on the ground, which might prevent the implementation of concrete projects (Warnecke, 2010).

Next to these more general country factors, diaspora institutions, which Gamlen (2019a) defines as 'state institutions and practices that apply to members of that state's society who reside outside its borders' (p.480) can constrain or enable diaspora mobilisation in various ways. These emigration specific aspects, such as the emigration regime including the legal framework that governs the legal position of emigrants (e.g. dual citizenship, overseas voting rights, bilateral agreements) as well as the institutional framework and initiatives targeting the emigrant population or diaspora involvement influence the space for diasporic transnational political action. Legal and institutional mechanisms such as dual citizenship, voting and representation rights for non-resident citizens define the space for formal political involvement with the origin country (Délano \& Gamlen, 2014). However, even if these institutions are formally in place, emigrants or refugees may be either unwilling due to fear of persecution or face practical challenges to engage in formal mechanisms, for instance, if voting in elections requires physical presence in the country of origin (Bekaj \& Antara, 2018).

Although states are not able to exercise their full sovereignty abroad, countries of origin can introduce long-distance levers and policies in order to monitor and exert control over their emigrant population. Turkey (Østergaard-Nielsen, 2003a), Morocco (Brand, 2006; de Haas, 2007) and Tunisia (Brand, 2006) have been examples in which state-run institutions abroad were involved in surveillance and intelligence measures to repress diaspora political activism and to prevent the emergence of a political opposition from outside. Comparing diaspora-sending states relations in the context of Morocco, Tunisia, Lebanon and Jordan, Brand (2006) shows how in the Moroccan and Tunisian cases, both governments established institutions abroad to control and monitor their emigrant population. In early 1970s, in response to increasing mobilisation of expatriate students and workers as part of broader labour union struggles in Europe, along with a rising internal opposition engaging in coup attempts and other forms of subversion, the Moroccan state sponsored the establishment of friendship associations abroad, called amicales (in French) or widdadiyyat (in Arabic) to extend its control beyond the borders of the nation. On the one hand, these organisations officially served in the interest of the expatriate communities by providing social and cultural services 
aiming at strengthening the ties to the country of origin. At the same time, they exercised state coercion by monitoring, intimidating and penalising those who took part in any kind of activism either at home or abroad. Similarly, in the Tunisian case, the expatriate communities were seen as integral part of the homeland, which hence required the same measures of authoritarian control as within the borders of the nation.

When in the late 1980s and 1990s Turkey realised that the vast majority of its workers abroad would not return but most likely settle permanently in the destination countries, the government implemented several measures to strengthen economic, political and cultural ties with its emigrant population. At the same time, the government used means of long-distance policing to control and penalise political dissidence in particular by left-wing and trade union activists, or Kurdish groups, who tried to influence the Turkish political landscape from abroad. The Turkish government exerted pressure on destination country authorities at various levels, urging them to restrict activities of oppositional groups ranging from the Maoist New Left to radical Sunni Muslim groups such as the ICCB/Kaplancilar and the Kurdish PKK in particular. Further, coordination councils, initiated and financed by the Turkish embassy, sought to promote dialogue and cooperation among Turkish migrant and diaspora organisations, yet only actively supported and funded organisations with a clear pro-Turkish stance. Further, the Turkish government has been accused of employing the Turkish Secret Service [Milli Ishhbarat Teskilati (MIT)] to monitor the emigrant population, with secret agents operating in Germany. Measures were also taken to threaten or discipline political dissidents by not renewing their passport and hence hindering people from visiting or returning to Turkey or by detaining and interrogating activists on return visits (Østergaard-Nielsen, 2003a). Likewise, in the Syrian case, a range of studies showed how the Syrian government exercised its control beyond the borders of its territorial jurisdiction, by actively repressing oppositional individuals, groups and movements that challenged its rule. Long-distant political oppression has been documented in Sweden (Jörum, 2015), the United Kingdom (Moss, 2016), the United States (Moss, 2016b; Qayyum, 2011), and in the present case of Germany. For instance, Moss (2016) showed that both in the context of the United Kingdom and United States, the Syrian government positioned informants in social clubs and mosques to monitor political disobedience among the emigrant population. Those who voiced their discontentment openly experienced direct personal threats or punishment of their relatives at home in Syria.

In contrast, socio-economic and political incentives provided by the country of origin can enable diaspora contributions to peace and reinforce an interest in the origin country's development (Burgess, 2014). The programme 'Tres por Uno' of 
the Mexican government is an example of policies that aim at leveraging the potential of diaspora contributions for local development. The goal of the programme is to promote diaspora philanthropy, through the provision of matching grants for projects of diaspora organisation aiming at contributing to local and regional development (Newland et al, 2010). In the case of Rwanda, the government showed that engaging the diaspora is a central part of peacebuilding and post-genocide state building. Yet, the Rwandan diaspora engagement policy did not appeal to the diaspora as a whole but rather favoured specific fractions or subgroups creating an environment for inclusion and exclusion for particular groups (Turner, 2013). Attitudes of governments and local elites towards different diaspora groups and vice versa therefore determine if a coalition is formed or a relationship is rejected (Antwi-Boateng, 2012; Koinova, 2011). Policies and strategies targeting the diaspora also depend on how the emigrant population is discursively and symbolically included in the nation. In some cases, origin country actors might frame the diaspora as a distant member of the national community and seen emigrants as hero and saviour of the nation, while in other cases those in exile might be depicted as troublemakers and traitors (Boccagni et al., 2016).

Important factors in the country of destination are migrant incorporation regimes and multiculturalism policies. In general, more democratic countries that adopt cultural pluralism and multiculturalism provide more freedom and space for diaspora activism and enable diaspora groups to unfold their ethnic and religious identities (Kadhum, 2014; Shain \& Barth, 2003; Sökefeld, 2006). Since diasporas do not act in a political vacuum, the measures they implement and the strategies they choose often match with the host country's policies and the broader public discourse (Al-Ali, 2007; Østergaard-Nielsen, 2003b; Koinova, 2014a). While these might be favourable for some diaspora groups, they can be constraining for others. For instance, Eritrean groups were much more able to raise awareness in Germany where their case was seen as justified, while Kurdish diaspora groups faced more challenges due to the ban of the Kurdistan Workers' Party (PKK) and the tension between Kurdish and Turkish groups importing the conflict to Germany (Turner, 2008). However, when Kurdish groups changed their goal from supporting communism and socialism to promoting human rights and democracy, they received more support from German policymakers and NGOs (ØstergaardNielsen, 2003b). Similarly, Liberian diaspora groups in the US changed their strategies from more deconstructive actions to peace promotion due to shifting demands in the country of origin, changes of the US foreign policy towards the promotion of democracy in Africa and regional and international efforts in promoting peace-building norms (Antwi-Boateng, 2012). However, framing demands in the language of development, human rights and democracy can also be a cover for a hidden agenda of diaspora groups, which actually aims at 
favouring their own families, clans or ethnic groups (Horst et al., 2010). Moreover, a perceived lack of interest towards diaspora stances could also motivate diaspora groups to take action in order to raise awareness for their claims (Hess \& Korf, 2014). It is thus important to highlight that the public discourse is also shaped and influenced by diaspora actions (Horst, 2013).

The institutional framework and funding mechanisms in the destination country also influence the capacity of diaspora organisations to contribute to peace and development in the country of origin and often shape the focus and the activities of diaspora organisations. In many countries, diaspora organisations often face a lack of structural funds and heavily rely on the contributions of diaspora members to fund their operational budgets. Such financial arrangements may lead to competition for resources among groups, which could lead to increased tensions and conflicts between different fractions (Warnecke, 2010). Moreover, studies report that counter-terrorism laws and measures introduced after $9 / 11$ pose a risk of criminalising financial transactions from diasporas. Hence, these laws and measurements might limit the ability of groups to generate both internal and external funds, since accountability and transparency of the use of financial contributions are often limited in conflict settings. Counter-terrorism measures also create practical challenges because negotiating with armed non-state actors is often crucial in gaining access to people in need (Hammond et al., 2011; Svoboda \& Pantuliano, 2015).

The legal framework based on which a legal status, electoral rights, access to citizenship, and the freedom of association are granted, defines the degree of exclusion and inclusion of migrants and refugees into the political system of the host country and as such structure the space for conventional political participation such as voting, party membership or the running for elections. Whereas permanent residence status enables migrants to enjoy similar social, economic and political rights as citizens, asylum seekers, refugees, temporary or undocumented migrants often suffer from restriction or even exclusion of rights, leading to a stratified system of socio-legal entitlement for the migrant population (Ruhs, 2010). As a result, different legal categories of migrants face distinct socioeconomic conditions that also influence the capacity of migrants and refugees to become politically involved in both the host and home country (Al-Ali et al., 2001; Martiniello, 2006).

According to Cinalli and Giugni (2011), the political and institutional context of the destination country (at national, regional and local levels) including general policies towards immigrants, policies towards migrant associations as well as the access to public authorities and formal institution, defines the relative openness or 
restrictiveness towards migrants' and refugees' political action and claims-making. Furthermore, the authors stress the importance of the discursive and symbolic dimension of opportunities, which refers to the prevailing public discourse towards specific immigrant groups and immigration more in general, that legitimises certain collective identities, actors and group-specific demands while constraining the mobilisation of others. While discursive opportunities can be volatile as these may change in response to specific events, they are also influenced by the way in which the notion of nationhood is historically constructed and how far immigrants are discursively and symbolically included in the nation. Hence, countries which adopt a more pluralist or multicultural approach tend to provide more freedom and space for the cultivation and practice of collective identities and claims-making. In contrast, if migrants or refugees face a restrictive space due to limited access to citizenship and political institutions and/or an unfavourable public discourse, mobilisation efforts may turn towards political issues related to the origin country (Koopmans, 2004).

In the international sphere, political opportunities and constraints are shaped by supranational institutions such as the United Nations or the European Union, international non-governmental organisations (INGOs) as well as by international humanitarian and human rights regimes. Supranational institutions can provide a platform for advocacy where diaspora actors can mobilise support and call for action and international recognition of their cause (Chaudhary \& Moss, 2019). In the humanitarian system and development cooperation, UN agencies and international humanitarian organisations cooperate with diaspora actors in responding to the needs of the target population either via funding or partnership. In the case of Syria, Svoboda and Pantuliano (2015) argue that diaspora organisations were mainly used as service providers, which not only risked a depoliticisation of diaspora action in the name of neutrality, but also the reinforcement of the imbalance of power inherent to the humanitarian system. Counter-terrorism laws and measures introduced after 9/11 can pose a risk of criminalising financial transactions by diaspora actors in cases where the conflict is related to the security discourse, potentially limiting the ability of groups to generate both internal and external funds (Chaudhary \& Moss, 2016). In his book 'Human Geopolitics: States, Emigrants and the Rise of Diaspora Institutions' Gamlen (2019b) emphasises the role of international organisations, aid donors and the broader global migration regime in being a key driver of the rise of diaspora institutions worldwide. As such, supranational institutions not only shape diaspora mobilisation directly by offering financial support to diaspora organisations, but also indirectly through the promotion of diaspora institutions both in sending and receiving states. 
Transnational political opportunity structures, both in the country of origin and the destination country, help to explain why the success of diaspora groups in homeland conflicts often vary over time and place, since these provide both opportunities and constraints for diaspora mobilisation. However, these seem to be group and conflict specific and therefore might empower some groups, while also constraining others. Thus, different groups even within the same diaspora, face different opportunities and constraints within the transnational field, which shape the nature, forms and aspirations of mobilisation. Koinova (2012a) introduces a more dynamic and relational approach for investigating the influence of transnational political opportunity structures, since she argues that research should take into account the positionality of diaspora political entrepreneurs, i.e. the relational position they inhabit in the transnational social field. She defines diaspora positionalities as 'the relative power that diaspora entrepreneurs perceive as deriving from their social positions occupied in a specific context [and as] both a perceptual and relational category' (p. 101). Among other aspects, a proximity to the majority race and religion and a comparative advantage of place vis-à-vis other segments of the network influence the power and positionality of diaspora groups in the transnational space.

Gabrielli, Gsir, and Zapata-Barrero (2017) argue that origin country factors can influence migrants' political and civic participation in the destination country in various ways. Focusing on the micro-level, the 'origin country effect' refers to the civic and political capital that migrants acquired prior to their migration, which includes experiences with civic and political education and culture, as well as the political socialisation within a given government type. In case of authoritarian or corrupt governments, those who left may carry a general mistrust towards political institutions with them, perhaps deterring them to become politically involved in the host country. The 'origin country impact' refers to the influence of emigration and diaspora policies on migrants' destination country political participation at the macro level, as in the case for example when origin country governments mobilise their emigrant population to lobby their host government in their interest.

In sum, transnational political opportunities consist in more general origin and destination country factors, such as the respective political systems in place (e.g. absence of a central government, authoritarian regime vs democracy) as well as the relative stability of the country (conflict, post-conflict, economic/political crises, natural disasters). On the other hand, migration specific aspects such as the emigration and immigration regimes that guide the legal and institutional framework (citizenship, voting, civil rights of migrants) as well as policies targeting the immigrant or emigrant population are crucial structural and relational factors that influence the space of diaspora mobilisation. Next to 
government systems and practices, an analysis of opportunities needs to address the symbolic dimension of state practices towards the diaspora and immigrant or emigrant population more in general in order to understand how the diaspora is discursively and symbolically included in the nation and who is included or excluded from the discourse.

\subsection{Conclusion}

This chapter forms a substantive base for the remainder of this dissertation. If both conflicts and diasporas are understood as being socially constructed, it is important to engage in an analysis that links the macro-sphere of contexts and the structural embeddedness of human experiences with the micro-realm of interpretations, negotiation of meanings and construction of identities. Hence, the process of diaspora mobilisation is not only shaped by the societal, institutional, legal, political and cultural environment present in the origin and destination country contexts, but also by the migrants' aspirations, senses of belonging and social locations. As such, destination and homeland influences shape the construction and mobilisation of collective identities and it is the interactions of factors in both contexts that define the membership to political communities in which collective claims-making is negotiated (Koopmans, 2004). Figure 2 summarises in detail the different dimensions of the diaspora mobilisation process, as well as the influencing factors at the macro- and the micro-levels.

With regard to the transnational political opportunities, both the literature on transnational and diasporic political action, as well as the literature on political inclusion and participation in destination countries stress the importance of the legal, institutional, and political context in which refugee and migrant politics take place, i.e. the exogenous factors enabling or constraining participation, representation and mobilisation. Chapters 4 and 5 provide an overview of the structural environment of the Syrian diaspora mobilisation in Germany by mapping the origin country context and the destination country context, respectively. By providing a detailed account of the macro-level transnational opportunity structures present in the Syrian diaspora mobilisation in Germany, this study is able to embed the empirical analysis into the historical and contemporary context.

Addressing the lack in research investigating the intersection of destination and origin opportunity structures, Chapters 6, 7, 8 and 9 situate the analysis of the emergence and trajectories of the different dimensions of diaspora mobilisation in the transnational context. Each chapter sheds light on both destination and origin country influences and explores in detail the interconnectivities of the 
transnational social field of Syrian diaspora mobilisation. Furthermore, the chapters contribute to an in-depth exploration of the temporal dimension of diaspora mobilisation. Transnational opportunities are seldom fixed and static, as changes in the structural level of diaspora mobilisation can lead to shifting configurations of power and transform the strategies, spaces and trajectories of diaspora mobilisation (Koinova, 2018). Taking into account the volatility of transnational political opportunities, the chapters explore how changes in context shape the trajectories of diaspora mobilisation over time.

Given the relational and interactive process of collective identity formation and consciousness-building, Chapter 7 seeks to provide a detailed investigation of the re-construction and de-construction processes of the Syrian diaspora consciousness. In doing so, the chapter shows how different diaspora actors struggle not only over the definition of the transnational imagined community but also over the representation and legitimation of their voices. It argues that the socio-political dynamics present in the diaspora mobilisation process are a result of both influences of the origin and destination country context. While it is widely accepted that diasporas are multi-layered, heterogeneous, and dynamic social formations, conflict settings in many analyses of diaspora mobilisation impose a communal identity without an investigation of the broader processes in place. This approach, however, potentially precludes the multiple identities, connections, relations and networks that are not defined according to ethnoreligious or national boundaries. As such, the chapter contributes to the field of diaspora studies by exploring these dynamics and interactions of diaspora consciousness-building and collective identity formation and their embeddedness in the structural context.

Focusing on the mobilising structure, Chapter 8 explores the evolution of Syrian diaspora actors engaging in the construction of the imagined community. It argues that diaspora mobilising structures and the set of actors should not be perceived as fixed and static, but rather as highly dynamic and continuously changing. The chapter highlights how the changes of diasporic mobilising structures were not only a result of the more contextual dynamics, but also of displacement of Syrians to Germany. So far, limited attention has been paid to the way in which forced displacement may influence the process of diaspora mobilisation, since most of the research has focused on the actors who were already established in the country of destination and their relation to actors engaging in the conflict in the country of origin. However, the chapter shows that with the displacement of people, political ideas, projects and initiatives also travel with them, leading to a diversification of mobilising structures. 
Despite the growing recognition of the transnational approach, most studies found in the diaspora literature limit their analysis to transnational practices and actions directed towards the homeland. This perspective neglects however the fact that diaspora actors can and often do influence political processes both in the country of origin and the country of destination. Chapter 9 addresses this gap by shedding light on the various transnational practices of Syrian diaspora actors and showing how these contribute to political and societal transformations in Germany and Syria. In so doing, the chapter emphasises the circularity of political remittances and argues that further research needs to move beyond a uni-directional investigation of transnational transfers. The analysis of the temporal dimension of transnational practices further suggests that changes in the transnational political opportunities may not only change the type of diasporic actions, but also the contextual focus and channels of collective action. In the case study at hand for instance, as avenues for direct influence on the country of origin became more restrictive, diaspora political entrepreneurs capitalised on the opportunities of expression and protest in the destination country to indirectly influence decisionmaking towards their cause, or shifted the focus of actions towards influencing the situation in the country of settlement. 
Figure 2: Diaspora mobilisation process and influencing factors
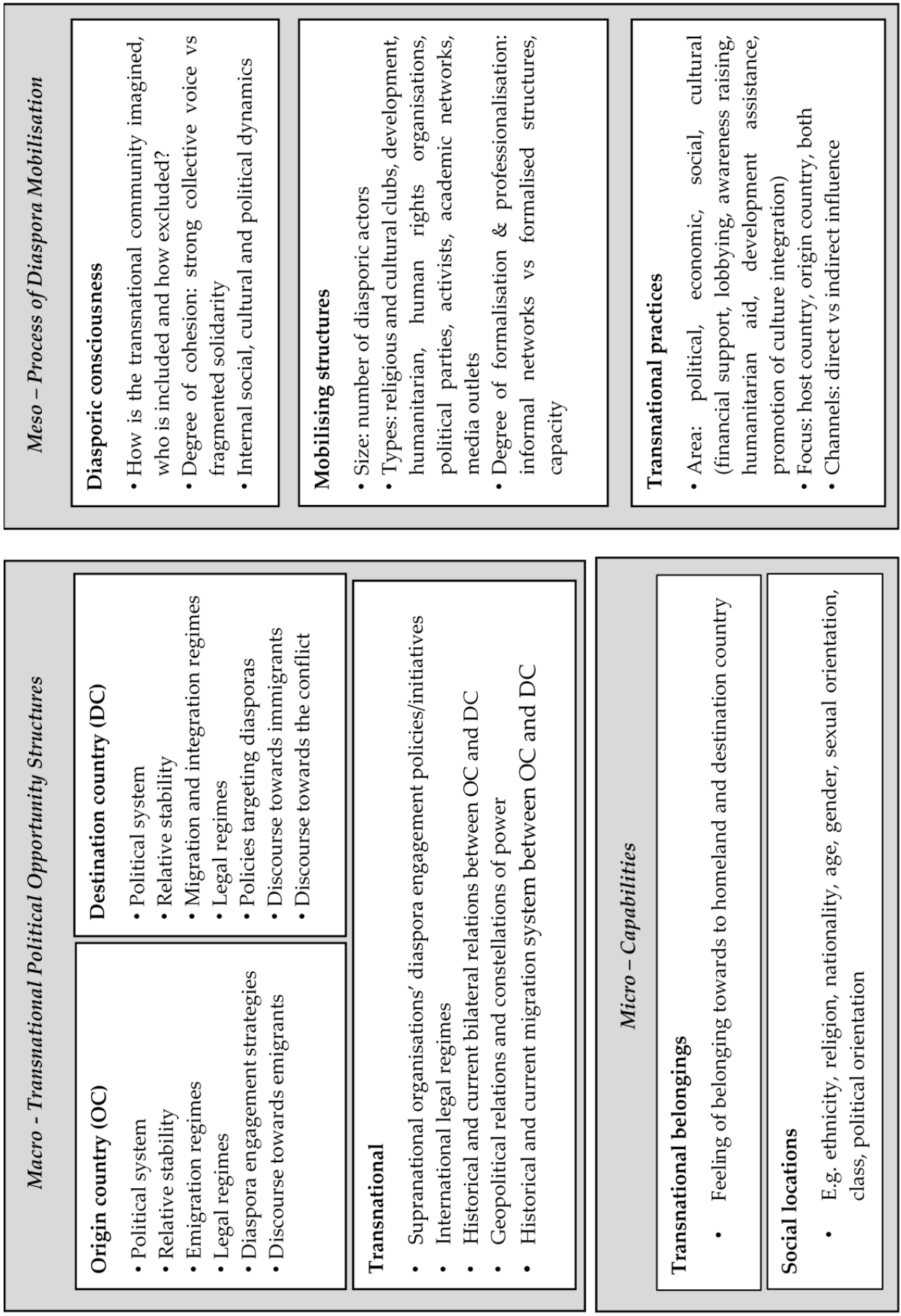



\section{Chapter 3: Methodology}

This chapter provides an overview of the methodology used in this study and discusses some practical and ethical considerations. As the previous chapter has outlined, this research understands diaspora mobilisation as a process of social construction, as contextual, situated and embedded in specific historical, political, social, and cultural contexts. The empirical analysis draws on a multi-level analysis to examine the interconnectivity and interaction of different factors at the micro and macro levels and how these factors shape trajectories of the diaspora mobilisation process (meso-level). Given the dynamic and complex process of diaspora mobilisation and the explorative nature of the research questions, a qualitative case study approach was best suited for this research.

\subsection{Case selection}

The case study approach provides a detailed in-depth understanding of a specific problem, as it enables an analysis of multiple perspectives that are embedded in a specific context. It therefore provides a useful method, since the understanding of the research topic needs to be comprehensive and contextualised (Lewis, 2011). In order to explore the process of diaspora mobilisation in conflict-settings in depth, the Syrian diaspora in Germany was chosen as a case. The selection was based on the following three criteria:

1) Current conflict in the country of origin

2) Relevant destination country

3) The existence of some degree of internal organisational framework, transnational links and practices

First, in order to analyse the dynamics of diaspora mobilisation, an ongoing conflict was chosen to enable an exploration of developments throughout the course of the conflict. At the start of this research project in 2012, the initial peaceful movement that took to the streets in Syria in March 2011, had already escalated into a militarised conflict, with huge scales of violence, displacement and destruction across the country. At the time of writing, the Syrian conflict has become known as one of the most dramatic humanitarian and security crisis in the world, causing between 400,ooo to 500,000 deaths, leaving 11.7 million people in need of humanitarian assistance and provoking deepened sectarian violence across the region (Human Rights Watch, 2019; OCHA, 2019). Since 2011, 6.2 million Syrians have been internally displaced, and over 6.7 million people have been forced to move across the borders and seek refuge in other countries. While Syrian 
refugees have been granted asylum in 129 countries worldwide, the vast majority are hosted in their immediate neighbouring countries including Turkey, Jordan, Lebanon, Iraq and Egypt and, to a lesser extent, in North Africa, Europe and the United States (UNHCR, 2019). Syrian diaspora groups are a particularly interesting case given the high relevance and huge scale of the Syrian conflict.

Germany has become Europe's largest destination country for Syrian immigrants, with 813,000 persons having a Syrian migration background in 2018 (Statistisches Bundesamt, 2019a). With regard to transnational engagement Germany runs several programmes at local, regional and national levels that promote the activities of migrant organisations both in the countries of origin and in Germany. Some civil society initiatives of Syrians in Germany are financially supported by the Federal Office and the German Development Cooperation (GIZ) (Ragab, Rahmeier \& Siegel, 2017).

Informal talks with a diverse range of stakeholders at the beginning of this research project in 2012 revealed that the initial peaceful uprisings in Syria in March 2011 not only influenced Syrian society in the country of origin but also Syrians living abroad in Germany, who started to support the initial peaceful movement from abroad. At the same time, there remains a considerable lack in literature on Syrian diaspora groups, particularly regarding the nature and dynamics of their engagement with Syria, the impacts of that engagement on the current conflict, and the potential role that such engagement could play in the future development and reconstruction of the country.

\subsection{Data collection}

This research made use of an exploratory approach and employed a mix of methods for data collection and analysis. The literature review on diaspora mobilisation in conflict-settings and its contribution to conflict, peacebuilding and reconciliation served as a basis for the development of the conceptual framework. The analysis of secondary data and statistics aimed to provide an overview of the demographic and socio-economic composition of the Syrian immigrant population in Germany. The main source of data consists in semi-structured, in-depth interviews with members of the diaspora, aiming at exploring the structures and process of Syrian diaspora mobilisation in Germany. Additional insights were gathered through unstructured interviews with other relevant stakeholders, as well as through information obtained from social media pages and websites of the diaspora organisations and initiatives. Finally, the collection of data through participant observations (see Appendix IV) sought to enable an investigation of the relational, contextual and cultural aspects, as well as the underlying dynamics of 
diaspora mobilisation. Before turning more in detail to each of the main data collections tools, two important caveats of this study will be addressed and discussed briefly.

First, as outlined in the theoretical section, this research focuses on the organised Syrian diaspora, i.e., on Syrian diaspora political entrepreneurs, their organisational framework, transnational links and practices. The process of diaspora mobilisation, with a specific focus on the actions of diaspora organisations, networks and initiatives, forms the units of analysis of this study. Bush (2008) defines diaspora organisations as 'complex, formal, informal or semiformal organisations that articulate and pursue goals that are asserted to be representative of the interests and aspirations of 'the diaspora' as a whole' (p.195). As collective action of diaspora groups often tends to be the result of transnational mobilisation activities by a small but often powerful elite (Adamson, 2008; Portes et al., 2007), the findings should not be considered as representative for the Syrian immigrant population as a whole. What Glick Schiller (2013) calls the 'ethnic association fetish', involves the risk of limiting the analysis to the voice of a small but powerful elite, whose legitimation can potentially be highly contested. In addition, the focus on the institutionalised and organised diaspora might conceal transnational mobilisation of diaspora members that goes beyond formal means of engagement. To enable an investigation beyond institutionalised action, engaged individuals, many of them being artists and young activists, have been included in the sample.

Another important caveat of this study is that one should not treat diasporas as an extension of the nation-state model, implicating that there exists conformity between territory, culture and identity. In particular, since the WWII post-war era, economic, political and cultural boundaries are shaped and changed constantly, resulting in new claims of membership, belonging and identity (Soysal, 2000). Identities are hybrid, fluid and multi-layered and, hence, boundaries of diaspora groups are constantly drawn and redrawn (Mavroudi, 2007). West Asia is the birthplace and spiritual centre of diverse religions and home to numerous ethnic groups, scattered across various countries. As a result, Syrian society is characterised by a rich diversity in terms of ethnicity and religion, which is also reflected in the diaspora. In addition, this also means that imagined communities of diasporas are not necessarily limited to national borders, but can span over different countries of origin, like in the case of the Kurdish or Aramaic/Assyrian diasporas, resulting in competing territorial claims of contested homelands.

The focus of this study lies on diaspora organisations that explicitly target Syria or the Syrian immigrant population in Germany. Hence, Kurdish organisations that 
pursue the objective of an independent Kurdish state, as well as cultural associations that were founded for the purpose of preserving the Aramaic cultural heritage, representing the interests of the Aramaic Christians in Germany, were excluded from this study. This does not mean that these objectives and claims are not legitimate or relevant but are rather perceived as claims of the Kurdish or Aramean/Assyrian diaspora, respectively. However, Kurdish and Aramaic organisations have been included, when they were identified (or identified themselves) as part of the Syrian diaspora, in order to capture the heterogeneity of diaspora mobilisation. It has to be acknowledged that this selection was not always straightforward, because the boundaries of diasporas are hybrid, dynamic and multi-layered. For instance, a Kurdish organisation in this study clearly identified itself as being part of the broader Syrian diaspora at the beginning of the uprising, yet following the increasing escalation of the conflict, as well as the rising autonomy of the Kurdish region in northern Syria, became more aligned with the Kurdish cause and independence.

\subsubsection{In-depth interviews}

As shown in Chapter 2, diaspora groups should not be perceived as fixed, but rather as situated in the historical context and process of political mobilisation, and therefore dynamic in space and time (Mavroudi, 2007). As a result, researchers analysing diaspora mobilisation are confronted with constantly changing units of analysis, given the often high fluctuations within the diaspora community in response to external and internal dynamics (Warnecke, 2010). In particular, the Syrian case, which is characterised by highly complex and dynamic conflict and migration patterns, poses a challenge to systematic and rigorous data collection. As will be shown throughout the study, crucial events, such as the emergence of the initial peaceful movement, the violent escalation of the conflict, as well as the more recent displacement to Germany, activated members of the Syrian diaspora to take action and to contribute to efforts towards creating a peaceful society, both in Syria and Germany. On the other hand, some organisations dissolved and became inactive, sometimes due to internal conflicts or frustration over the continuing deterioration of the situation in Syria. Exploring these dynamics and developments over the course of the conflict, constitutes an essential contribution to the understanding of the diverse mechanisms that shape diaspora mobilisation.

To gain an overview of the organisational landscape, a mapping of Syrian diaspora organisations in Germany was conducted, using different channels for gathering the information. As a first step, a search was conducted in the Common Register Portal of the German federal states, which maintains a database of all registered associations in Germany. In addition, extended desk research was conducted to 
collect contact details of each organisation and to identify additional unregistered more informal initiatives. This database was frequently updated during the research process.

In addition to the mapping exercise, snowball sampling was used to identify diaspora initiatives that are not formally registered and do not have a German web-presence. Further, this strategy was also used to purposively sample individuals based on specific characteristics such as gender, age and minority background in order to ensure that the heterogeneity of the diaspora was captured in the sample. This method was shown to be specifically effective with regard to the gender and age categories. While many participants stress the importance of the role of women both in the Syrian and diasporic movement, in the majority of cases, responses to interview requests came from male members of the Syrian diaspora. This might partly be explained by Syrian migration patterns to Germany, which tend to be characterised by the more high- and medium-skilled, maledominated immigration (see Chapter 5.2.). Yet overall, women showed more hesitation to participate in the study than men. By approaching actively engaged women via other respondents who participated in the study, trust could be built, and participation of this target group was facilitated. With regard to the younger generation, their engagement tends to be characterised by more non-hierarchical, loose structures and networks. As a result, the mapping exercise was not able to capture the full extent of this more informal engagement. Reaching out to this target group via snowball sampling enabled an investigation of diaspora mobilisation beyond institutionalised action by including individually engaged members in the sample, such as political and media activists, musicians and artists.

This dissertation builds on previous research conducted as part of the author's master thesis which explored how social and political transformations in Syria in 2011 influenced the Syrian diaspora consciousness in Germany. Within this previous study 13 interviews with 16 members of the Syrian diaspora were conducted between September and October 2012. Between November 2012 and December 2015, no active fieldwork took place. However, to follow up with ongoing developments, diaspora events such as meetings and protests were attended, and interviews with seven diaspora members were conducted.

The main fieldwork for the doctoral project was carried out between January and July 2016. Based on the mapping exercise explained above, all identified organisations were contacted via email, which next to a brief description of the study, included information on the interview process, an explanation of voluntariness and confidentiality, as well as the contact details of the researcher. In general, the response rate to the email request was low. In the case were numbers 
were available, the organisations were contacted via phone, which generally resulted in greater response rates and willingness to participate in the study. Further, attending information events, cultural activities, meetings and protest actions organised by diaspora political entrepreneurs, proved to be an important approach to gain access and build trust with Syrian diaspora groups. Social media platforms like Facebook, were essential for identifying these events and also served to generate further contacts. As mentioned above, snowball sampling was used to identify individually engaged activists, or more informal engagement based on loose structures and networks, as well as to ensure that the heterogeneity of the diaspora with regard to gender, age and minority background was captured in the sample. Using these different sampling strategies, 34 interviews with 35 representatives of the Syrian diaspora in addition to one stakeholder interview were conducted within this fieldwork period.

In October 2016, the German Development Cooperation office (GIZ) commissioned UNU-MERIT to carry out a diaspora mapping study on the Syrian diaspora in Germany. The main aims of the study were to gain insights into the profile of the Syrian diaspora in Germany, through a mapping and documentation of Syrian diaspora organisations, associations and initiatives, and to analyse their contributions to peace, development and reconstruction in Syria. Moreover, the research identified several avenues for cooperation between diaspora organisations and GIZ in order to develop recommendations regarding a context-specific and conflict-sensitive strategy for approaching the organised diaspora. Within this study 17 interviews with 19 members of the Syrian diaspora and one formal stakeholder interview were conducted between October 2016 and December 2016. In addition, informal and unstructured interviews with GIZ staff members were carried out, to gain an overview of the work of the German development cooperation with regard to the Syrian context and in the field of migration and development more in general.

In addition, this dissertation makes use of data arising from research conducted by the author in 2017 for the International Institute for Democracy and Electoral Assistance as part of its Refugees, Asylum Seekers and Democracy project, funded by the Robert Bosch Foundation. Recognising the dual role of refugees and asylum seekers as political actors in their host and origin countries, the project aimed to generate comparative knowledge on the impact of refugees and asylum seekers on political life through formal and informal means of political participation. The author's case study focused on Afghan and Syrian asylum seekers and refugees, who are among the largest groups of refugees and asylum seekers in Germany. It explored the opportunities and challenges regarding their civic and political participation in Germany, and the ways in which they can participate in peace and 
democracy-building in their countries of origin. As part of this study nine in-depth interviews were conducted between June and July 2017 with Syrians who were selected based on their active political involvement in Germany, their country of origin or both.

In total 80 formal interviews with 66 representatives of the Syrian diaspora and 1 formal stakeholder interview were conducted between September 2012 and July 2017. The majority (40) migrated before the outbreak of the conflict. Twenty participants had a conflict-related migration history, while the remaining six can be considered as part of the second generation since they were either born in Germany or migrated as young children. The duration of stay in Germany at the time of the interviews ranged from one to 41 years, hence, covering various phases of Syrian immigration to Germany. The diaspora respondents had diverse reasons for migration, ranging from work and education, to political asylum. All but three respondents were either studying or had a university degree. Moreover, with 55 respondents being male, the sample method unfortunately did not allow for a demographic spread of the sample in terms of social class/educational background and gender balance. With regard to ethnic or religious affiliations, the study was able to capture a great diversity, including respondents who (at least partly) identified themselves as being Kurdish, Palestinian, Turkmen, Christian, Ismaili, Muslim, Alawi, Druze, or Aramaic.

It has to be emphasised that the findings of this study are based on the opinions of a very selected group, whose perspectives are likely informed among other things by their socio-economic status, their migration status and their demographic characteristics. While this is not inherently problematic, because collective action of diaspora groups often tend to be a result of transnational mobilisation activities by a small elite of political entrepreneurs (Adamson, 2008; Portes, Escobar, \& Radford, 2007), it should be emphasised that a different demographic mix of individuals potentially would have led to a different understanding of "the diaspora" and its means of engagement. As such, the findings are not generalisable to the Syrian population in Germany as a whole. However, the dissertation contributes to a deeper understanding of the dynamic process and mechanisms of diaspora mobilisation, by shedding light on the collective level of transnational mobilisation, its structures, agents and practices. At the same time, further research should investigate the nexus of diasporas and conflicts beyond elite mobilisation, since the current approach involves the risk of limiting the analysis to the voice of a small but powerful elite, whose legitimation might potentially be highly contested.

The interviews were semi-structured based on an interview guide (see Appendix I) that was divided into five main sections: 
1) Migration history: As an introductory question, respondents were asked to talk about their migration history, about their lives before leaving Syria, their reasons for migration, their decision to migrate to Germany as well as their relationship to Syria more in general.

2) Subjective view on the Syrian diaspora: This section aimed at generating an overview of the Syrian diaspora in Germany (both organised and unorganised) with regard to the composition in terms of socio-economic factors, ethnicity, political aspirations and religion, their networks and potential lines of conflict and fragmentation.

3) Basic organisational information: This topic included questions about the engagement, focusing on the motivation, the structure, and the goals of the organisations as well as their sources of funding.

4) Current organisation activities: Questions in this section of the interview dealt with peacebuilding and potential contributions regarding the reconstruction process. They sought to explore the perceptions of peace and to maintain an overview of the activities carried out in Syria, the neighbouring countries and Germany.

5) Cooperation: This section aims at understanding the forms of cooperation and networks that exist among diaspora organisations, as well as with regard to other actors, such as policymakers, NGOs and INGOs, both in the context of Germany and Syria.

6) Main challenges and future plans: This final section aimed at exploring the specific activities planned in the (near) future and further aspirations in particular with regard to the peace and reconstruction process. Another focus was to uncover potential challenges and barriers the organisations face in their engagement.

In general, the sequence of the questions was applied in a flexible manner, allowing for fluid discussions and adjustments with regard to the individual situation during each interview. Based on the respondents' wishes, all but two interviews were recorded and transcribed, to ensure an in-depth analysis of the data. The respondents were given the possibility to choose the format and the location of the interview. The vast majority were individual one-to-one interviews, whereas five were conducted in groups ranging from two to five persons. Fifty-six of the interviews were carried out in person in diverse cities of Germany, 15 were conducted via Skype and 10 via phone. The location of the interviews was chosen by the participants. In some cases, interviews were conducted at their homes, in 
other cases at the office of the diaspora organisations or in public places such as cafes or restaurants. Regarding the language, interviews were either conducted in English or in German. The choice of language comes with several limitations which may have influenced the overall composition of the sample. Given that diaspora mobilisation was embedded in the German context, most actors identified in the mapping had sufficient knowledge of either the German or the English language. However, the choice of language may still have shifted the sample towards the more formalised and visible actors of the Syrian diaspora and hampered the access to more informal and recent initiatives that mobilise in the Arabic language. As a result, the findings might be biased towards the more organised, established and better educated diaspora political entrepreneurs, whose discourses and actions are also shaped by the political opportunities in the German context. At the same time, the choice of conducting interviews without translation also enabled a better control of the potential impacts of the research as well as the possibility to build trust and relations with the participants. As outlined in Chapter 3.4., next to potential harm during the interview process, researchers have to anticipate the potential negative consequences that participation might entail for the respondents. The specific security dimensions, as well as socio-political dynamics of diaspora mobilisation required continuous efforts to build trust and to ensure a positive outcome of the research process.

\subsubsection{Participant observation}

Rooted in traditional ethnographic research, participant observation is a qualitative data collection tool that enables an investigation of multiple perspectives, underlying dynamics, intersecting hierarchies and power dimensions within the community under study (Mack et al., n.d.). While historically social movement theories focused on structural aspect of mobilisation, or the rational and strategical choices of the movement actors, the cultural turn puts emphasis on the internal movement processes, and the micro-realm of emotions, interpretations, negotiation of meanings and construction of identities (Davis, 2002).

Participant observation was used to supplement the data gathered through interviews, as this method helped to gain further insights into the more underlying dynamics of diaspora mobilisation (see Appendix IV). The researcher's participation in protests, demonstrations and information events across different cities in Germany, such as Berlin, Cologne and Hamburg, hence, helped to discover the cultural aspects of Syrian diaspora mobilisation, including its expressive symbols, rituals, dominant frames and their potential contestations and negotiations among the different groups involved. In addition, cultural productions, such as art exhibitions, film screenings and music concerts of Syrian 
cultural activists were attended in different sites across Germany. Diasporic art productions, such as painting, drama, dance, music, literature, photography and film provide diaspora groups with a creative space for the exploration and expression of identities and are powerful tools for addressing political struggles within both host and origin country context. As such they are important sites of social transformation (Martiniello \& Lafleur, 2008). The attendance of meetings of diaspora groups, initiatives and organisations, as well as countless informal conversations, further, helped to explore the more underlying factors, such as intersecting hierarchies of unequal power relations due to gender, class, ethnicity and generation.

In addition, participant observation was undertaken at several events organised by different stakeholders engaging with the Syrian diaspora in Germany and in other country contexts. These included the 'Syrian diaspora business Forum' hosted by the World Bank Group and GIZ on 27-28 February 2017 in Eschborn, Germany, 'The Role of Diaspora organisations in supporting durable solutions for Syrians displaced' conference hosted by the Danish Refugee Council and the Durable Solutions Platform on 24 $4^{\text {th }}$ November 2017 in Berlin, the 'Sounding Board Meeting for Syrian Leadership Programme in QICS' organised by GIZ on 30 January 2018 in Berlin, as well as the 'The Syrian Diaspora in the Aftermath of 2011' workshop organised by the Arab Reform Initiative on 12 April 2018 in Paris. These events not only provided the opportunity for exchange with a diverse range of actors that seek to engage with Syrian diaspora groups, but also to explore the relational and interactive dynamics between diaspora actors and stakeholders, and how these further influences the process of diaspora mobilisation.

Field memos were produced for each of the attended events and include both descriptive and reflective information as well as notes that situate the event in the broader analysis. Emphasis was put on the physical setting and social environment, information on the participants, their interactions and specific behavioural aspects, such as, conflicts, negation of meanings and other forms of contestation. In addition, visual recordings, such as videos and images were taken in order to complement the data analysis with visual material.

\subsubsection{Supplementary quantitative data sources}

Given that the dimension and nature of diaspora involvement depends on the size, composition and distribution of diaspora groups, as well as on individual capabilities and aspirations, it is essential to understand the broader migration patterns as well as the social, economic and political circumstances and conditions that Syrian migrants encounter in the destination country. Hence, secondary data and statistics were reviewed in order to provide an overview of the demographic 
and socio-economic composition of the Syrian immigrant population in Germany. Data was retrieved from three main sources, each providing different information on different categories of Syrian immigrants such as Syrian citizens, people with a Syrian migration background and asylum seekers.

First, the German Federal Statistical Office collects annual data on the immigrant population residing in Germany, where information is available on gender, age, average length of stay, and residence status for each nationality. The data only captures the immigrant population that does not have German citizenship, and does not provide separate information for Syrian nationals on educational level, labour market performance, or other socio-economic key statistics (Statistisches Bundesamt, 2019b). Next to this, the Federal Statistical Office annually provides data on the socio-economic and demographic characteristics of the population with a migration background residing in Germany. A person has a migration background 'if he or she or at least one parent does not have German nationality by birth' (Statistisches Bundesamt, 2019a, p. 4). Since the year 2015, persons with a Syrian migration background are captured by the census.

\subsection{Qualitative data analysis: Thematic analysis}

Thematic analysis is a technique for summarising and organising text and involves multiple coding levels that are used as a categorising strategy for qualitative data in order to identify the most salient constellations of meanings present in the dataset. The main aim is to discover patterns and to develop themes that categorise the issue under study into generic concepts and to a more generalisable theory (Boyatzis, 1998). The method is one of the most prevalent analytical strategies used in qualitative research, as the technique is not tied to a specific discipline or epistemology but can be employed in positivist, constructionist as well as realist approaches and theories. It is, therefore, a method which allows for detailed and complex interpretations and is able to present and to problematise multiple truths of socially and historically located research phenomena (Braun \& Clarke, 2006).

To ensure transparency and scientific rigour with regard to the process of how meaning is created from qualitative data, it is important to follow a streamlined step-by-step process of thematic analysis. In general, the procedure includes the organising and sorting of data through coding, the connecting and grouping of codes through the creation of categories and sub-categories and the creation of themes by identifying connections and relationships between the categories (Braun \& Clarke, 2006; Green et al., 2007; Saldaña, 2013). 
Figure 3: A streamlined codes-to-theory model for qualitative inquiry

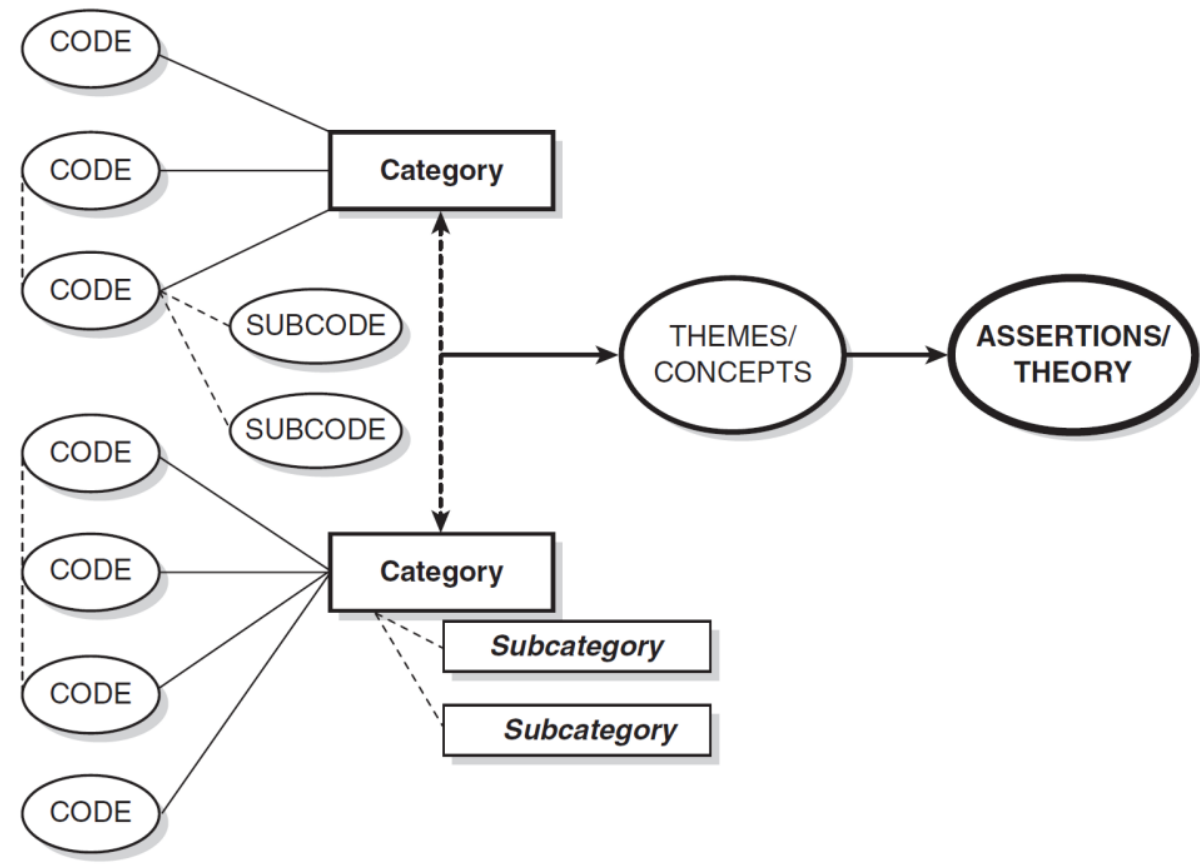

PARTICULAR

GENERAL

Source: Saldaña 2013, p. 13

It is important to mention that the process of thematic analysis did not follow a linear, step-by-step procedure, but rather was characterised by a reflective, cyclic and iterative process, moving back and forth between data collection and analysis and the review of theories and concepts. Keeping this in mind, the following sections provide a detailed description of the different steps followed in the data analysis.

\subsubsection{Getting familiar with the data}

The first step is to get familiar with the bundle of data and text collected and produced during the research in order to organise the search for meanings, patterns, trends and themes. It is a time-consuming process, which involves the reading and re-reading of interview transcripts, field notes and other documents used, as well as the multiple listening of the interview recordings (Braun \& Clarke, 2006; Green et al., 2007). Mason (2002) suggest three modes of reading the data and getting familiar with a text, namely literally, interpretively or reflexively. Reading a 
text literally means looking at the content, form and structure, hence, on the 'what and how' something is being said. Through interpretive reading the researcher constructs his or her own interpretation of what the text means, by identifying underlying ideas, assumptions, discourses, norms and rules, as well as representations and constructions of a social phenomenon or determining causal mechanisms of social action. It is, therefore, the identification and interpretation of the latent meaning of the text. Finally, through reflexively reading a text the researcher explores how his or her position, values, orientations, lived experience and epistemological viewpoint shape the generation and interpretations of the data. Commonly, qualitative researchers make use of all three modes of organising and reading the data in an iterative process, in which interpretations, reflections, and data collection dynamically flow and interact during the data analysis (Crabtree \& Miller, 1999). Getting familiar and organising the data collected is, hence, a crucial step to make sense of the phenomena under study and to build a foundation for a detailed and systematic analysis.

\subsubsection{The process of coding}

The process of coding involves the labelling of similar text passages with a code in order to prepare the interview transcripts and field notes for comparisons and for the identification of any patterns during the further analysis. Codes are the most basic segment, or element, of the raw data or information that can be assessed in a meaningful way regarding the phenomenon' (Boyatzis, 1998, p. 63). By giving meaningful and descriptive names to themes, topics, concepts, terms or phrases that occur in the data, the process of coding helps to organise and sort the information obtained during the data collection. Coding is both a reflective and iterative process, as codes might be added, redefined or eliminated during the research process (Braun \& Clarke, 2006; Green et al., 2007).

Code books can be useful tools to ensure rigour and transparency concerning the data coding process. Herein, it is necessary to not only provide a clear definition and detailed description of the code, but also to identify the boundaries based on inclusion and exclusion criteria regarding how and when to code a segment with a particular label (Bernard et al., 2016). The development of the code book depends on the choice of data analysis approach. If an inductive approach is used, the process of coding is bottom-up and data driven, meaning that the text is carefully coded without using a pre-existing coding frame and independent from the researcher's theoretical or analytical preconceptions. In contrast, a deductive approach tends to be more theory driven, since codes are developed based on the analytical framework chosen prior to the coding process (Fereday \& MuirCochrane, 2006). 
In line with Fereday and Muir-Cochrane (2006), the analysis of this research applied a hybrid approach, by using both a deductive coding scheme, guided by the introduced analytical framework and research questions, as well as an inductive coding scheme, to reveal aspects of diaspora mobilisation not considered by the current body of literature. As a first step, a code book was developed which included the main factors (both at macro and micro levels) identified in the analytical framework (see Chapter 3) as influencing the process of diaspora mobilisation. Based on this, the gathered data was coded, and the reliability of the manual was tested and eventually modified to make it applicable to the dataset of this research. In a second step, data was coded inductively, to not only reveal aspects of diaspora mobilisation not considered by the current body of literature but to also take the contextuality and case-specific nature of diaspora mobilisation into account. The software NVIVO was used for coding and analysing the data. The following table 3 provides an extract of the code book developed.

Table 3: Extract of Code book

\begin{tabular}{|l|l|}
\hline Mnemonic & Threats \\
\hline Short description & Threats to life, security and well-being \\
\hline Detailed description & $\begin{array}{l}\text { Accounts of participants that relate to personal } \\
\text { experience with long-distance regime politics }\end{array}$ \\
\hline Inclusion Criteria & $\begin{array}{l}\text { Accounts of detention, torture, or other threats to life } \\
\text { experienced when returning to Syria or other threats to } \\
\text { personal security experienced in Germany }\end{array}$ \\
\hline Exclusion Criteria & $\begin{array}{l}\text { If accounts of long-distance regime politics are not } \\
\text { related to personal experiences, if accounts relate to } \\
\text { experiences prior to the migration }\end{array}$ \\
\hline
\end{tabular}

\subsubsection{Categorisation}

While codes help to reduce, sort and organise the data collected, categories seek to define and describe the links and relationships within a set of codes. The main aim of this step of the analysis is to link the codes into coherent categories that describe the different participants' perspectives on the issue under investigation. Given the complexity of qualitative data, the identified relationships are seldom straightforward but often contain contradictions and exceptions (Green et al., 2007; 
Saldaña, 2013). According to Green at al. (2007) 'analytic categories are 'saturated' when there is sufficient information for the experience to be seen as coherent and explicable' (p. 548).

For example, with respect to the historical origins of state-diaspora relations, this research identified various means of long-distance measures implemented by the Syrian regime to influence the process of diaspora mobilisation in Germany, including personal threats to life and limb, the use of violence or menaces against relatives in Syria and surveillance measures in the destination country. As result, the codes 'personal threats', 'punishment of relatives in Syria', and 'surveillance measures in the destination country' were categorised under the major heading measures of long-distance regime repression.

Next to descriptive topics, categories can be created to capture conceptual processes to identify key elements, concepts and dimensions of the phenomenon under study and to discern possible relationships and interlinks (Saldaña, 2013). For instance, the category effects of long-distance regime repression, which includes the codes 'direct repression of political mobilisation', 'culture of fear and mistrust' and 'troubled relationship to the homeland' bundles the different perspectives of respondents on the effects of long-distance repression at the individual and collective levels.

Categories can also help to define and identify separate groups among the respondents to indicate areas of consensus in response to the research questions as well as areas of conflicting perspectives and experiences (Fereday \& MuirCochrane, 2006). For instance, during the organisation of codes, the analysis identified divergent perspectives, which tend to be shaped by different exposure and experiences with the conflict and distinct migration trajectories. As a result, respondents were assigned two categories, namely older generation, for respondents who migrated prior to the conflict and new generation for respondents who migrated after the outbreak of the uprising, in order to enable a comparison between the groups. Given that these groups are also internally heterogeneous, sub-categories such as age, gender, religion and ethnicity were created to further cluster the differences identified between the responses in a group.

\subsubsection{Identification of themes}

After defining codes and bundling them into coherent categories, this step of analysis seeks to identify themes in the data that capture the relationship between categories and sub-categories. As such, the development of themes allows for a higher level of abstraction and interpretation, by identifying the conceptual or 
sequential relatedness of categories. It is in this phase that the more analytical and interpretive work of the data analysis begins (Green et al., 2007). The double criteria of 'internal homogeneity and external heterogeneity' developed by Patton (2002) offers a good strategy to test the accuracy and the reliability of the identified themes. Internal homogeneity serves to check whether the data collected within each theme or within a category cohere in a meaningful way, whereas external heterogeneity demands that there exist identifiable differences across individual themes or categories. In order to produce strong evidence, themes must not only be tested with and across the data but also against theoretical concepts, by linking the themes with social theory to derive broader explanations on the phenomenon under study (Green et al., 2007).

Thematic maps are a useful tool to visualise the different relationships between codes and categories and how these explain a more overarching theme (Braun \& Clarke, 2006). The following gives an example on how the analysis moved from codes to categories to more overarching themes (see Figure 4). As identified before, surveillance measures conducted by the Syrian regime in Germany engendered feelings of fear and mistrust among Syrians living in Germany, which limited the ability of diaspora actors to generate and maintain a strong collective identity and diaspora consciousness. Along with other long-distance instruments and policies, the Syrian government, through this 'transnationalism from above', was able to create geographies in which human and political spaces transcended territorial boundaries and to repress any form of diaspora mobilisation from below. 
Figure 4: Thematic map: Transnationalism from above

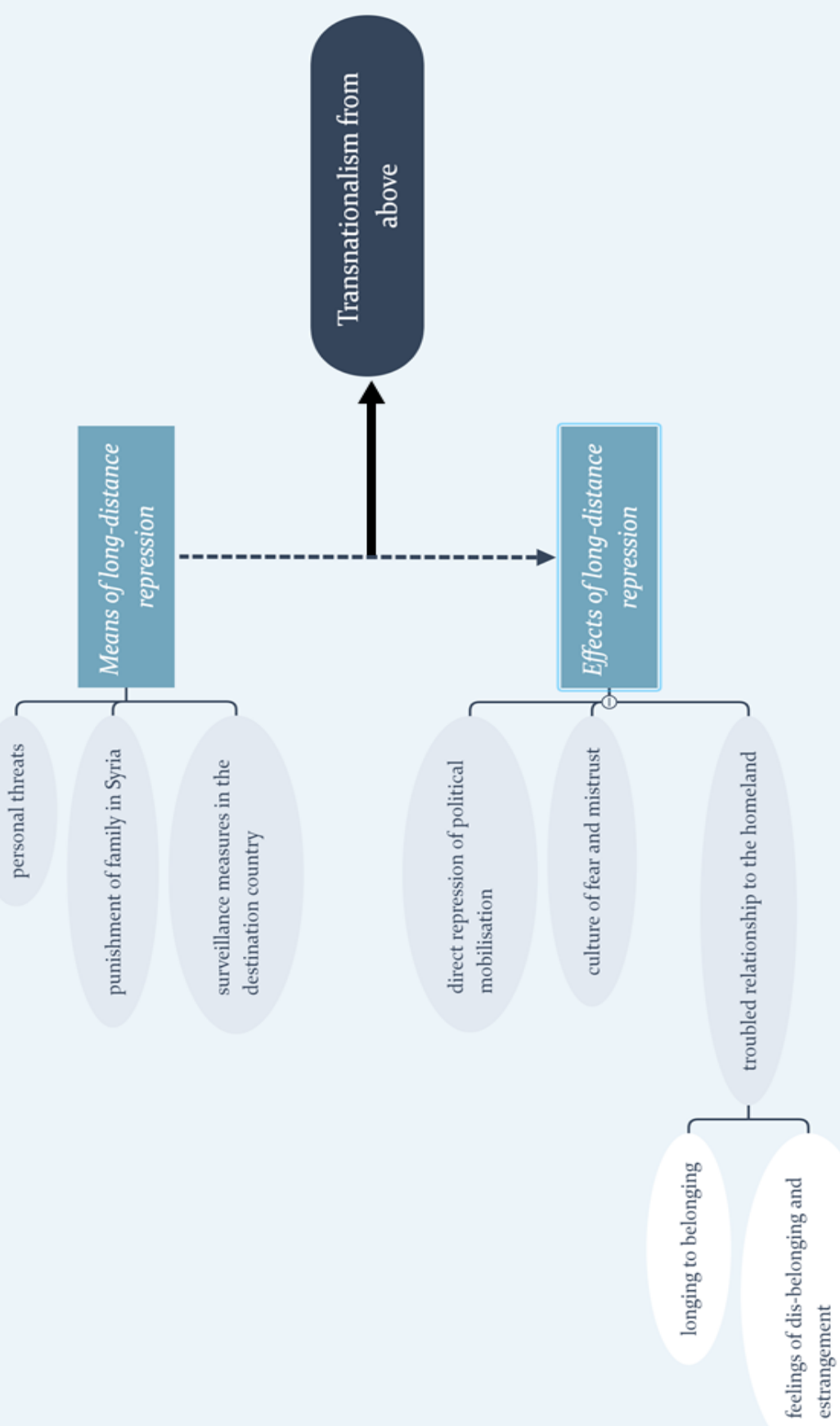




\subsection{Practical challenges, opportunities and ethical considerations in doing research in an on-going conflict setting}

This section discusses the practical challenges and opportunities as well as the ethical considerations arising from a qualitative approach in diaspora and conflict research, in particular with regard to sensitive topics such as the personal migration and conflict experience of the participants, potential security risks for the target group and the researcher's responsibility more in general. In order to ensure that the dissertation complies with the ethical standards, this study sought clearance from the Ethical Review Committee Inner City (ERCIC) of Maastricht University in 2015.

\subsubsection{Practical challenges and opportunities}

As a first caveat, the challenges and opportunities of conducting research in an ongoing, complex and very dynamic conflict setting must be acknowledged. During the course of the dissertation, the constantly changing conditions both in Syria and in Germany represented the major challenges for conducting systematic research. The main difficulty was related to the highly dynamic nature of the Syrian conflict and the diasporic response to it. The term reactive diaspora was highlighted in a wide range of interviews, meaning that respondents felt that they lived in a constant mode of reaction in order to address the multitude of needs arising from the conflict. Capturing and making sense of the dynamics while these were still on-going presented one of the biggest challenges in the research process.

Adding to the already existing complexity, the repercussions of the conflict were not spatially isolated but also increasingly unfolded in the destination country. As mentioned earlier, during the fieldwork phase, Germany became the major destination for Syrians seeking protection in Europe. The increasing numbers of people seeking protection in Germany not only changed the migration and integration regimes, and German policies targeting Syrian diaspora mobilisation, but also engendered shifting public discourse and attitudes towards immigrants and refugees in Germany. As a result, the dynamics present in the origin country context as well as the changes in the contextual dimensions of the destination country led to a great volatility of the transnational political opportunity structures.

Moreover, displacement not only affected the research environment and fields but also the size and the nature of the target group. As will be shown in Chapter 8, the number of Syrian diaspora organisations steadily rose after 2011. Migration had an influence on the increment, in so far as new actors, many of whom were active 
inside Syria or in the neighbouring countries before their displacement to Germany, continued their activism from abroad, thereby entering the space of diaspora mobilisation. At the same time, diaspora organisations also dissolved and became inactive leading to a high degree of dynamic change and fluctuation within the diaspora organisational structures. To capture these changes the mapping of diaspora organisations, as mentioned above, was frequently updated during the research process.

As a result, there was a need for reactive research in order to adjust and respond to the constantly changing research environment. This also offered the opportunity to move beyond a static analysis of diaspora mobilisation in conflict settings, by following participants over longer periods of time to capture potential changes in their aspirations, perceptions and forms of engagement. Tracing the different events and factors shaping diaspora mobilisation at different points in time made it also possible to unpack more in-depth the mechanisms behind these processes.

In addition, the relevance and timeliness of the topic enabled a proactive engagement with other stakeholders interested in the process of Syrian diaspora mobilisation, such as host country government institutions and agencies, international organisations, INGOs and other civil society actors. This made it possible to produce, in addition to the academic research of the doctoral dissertation, policy-oriented studies aiming to inform decision-making and policy formulation and to provide recommendations regarding a context-specific and conflict-sensitive strategy for approaching the organised diaspora. This also offered the opportunity to timely disseminate the findings and share the insights of the doctoral research project with a broader audience.

\subsubsection{Interviews on sensitive topics}

It has been widely acknowledged that interviews on sensitive topics can cause emotional distress for participants, as questions might evoke experiences of trauma or other negative memories and emotions (Trimble \& Fisher, 2006). The devastating situation in Syria, with high levels of violence and destruction, to which respondents are exposed through regular contact with friends and family members remaining in Syria, as well as through their active engagement in the Syrian conflict, might lead to the experience of conflict-related trauma from a distance. In other cases, respondents who came more recently to Germany, have themselves been the victims of violence and persecutions, experienced political detention or other human rights violations, and were confronted with traumatic experiences during their migratory journey. As the interviews involved not just questions on diasporic action in Germany, but also on past and present experiences 
and future aspirations related to conflict and migration, the interview setting had the potential to bring up emotional distress, traumatic memories or negative emotions.

In order to reduce potential harm resulting from participation in the interview, an informed consent was sent to potential participants beforehand. This included a brief description about the aims and the content of the study, information on the interview process and explanations of voluntariness and confidentiality. Further, it stressed the right of the respondent to deny answers to questions he or she did not feel comfortable with and to withdraw from the study at any time with no adverse repercussions. This information was given once again before the start of each interview and informed consent was gathered verbally to ensure that the autonomy of the participants in the interview process was granted. Permission was also asked to record the interview, whereby strict confidentiality was stressed and the use of the recordings was explained. Gathering informed consent is crucial to protect the autonomy, as it informs participants about the content of the study, their rights to voluntariness and the potentially broader consequence of participation (Orb et al., 2001).

As questions related to conflict and migration could evoke negative memories and trauma, these were kept broad without probing or follow-ups. For instance, the question 'How was your life before you left Syria' provided the respondents a broad space and the freedom to reflect on his or her experience as detailed as he or she felt comfortable with. While some participant responded briefly to this question, others gave detailed accounts of the experience of repression and violence before and during the conflict. In general, the feedback given by the respondents on the interview process acknowledged the provided space for critically challenging stereotypes, dominant narratives and the autocracies conducted by conflict parties, and highlighted the importance for their voices to reach a broader audience. Similar benefits of qualitative interviewing have also been documented in other studies, which stressed that respondents reported, among other things, a feeling of empowerment, self-acknowledgment, and selfawareness and appreciated that their voices were being spread and acknowledged (Beck, 2005; Hutchinson et al., 1994).

\subsubsection{Security risks}

Next to potential harm during the interview process, researchers in social sciences, and in particular those who are dealing with sensitive topics, have to anticipate the potential negative consequence that participation might entail for the respondents. With respect to diaspora mobilisation in conflict settings, researchers have to be sensitive towards the security needs of the target community (Warnecke, 2010). 
Although states are not able to exercise their full sovereignty abroad, countries of origin can introduce long-distance instruments and policies to monitor and exert control over their emigrant population. In the case of Syria, state-run institutions of the Assad government abroad were involved in surveillance and intelligence measures to repress diaspora political activism and to prevent the emergence of a political opposition from outside. Given the potential of regime surveillance in Germany and potential pressure from conflicts groups on relatives remaining in Syria, diaspora political entrepreneurs and their families risked political persecution in their country of origin, if information on their engagement was published and linked to their identity. To protect participants against these negative consequences of participation, the research only used anonymised data of the interviews and privacy was ensured through strict confidentiality. Results of this study that have been published or presented, have not been linked to individual names and other personally identifiable information.

Moreover, research assistants, who were involved in the transcription process, were asked to sign a confidentiality agreement to ensure that they hold the identification of any individual that may be inadvertently revealed during the transcription of audio-taped interviews, or in any associated documents in strictest confidence. Furthermore, it was stressed that all study-related audiotapes and materials should be stored in a safe, secure location and all electronic files containing study-related documents be deleted from computer hard drives and any back-up devices after completion of the task.

\subsubsection{Researchers' responsibility}

Researchers in social sciences, and those who conduct research on vulnerable populations in particular, often do not just want to contribute to a broader understanding of the topic under study but are also motivated by a strong desire for reducing the suffering of the affected population. Within this 'dual imperative' (Jacobsen \& Landau, 2003), researchers have to respond not just to the need of the academic community by conducting systematic research based on scientific rigour, but also to the needs of stakeholders in producing policy sensitive and relevant results that have the potential to contribute more directly to social change and transformation. Moreover, Mackenzie, McDowell and Pittaway (2007) argue that research with vulnerable communities should move beyond the basic standards of harm minimisation by recognising an obligation to generate reciprocal benefits for communities through the research.

There is now a growing awareness of potential ethical dilemmas that evolve in migration studies between ensuring that the needs and goals of the research are 
met, while at the same time the rights of participants remain protected (Birman, 2006). Over the last years the Syrian conflict escalated into one of the most dramatic humanitarian crises of recent times. Moreover, the growing number of refugees and asylum seekers in Europe is increasingly leading to an emotionalised, polarised and politicised media, political and social discourse. A potential conflict could therefore arise between conducting an academically sound and policy relevant research one the one hand, while at the same time protecting the respondents and the Syrian population in Germany more generally. Potential findings from the research could be used by other stakeholders to vindicate powerful stereotypes about Syrian refugees and immigrants in Germany, hence threatening their position in society and contributing to further experiences of marginalisation. Before publishing the research findings, the consequences of the dissemination for international, national or regional discourses on the contributions of the Syrian diaspora to peacebuilding and on the Syrian migrants and refugees in general have been considered carefully, through a reflection on how the results would be received, discussed and used and how to achieve a balance between the harm and the benefit that these findings may entail.

\subsection{Reflections on the researcher's positionality}

Understanding the qualitative inquiry as a social construction means that there is a need to reflect on how the positionality of a researcher may shape the encounters, processes and findings of a research journey. This dissertation recognises that authors are embedded in the research process, and as such should be aware of how they position themselves in the field, in relation to the participants of a study and with respect to the analysis and writing of their findings. Discussions on the researcher's positionality can also centre around the question of how the positioning of a researcher may engender distinct epistemological or ontological approaches (Carling et al., 2014).

In migration studies, much attention has been paid to exploring the issues of positionality, with respect to the interaction and encounters between the researcher and the participants of a study in the field. Herein, the researcher's positionality is

commonly discussed based on the insider-outsider dichotomy. Considered as insiders are those who belong to the minority group under study and who, given this relation, are claimed to benefit from greater access to the target group, necessary language skills, trust, in-depth insights and a better understanding of cultural complexities. In contrast, outsiders are often framed as belonging to the majority group in a research setting and are considered as less emotionally attached and therefore more able to be objective concerning the research topic. However, the insider-outsider approach has been criticised as it risks to essentialise 
identities and to narrow people's identifications to a single, often ethnonational, marker. Such an approach also masks the distinct power relations potentially present beyond the minority-majority positions, such as social location based on the intersection of class, migration experience, age, gender and sexuality, among others. More recently, calls have been made to reflect on one's positionality based on a more hybrid approach, which takes into account the multiple intersections of identities and how these complex sets of categorisations may shape qualitative inquiries in a more fluid, context-specific and relational way (Baser \& Toivanen, 2017; Carling et al., 2014; Nowicka \& Cieslik, 2014; Ryan, 2015). Carling, Erdal and Ezzati (2014) highlight that beyond the dichotomy of insider-outsider categorisation, researchers may inhabit a third position, which crosscuts the socially constructed boundaries of groups in different ways. They argue, for instance, that researchers may gain a position as 'insiders by proxy', in which they do not belong to the migrant group under study but may reach closer connections and a sense of commonality due to their own migration experience or background.

Reflecting on my own positionality during the field work process, I find this hybrid approach very suitable. I often found myself in a hybrid position, not as an insider, but also not fully in an outsider position. This position was further shaped by several intersections, i.e. being a child of a Palestinian father, but born in Germany, having lived for a short period in Damascus, being a secular woman and a visible migrant for most segments of the German society. All these aspects shaped my qualitative inquiry in several ways. For instance, my Palestinian background may have encouraged some respondents to more critically discuss the geopolitical root causes of the Syrian conflict resulting from western colonialisation and imperialism, as many times in interviews reference was made to the Palestinian cause. Knowledge about the Syrian context, which I gained partly during my stay in Damascus in 2008 but also through conducting extensive readings on the country's history, was essential to overcome issues of mistrust and fear among the participants. My awareness of the repressive context in which mobilisation takes place, encouraged many respondents to speak openly about opportunities and challenges they face in their engagement. In the same vein, my visible migration background as well as distinct experiences of growing up as part of the second-generation of migrants in Germany, may also have encouraged some participants to talk more openly about the challenges they face with regard to the German context. Sharing experiences of discrimination and racisms, as well as processes of othering, in which the identity becomes ascribed by the majority society may not only have helped me to generate critical accounts from the participants but also highly informed the analysis of some aspects of my findings. 
However, it has to be emphasised that these intersections were not static, nor did they matter in all of the encounters. During the interviews respondents sometimes drew similarities of my and their experiences or related to some aspects of my presumed identity, in others the differences were highlighted, while again in many other situations the positionality did not seem to play a crucial role at all. Employing the metaphor of a dance, Ryan (2015) explored how 'interviewer and interviewee continually move around each other positioning [themselves] in relation to each other - sometimes in harmony other times in dissonance" (p.15). She highlights that different social categories and facets of identity such as gender, age and professional status may create moments of sameness, but also of difference at different points in time, through which the positionality is dynamically negotiated during a research encounter.

While reflections on positionality should take into account diverse identity makers, this however does not mean that ethnicity or nationality should be fully neglected. Instead, Baser and Toivanen (2017) highlighted how ethnicised positionalities can become politicised and depoliticised to a varying degree in research encounters. Reflecting on their experiences in researching Kurdish diaspora groups in various destination country settings, they explored how their position as apparent outsiders, in one case in relation to power dynamics concerning the homeland, and in the other with respect to the host country, led to ethnicised positionalities during the fieldwork encounters. Yet, the building of trust, in-depth knowledge and greater familiarity with the topic, as well as changing political contexts, led in some cases to a depoliticised positionality in relation to the researchers' ethnic background throughout the fieldwork, in which ethnonational markers became more or less irrelevant for the research encounters.

Similarly, the politicised nature of this research has to be recognised, as mobilisation was not only shaped by the security dimension, but also by sociopolitical dynamics present in the diaspora mobilisation process. Building trust and relationships was essential to get access to Syrian diaspora actors in Germany. Approaching potential respondents via email generally resulted in a low response rate. Instead, attending events and protest organised by Syrian diaspora political entrepreneurs represented a crucial step in building personal contacts and relations. In addition, the investment of efforts and time to build trust was necessary, as willingness to conduct an interview was often only achieved after several meetings persons beforehand. Despite the security risks present in the mobilisation, many respondents showed considerable openness to share the perceptions and stories, as the perceived the research as an opportunity to spread their voices to a broader audience. 


\section{Chapter 4: Mapping the Origin Country Context}

Figure 5: Map of the Syrian Arab Republic

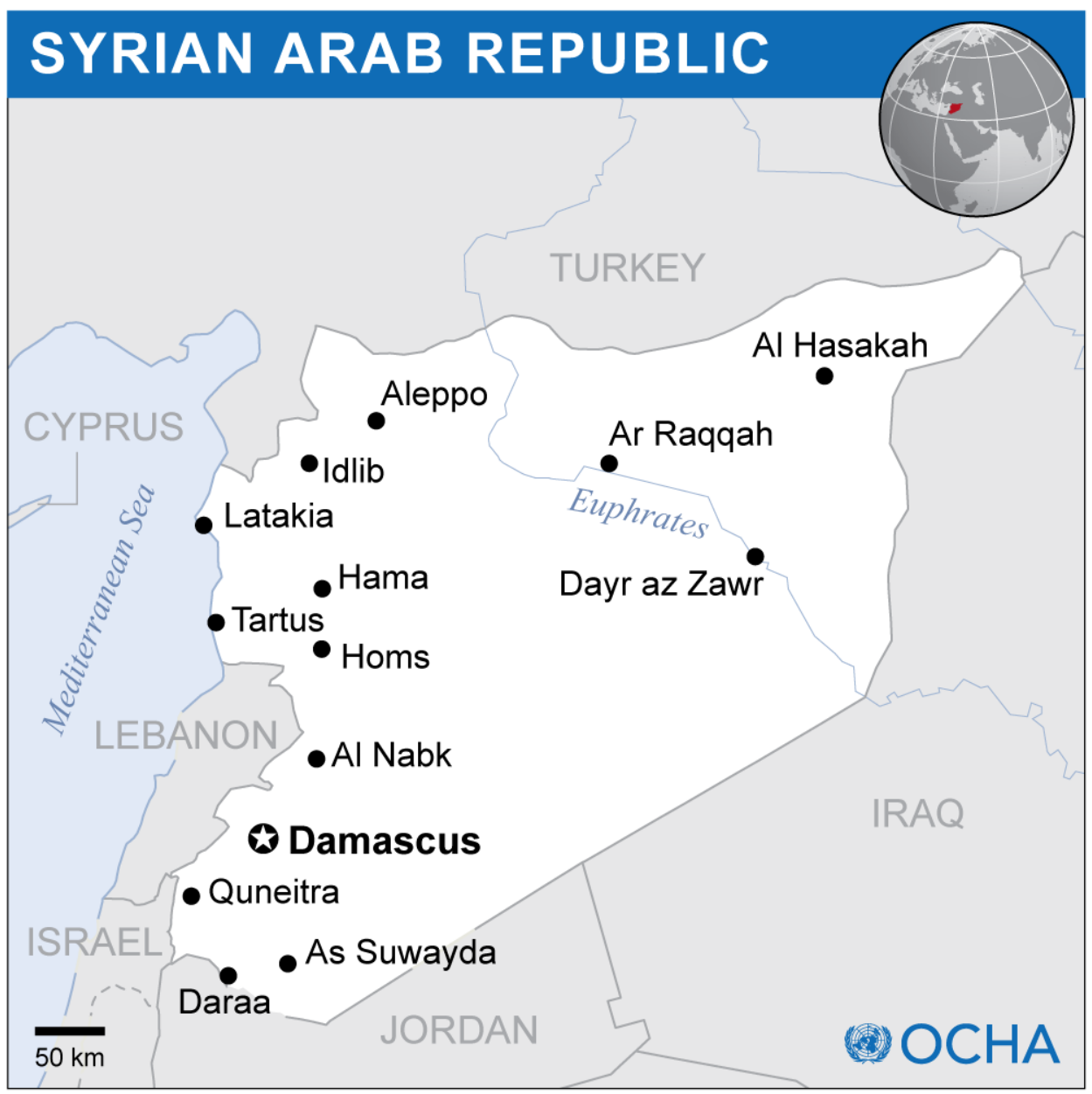

Source: UNCS, OCHA, Government of Syria

In order to situate the process of Syrian diaspora mobilisation into the historical and contemporary context, this chapter provides a brief overview of the Syrian conflict and the different actors engaged in it, as well as the mechanisms and dynamics that have characterised the different conflict trajectories. The second section of this chapter seeks to shed light on the state-diaspora relations, by analysing the different contextual factors shaping the process of mobilisation, such 
as the relevant legal frameworks, the diaspora engagement institutions and strategies, as well as the Syrian government discourse towards emigrants.

\subsection{The Syrian conflict}

What started in Syria in March 2011 as an initial peaceful movement of people demanding freedom, justice and democracy, has escalated into one of the world's most dramatic humanitarian and security crisis. Given the highly complex and dynamic nature of the Syrian conflict, a comprehensive analysis of its causes, actors and dynamics lies way beyond the scope of this thesis. Moreover, as explained earlier, if conflicts are understood as socially constructed, there is not just one interpretation of reality and its 'truth', but rather the issues under dispute who are the adversaries, who is the 'good' and who is the 'evil' - are often heavily contested and tend to involve competing narratives about the conflict. At the same time, it is important to situate the analysis of diaspora mobilisation in the broader historical and contemporary context of the conflict. Rather than claiming to be a 'true' representation of the conflict, the following sections aim at providing a broader understanding of the conflict dynamics, processes and developments over time. It has to be acknowledged that as in other conflicts, different realities exist in the Syrian case. The provided representations were chosen because they closely reflected the narratives of the first-hand accounts of Syrian activists as well as of the other diaspora representatives interviewed for this study. The first section discusses the historical background and the historical roots of the conflict, mainly focusing on the period from independence until the outbreak of the revolution. Then follows a brief description of the initially peaceful movement that took to the streets in March 2011 and that challenged the Assad government with demands for freedom, democracy and human rights. The third and fourth section seek to provide an understanding of the mechanisms and dynamics of the processes of militarisation and radicalisation respectively.

\subsubsection{Roots of the conflict}

Syria is located in Western Asia, bordering Lebanon to the southwest, the Mediterranean Sea to the west, Turkey to the north, Iraq to the east, Jordan to the south, and Israel to the southwest. It can be considered as a multi-ethnic and multireligious country that is home to various religious and ethnic groups such as Sunnis, Christians, Alawites, Druze, Isma'ilis, Yazidis, and Jews, as well as Arabs, Kurds, Turkomans, Assyrians, and Armenians among others. According to Minority Rights Group International (2018) demographic data for Syria is unreliable, yet their statistics estimate that Sunni Islam (75 percent), Alawite Islam (12 percent), as well Christianity (10 percent) and Druze (3-4 percent) represent the 
main religions in the country. Around 2-2.5 million Kurds form Syria's largest ethnic minority, whereas Armenians, Circassians and Turkomans present smaller minorities. In addition, the country hosts large numbers of Palestinian and Iraqi refugees. Syria's history has been marked by the rule of several empires that all contributed to the ethnic and religious diversity of today's society. Given that it is beyond the scope of this thesis to illustrate the entire history of the country, the following section briefly describes the emergence of the Syrian state as well as the state building process under the regime of Hafez and Bashar al-Assad. After the First World War, France and Britain signed the Sykes-Picot agreement, separating the region into French and British zones, which instead of considering geographical or cultural lines, created artificial borders that cut across ethnic and religious communities. The geography of Syria under French national polity was subdivided into four semi-autonomous mini-states, which were responsible for the administration and the governance of the mandate. These included an Alawi state in the mountains of Latakia and the Jabal Druze state in the southern region of AsSuwayda, next to two quasi-autonomous governments of Aleppo and Damascus. To secure its political and economic domination, France employed a policy of 'divide and rule', in which the state boundaries partly reflected the sectarian makeup on the ground. Fomenting religious and ethnic antagonisms was the primary strategy to reinforce political fragmentation and to prevent the rise of Arab nationalism through the creation of a Syrian national identity. After several waves of popular resistance to the French occupation, French troops evacuated in 1946, creating space for the formation of an independent nation-state (White, 2007).

After the waves of political power struggles that followed the Syrian independence from French occupation in 1946, the Baath party seized full control over the country in a military coup in 1963 . While the party presented the takeover of the government as a revolution of the people, regime change was rather characterised by a secret alliance between a handful of military officers than by mass mobilisation from below. Among them was Hafez al-Assad, the father of the current President and a member of the air force at the time. In its 'revolution from above', the Baath party sought to improve the lives of workers, who historically suffered marginalisation due to the hegemony of the Sunni landlord-merchant elite, who had controlled both the economic and political spheres. At the same time, the decade was also characterised by internal power struggles within the Baath party, in which various factions competed for power and control. In 1966 Assad became Minister of Defence and with the help of high-ranked military officers took sole authority in 1970, which he kept until his death in 2000 (Hinnebusch, 2002). 
During the 1970s, the regime of Hafez al-Assad was able to consolidate and stabilise its power. The constitution of 1973 designated Syria as a Socialist People's Republic with a presidential system, in which the Baath party was established as the dominant and ruling unit. In order to broaden the base of the Baath regime different bodies were established to co-opt a variety of political factions. In 1971, a new People's Council, which included smaller parties such as Nasserists, Communists and Arab Socialists, was formed as the legislative authority. Established in 1973, the National Progressive Front, a body that included different factions ranging from Baathists to Nationalists and Communists, was conceded a share of state office and a consultative function in state policies. However, the Baath party held the majority in each of the institutions, and the party's representatives occupied several key positions ranging from the Presidency and the office of the Prime Minister to the departments of Defence, Foreign Affairs, Education, Information, Interior and Economic. Hence, politically, the regime favoured its absolutist rule and failed to provide a real space for party pluralism (Dawisha, 1978).

The socialist project was realised through the distribution of land to landless farmers and the nationalisation of the banking sector and major industries, through which significant segments of the middle and working classes were offered employment in the public sector, as well as through the monopolisation of foreign trade. Social programmes such as free healthcare and education and the subsidisation of products were provided and financed from oil revenues (Dahi \& Munif, 2012). Next to socialism, pan-Arab nationalism continued to be the dominant ideological doctrine to broaden the social basis of constituencies and to prevent political factionalism along ethnic or religious lines. According to Hinnebusch (2008):

\section{"Arguably Arab nationalism was the most successful ideology in filling the post-Ottoman identity vacuum because it best bridged the Syrian 'mosaic', bringing together the Arabic-speaking minorities, most significantly the Alawis and Christians, with the Sunni majority, albeit excluding non-Arabs such as the Kurds" (p. 264).}

Ethnic minorities, including Kurds, Armenians, and Turkmans, however, were incorporated into the national discourse based on the principle of national unity, in which community groups enjoyed equal civil rights, while at the same time being culturally forced to assimilate to the Arab nationalist paradigm (al-Haj Saleh, 2017). Educational institutions, youth, women, peasant associations helped to spread the Baath party's ideology across a broader social base (Hinnebusch, 2002). 
At the same time, Assad counted heavily on a patrimonial strategy by appointing family, clan, and tribe members as well as representatives of the broader Alawi community to which he belonged to key positions in the party and the security apparatus. These measures aggravated the already disproportionately high representation of minorities in the military, which had been a result of unequal recruitment under the French occupation. The promotion of rural-urban migration in particular from areas of Alawi majority to fill jobs in the growing public sector further heightened the perception of Alawi domination in the state system. To coopt a broader section of society, members of the Sunni Damascene merchants were granted key positions in the party, such as the Ministry of Defence and at the Foreign Ministry. Clientèlism became the primary avenue to ensure jobs, prestige and power (Hinnebusch, 2002).

According to Omran ( 2014):

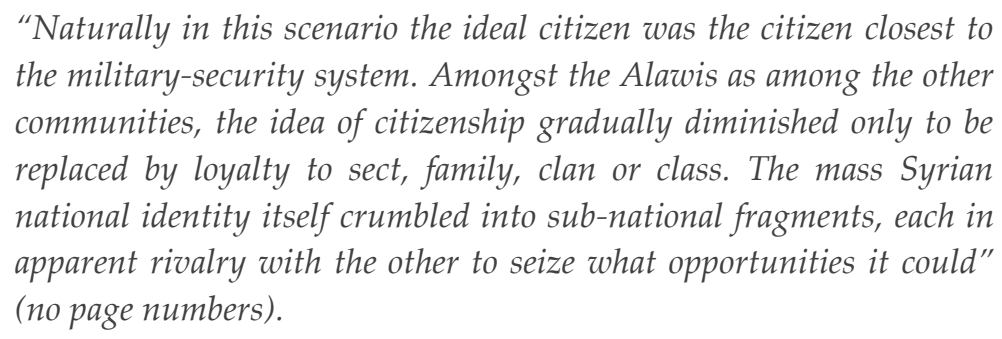

Next to fostering an ideology based on consent, the regime ensured its power through coercion, by violently suppressing several uprisings that challenged its rule. The regime's coercion was established through two pillars, the army responsible for protection against outside threats and the mukhabarat, which consisted in multiple intelligence and security agencies executing control over the population to eliminate the internal risk of rebellion against the regime. Moreover, the state of emergency, in place since 1963 and justified by the conflict with Israel, criminalised any form of political organisation, further diminishing the margins for internal political disobedience. The constant state surveillance of the citizens led to a depoliticisation of the Syrian society (Hinnebusch, 2002).

The country's economic instability in the mid-1980s, resulting from the oil price crisis which led to decreasing aid from Gulf donors, was further exacerbated by the weakening and later collapse of the Soviet Union, one of Syria's key allies. The sharp decline in foreign aid from Arab and Soviet donors demanded economic reforms, as the regime was increasingly unable to bear the financial burdens of its state apparatus. Economic liberalisation sought to foster private sector investments, while subsidies were cut to reduce state expenditures. The liberalisation of trade and exchange rates led to an integration of the Syrian 
economy into the global market in the 1990s. Yet, the socio-economic policies implemented by the regime led to the concentration of wealth and power in the hands of a new emerging bourgeoisie and the old landlords, which further marginalised landless peasants and the urban middle and working classes (R. A. Hinnebusch, 1995, 2002).

The political and economic crisis led to rising resistance, which eventually would take to the streets to challenge the ruling of the regime. By the end of the 1970s, a 'new left' embodied in the League of Communist Action, increasingly challenged the ruling of Assad. In addition, Islamist groups started an uprising, which escalated due to harsh repression into a sectarian campaign by the armed faction of the Muslim Brotherhood. The 1982 massacres of Hama, in which regime suppression caused between 10,000 and 20,000 casualties, marked the bloody end of the revolts (Dahi \& Munif, 2012; Yassin-Kassab \& Al-Shami, 2016).

After the death of Hafez al-Assad, his son Bashar was declared President in a referendum without any opponent. Being perceived as outward looking, a new age of modernisation was expected, as he promised to fight against the lumbering bureaucracy and corruption. Inspired by the promises of political and economic reforms, intellectual forums and civil society organisations flourished in Damascus in the early 2000s. For instance, the Forum for National Dialogue, established in 2000 by Riad Seif, a businessman and independent member of the People's Assembly, as well as the Jamal Atassi Forum hosted weekly discussions around social, political and economic topics, marking the beginning of the so-called Damascus spring. The movement was modest in nature, as representatives demanded political reforms such as more freedom of expression, the rule of law and independent judiciary, and the end of the emergency law, rather than radical political transformations or the overthrow of the regime. Also, activism was mainly based on the publishing of statements and manifestos in print media and discussions in public forums, but, except some smaller protest, did not take the struggles to the streets. While initially the Assad government tolerated the movement and promised further reforms, it violently put it to an end just after a few months, turning the short-lived spring into winter. Key figures of the movement were detained, debating clubs and forums were forced to close down, and the rest of civil society went underground. To justify its measure, the regime accused the movement of pursuing an agenda of western interests and of infiltrating sectarian sentiments to divide the nation (Dahi \& Munif, 2012; YassinKassab \& Al-Shami, 2016).

In 2004, clashes between supporters of rival Kurdish and Arab teams at a football game in Qamishli were violently suppressed by security forces, which killed at least 36 people, the majority of whom were Kurds. The event sparked spontaneous 
riots and protests across the Northern region of Syria, as well as acts of solidarity in Damascus and Aleppo, which both hosted a considerable Kurdish population. The uprisings were the result of the accumulation of historical Kurdish grievances due to cultural and economic marginalisation. Even though the majority of the 1.5 to 2 million Syrian Kurds enjoyed equal rights as citizens, assimilative policies denied them the right to learn, speak and publish in the Kurdish language, or to otherwise cultivate their heritage, traditions, customs and culture. Another significant proportion of Kurds, around 120,000, were refused to hold citizenship and found themselves stateless, and hence, excluded from any fundamental rights, such as the right to own land, travel or attend higher education. Next to groupbased grievances, developments in the region may have spurred the movement, as the transitional constitution of Iraq granted the right to Kurds to establish a more autonomous area in the Northern provinces. Within one week, regime forces put a violent end to the Kurdish uprising, by entering with tanks in Qamishli and other cities in the north of the country. Another attempt to organise and unify political opposition was the Damascus Declaration for Democratic National Change of 16 October 2005, which called for the end of the emergency law and transition towards democracy. The group of signatories was comprised of oppositional figures from various backgrounds, including religious, secular, Kurdish and Arab groupings. As previously, the regime responded quickly and violently, by arresting key figures of the movement. At the same time, the Damascus Declaration also suffered from internal fragmentation, divisions and power struggles inherent in the different ideologies that sought to be united. Similar to the Damascus spring, it was also unable to mobilise the broader public by taking the resistance to the streets, nor to include younger people who formed a considerable segment of the Syrian population (Yassin-Kassab \& Al-Shami, 2016).

Hence, politically the regime under Bashar al-Assad continued to implement a policy of 'Stability and Continuity', which repressed any forms of resistance against his rule or attempts by oppositional movements to promote political transformations. Under the dogma of 'modernisation and development', economic reforms were implemented to pave the way towards a 'social market economy' through economic liberalisation and privatisation (al-Haj Saleh, 2017). To secure his authoritarian rule, Bashar al-Assad counted on nepotism and favouritism, leading to an economy of 'Authoritarian Neoliberalism', in which entrepreneurs depended heavily on the protection of the state. A famous example, perceived as the embodiment of these practices is Rami Makhlouf, cousin of Bashar al-Assad and owner of the Syriatel Mobile Network provider, whose economic empire came to exceed US $\$ 3$ billion in less than a decade. At the same time, key subsidies were cut, marginalising, in particular, the (mostly Sunni) peasantry. Hence, the economic profits benefited first and foremost the political and economic elite, 
leading to high inequality and poverty among the lower and middle classes of the country (Dahi \& Munif, 2012; R. A. Hinnebusch, 2012). GDP per capita increased from $\$ 2,480$ in 2003 to $\$ 5,120$ in 2010, and economic growth reached its peak with 6 per cent in 2009. At the same time, high population growth in Syria was challenging the labour market, leading to an unemployment rate of up to 30 per cent. Moreover, between 11 per cent and 30 per cent of the population lived under the poverty line, in particular in the rural areas (Wieland 2012). As policies mainly favoured the economic centres of Aleppo and Damascus, this led to high geographical discrepancies and marginalisation of the suburbs and rural or peripheral regions of the country (al-Haj Saleh, 2017). Hence, the ruling of Bashar al-Assad was characterised by many reform attempts and as many setbacks, and therefore as a 'decade of lost chances' (Wieland, 2012). Despite several attempts to transform the country into a modern social market economy with more political freedoms, Bashar al-Assad heavily relied on key players in the apparatus of his father.

\subsubsection{The Syrian revolution}

In December 2010, the self-immolation of Mohamed Bouazizi in Tunisia led to protests, civil resistance, uprisings and upheavals in countries across the MENA region. Using diverse forms of popular resistance such as civil disobedience, protest, demonstrations and occupation of public spaces, these movements called for an end of government repression and corruption, for freedom, democracy, and human rights. Inspired by the events happening in countries like Bahrain, Egypt, Libya, Morocco, Oman, Tunisia and Yemen, calls were made for a Syrian 'Day of Rage' on 4-5 February 2011, but due to the fear of harsh government suppression, these did not result in major protests or demonstrations. These happened only in March 2011, when the spirit of the 'Arab Uprisings' caused widespread and largescale resistance in Syria. The trigger of the peaceful protests was the arrest and torture of a group of children, who wrote the slogan 'The People Want the Fall of the Regime!', a popular slogan among demonstrators in Tunisia and Egypt, on the walls in Dara'a, a town in the South of Syria. In response, thousands of family members and their supporters organised a demonstration, demanding the release of their children and the resignation of Atef Najib, the chief of the security forces in Dara'a and cousin of President Bashar al-Assad. The security forces forcibly suppressed the protest, killing at least four people, and more were killed at their funeral which turned into a mass demonstration. The spark that ignited the 'Children of Dara'a' spread quickly through social media and led to numerous demonstrations and protests mainly in the cities of Hama, Raqqa, Deir al-Zor and Homs (Yassin-Kassab \& Al-Shami, 2016). 
The 'peripheral' towns as well as the suburbs of the cities became the centre of resistance, which historically tended to be marginalised as the 'modernisation and development' policies mainly favoured the economic centres of Aleppo and Damascus. Moreover, the economic profits benefited first and foremost the political and economic elite, leading to high geographical discrepancies as well as to inequality and poverty among the lower and middle class of the country (al-Haj Saleh, 2017). Hence, it was the shared grievances of those deprived by the neoliberal reforms, which mobilised the mass to challenge the government, while the centres of Aleppo and Damascus, which hosted the large share of the political and economic elite, initially remained less involved in the popular resistance. Next to economically marginalised people, also the traditional political opposition of the Damascus Spring and the Damascus Declaration mainly from the middle class, as well as new youth activists, took part in the protests (Yassin-Kassab \& Al-Shami, 2016). The movement was hence what al-Haj Saleh (2017) called a revolution of the common people, as the protests initially united different sections of society, crosscutting gendered, class, ethnic or religious hierarchies. Women played a leading role in the uprising, organising protests, demonstrations and local coordination committees. Next to engaging in general acts of resistance, women-led grassroots initiatives emerged to break down the traditional patriarchal structures of gendered hierarchies and to foster women empowerment. For instance, in Aleppo women founded Radio Nassem, which broadcasted the daily struggles of Syrian women to counter inherited notions of gender roles and stereotypes (YassinKassab \& Al-Shami, 2016).

In addition, the mass mobilisation was non-violent in nature and made use of a peaceful and anti-sectarian discourse, by framing the action based on notions of freedom, dignity and human rights. In the initially protests, slogans like 'selmiyyeh, selmiyyeh' (peaceful, peaceful) or 'wahid, wahid, wahid, as-sh'ab assuri wahid' (One, one, one the Syrian people are one), emphasising national unity, dominated the streets (Yassin-Kassab \& Al-Shami, 2016). Rather than an overthrow of the regime, protesters called for political and social reforms, among other things, for an end of the emergency law, political freedoms, the release of political prisoners, the fight against corruption as well as the enhancement of social and economic opportunities for a broader social base (Wieland, 2012).

From the beginning, the movement lacked a clear leadership based on party mobilisation or shared ideology, but it was instead characterised by spontaneous, decentralised resistance resulting from accumulated social, economic and political grievances. Local Coordination Committees (LCCs) were formed in nearly every Syrian city. These informal decentralised networks with non-hierarchical structures aimed to link activists around the country in order to organise protests 
and to report on current developments. The LCCs were the main pillars of civilian demonstrations and were committed to non-violent resistance (Schweitzer et al., 2012).

According to the regime narrative, on the other hand, the protests were not an indigenous movement, but instead armed Islamist terrorists infiltrated by outside actors to destroy the country and its people. The regime presented itself as the sole legitimate body able to defend the Syrian people from a foreign conspiracy, aiming at destabilising the country to ensure hegemony through colonial and imperial domination. The regime also portrayed itself as the historical and present guardian of the minorities, who would suffer from oppression, persecution and marginalisation under an eventually emerging Sunni state. In contrast to the oppositional narrative, which framed the movement as non-violent, domestic and united, the regime discourse favoured the image of a violent, armed terrorist movement infiltrated by exogenous forces, aiming at destroying Syrian unity. By discrediting the protesters as religious, violent others, the regime not only introduced a sectarian element into the peaceful struggle to mobilise loyalty from minorities, but also tried to delegitimise the protesters' demands internationally by feeding into the American-led 'War on Terror' discourse (Phillips, 2015; Pinto, 2017).

Following its earlier path of violent repression in the 1970s and 1980s, the regime opted for military solution employed against civilian protesters to crackdown the growing resistance. For instance, not even two months into the uprising, the centre of Dara'a was almost entirely in the control of protesters, who occupied the streets and public spaces, and the regime was only able to re-establish its control through an extensive military operation. Protests and demonstrations, which had spread across the country, were frequently targeted by gun-fire, and peaceful activists were detained, tortured and killed. Next to the army, the regime subcontracted its repression to the shabiha, pro-regime armed militias, which were accused to be responsible for war crimes ranging from looting, torture and rape to mass-killings and other forms of ethnic-based violence. These paramilitary groups recruited people from various backgrounds, such as impoverished youth from Alawi backgrounds, members of local gangs and released prisoners. Yet, in some areas they had a strong ethnic component, being largely comprised of members of the Alawi and Shia sects (Phillips, 2015; Pinto, 2017; Yassin-Kassab \& Al-Shami, 2016).

At the same time, the regime acknowledged the need for transformation and implemented social and political reforms in order to appease the broader population. To co-opt sections of the society, the regime increased the salaries of civil servants, granted citizenship to stateless Kurds, and provided some privileges to tribal or religious groups. Political reforms such as the amendment of the party 
law and the abolishment of the emergency law however tended to actually favour regime control rather than provide new space for political participation. For instance, the state of emergency was replaced by a Counter-Terrorism Law, which provided a framework for implementing harsh measures against anti-regime activists. Despite incremental changes, the new party law still enabled the regime to restrict and control party formation, hence leaving no room for an independent opposition. For many, these reforms gave too little and came too late and were even less able to indemnify the excessive use of regime violence. As a result of harsh regime repressions, modest demands of reforms were replaced by a call for the overthrow of the regime (Hinnebusch \& Zintl, 2015; Yassin-Kassab \& Al-Shami, 2016).

\subsubsection{Militarisation and the rise of the armed opposition}

Already in September 2011, Al-Haj Saleh (2017) anticipated that the country was moving towards a situation which he called 'the state of nature' which results in 'politics of subsistence, focused on survival and self-protection' (p.65). The need for survival would shift the focus towards meeting the basic needs of protection and away from the more abstract and emancipatory demands of the revolution. When the regime of Assad changed its tactics from a 'security solution', targeting mainly sites of protests and political activists, towards a 'military solution' to combat the insurgency, characterised by indiscriminate attacks on civilian populations and infrastructure, a spiral of violence was triggered leading to a militarisation of the conflict (R. Hinnebusch \& Zintl, 2015).

Whereas the first six months of the revolution were marked by peaceful forms of resistance, from August 2011 onwards an armed component of the movement evolved gradually. Soldiers, who refused to shoot on peaceful demonstrators defected from the army and joined the movement. Eventually, these defectors formed the Free Syrian Army (FSA), to protect the peaceful protest and demonstrations from regime aggression. In parallel, more and more civilians, who suffered from the extreme violence, became disillusioned that the regime could be defeated by non-violent means. Civilian armed groups were formed, mainly operating locally, with some of them unifying under the umbrella of the Free Syrian Army. Militarisation was, hence, a result of regime repression and violence rather than a strategic collective choice of the opposition forces. It has to be emphasised that the FSA was acting as an umbrella that tried to coordinate many different armed groups that often tended to operate independently and locally. It considerably lacked a monopoly over arms, a clear command structure, funding and central recruiting mechanisms, which greatly challenged its efficiency. Funding and weapons were also supplied from regional actors, such as Qatar and 
Saudi Arabia, yet, never consistently nor in high quality or quantity. In spring 2012, efforts had been made to create a better functioning leadership and more efficient decision-making processes, through the establishment of a regional military council responsible for the distribution of funding and weapons (al-Haj Saleh, 2017; Yassin-Kassab \& Al-Shami, 2016).

The summer of 2011 also witnessed the establishment of more formal political bodies that tried to represent the revolution both inside and outside Syria. The first was the National Coordination Body for Democratic Change (NCB), which was established in Damascus in June 2011 by prominent oppositional figures. The NCB had a relatively moderate stance, called for dialogue with the regime and the remaining of Assad as the head of the country during transition. Members included mainly secular left-wing political parties and independent activists. It was committed to peaceful change and rejected the armament of the opposition. Whereas its presence inside Syria had an advantaged as it allowed it to follow more closely the developments on the ground, it represented also a significant challenge as the space for more radical actions was very much constrained due to regime monitoring. The second body was the Syrian National Council (SNC) established in Turkey in August 2011, with the aim to unify the oppositional groups under one umbrella and to represent the voice of Syrian opposition internationally. The SNC tried to incorporate a diverse range of actors, including exiled members of the Damascus Declaration and the Muslim Brotherhood, Kurdish parties, the Assyrian Democratic Organisation, representatives from LCCs as well as independent activists. Initially, the body enjoyed popular support inside Syria and was recognised internationally by the 'Group of Friends of the Syrian People', an international diplomatic collective of countries and bodies aiming to support the Syrian opposition and to increase pressure on the Syrian government, as the legitimate representative of the oppositional movement. Soon, however, internal divisions and power struggles, as well as accusations of corruption and Muslim brotherhood domination, highly weakened the position and influence of SNC both internationally and inside Syria. In November 2012, the National Coalition for Syrian Revolutionary and Opposition Forces was formed in Doha, Qatar and was joined by the SNC, to unify main opposition groups and to establish an interim government in exile (Yassin-Kassab \& Al-Shami, 2016).

Next to the establishment of national political bodies, alternative governance structures also emerged at local level. When by mid-2012 the regime lost its power in many areas of the country, communities suffered major shortages in public goods and basic services, such as healthcare, education, and electricity. In response, LCCs, local grassroots civil society organisation, activists, religious groups and local community leaders filled the void left by the regime by 
establishing ad hoc Local Administrative Councils (LAC) to meet the need of municipal governance functions. While there is no estimate of the exact number, it is assumed that hundreds of Local Administrative Councils were established in Syrian cities, towns and villages. Often these councils tended to provide key public services such as humanitarian aid, education and health as well as the maintenance of public infrastructure, including water and sanitation and waste disposal. Others also performed legal duties, resolved local conflicts and were responsible for the coordination between civilians and armed groups. While the structure, size and capacity varied across the councils, most of them tended to implement a form of representative democracy, with sometimes holding free election. Members included next to younger generation activists, revolutionary and civil society groups, local tribal or family leaders as well as technocrats such as former regime administrators, engineers, teachers, and lawyers. Financial resources mainly came from donations by locals and Syrian expatriates, in addition to funding from international donors, such as NGOs and governments which made the LACs also vulnerable to external influence. Hence, in opposition-controlled areas LACs played an important role in the service delivery of public goods and were seen as crucial drivers for the country's future democratic transition. At the same time, a lack of financial and qualified human resources as well as weak structures of responsibility and authority, were frequently identified as major challenges for effectiveness. The diverse composition of actors in some cases led to conflicting interests and aspirations and in competition of control and power among the actors. Moreover, the influences of autonomous armed groups, who were executing political, cultural and economic power, often undermined the civilian structure and therefore further limited the ability of the LACs (Khalaf, 2015; Khoury, 2014).

The withdrawal of regime forces was celebrated as a liberation, but heavy bombardments and sieges of opposition-controlled areas caused a drastic increase of casualties, the destruction of entire neighbourhoods and villages, especially in Homs, Hama and Idlib and resulted in one of the world's most dramatic humanitarian crisis. According to the United Nations Office for the Coordination of Humanitarian Affairs (OCHA, 2012), by the end of 2012, all of the 14 governorates had been affected by the conflict. Estimates suggest that around 4 million people were in need of humanitarian assistance and 3 million people faced risk of food insecurity. Electricity cuts and shortage of fuel further exacerbated the humanitarian crisis. In addition to the countless homes, public infrastructure goods such as schools and hospitals as well as water and sanitation systems were demolished. The year was also marked by large scale forced displacement, with the number of IDPs reaching 2 million, in addition to 525,465 refugees who sought protection in the neighbouring countries. Children made up half of the displaced 
population. Women and girls found themselves increasingly in vulnerable positions, by being exposed to gender-based violence, such as rape and other forms of sexual violence (OCHA, 2012).

The large-scale regime aggression, which used tanks and other forms of military means to combat the uprisings, created increasing popular support for armed forms of resistances. At the same time, many civilians, LCCs and other grassroots initiatives continued to call for a peaceful nature of the revolution, reviving the slogan of 'selmiyyeh' (peaceful) in the streets. Supporters of non-violence feared that with the escalation the revolution would lose its popular support, in particular from the middle class inside the country, as well as from external democratic forces. Moreover, there were concern that militarisation would lead to an unending spiral of violence and further unpredicted escalation of the conflict (Yassin-Kassab \& Al-Shami, 2016).

\subsubsection{Sectarianisation of the conflict}

As the conflict escalated, religious belonging as well as ethnic and linguistic distinctiveness not only emerged as an important aspect of self-identification, but also became more silent and politicised. Whereas the initial protests predominantly used inclusive and anti-sectarian frames, over time religious symbols and rhetoric acquired more and more prominence. Although elements of sectarianism were present since the onset of the Syrian conflict, huge scale sectarian violence in form of mass killings, ethnic cleansing or ethnically motivated sexual violence were largely propelled by the rise of the so-called Islamic State or other militant groups such as the Al-Qaida linked Al-Nusra Front, which dominated the battle fields by the year 2014. But also, the shaheeba, militant paramilitary groups loyal to the regime of Assad, or the Shi'a brigade Dhu al-Fiqar have been accused of exacerbating the sectarian dimension of the Syrian conflict. Given the country's great heterogeneity in terms of religion, origin and ethnicity, sectarianism was seen as inevitable or frequently used as an explanatory factor for increased violence. However, these assumptions rest on a primordial understanding of culture, as they see the Syrian conflict as a result of long-entrenched ancient Sunni-Shia hatred. As the previous sections have shown, sect-based identities have been constructed and employed by various actors throughout the country's history, ranging from colonial powers, the regime of Assad to other more recent conflict actors. Hence, according to Pinto (2017) the process of sectarianisation has 'unfolded on multiple levels: top-down (state generated), bottom up (socially generated); outside-in (fuelled by regional forces); and inside-out (the spread of Syria's conflict into the neighbouring states)' (p.123). 
First and foremost, the large-scale regime violence in form of indiscriminate attacks on civilian populations, using tanks, missiles, barrel bombs and chemical weapons, has been identified as one of the main causes of the increasing sectarianisation of the conflict. As Phillips argues (2015) sectarianism flourished heavily in areas and regions which experienced large-scale death and destructions, or which were besieged, rather than in the ones with minor exposure to the conflict. The regimecontrolled coastal areas, Tartous and Latakia, and the Jabal Druze in the southern region of As-Suwayda were largely spared by indiscriminate bombings. While sectarian tensions were also present in these regions, it was in areas such as Eastern Aleppo, the suburbs of Damascus or Homs, which saw the rise of militant jihadist groups. Hence it was not only the intensity but also the selective use of means of violence, which was fuelling the conflict with sectarian elements. In ethnically and religiously mixed areas, bombing occurred mainly in Sunni-dominated streets or districts. In contrast to the Sunni population, which became a victim of collective punishment, members of minorities were threatened individually by the security apparatus (Pinto, 2017).

In times of larger-scale insecurity and instability, religiosity and faith emerged as an important framework for survival for the victims of the conflict, in particular when facing constant threat of death. Moreover, as the national state was failing and fragmenting, increasingly sub-national identifications became the available points of reference. The use of religious slogans such as 'Ya Allah Malna Ghairak ya Allah' (Oh god we have nothing but you) could be more interpreted as a search for hope, support and orientation to people in desperate situation, rather than a deeply entrenched ideology (al-Haj Saleh, 2017; Yassin-Kassab \& Al-Shami, 2016). At the same time, the rise of religiosity both in moderate and extreme forms, contributed to the consolidation of ethno-sectarian divisions of the Syrian society. Due to the mounting Sunni vocabulary used in many anti-regime protests, members of minorities, such as Alawis, Christians, Druze and Ismailis, increasingly felt excluded in the oppositional movement, as they did not feel represented in the Sunni-dominated discourse. Sub-national identification was further reinforced by rumours and the spread of misinformation, which contributed to the process of othering based on ethnic or religious divides (Pinto, 2017).

It was not only the presence of structural violence, but also a diverse range of actors, both internal and external, that accelerated the creation of the concept of the enemy, by mobilising inter-communal divisions to gain power and influence. As mentioned earlier, from the onset of the uprising the regime of Assad justified its measures based on sectarian discourse on Islamist terrorism and a threat of Sunni domination. Meanwhile, given its lack of clear leadership, the fragmented 
opposition was unable to maintain an inclusive national framework, which would have allowed it to encompass the various sections of the Syrian society. Frequently, both sides, the regime and the opposition, accused each other of committing acts of ethnic-based violence, which fed into the sectarian discourse. Although the religious establishment of Syria was equally fractured along political lines, internal and diasporic religious leaders, such as Sunni and Shi'a sheikhs and Christian clerics, deployed sectarian discourses to mobilise their community members for either side (Phillips, 2015; Pinto, 2017).

Even though the FSA initially received funding from France, the United States and Turkey among others, it was not sufficient to establish a functioning structure nor to defeat the regime forces, which were able to maintain their military strength through support from Russia and Iran. By contrast, jihadist groups benefited from money and weapons from Gulf donors, such as Saudi Arabia and Qatar. As a sectarian discourse and appearance was especially appealing to founders from the Gulf, some moderate groups changed their names, symbols and speech to attract support. Hence, it was sometimes not merely out of ideology but also out of necessity and rationality that some of the armed groups increasingly used religious symbols and sectarian rhetoric (Phillips, 2015; Yassin-Kassab \& Al-Shami, 2016). Due to lacking capacity, the FSA suffered from growing disorganisation and corruption, whereas jihadist groups benefited from their reputation of providing discipline and order. In particular, in opposition-controlled areas, where emerging local authorities struggled to establish a stable social and political environment, the strict rules and hierarchical structures of the jihadist groups, as well as their provision of social services to the suffering population, contributed to a sense of stability and safety. According to Pinto (2017):

\section{"Better armed, more tightly disciplined, and hell-bent on establishing their vision of public order, Jihadist groups such as Jabhat al-Nusra and ISIS offered some semblance to populations left on mercy to the unbounded state brutality, with barrel bombings and murderous incursions of the army and the shabiha, or the racketeering of rogue militia elements" (p.139).}

It was not only the active support for sectarian groups by external actors but also the inactivity of the international community, which further contributed to the sectarianisation of the conflict. When in August 2013 the regime was accused of using chemical weapons against the civilian population, clearly crossing the redline set by US President Barack Obama, the West nevertheless continued to show an unwillingness to intervene militarily. For many, this was perceived as a freeride ticket for the regime of Assad, which whatever crimes against humanity it committed, did not face any significant consequences. Given the lack of support for 
moderate actors and the disengagement in finding a political solution to the Syrian conflict, people and the moderate opposition increasingly felt abandoned by the West, turning their hope to more radical fractions of the conflict (Yassin-Kassab \& Al-Shami, 2016).

Phillips (2015) argues that despite the rising sectarian discourse and the unspeakable crimes against humanity committed in the name of religion, Syrian ethno-religious identifications were seldom cohesive and accepted across groupings, but instead were interpreted with various meanings and tended to be fluid in nature. As multi-layered constructs, sources of identity should not be considered just along ethnic and religious lines, but also based on gender, class, region or political ideology, making it possible to cross-cut sectarian ties through other networks of solidarity. Nor were the ideologies of jihadist groups accepted by a significant share of the Syrian population. Despite their potential ability to generate feelings of security and stability, these groups continued to be challenged by acts of civil resistance. In the winter of 2013/2014 popular protest were organised in the north of Syria challenging both the regime and IS repression (Yassin-Kassab \& Al-Shami, 2016). When Raqqa became a stronghold of the socalled IS in April 2014, a group of local media activists who had organised themselves since the uprising to raise awareness on regime repression, saw themselves confronted with a newly emerging threat. Well before the international media captured the rise of the so-called IS, the group launched the campaign Raqqa is Being Slaughtered Silently (R.B.S.S) to document the atrocities committed by the Islamist group, by raising global awareness via social media. Their underground activism was not only aiming at exposing the crimes internationally, but also at fighting the spread of the IS-ideology internally.

\subsubsection{Conclusion - Syria's many questions}

Over the past years, the Syrian conflict has caused over 400,000 deaths, displaced more than 13 million people, left 11.7 million people in need of humanitarian assistance and deepened sectarian violence across the region (OCHA, 2019; United Nations Secretary-General, 2016). In 2015 Assad began to lose power, but Russia's direct military involvement on the side of the regime in September 2015 turned the war in the regime's favour. The recapturing of Aleppo in late 2016 was a major turning point for the Syrian Army as it gained an important strategic advantage in north-western Syria against the Free Syrian Army. In November 2017, the Syrian army and its allies claimed to have recaptured the last major city under the control of the 'Islamic State' terrorist militia, marking a further milestone in gaining control over the country (BBC, 2017). 
Besides military victories of the regime, political processes such as the Geneva, Astana and Sochi talks continued their efforts to pave the way for a political solution to the conflict. The first round of Geneva peace talks initiated by the then UN peace envoy to Syria Kofi Annan was held in June 2012 in Geneva, bringing various actors together to set the guidelines for a peace process and to pave the way for the establishment of a transitional government. With the continuation of the conflict, the Geneva talks under UN's auspices pursued the goal of a peaceful transition, yet after several rounds actors were unable to forester a political solution to the Syrian conflict (Lundgren, 2016). Next to the UN peace processes, Russia initiated the Astana talks in 2017, which were endorsed by two main regional players, Iran and Turkey, to facilitate indirect negotiations between the regime and the opposition. As a result of these international efforts, some progress was made in the peace-making process when Turkey, Iran and Russia agreed on establishing de-escalation zones in Syria. The Russian-led agreement, signed in the Kazakh capital of Astana in May 2017, promised unimpeded humanitarian access to besieged areas and the return of refugees to the northern cities of Homs, Ghouta, south Dara'a, and Idlib. Given a loophole in the agreement that allowed for continuous operations against 'terrorists,' a term used to describe the entire opposition in the regime's language, the agreement was not only seen as a measure to promote stability and de-escalation, but also as a war management strategy by the regime and its allies to seize additional territories (Hinnebusch \& Imady, 2017). Building on the Astana processes, Russia initiated and hosted the Syrian Congress on National Dialogue in Sochi in 2018 to reactivate the deadlocked UN process. The process brought together 1,500 delegates from different parties of the Syrian conflict to negotiated a political transition, yet critics argued that it was a Damascus-dominated dialogue that side-lined the opposition (Barnard, 2018).

Given the regime's military and territorial gains, it is argued that Assad effectively won the Syrian war and will most likely remain in power. At the same time, various friendship-hostility configurations between the US, Turkey, Syria, Saudi Arabia, Russia, Israel and Iran are adding a strong regional and international component to the conflict, making it likely that reconstruction efforts in the future will be fragmented and incremental (Van Veen, 2019). In addition, the question of refugees and Internally Displaced Persons (IDPs), including their sustainable return, or political participation from a distance, has been largely ignored in the different international political talks. As a result, more than half of the country's pre-war population tends to be currently excluded from the formal political processes that seek to define the future fate of the country (Batrawi \& Uzelac, 2018). 
At the time of writing, the Syrian conflict is being fought on multiple fronts. It is not merely a power struggle between regime and opposition forces, but also manifests itself in dichotomies of Sunni vs. Shia, minority vs majority, religious vs secular, rural vs urban, upper vs under class and other socio-political divides. These are largely propelled by a geopolitical quest for power, in which international powers such as the US and Russia, as well as regional actors including Saudi Arabia, Qatar, Turkey and Iran scramble for dominance and power to establish their influence in the region (Phillips \& Valbjørn, 2018). Resolving the conflicts within the broader Syrian society will be a long-term endeavour, heavily challenged by the fact that the sovereignty of the Syrian government continues to be contested and that the future of Syria's displaced population, which accounts for almost half of the overall population, remains uncertain.

\subsection{Socio-political space of diaspora mobilisation in Syria}

This section briefly discusses the overall approach of the Syrian government with regard to emigration and diaspora issues and discusses the historical and recent state-diaspora relations. It highlights the legal framework relevant for transnational politics, as well as the institution responsible for diaspora engagement, along with its mandate and programmes.

\subsubsection{Socio-political framework of emigration}

Until now, the relationship between the Assad government and the Syrian diaspora groups in Germany and other destinations has been marked by tensions, not at least because in the past many of the Syrian elite, escaping the rigid regulations implemented by the socialist regime, found exile abroad. Although states are not able to exercise their full sovereignty abroad, countries of origin can introduce long-distance instruments and policies to monitor and exert control over their emigrant population. Research, including findings of this study, has shown how Syrian government state-run institutions of the Assad government abroad have been involved in surveillance and intelligence measures to repress diaspora political activism and to prevent the emergence of a political opposition from outside. Syrian diaspora political entrepreneurs were detained and interrogated when they visited Syria or their family in Syria was threatened (Jörum, 2015; Moss, 2016b; Qayyum, 2011). At the same time, Bashar Al-Assad in the first decade of his presidency stressed the important role of expatriates in supporting the national economy and tried to reach out to Syrian diaspora groups to harness their potential for the development of the country. As a result, until the uprisings in 2011, the engagement of the Syrian diaspora was limited to the economic, social and cultural 
spheres. According to respondents, the Syrian diaspora organisations that existed before the conflict were by many perceived as a long arm of the Assad government, which tried to politically control those living abroad via these organisations. While in 2013, at least formally, attempts were made to engage with the diaspora and to promote national dialogue to bring an end to the crisis (MPC Team, 2013), these action to a vast extent, as will be shown in the next section, were selective in nature, mostly favouring those who presented themselves as loyal to the regime.

With respect to the legal framework, the government provides very limited opportunities for transnational politics and political action for Syrians living abroad. Syrian law generally does allow double citizenship but considers a Syrian citizen with dual citizenship a Syrian first. A person forfeits nationality if he or she acquires a foreign nationality provided that a decree has been issued, based on his or her request and upon recommendation by the Minister of Interior, allowing him or her to abandon his or her nationality after having fulfilled all his or her obligations and duties towards the state (Art. 10 Legislative Decree 276 of 1969). De facto, however, abandonment of the Syrian citizenship is regularly refused (Beauftragte der Bundesregierung für Migration, Flüchtlinge und Integration, 2018). The right to apply for and to occupy official government positions has been restricted to a certain extent, making it more difficult for Syrian emigrants to influence political processes in the origin country, through engaging in transnational politics through conventional means. For instance the Article 152 of the 2012 constitution states that no person carrying another nationality in addition to the nationality of the Syrian Arab Republic, might occupy the office of President of the Republic, Vice-president, Prime Minister, deputy prime ministers, ministers, members of the People's Assembly or members of the Supreme Constitutional Court. In addition, Paragraph 5 of Article 84 of the 2012 constitution declares that the President should be a resident of the Syrian Arab Republic for no less than 10 years continuously upon being nominated, disenfranchising especially those, who left the country during the conflict, to run for this office.

According to Article 99 of Capital 13 of the electoral law every Syrian citizen who lives outside the country has the right to vote in presidential elections in the Syrian embassies according to the electoral law. The citizen who would like to take part should register in the electoral list in the embassy to participate in the election. In the most recent presidential referendum in June 2014, officially registered refugees with an exit stamp were entitled to vote at Syrian embassies of countries such as Lebanon, Iran and Jordan. As reported by the Syrian state-run Sana news agency, voting was possible in 43 embassies, while many governments opposed to the Assad regime, such as the United Arab Emirates, France, Belgium, the United 
Kingdom and Germany, banned the embassies from facilitating elections on their territories. Moreover, the international community, including the European Union and former UN Secretary-General Ban Ki-moon, condemned the June 2014 election as illegitimate, as voting within the country was possible in government-controlled areas only (BBC, 2014; Darke, 2014; Reuters, 2014).

\subsubsection{Relevant institutions and general diaspora engagement policies}

The Ministry of Expatriate Affairs was established in 2002 with the aim to strengthen the ties between the country and its emigrant population, by promoting the development and cultivation of a national identity and an emotional attachment to the country of origin. Other responsibilities included the establishment of an information management system to facilitate exchange between the ministry and Syrians abroad as well as the monitoring of cultural, social, and economic activities of the emigrant population. In light of the country's policies of economic modernisation and opening, the ministry also sought to encourage and facilitate investment and knowledge transfer by Syrians living abroad (ICMPD \& IOM, 2010). To foster the links with expatriates, the Ministry organised two major diaspora conferences, the first of which was held in Damascus in October 2004, under the motto 'With Expatriates for Development' and the second in May 2007 under the heading 'The Homeland Invests: Together We Build the Future'. Both conferences mainly touched upon four fields of activity to harness the potential of Syrians living abroad. First, the discussions stressed the importance of strengthening the identification and belonging to the homeland, by promoting activities of diaspora groups that seek to support the learning of the Arabic language among the second and third generations. Second, the objective was to cultivate and spread a positive image of Syria abroad through cultural exchange and media, including the founding and supporting of media units and organisations, and the organisation of exhibitions on the Syrian country, its history and culture abroad. The third field of action was the promotion of knowledge transfer and economic investment to foster the contribution of diaspora groups in the development of the country of origin. Among this, diaspora groups were encouraged to support medical collaboration and the development of medical services through scientific exchange, collaboration and education in this field. Besides, investment and economic exchange was should be fostered through the establishment of the 'Expatriate Fund for Human Development' to support development in Syria. Finally, another recommendation sought to reform and modernise institutions in order to ensure the freedom of expression, to encourage the civil society to play a leading role in the reform process, and to include diaspora groups in the decision-making process (Ministry of Foreign Affairs and Emigrants, 2019). 
Next to fostering exchange with expatriate communities, the Syrian government issued the law no. 16 in January 2007 to organise and support the work and activities of the diaspora groups. The law included regulations related to the objectives and activities of Syrian diaspora associations abroad. According to the law, an association is defined as an independent body which is allowed to engage in cultural, social and economic activities to support the ties with the homeland among the Syrian emigrant population. Actions of the organisations should promote the well-being and integration of Syrians in the respective destination countries. Besides, the organisations are asked to serve as bridge-builders between the countries of origin and destination, and as such, should deepen the relations and strengthen cooperation and exchanges at different levels. Some of the activities can be done in coordination with the ministry or the embassies. Besides, the association can contact and coordinate with the embassies to solve and follow up issues related to the expatriates (Ministry of Foreign Affairs and Emigrants, 2019).

In 2011, the Ministry of Expatriate Affairs merged with the Ministry of Foreign Affairs into the Ministry of Foreign and Expatriate Affairs (Legislative Degree No. 50/2011). In accordance with the previous objectives, the ministry stresses the important role of Syrian expatriates in supporting the country in the fields of management, education, tourism, economy and trade. Besides, expatriates are considered as ambassadors for Syria (culturally and politically) who should be supported. According to the Ministry's website the main objectives of the ministry are to implement the state's policies and to coordinate with and support other ministries in supporting expatriates and diaspora groups and their affairs, with the aim to enhance ties and national affiliation among Syrian expatriates and to support the activities of the expatriates and diaspora groups in the cultural, social and economic fields to preserve their national identity (Ministry of Foreign Affairs and Emigrants, 2019).

While no new official programmes and activities have been communicated on the website since the outbreak of the Syrian conflict, the Syrian government has organised several meetings with delegations of Syrian expatriates living in a diverse range of countries, such as Poland, Romania, Sweden, United States, Kuwait, France, Germany and Egypt. In general, the meetings stressed the importance of enhancing the contacts with the expatriates and highlighted their role in supporting the national economy and rebuilding process (economic, touristic, infrastructure, education, providing humanitarian assistance). Further, expatriates where asked to counter the discourse against Syria and the supposedly wrong information spread about the country and its government. For instance, in a meeting with a group of expatriates in Damascus in August 2008, the establishment of the World Assembly of Syrian Expatriates - Warsaw Statement 
Group was announced. The group included expatriates from Poland, Kuwait, United States and Sweden, and aimed at supporting the country with experience and funding for the rebuilding process, as well as in participating in shaping the future of a 'secular' and 'developed' Syria. The group called for allowing expatriates to be represented in the People Assembly and to have a consulting role. Besides, they called for support for the role of expatriates in the national reconciliation the Syrian-Syrian dialogue (al-Sabbagh, 2016).

While the discourse of the regime officially highlights the vital role of expatriates in rebuilding the country, the policies and practices of the government seem highly selective, engaging only with those who show and voice loyalty to the regime. Besides the calls for national dialogue, no genius attempts have been made by the government to engage with Syrian diaspora actors who position themselves in opposition to the regime. The regime stance is also reflected in the overall approach towards the displaced population. Whereas frequent calls have been made for refugees to return to the homeland, it seems that the general discourse tends to categorise the refugees either in wanted or unwanted returnees. On the one hand, the wanted Assad sympathisers, who show loyalty to the current regime, and those unwanted returnees who are either labelled as traitors, terrorists and security threats or as socially, culturally and economically posing a burden to the progress and reconstruction of the country of origin (Batrawi \& Uzelac, 2018). 



\section{Chapter 5: Mapping the Destination Country Context}

Figure 6: Map of the Federal Republic of Germany

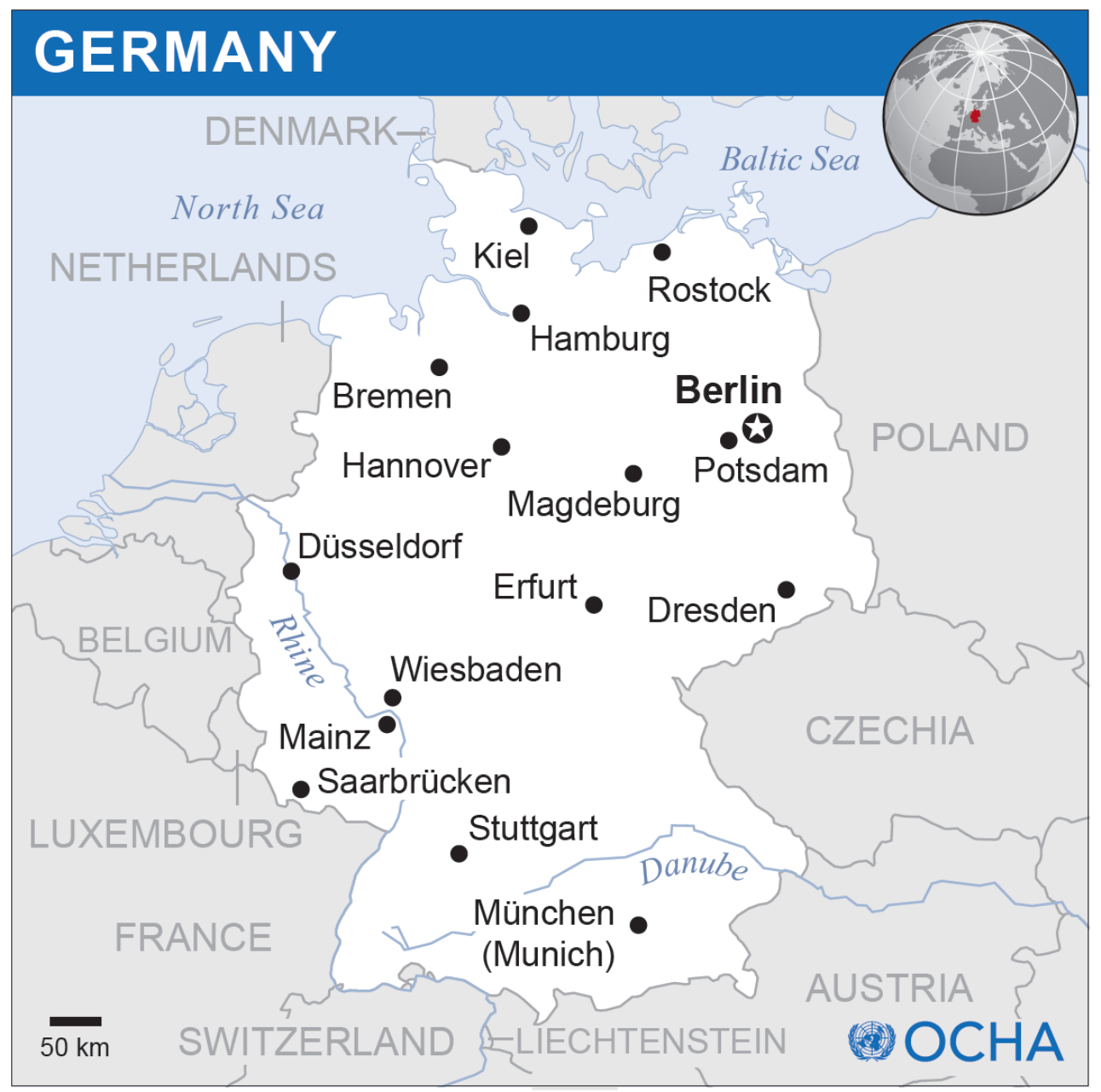

Sources: ESRI, OCHA, UNGIS

Given that the dimension and nature of diaspora involvement depends on the size, composition and distribution of diaspora groups, as well as on individual capabilities and aspirations, it is essential to understand the broader migration patterns as well as the social, economic and political circumstances and conditions that Syrian migrants encounter in the destination country. This section provides a short overview of emigration trends from Syria more generally, before turning to a description of the characteristics of the Syrian immigrant population in Germany. 
The last section provides an analysis of the socio-political space of diaspora mobilisation in Germany, by taking into account the institutional and discursive dimension of citizenship and incorporation regimes, relevant actors, institutions and policies targeting diasporas, as well as programmes and policies that specifically target the Syrian diaspora in Germany.

\subsection{Syrian emigration profile}

Syria has a long emigration history, characterised by several waves of emigration. Historically, high population growth, socio-political events and economic factors such as low economic growth and high rates of unemployment were the main push factors for migration, while nowadays it is violent conflict that is causing mass displacement, both internally and internationally. In general, one can observe four waves of emigration leading to an emigration profile that differs in terms of destination countries, the type of movement and the period of emigration.

- The first wave of emigration was observed in the mid-19th century, in which poor living conditions and obligatory military service enforced by the Ottoman Empire led to migration flows mainly to the US, South America, Europe, and Australia (Mehchy \& Doko, 2011).

- The second wave of emigration from the mid-1950s onwards was characterised by emigration of the Syrian elite such as entrepreneurs, capitalists and professionals, who were escaping the rigid regulations implemented by the socialist regime. In combination with flourishing economies and employment opportunities in the receiving countries, these factors caused migration flows mainly to Lebanon, the Gulf countries, Europe and to a lesser extent to the US (Di Bartolomeo et al., 2012; Mehchy \& Doko, 2011).

- The third wave from the mid-1970s onwards was distinguished by labour migration to the Gulf States due to the expansion of the oil-based economy and the resulting economic opportunities. After governments of the Gulf States implemented policies limiting the number of Arab workers in the 1980s, emigration rates to these countries declined. Moreover, the end of the civil war in Lebanon (1975-1989) created labour shortages that further encouraged migration especially of lower skilled workers until 2005. In this year, the assassination of the then Lebanese Prime Minister Hariri led to political instability between Lebanon and Syria (Mehchy, Mahadi Doko 2010; Di Bartolomeo et al. 2012). Beside emigration to Arab countries, smaller flows of asylum seekers migrating to Europe formed a part of this emigration period (ICMPD \& IOM, 2010). 
- The fourth wave of emigration is recent. The violent conflict that started in 2011 has caused massive refugee outflows as well as internal displacement. It is estimated that the conflict has displaced almost 12.6 million people as of the end of 2017, with around half of the population (6.2 million) being internally displaced. Moreover, the number of refugees and asylum seekers has reached more than 6.4 million. Of these, the great majority moved to neighbouring countries, with Turkey $(3,424,200)$, Lebanon $(992,100)$ and Jordan $(6,655,400)$ hosting the major part of Syrian refugees in the region. In Europe, Germany and Sweden have become the major destination countries for displaced Syrians, hosting a total number of 496,700 and 103,600 respectively (UNHCR, 2019).

Given that the Syrian government does not publish any statistical information on their emigrant population, no exact numbers on the Syrian emigrant population can be provided from an origin country perspective. According to the Syrian migration profile published by the Migration Policy Centre (De Bel-Air, 2016), the total stock of Syrian nationals residing abroad based on receiving country statistics was estimated at around 7.3 million as of November 2015, of whom 5.6 had left Syria since the outbreak of the conflict in 2011. The most recent statistics by the Population Division of the United Nations' Department of Economic and Social Affairs (2019) estimate the total stock of Syrian migrants at 8,225,499 in mid-2019, compared to 1,084,203 in mid-2010. Table 4 provides an overview of the top destination countries of Syrian migrants in mid-2019. The region of Western Asia was hosting the majority of Syrian migrants, representing 83 percent of the total stock in mid-2019. The two major destination countries neighbouring Syria, Turkey and Lebanon, alone hosted 50 percent of the total stock of Syrian migrants in 2019. Other important destination countries were the Gulf States, with Saudi Arabia hosting almost 803,000 Syrian migrants. In Europe, Germany, Sweden, and to a lesser extent the Netherlands have become major destinations for Syrian emigrants in 2019. While the data provides a global overview of Syrian migration, including forced displacement, and allows for the comparison of countries and world regions, it nevertheless comes with certain limitations. In particular, differences in data collection practice (censuses, population registers, or representative surveys) as well as different definitions of migrant populations (e.g. foreign born vs. foreign nationals) used among the countries, make a comparison more challenging. For instance, where data is based on foreign nationals such as in the case of Germany, migrant statistics may include persons who were born in the country of residence and may have never lived abroad. In addition, refugees and asylum seekers are not always covered in censuses, especially in regions of the global south, where large segments of the displaced population live in camps. As a result, refugee statistics reported by international agencies such as UNHCR present the only source of 
information on persons who are formally recognised as refugees or find themselves in refugee-like situations.

Table 4: Top 10 Destination Countries for Syrian Migrants, mid-2019

\begin{tabular}{|l|l|l|}
\hline Country & Stock number & $\%$ of total stock \\
\hline Turkey & $3,743,494$ & $46 \%$ \\
\hline Lebanon & $1,162,305$ & $14 \%$ \\
\hline Saudi Arabia & 802,915 & $10 \%$ \\
\hline Jordan & 724,508 & $9 \%$ \\
\hline Germany & 589,628 & $7 \%$ \\
\hline Iraq & 258,144 & $3 \%$ \\
\hline Sweden & 181,793 & $2 \%$ \\
\hline Egypt & 124,688 & $2 \%$ \\
\hline United States of America & 91,663 & $1 \%$ \\
\hline Netherlands & 70,713 & $1 \%$ \\
\hline
\end{tabular}

Source: United Nations, Department of Economic and Social Affairs, Population Division (2019). International Migrant Stock 2019. (United Nations database, POP/DB/MIG/Stock/Rev.2019).

Unfortunately, limited data is available on demographic and socio-economic characteristics of the Syrian emigrant population. OECD estimates indicate that Syrian immigrants in OECD countries have an intermediate skill level, with 34.1 per cent being low and 34.5 per cent highly educated in 2011 . When it comes to the distribution of employment of the Syrian immigrant population in OECD countries, however, 43.1 per cent were employed in highly skilled jobs, and slightly less than half $(48.9 \%)$ in medium skilled occupations, whereas only 8.1 per cent worked in low skilled occupation in 2011. Among the OECD countries, France, the United Kingdom and Canada, had the highest share of highly skilled Syrian immigrants, with more than 50 per cent of the Syrian immigrants being highly educated, whereas in Germany the rate of highly skilled was estimated at 22.4 per cent (OECD, 2015). In contrast, emigration to non-OECD countries tends to be characterised by low skilled migration, with older estimates (excluding Gulf States 
and Lebanon) from 2001 indicating that with 51.4 per cent slightly more than a half of Syrian immigrants had a low level of education, while only 14.4 per cent were highly skilled (OECD, 2001). Similarly, Syrian emigration to Lebanon was mainly characterised by male dominated, lower skilled, circular migration patterns (Balanche, 2007).

\subsection{Characteristics of Syrian immigrant population in Germany}

This section provides an overview of the Syrian immigrant population in Germany. The German Federal Statistical Office collects annual data on the immigrant population residing in Germany, where information is available on gender, age, average length of stay, and residence status for each nationality. The data only captures the immigrant population that does not have German citizenship and does not provide separate information for Syrian nationals on educational level, labour market performance, or other socio-economic key statistics. Instead, a micro-census conducted every year informs on the educational status and income situation of the population with a migration background. However, these statistics underrepresent very recently arrived Syrian asylum applicants, while their data is overall skewed towards the migrant population that arrived after 2011.

Germany has become Europe's largest receiving country for Syrian migrants, hosting in total 745,640 individuals with Syrian citizenship in December 2018 up from 30,133 in December 2010, the year before the eruption of the conflict. After Turkish and Polish nationals, Syrian nationals represented the third largest immigrant group in Germany in 2018. As this number only captures the immigrant population that does not hold German citizenship, it does not include Syrians who have been naturalised or second generation Germans of Syrian origin (Statistisches Bundesamt, 2019a). Microcensus data asking for a person's migration background indicates that 813,000 people of Syrian origin resided in Germany in 2018, of which 711,000 had an own migration experience. In addition to persons with a Syrian citizenship, migration background includes individuals with a German citizenship whose parents have migrated to Germany from Syria or who themselves migrated and have taken up German citizenship (Statistisches Bundesamt, 2019b). Looking at the historical data, one can observe that the numbers of Syrian nationals residing in Germany sharply increased since 2011, given the massive displacement caused by the Syrian conflict (Figure 7). 
Figure 7: Syrian citizens in Germany 1970-2018

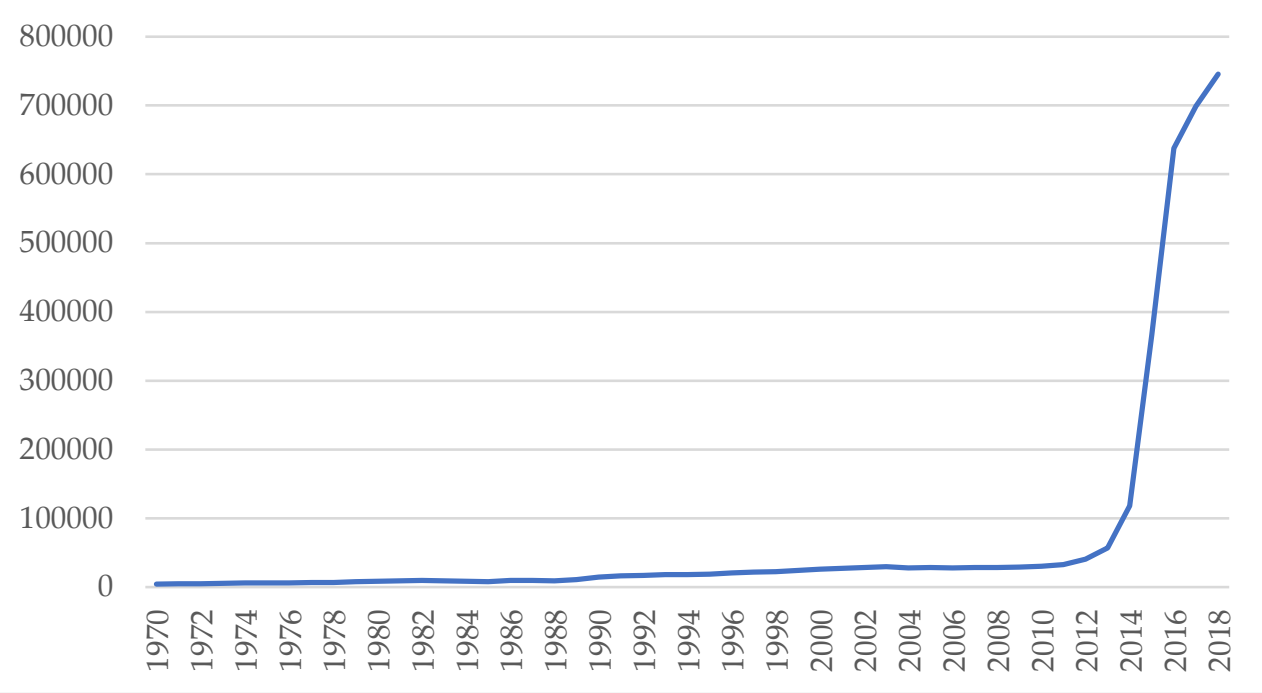

Source: Statistisches Bundesamt, 2019a, 3 Foreign population by nationality and sex

Table 5 provides an overview of the residence status of Syrian citizens residing in Germany in 2018. As the table indicates, the vast majority of Syrian citizens had a limited residence permit (83\%). More than two thirds of Syrian citizens $(69 \%)$ received temporary protection based on humanitarian grounds, followed by 98,660 persons who received a residence permit for family reasons. Around 51,000 were granted residence based on their submission of an application for a residence permit. Next to that, 57,375 Syrians were still residing in Germany without a residence permit (Statistisches Bundesamt, 2019a). This category includes registered asylum seekers who have not yet filed an application for asylum or who have not yet been granted a preliminary residence permit on grounds of seeking asylum (Aufenthaltsgestattung) (Statistisches Bundesamt, 2016). 
Table 5: Residence Status of Syrian Citizens in Germany, December 2018

\begin{tabular}{|c|c|c|c|}
\hline & Men & Women & Total \\
\hline Permanent Settlement Permit & 9,465 & 4,820 & 14,285 \\
\hline Limited Residence Permits & 375,545 & 246,655 & 622,200 \\
\hline Education & 2,495 & 645 & 3,140 \\
\hline Work & 1,495 & 310 & 1,805 \\
\hline Humanitarian grounds & 333,675 & 182,755 & 516,430 \\
\hline Family reasons & 36,825 & 61,835 & 98,660 \\
\hline Other & 1,055 & 1,105 & 2,160 \\
\hline No residence permit required & 275 & 160 & 435 \\
\hline $\begin{array}{l}\text { No need for residence permit, Stateless } \\
\text { Persons }\end{array}$ & 20 & 20 & 40 \\
\hline EU Mobility & 255 & 140 & 395 \\
\hline $\begin{array}{l}\text { Application for residence permit } \\
\text { submitted }\end{array}$ & 30,015 & 21,335 & 51,350 \\
\hline Without residence permit & 32,580 & 24,795 & 57,375 \\
\hline $\begin{array}{l}\text { Exceptional Leave to Remain } \\
\text { (,Duldung') }\end{array}$ & 2,330 & 1,380 & 3,710 \\
\hline $\begin{array}{l}\text { Temporary residence permit } \\
\text { ('Aufenthaltsgestattung') }\end{array}$ & 11,755 & 9,100 & 20,855 \\
\hline Without Status & 18,495 & 14,315 & 32,810 \\
\hline Total & 447,880 & 297,760 & 745,640 \\
\hline
\end{tabular}

Source: Statistisches Bundesamt, 2019a, 11 Foreign population as at 31.12.2018 by nationality, residence status and gender

Looking at the geographical distribution, one can observe that with 206,240 Syrian nationals, North Rhine-Westphalia hosted the highest share of Syrian citizens 
residing in Germany in December 2018, followed by Lower Saxony $(79,930)$, Baden-Wuerttemberg $(78,145)$ and Bavaria $(72,565)$ (Figure 8). Given that a significant proportion of Syrian nationals arrived in Germany after the outbreak of the crisis as asylum seekers, the distribution might be highly influenced by the 'Königstein Key', which regulates the initial distribution of asylum seekers among the Federal States (Bundesländer) based on tax revenues and population numbers. The key determines in which Federal State a prospective asylum seeker has to apply for asylum upon arrival in Germany.

Figure 8: Geographical distribution of Syrian citizens in Germany, December 2018

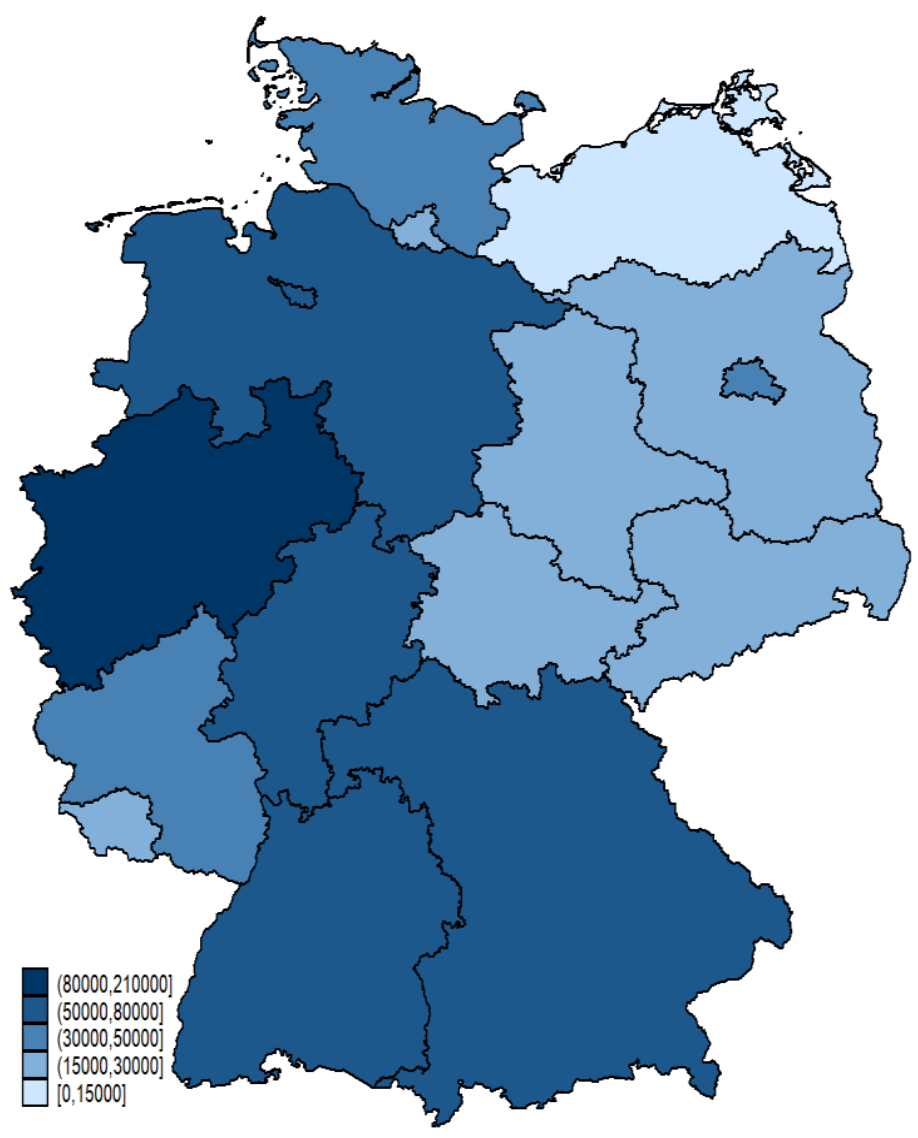

Source: Statistisches Bundesamt, 2019a, 10 Foreign population on 31.12.2018 by nationality and federal states

The Federal Statistical Office annually provides data on the socio-economic and demographic characteristics of the population residing in Germany with a migration background (Statistisches Bundesamt, 2019b). The latest data gathered 
stems from the year 2018. Given the high proportion of Syrians who have arrived since 2011 in comparison to the number of pre-2011 Syrian migrants, the data is overall likely to disproportionally reflect the characteristics of the new refugee population. As the microcensus data does not inform on the legal status of the surveyed population, a comparison between the two migrant groups is impossible. In addition, the microcensus does not account for second-generation migrants of German citizenship where only one parent migrated from Syria. Still, it can add to a more comprehensive picture of the Syrian immigrant population, by including those members who have obtained German citizenship through naturalisation or birth in Germany.

Looking at the demographic characteristics of the Syrian immigrant population in Germany one can observe, that with 60.5 per cent being males with an average age of 25.5 years, young men accounted for a high proportion of the persons with a Syrian migration background in Germany in 2018. When disaggregated by age groups, as shown in figure 9, the number of men always exceed those of Syrian women except of the group of $0-5$ ages where number of girls $(50,000)$ is slightly higher than the number of boys $(49,000)$ (Statistisches Bundesamt, 2019b).

Figure 9: Syrian immigrants in Germany by sex and age group, 2018

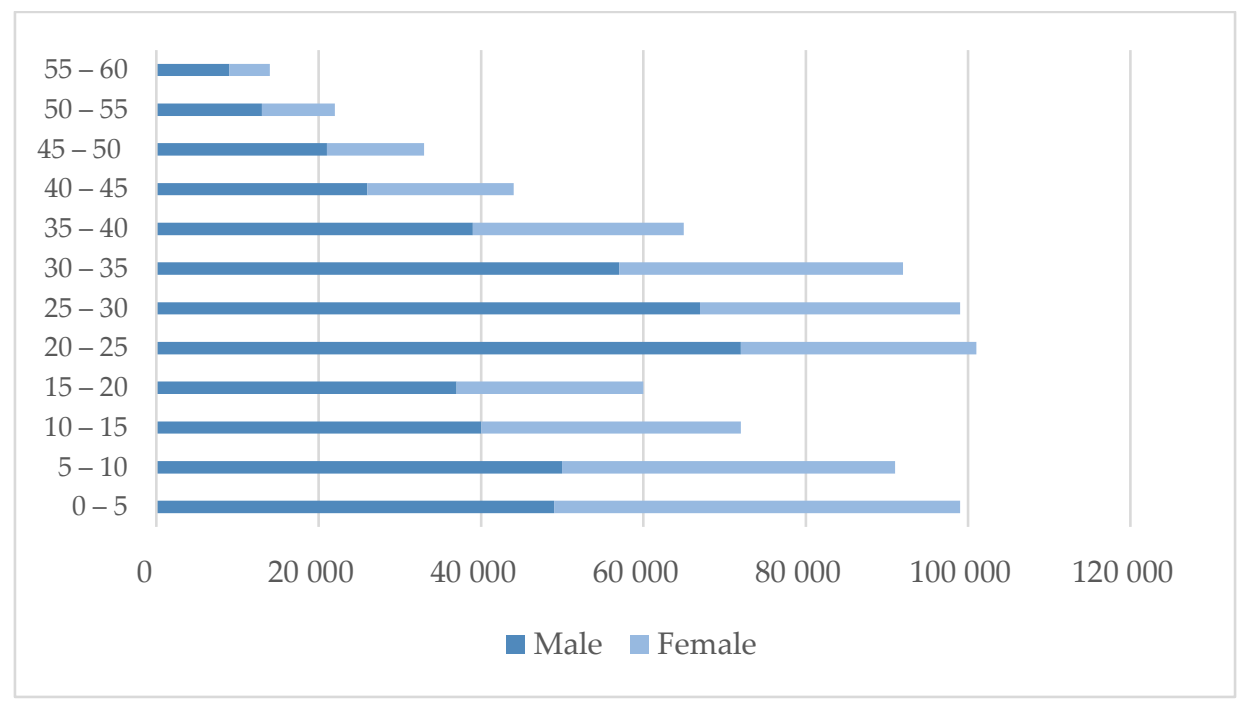

Source: Statistisches Bundesamt, 2019b, 2 Population 2018 by migration status, age groups and sex

Compared to the total population residing in Germany, the Syrian immigrant population exhibited a very young population profile, with children under the age 
of 18 accounting for more than one third in 2018. The average age of persons with Syrian migration background was at 24.7 years, in contrast to a mean of 44.4 years for the total population (see Figure 10) (Statistisches Bundesamt, 2019b).

Figure 10: Age groups of the Syrian population and total population in Germany, 2018

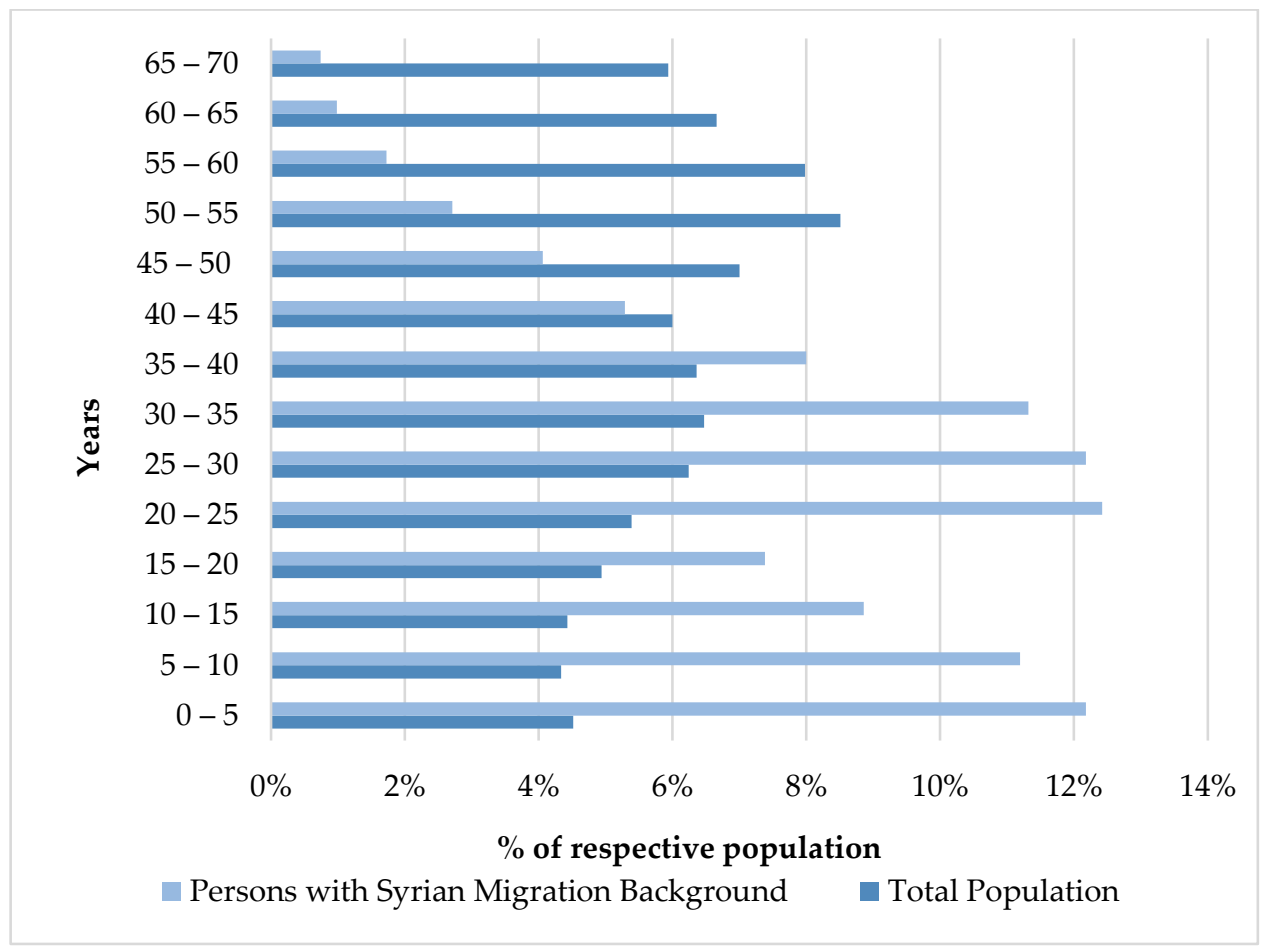

Source: Statistisches Bundesamt, 2019b, 2 Population 2018 by migration status, age groups and sex

The education profile of the Syrian immigrant population appeared very polarised. Due to the relative youth of the population, a much higher proportion of persons with a Syrian migration background was still receiving education or was not yet required to attend school (39\%) in 2018, compared to 17 per cent of the total population. The proportion of Syrians without any formal education was at 19 per cent in comparison to 4 per cent of the total population (see Figure 11) (Statistisches Bundesamt, 2019b). 
Figure 11: Educational status of persons with a Syrian migration background, 2018

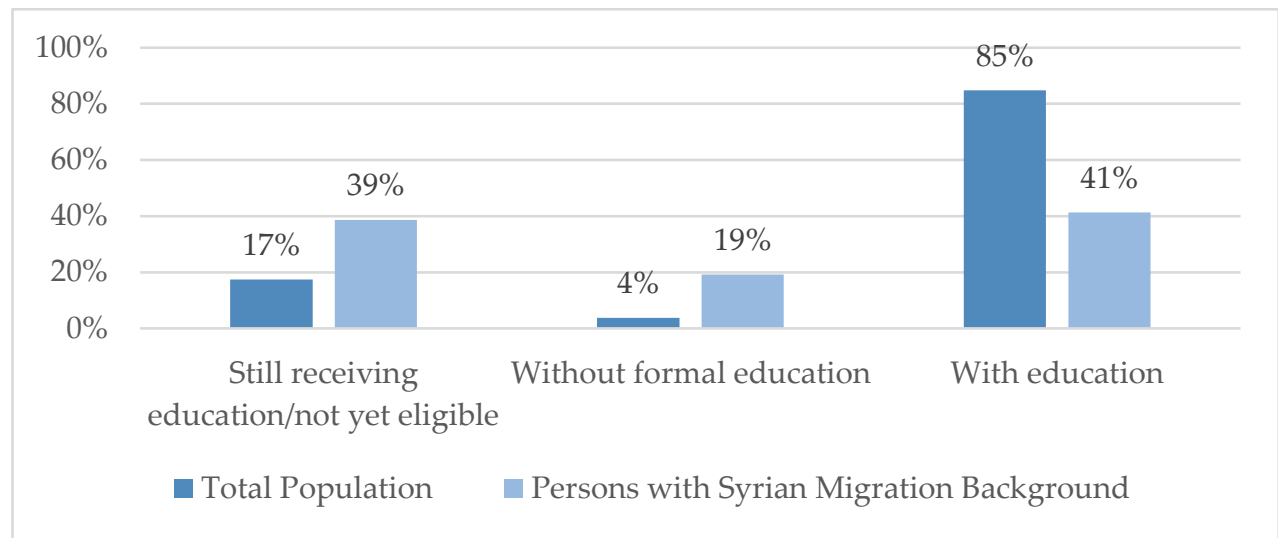

Source: Statistisches Bundesamt, 2019b, 8 Population 2018 by migration status, general school leaving qualification and gender

Yet as Figure 12 shows, among those with education the share of persons with a completion of compulsory basic secondary schooling (Hauptschulabschluss) was smaller within the Syrian immigrant population (24\%) when compared to the total population (32\%). In addition, the percentage of Syrians with a general qualification for university entrance (Abitur) (57.0\%) exceeded that of the total population (27.0\%) significantly (Statistisches Bundesamt, 2019b).

Figure 12: Secondary school qualifications of persons with a Syrian migration background, 2018

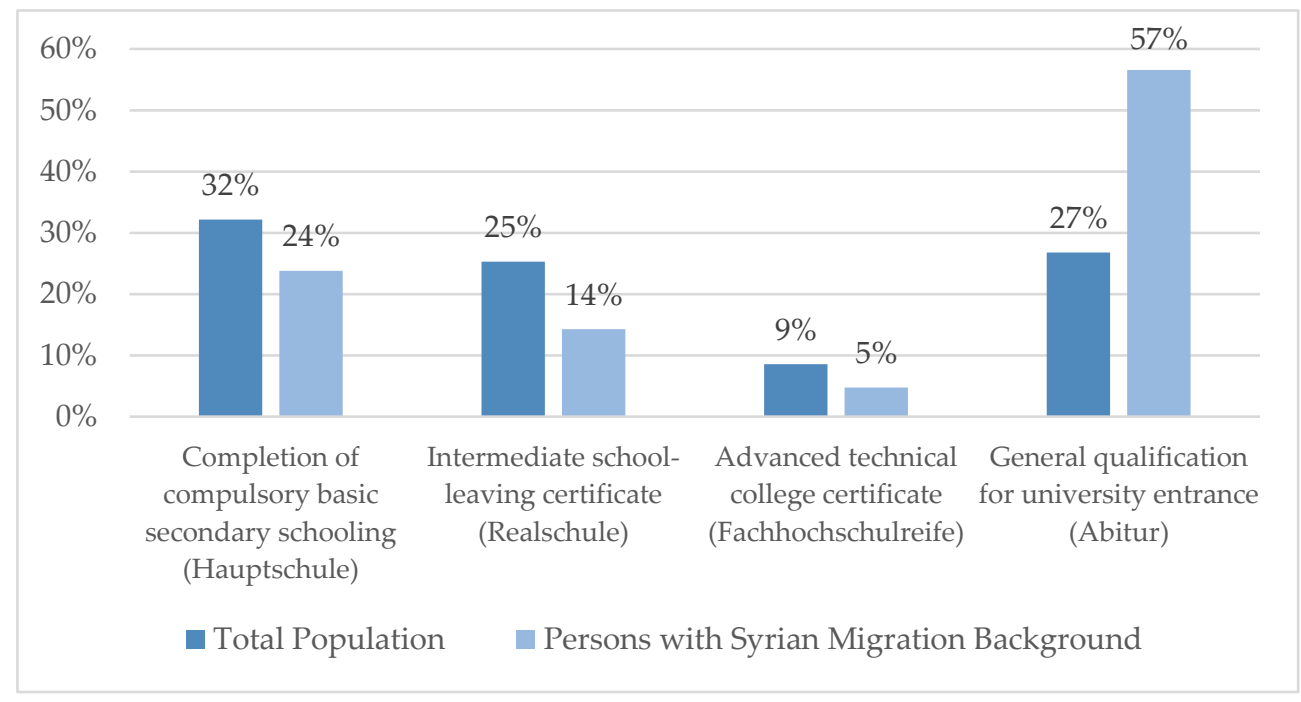

Source: Statistisches Bundesamt, 2019b, 8 Population 2018 by migration status, general \#school leaving qualification and gender 
The demographic characteristics resulted in an economic situation for the Syrian immigrant population that was very different from that of the general population. As Figure 13 illustrates, the population group with a Syrian migration background displayed a higher proportion of economically inactive people $(75 \%)$ and fewer gainfully employed (68\%). This can be attributed to the fact that persons under the age of 15 and people still gaining an education made up a considerable part of Syrian immigrants in Germany in 2018. In addition, Syrians who were still in the asylum procedure and had not yet acquired the right to work were likely to be among the group considered economically inactive. The unemployment rate of the Syrian group was at 39 per cent in 2018, considerable higher than that of the total population (4\%) (Statistisches Bundesamt, 2019b).

\section{Figure 13: Labour force categorisation, 2018}

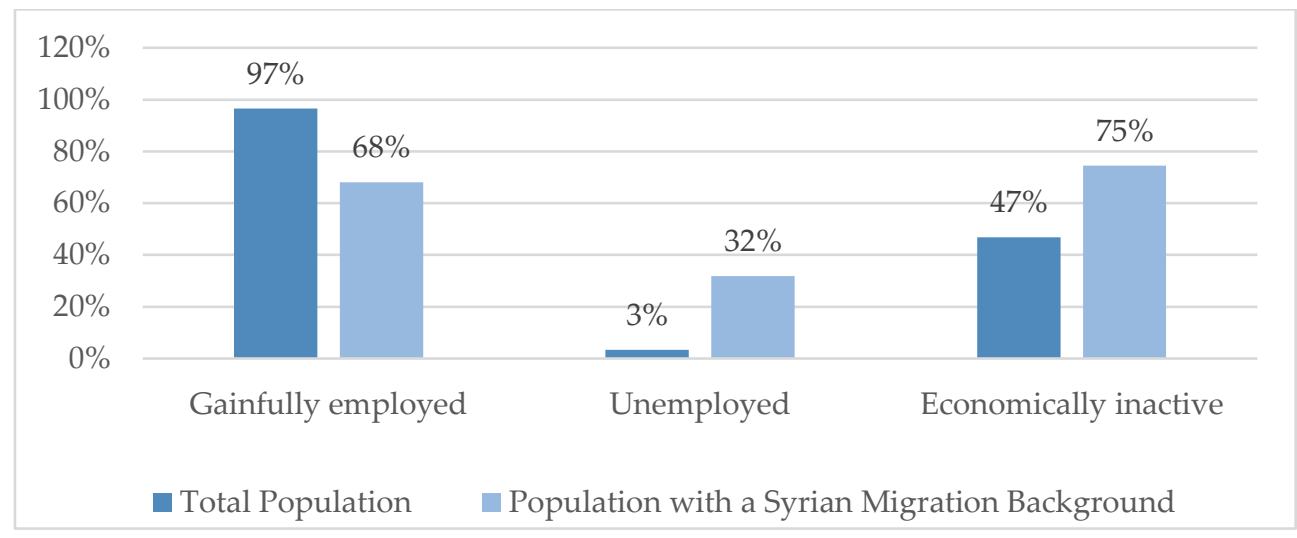

Source: Statistisches Bundesamt, 2019b, 16 Population 2018 by migration status, occupational status, economic sector, income and sex

As the proportion of gainfully employed persons among the population with a Syrian migration background was considerably low, their income source profile naturally differed from that of the general population. As Figure 14 shows, only 4 per cent indicated wage from employment as the main source of income. Instead, more than half $(54 \%)$ sourced their main income from unemployment benefits and other governmental support, a figure that was only at 7 per cent for the total population residing in Germany in 2018. In addition, support by family represented a crucial source of income, accounting for 42 per cent among the population with a Syrian migration background (Statistisches Bundesamt, 2019b). 
Figure 14: Income categories, 2018

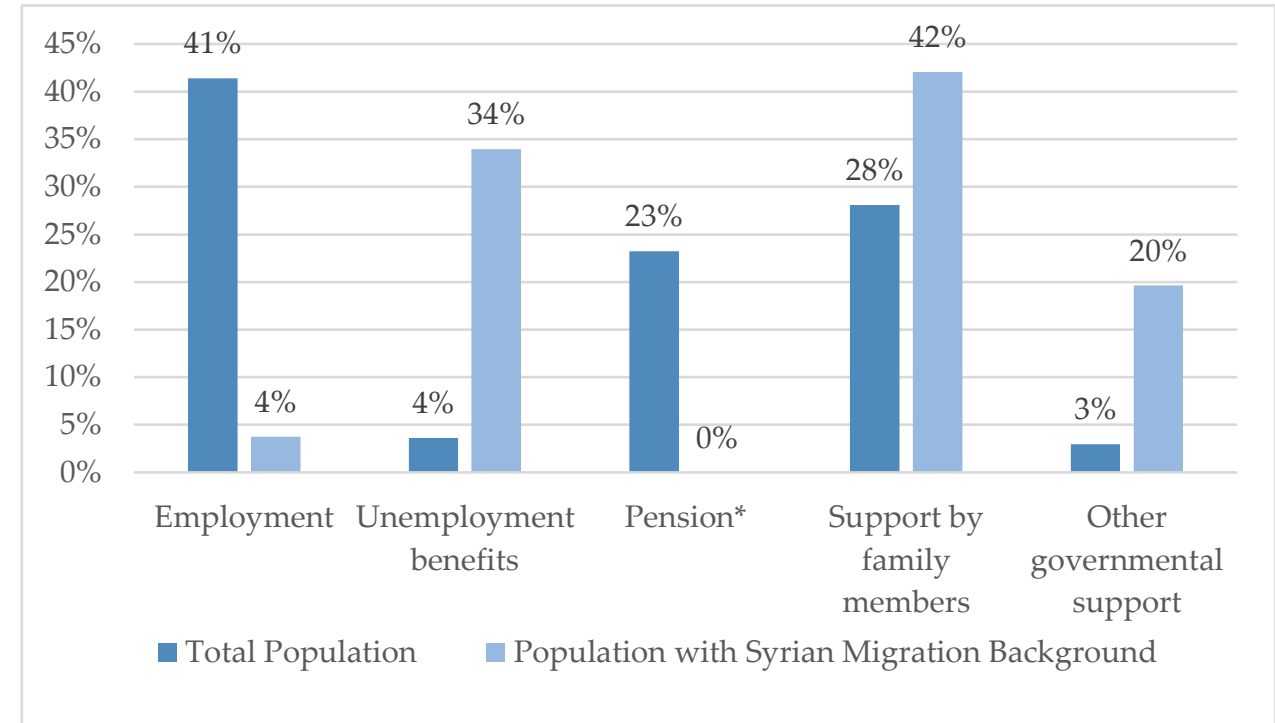

Source: Statistisches Bundesamt, 2019b, 15 Population 2018 by migration status, main livelihood and sex, * Note: Number of persons with a Syrian background not specified

Syrian households on average were comprised of more household members; however, the number of gainfully employed persons earning a wage to support the household was much lower. This situation resulted in an average net income per Syrian household member that was less than half of that of the household member of an average German household in 2018 (see Table 5).

Table 6: Household characteristics and income situation, 2018

\section{Total Population with \\ population Syrian background}

\begin{tabular}{|l|l|l|}
\hline Average number of household members & 1.99 & 2.72 \\
\hline $\begin{array}{l}\text { Average number of gainfully employed } \\
\text { persons per household }\end{array}$ & 1.03 & 0.49 \\
\hline \begin{tabular}{l} 
Average net income per household $(€)$ \\
\hline $\begin{array}{l}\text { Average net income per household } \\
\text { member }(€)\end{array}$
\end{tabular} & 1,574 & 1,662 \\
\hline
\end{tabular}

Source: Statistisches Bundesamt, 2019b, 11 Private households 2018 by migration status, household size, employed persons and income 
With regard to ethnic and religious affiliations, information is only available on Syrian asylum seekers. Arabs (56\%) represented the numerically largest groups of Syrian asylum seekers in 2018, followed by Kurds (31\%), unknown ethnicity (11\%), other $(1 \%)$ and Palestinians $(0.3 \%)$. With regard to religious affiliation, the majority of Syrian asylum seekers were Muslims (84.4\%), whereas Christians accounted for 1.8 per cent and Yezidis for 1.5 per cent (BAMF, 2019).

As stated previously, it is a great challenge to provide a sound overview of the Syrian immigrant population in Germany. One of the main limitations is certainly the fact that the most up-to-date data with a more inclusive definition overrepresents the characteristics of more recently arrived Syrian migrants. Moreover, the different data sources - providing different information on different categories of Syrian immigrants such as Syrian citizens, asylum seekers, and students present a challenge for a detailed comparison within the Syrian immigrant population. In addition, given the recent arrival of a large segment of the Syrian immigrant population, a comparison between the total German population and the Syrian population has to be taken with caution. As such, socio-economic differences among the population may diminish over time, once Syrians become more settled and established in Germany. Yet, the available statistics hint to rather medium- to highly-skilled immigration patterns, which are also reflected in the subjective view on the Syrian diaspora outlined in the following chapter.

\subsection{Socio-political space of diaspora mobilisation in Germany}

This section briefly discusses the overall approach of the German government with regard to migration and its response to the increasing number of persons seeking protection in Germany. It highlights the different institutions responsible for integration as well as development, along with their mandates and programmes specifically targeting migrants/diaspora engagement, by providing examples of different kinds of support models that exist to promote diaspora engagement at national, regional and local levels. The section concludes with an illustration of selected programmes in place that are directly targeting the Syrian diaspora in Germany, through examples of initiatives at different levels (local, national, European and national) implemented by various actors (government, NGOs, international NGOs and IO). 


\title{
5.3.1. Germany's stance and response to the Syrian conflict
}

From the beginning of the conflict, the German government has supported the opposition as a member of the Group of Friends of the Syrian People ${ }^{1}$ and hosted a field office of the National Coalition in Berlin. In August 2011, the then foreign minister Guido Westerwelle in a press statement called the Syrian President Bashar Al-Assad to step down sating that:

\begin{abstract}
"In spite of all the appeals made to it, the regime in Damascus continues to unrelentingly stifle the legitimate demands of the people of Syria with violence, torture, and mass arrests. This goes against all obligations of morality and international law. The German Government and our partners believe that by choosing this path of repression, President Assad can no longer legitimately lead Syria into the future. By stepping down he would clear the path for the fresh start needed in Syrian politics" (Auswärtiges Amt, 2011).
\end{abstract}

In February 2012, following the arrest of two people suspected of espionage for Syria, four members of the Syrian embassy in Berlin were deported and in May of that year Germany declared the Syrian ambassador as persona non grata and expelled him from its territory (Auswärtiges Amt, 2012). Due to the Syrian conflict that began in 2011, Germany suspended all development cooperation with Syria in May 2011, in line with EU decisions. At the end of April 2011, all German experts had left Syria. Instead, the Federal Foreign Office and the Federal Ministry for Economic Cooperation and Development (BMZ) intensified their work in Syria's neighbouring countries. There, the Federal Foreign Office is responsible for humanitarian aid, while BMZ provides structure-giving transitional aid, focusing on supporting host communities and refugees, food security and the rebuilding of social and economic infrastructures. Germany has emerged as important donor and provided a total of around 5.4 billion euros between in 2012 and 2017 to tackle the consequences of the conflict (BMZ, 2019). The Federal Foreign Office is the German institution responsible for the coordination of humanitarian aid. Since the beginning of the crisis, humanitarian aid in Syria's neighbouring countries has become an essential component of Germany's emergency relief measures aimed to ensure the survival of refugees and internally displaced persons. The Federal

${ }^{1}$ The Group of Friends of the Syrian People is an international diplomatic collective of countries and bodies aiming to support the Syrian opposition and to increase pressure on the Syrian government (Harris, 2012). 
Foreign Offices thus finances sector- and country-overarching aid projects of the UN, the Red Cross and various German NGOs.

As a federally owned enterprise, the Deutsche Gesellschaft für Internationale Zusammenarbeit (GIZ) supports the German government in achieving its objectives in the field of international cooperation for sustainable development. While GIZ had to suspend all its activities in Syria in 2011, it still carries out projects under BMZ special initiatives in Syria's neighbouring countries.

\subsubsection{Socio-political framework of migration}

In response to the sharp increase in the number of asylum seekers in Europe, which reached its peak in 2015, Germany initially operated a so-called open-door policy, with Chancellor Angela Merkel advocating for a Willkommenskultur, a welcoming culture, for those seeking protection in Germany. In the summer of 2015, the German government stated that it would allow Syrians to apply for asylum regardless of the country through which they had entered the European Union. Merkel's famous quote 'We can do this' (Wir schaffen das!), not only helped to mobilise support, hospitality and solidarity among the broader public, but could also be understood as signifier of a general shift in the national narrative, from an ethno-cultural understanding of the nation towards a public imaginary of a country of immigration (Holzberg et al., 2018). All over Germany, refugees were welcomed at train stations, where people cheered, applauded and handed over flowers, gifts and material aid, events that later were framed as the September fairy tale in media and public speeches. Countless individuals and grassroots initiatives emerged that provided assistance in form of healthcare, language classes, bureaucratic assistance and material aid to those newly arrived in Germany (Holmes \& Castañeda, 2016; Vollmer \& Karakayali, 2018). While noble in nature, the actions and reactions among local populations also contributed to the rise of the humanitarian narrative in which an ahistorical and apolitical state of emergency and 'crisis' was constructed. In their analysis of volunteer response to the so-called 'refugee crisis', Fleischmann and Steinhilper (2017) argue that actions and motivations were framed as an apolitical help to relieve suffering. The dispositif of help constructs refugee solidarity as a humanitarian response in times of crisis, engendering a depoliticisation as support for refugees became disembodied from the political, spatial, and historical context of displacement. The helping mentality is in that sense problematic, as it constructed the binaries of the strong saviour, in that case the volunteers, and the weak receiver of aid, the refugee.

At the same time, events such as the terrorist attack in Paris in November 2015, the mass sexual assault that occurred on New Year's Eve in Cologne in 2015 and the terrorist attack in Berlin in December in 2016 contributed to rising polarisation, 
xenophobia and Islamophobia among the broader German public. Given that perpetrators in the first incidents were allegedly northern African men and the socalled Islamic State claimed to be responsible for the Paris and Berlin attacks, migrants and refugees were increasingly identified as vectors of risk, terrorism and insecurity in media reports, political statements, and popular discourse (Vollmer \& Karakayali, 2018). By the end of 2015, German policies were already becoming more restrictive, with the introduction of rigid controls at the Austrian and Czech borders and a series of amendments to the legal framework regulating reception and asylum application processes, deportations, and access to integration measures with regard to language, labour and education. In addition, there was increasing resistance to immigration, as right-wing movements such as the Patriotic Europeans against the Islamisation of the Occident increasingly gained public support (Geddes \& Scholten, 2016) and the right-leaning party Alternative for Germany (AFD) entered Parliament in the 2017 elections.

With respect to the legal framework, the restrictiveness of Germany's citizenship regime has widely been criticised, in which citizenship was historically granted on the basis of descent, building on an ethno-cultural understanding of the nationstate. The German approach to incorporation and citizenship is highly reflected in the public and political discourse, in which heated debates frequently question the German self-conception as country of immigration. The ever-recurring discussion on the German guiding culture (deutsche Leitkultur) based on Christian-occidental values, that was coined among others by the Cristian Democratic Union in the 1990s, highlights Germany's difficult path from assimilation to multiculturalism (Ward et al., 2012). Yet, due to incremental changes based on continuous reforms, Germany is moving away from an ethno-cultural understanding of national belonging, towards extending citizenship rights to its immigrants. Reforms have included elements of jus soli (right of the soil) for immigrant children, provided that at least one parent holds a permanent residence permit and has been residing in Germany for eight years. Since Germany does not allow dual (or multiple) citizenship, individuals initially had to decide between the age of 18 till 21 years, which nationality they wanted to hold (Faist, 2004). The so-called choice obligation law was abolished in 2014, which thus enables immigrant children born or raised in Germany to hold dual citizenship (BMI, 2018).

When it comes to electoral rights, a large proportion of the immigrant population in Germany remains disfranchised, since the right to vote in German national, regional and local elections is not granted to non-European migrants. Nevertheless immigrants enjoy basic civil rights such as freedom of assembly and association, and the establishment of migration and integration councils (Ausländer-, Migrations-, Integrationsbeiräte) have been promoted in various German cities and 
municipalities to ensure political representation of migrants at the local and regional level (Roth, 2017). Regulation of the formation of these consultative bodies is governed by the different constitutions of the German Federal States. Berlin, Bremen, NRW and Hesse require municipalities with a certain proportion of nonGerman citizens to establish migrant advisory councils, whereas the constitutions of Baden-Württemberg, Bavaria, Lower Saxony and Mecklenburg-Western Pomerania do not have any specific regulations (Gesemann \& Roth, 2014). The composition, appointment of members and main statutes of the migrant advisory committees vary according to the different regulations in the constitutions. In some cases, representatives are elected by the non-German population, whereas in others, members are selected by the municipal council. Often, integration councils tend to have an advisory function, and therefore can only advocate for the interests of the immigrant populations but do not make binding decisions. Furthermore, it has been highlighted that next to the lack of decision-making power, the scarce financial resources of many integration councils limit their capacity to exert influence at the communal level (Hunger \& Candan, 2009). The low turnout for many council elections, which is on average around 10 per cent, poses another challenge to the legitimacy of migrant representative bodies (Vicente, 2011).

\subsubsection{Relevant institutions and general programmes for supporting diaspora groups}

Within the German Ministry of Interior (BMI), the Directorate Migration, Refugees, Return Policy is responsible for the migration and refugee policy of the Federal Government, including residence and asylum regulations, return related policies as well as issues regarding European harmonisation. The department supervises the Federal Office for Migration and Refugees (BAMF), which is responsible for the management of the asylum procedure and the promotion of migrant integration. The BAMF provides structural funds for migrant organisations to strengthen their role and participation in promoting migrant incorporation and social cohesion. In 2017, special attention was given to migrant organisations active in refugee aid (BAMF, 2016). Besides this federal initiative, there are several programmes at the state and local levels that aim to foster migrants' self-organisation. As an example at regional level, the Ministry for Labour, Integration and Social Issues of the German Federal State of NRW provides capacity development and financial resources, specifically targeted towards the needs of migrant organisations (MAIS NRW, 2017). Since programmes tend to be project-oriented, the resulting lack of permanent support structures, however, constitutes in most of the cases a challenge for the sustainability of migrant self-organisations (Gesemann et al., 2012; Gesemann \& Roth, 2014). 
Next to support for migrant organisations active in the field of integration, there are several initiatives that seek to promote development-oriented engagement of diaspora groups. In Germany, the topic of migration and development is high on the political agenda, with the Ministry for Economic Cooperation and Development (BMZ) and its implementing agency GIZ being the lead organisations in this field. The Centre for International Migration and Development (CIM), a joint operation of GIZ and the German Federal Employment Agency, implements the BMZ commissioned programme 'Migration for Development' (PME), which operates in five fields of action 1) Knowledge transfer by returning experts, 2) Diaspora cooperation, 3) Migrants as Entrepreneurs 4) Migration Advice, and 5) Migration Policy Advice. CIM's Sector Project Migration and Development is responsible for the development of instruments and concepts promoting the developmental potential of migration and advises the BMZ in this regard. Within the diaspora cooperation field of action migrant organisations can apply for financial support for implementing projects in their countries of origin (ICMPD \& ECDPM, 2013). Next to this targeted support, diaspora organisations can access financial resources through general $\mathrm{BMZ}$ funding schemes for NGOs active in development cooperation. Funding for NGOs is divided regionally in Germany. The Schmitz Stiftungen obtain funding from the BMZ and support WestGerman NGOs in projects which they intend to carry out with partner organisations in developing countries (Schmitz Stiftung, 2016). Stiftung Nord-SüdBrücken on the other hand supports East-German NGOs in projects to be implemented in developing countries or in Germany with the financial means supplied by the BMZ (Stiftung Nord-Süd-Brücken, 2016). BMZ's partner for the management of funding provided to German NGOs is Bengo: Engagement Global. Bengo acts as the advisory body for German NGOs regarding the securing of BMZ funding for projects and the implementation of projects in developing countries (Bengo, 2019).

\subsubsection{Specific programmes targeting Syrian diaspora groups}

Regarding policies and programmes specifically targeting Syrian diaspora actors in Germany, one observes an increasing involvement of German government institutions and other stakeholders in recent years. In 2013, the German Federal Foreign Office provided financial funds to the Berghof Foundation to facilitate the establishment of an umbrella organisation of German-Syrian relief organisations in Germany (Verband Deutsch-Syrischer Hilfsvereine eV, VDSH). Within the recent project 'Capacity building for civil society actors in Syrian relief aid', supported by the German Development Cooperation (GIZ) and the Federal Ministry for Economic Cooperation and Development (BMZ), members of VDHS received training in project management, accounting, and proposal writing to promote 
professionalisation as well as capacity development of Syrian diaspora organisations in Germany. Moreover, selected projects received seed funding for a six-month period to implement relief projects inside Syria or its neighbouring countries. Next to humanitarian-oriented support, VDHS receives structural funding from the Federal Office for Migration and Refugees (BAMF).

Furthermore, GIZ cooperates with various development partners and the Syrian diaspora to support reconstruction efforts in Syria. For instance, a diaspora project developed by the World Bank Group, The Center for Mediterranean Integration (CMI), International Organization for Migration (IOM), International Centre for Migration Policy Development (ICMPD) and diaspora actors, aims at fostering sustainable investment, long-lasting diaspora engagement and business opportunities in Syria as well as in refugee destination countries. After a first consultation process with Syrian diaspora political entrepreneurs, the conference 'Syrian Diaspora Business Forum' was held in February 2017, aiming at providing a platform to bring together development actors and the Syrian business community from across the globe to facilitate networking and knowledge exchange to develop concrete ideas for action.

Next to state actors, the Berghof Foundation, an NGO working for sustainable peace through the transformation of conflict, seeks to strengthen Syrian diaspora actors in Germany. The foundation provides capacity-building opportunities for Syrian political and civil society actors in order to include them in the political dialogue and support them in their work for the transformation of Syrian society. In addition, to activities within the programme group Middle East \& North Africa, the Berghof Foundation established a Liaison Office Syria in Berlin in June 2013, which received funds from the German Federal Foreign Office. By providing logistic and technical support, the office seeks to offer a forum for Syrian civil society actors to promote networks among them, but also to establish contacts with German ministries, political parties, foundations and other potential supporters.

Commissioned by the EU's Humanitarian Aid and Civil Protection Department, the Berghof Foundation together with the United Kingdom-based diaspora association Afford and the Danish Refugee Council implemented the Diaspora Emergency Action and Coordination (DEMAC) project in 2016. The project targets Syrian diaspora actors in Germany, Somali diaspora actors in Denmark and Sierra Leonean diaspora actors in the United Kingdom, as well as representatives of 'conventional' aid organisations. The main objective was to 'improve diaspora emergency response capacities and to facilitate the coordination with the 'conventional' international humanitarian system' (DEMAC, 2016). 
At European level, the Danish Refugee Council's Diaspora Programme aims at mapping, studying and consulting Syrian diaspora groups in Europe to enhance their role in supporting durable solutions to Syrian displacement. At the time of writing, the project was undergoing and structured around two phases. The first consisted in a mapping and study of Syrian diaspora in Europe as well as a series of consultations and concluded with a European conference. Building on the findings and recommendations from the first phase, the second phase provides targeted programming to selected organisations and networks, focusing on capacity enhancement, networking and coordination, as well as further research (DRC, 2018).

The initiative 'Syria of Tomorrow' (Syrien von Morgen) illustrates an example of diaspora support at the local level. Initiated in Wuppertal in 2016 by Syrian refugees of various ethnic, religious and political affiliations and supported by the municipality, the project aims at engaging Syrians to reflect, discuss and develop perspectives on the future of Syria and their own lives in Germany. Capturing topics such as the history of the Syrian conflict, democracy, forms of government as well as conflict resolution strategies, it further seeks to address conflict dynamics and resolutions both in the origin country context and within the refugee population (Stadt Wuppertal, 2016).

Hence, the diverse support structures targeting Syrian diaspora groups in Germany focus on capacity development, either through training or projectoriented funding, as well as through the strengthening of networks among diaspora groups in addition to fostering networks with conventional development and humanitarian actors. 



\section{Chapter 6: From Repression to Liberation - The Emergence of the Syrian diaspora in Germany}

If the emergence of diasporas is not a purely a result of migration and boundarycrossing processes, but instead a product of mobilisation through which a transnational imagined community is constructed based on a shared diasporic consciousness, it is therefore crucial to explore the factors that triggered Syrian transnational mobilisation in Germany. The analysis of this chapter is therefore guided by the following research questions:

- What events and developments triggered Syrian transnational mobilisation based on a shared diasporic consciousness?

- How is the diasporic consciousness discursively constructed?

By focusing on the historical origins of state-diaspora relations, the first section highlights how repressive long-distance policies of the Syrian regime directly prevented any form of transnational political mobilisation of Syrian diaspora groups in Germany, by forcibly repressing any attempts that challenged the regime from abroad. In addition, various measures of long-distance surveillance engendered mistrust and fear among the Syrian society at home and abroad, hence, limiting the ability to generate and maintain a sense of community. This lack of collective consciousness presented one of the major stumbling blocks for diaspora mobilisation. As the long-distance policies influenced the individual sense of belonging and dis-belonging among members of the Syrian diaspora, origin state repression also influenced indirectly Syrian diaspora mobilisation in Germany. As such, the lacking sense of national belonging negatively influenced the willingness to engage in a diasporic project.

The second section sheds light on the emergence of Syrian bottom-up diaspora mobilisation in Germany, arguing that the initially peaceful uprising that took to the streets in Syria in March 2011 can be perceived as a transformative event that triggered transnational mobilisation of Syrians in Germany based on a shared diasporic consciousness. While the extra-territorial reach of state power historically prevented any form of political mobilisation in the diaspora space, the movement in Syria broke down the walls of fear and inspired those Syrians abroad, who harboured historical grievances against the regime, to engage in diverse means of collective action. Those who engaged in the diasporic project did so based on a shared feeling of belonging, which reinforced a national consciousness of Syrian diaspora political entrepreneurs in Germany. Trust became an essential aspect of the sense of community, as the revolution was perceived as a moment of 
unification and cohesion. Several initiatives were formed in Germany to support the Syrian revolution. Thus, for those engaging in the mobilisation process, the revolution brought the Syrians more together beyond religious and ethnic boundaries.

\subsection{The era of Assad - A diaspora silenced}

The Syrian diaspora in Germany is characterised by heterogeneity in terms of religion, ethnicity and political aspirations, reflecting the rich diversity of the Syrian society. Moreover, the time and reasons for migration influenced its composition. Based on the accounts of the participants of this study, one can distinguish between two migration patterns. First, since the 1970s, Syrians have migrated to Germany for the purpose of studying, often in the fields of medicine and engineering. Second, two waves of forced migration can be observed. The first occurred in the early 1980s, when political unrests in the city of Hama forced many involved in the oppositional movement to seek political asylum abroad. Some respondents stated that Syrians of the 1980s generation, regardless of the reasons for migration, established communities with strong internal ties, cultivating Syrian traditions and customs in Germany. The violent conflict that has ravaged the country since 2011 engendered another wave of forced displacement, in which Germany has become the major destination country for Syrian refugees in Europe. In general, it is perceived that the Syrian community is still in the making, and that, given its size, this recent migration will lead to the establishment of new communities, once those who arrived recently have settled in Germany.

A range of studies showed how the Syrian government exercised its control beyond the borders of territorial jurisdiction, by actively repressing oppositional individuals and groups and movements that challenged its rule. Long-distance political oppression has been documented in Sweden (Jörum, 2015), the United Kingdom (Moss, 2016), the United States (Moss, 2016; Qayyum, 2011), and in the present case of Germany C). For instance, Moss (2016) showed that in the context of both the United Kingdom and the United States, the Syrian government positioned informants in social clubs and mosques to monitor political disobedience among the emigrant population. Those who voiced their discontentment openly experienced direct personal threats or punishment of their relatives at home in Syria. The operations of the Syrian secret services not only directly repressed any movement that opposed the government but also engendered mistrust and fear, further fragmenting Syrians living abroad. As Jörum (2015) also points out in the case of Sweden, this suspicion towards the others made it difficult if not impossible to connect and act collectively. 
In the case of Germany, the fatal assassination of the wife of Issam al-Attar in March 1981, who was killed by three armed men at her house in Aachen, may represent one of the most extreme forms of Syrian transnational repression. In fact, the lethal retribution was planned against Issam al-Attar, who was the then head of the Syrian branch of the Muslim Brotherhood and founder of the Islamic Centre Aachen (Islamisches Zentrum Aachen, IZA), which became the target of a bomb attack in January 1982. The branch is said to have played an important role in the preparation of the Syrian popular uprising of spring 1982. In both cases, the Syrian secret service was accused of being responsible for the attacks. While already in the 1980s, resistance against the Syrian government was transnational in nature as the diaspora engaged in long-distance politics to challenge the ruling regime, the extra-territorial reach of state power prevented large-scale diaspora mobilisation at this stage. The testimonies of the interviewees confirm how the arm of the Syrian regime extended as far as Germany. For instance, one respondent recalled how her family received direct threats due to her father's political activism:

"My father was a political refugee. We also couldn't return to Syria
anymore. Because he was politically active and a journalist, he was
working at the 'Deutsche Welle' [German radio station]. And we have
been persecuted. It means we had police protection. Therefore, people
couldn't organise themselves, as they can today" (I55b, representative
of a diaspora think-thank, second-generation, Dusseldorf, October
2016).

Others became a target of regime repression when they returned to Syria for family visits:

"I was last time in Syria in 2008, when I was arrested, interrogated and also the whole story, tortured and so on. Because someone had just written a report about me. Someone spied on me, wrote a report and sent it to Syria and said that I said things here against my country. So, they apparently wanted to teach me a lesson" (I8, media activist, pre-conflict migration, Skype, October 2012).

Where it was not possible to threaten activists directly, the family back home in Syria became a tool to silence political dissidents. A respondent who was active in the political uprising of the 1980s explains that it was mainly the fear of collective punishment directed towards his family that discouraged him from continuing his political involvement from Germany:

"Not actively, because as I said, I wasn't afraid of the danger. So, in the worst case they would kill me, one could accept that I would not 
be the first Syrian oppositional who was liquidated abroad [...] I was of course against the regime and my attitude was also clear to most and those around me. But the problem as an opponent, I had to watch out because my family members are still in Syria. And they are or were sometimes taken in clan custody, yes, in Syria. Because members of the opposition can be extorted through their family, it was clear to me that I was under surveillance" (I28, representative of advocacy organisation, pre-conflict migration, Hannover, March 2016).

As the following quote from a respondent, who was active in the 1970s and 1980s in German student movements and the Palestinian solidarity movement indicates, the regime not only targeted those who got involved in long-distance politics during the 19080s uprisings, but also Syrians who engaged in German politics or civil society:

\section{"I was actually active here in the German scene, and then my passport was not renewed. And they said from the embassy 'You have to go to Syria to extend the passport [..] And there I was with no passport for six years [...] And then my parents tried again and again with relationship and so on, finally the passport came. And I thought, now I can go, yes, I went there [to Syria] and then I was arrested at the airport" (I42, artist, pre-conflict migration, Aachen, April 2016).}

It is widely acknowledged that democratic countries that adopt cultural pluralism and multiculturalism provide more freedom and space for diaspora activism and enable diaspora groups to unfold their ethnic and religious identities (Kadhum, 2014; Shain \& Barth, 2003; Sökefeld, 2006). Yet, as the last extract shows, the regime's production of a transnational space, which was marked by an authoritarian control of diasporic political mobilisation not only limited the space for diaspora entrepreneurs to engage in the political process of the origin country, but also had the potential to prevent or discourage participation in the destination country context.

\subsubsection{Negotiation belonging and dis-belonging}

Al-Ali, Black and Koser (2001) stress the importance of transnational capabilities, which refers to the willingness and ability of diaspora groups to engage in political, economic, and social transnational activities. Capabilities include not just the more structural factors such as the political opportunities or constraints, which members of diaspora encounter in the transnational field, but also their agency, as for instance, the level of motivation to maintain group solidarity as well as the willingness and desire to re-establish links with the country of origin. Their 
definition of capabilities 'includes the extent to which individuals and communities identify with the social, economic or political processes in their home countries, which is a prerequisite for them to engage in transnational activities' ( $\mathrm{p}$. 581). A sense of belonging, hence, presents a significant precondition for establishing links with the place of origin and for engaging in transnational practices. However, it seems that aspirations and belonging towards the homeland in diaspora studies is often under-theorised as an attachment to the place of origin is often taken for granted, neglecting the factors and processes which may deconstruct or reconstruct territorial belonging to the origin place.

Many respondents emphasised their multiple embeddedness based on various categories, ranging from territorial belonging to Germany and places of residence to social locations structured along profession, gender and generation, among others. The notion of the homeland, too, embraced multiple yet often conflicting meanings. Belonging to the Syrian country and its people was for many an essential aspect of self-identification, often carrying an essentialised notion. As one of the participants put it:

"Syria is like my mother, you can't exchange it. And Germany is like
a wife, at the moment I'm married to Germany" (I28, representative
of advocacy organisation, pre-conflict migration, Hannover, March
2016).

At the same time, many respondents also articulated a troubled relationship with the homeland, which was not only characterised by an intense yearning to belong but also by feelings of dis-belonging and estrangement. In particular, those who left Syria in the 1980s due to political persecution, as well as their descendants, expressed a strong sense of Syrianness. In exile, the nostalgia for a mystic and romanticised, yet lost and distant place resulted in a feeling of homelessness and a deeply entrenched longing to belong:

"I feel Syrian and I am, so to speak, forced to live abroad. Well, Germany is my second home, but my parents didn't choose to live here or there. They had no choice but to live here. And I feel like I've been deprived of my home [...] For me it was always clear that I'm Syrian. Despite that I live here and I am thankful that I can live here under such conditions and circumstances. But my home, where I feel at home, where my culture, my language, my music and my food is that is still Syria" (I8, media activist, second-generation, Skype, October 2012). 
As the last extract exemplifies, for many the constructions of homeland were mainly related to the socio-cultural sphere, linked to family, heritage, tradition and community. Hence, it was to the culture and the people in Syria that the sense of belonging was directed. Due to the very fact that return or visits for those in exile were not possible, the sense of belonging remained in the margins of the imagination, rather than a lived experience, producing a space where the romantic and idealised homeland could be preserved.

In contrast, for those who were able to practise belonging by returning or visiting Syria, experiences with corrupt and authoritarian practices of the regime stood in stark contrast to the political freedoms they enjoyed in Germany and often led to feelings of dis-belonging and estrangement:

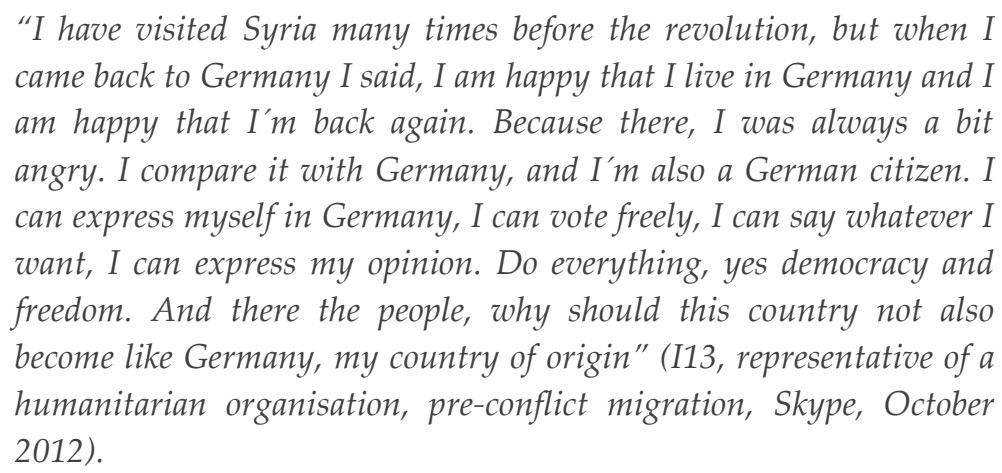

The troubled relationship with the home state was further amplified by a diaspora engagement policy that rather focuses on controlling and extracting obligations than on extending rights to Syrians abroad, to use Gamlen's (2008) words. As one respondent highlights:
"That was because of the regime, all the political and economic regulations. Assad and the regime have not made a friendly policy towards the diaspora. That's why they were never quite so inviting, so the people who were abroad and returned to Syria in the 90s, they always suffered from being asked for bakshish or bribes just because they have been abroad" (I1, academic, pre-conflict migration, Berlin September 2012).

While historically, the diaspora was perceived as a threat to national security that needed to be monitored and controlled, the 'modernisation and development' dogma put forward under Bashar al-Assad marked a change in the regime discourse. The government increasingly recognised the decisive role of the diaspora in nurturing the country's development and implemented several 
initiatives to harness the potential of the diaspora through the promotion of investment, economic cooperation and knowledge transfer. As the policy purely focused on economic liberalisation and neglected reforms of political institutions that would allow for more inclusive participation of the diaspora in the decisionmaking process, the change was by many perceived as merely symbolic. Given state repression that did not allow for any voice of dissent neither at home nor abroad, the only way of being engaged meant to actively support the regime. This further limited the aspiration to contribute to the home country's economic or political process:

"Before, there was no interest. Everyone was pleased due to
oppression and violence, and loyalty to the country has made them
not to say something against the country. They did not want to
abandon their land and spread a bad reputation" (I9, representative of
a humanitarian organisation, pre-conflict migration, Skype, October
2012).

Despite being emotionally attached to the country of origin, mistrust towards the government and its representatives abroad also negatively affected the identification with the homeland:

\begin{abstract}
"The representatives of Syria abroad have been the representation of the regime. And one is not so happy to say that this embassy represents me. I was never quite proud to say that I am Syrian. So, for me that was not an issue, the Syrian identity" (I1, academic, preconflict migration, Berlin September 2012).
\end{abstract}

Hence, government practices from the origin country not only directly repressed any act of political mobilisation of Syrian diaspora entrepreneurs in Germany, but also had an indirect effect as it limited a feeling of belonging and the willingness to engage in collective action directed towards the homeland.

\title{
6.1.2. Mistrust and fragmented solidarity
}

According to Sökefeld (2006) 'there can be no diaspora community without a consciousness of diaspora, in other words without an idea of shared identity, of common belonging to that group', albeit the nature and meanings of the collectivity can (and often tend to) be highly contested among the members. The notion of collectivity presents one of the central aspects of diasporas, which is characterised by group solidarity, loyalty and co-responsibility connecting scattered individuals grounded on an idea of a shared collective past and future (Brubaker, 2005; Cohen, 2008; Sheffer, 2006; Werbner, 2002). 
The long-distance policies of the Syrian regime not only directly repressed any diasporic action that challenged its rule but also fostered a culture of fear and mistrust, leading to highly fragmented solidarity among the Syrian population. The Syrian saying 'The walls have ears' illustrates the overall perception that even in the privacy of their own homes, people did not feel safe to speak out freely, as even close family and friends were perceived as potential betrayers:

\section{"In Syria, the man is afraid of his own wife and of his own children, and the woman is afraid of her own husband and everyone is afraid of the brother and the sister" (I15, representative of a humanitarian organisation, pre-conflict migration, phone, November 2013).}

The republic of fear allowed only one opinion, one ideology and one belief, and any form of dissent came with horrendous and even fatal consequences. The constant fear of surveillance was felt present at every place and in every interpersonal relationship, impairing any sense of collective trust and deteriorating the overall social fabric of the Syrian society. Prevailing mistrust pulled people apart, prevented any form of social action and was also present in the diaspora, as the operations of the secret services extended as far as Germany:

"Before the revolution most Syrians here, somehow did not trust each
other. Each one thought that the other is somehow from the
intelligence service or like that. So, there was hardly any activity
between the Syrians before the revolution. Even I had some problems
with that, I was once in a mosque and spoke out something about the
regime, and each Syrian there was very afraid, and they thought
maybe I am from the secret service myself" (I12, representative of a
student organisation, pre-conflict migration, Skype, October 2012).

Hence, even critical voices were met with suspicion and were seen as an attempt of the regime to disclose any form of dissent. The state of fear resulted in a depoliticisation of the Syrian society, preventing collective mobilisation around a shared consciousness. In particular, when compared to other migrant communities, many respondents described Syrians as individualists and loners who rather sought to assimilate into the German society or to connect to wider ethnoreligious networks of Arab, Muslim or Kurdish communities, than to establish their own collectivities. Fear and mistrust not only influenced the interpersonal and social relationships among Syrians in Germany, but the suspicion towards the others also made it difficult if not impossible to connect and act collectively: 
"We have a problem that, we as Syrians we could not really trust each other or work with each other. We had a heritage of repression, a heritage of a single body to control for everything. And people did not know how to initiate" (I10, civil society activist, post-conflict migration, Skype, October 2012).

Fear and mistrust, hence, could be seen historically as major stumbling blocks for collective mobilisation, given the highly fragmented solidarity and lacking sense of community among Syrians abroad.

\subsubsection{Transnationalism from above - The co-optation of diasporic mobilising structures}

As a result, many respondents emphasised that the relations among Syrians in Germany and their attachment to their homeland were limited to the socio-cultural sphere. While being individually in contact with other co-ethnics, there was hardly any indigenous, bottom-up diaspora network, cultivating a collective Syrian identity and collective ties to the homeland. There existed some Syrian-German friendship associations, which aimed to serve community interests. In particular, their goal was to support and strengthen the relationships between Syrians living in Germany, to promote their integration and to strengthen the ties with the country of origin. Officially, these organisations distanced themselves from political or religious goals, but were seen by many as an extension of the Syrian state, which tried to politically control those living abroad via these organisations:

"There weren't too many strong connections or networks. There was
a German-Syrian society to which many people belonged, but the
people were more involved for social reasons and could hardly express
their opinions freely. It was more of a social gathering, there was no
exchange of opinions, no political discussions, because of the many
secret services lurking everywhere. One was very reserved towards
Syrians, especially because one assumed that what one says is passed
on to the secret service. So, one met only on the surface as far as
exchange of opinions and discussions is concerned" (II4,
representative of a humanitarian organisation, pre-conflict migration,
phone, October 2013).

Rather than being diasporic in nature, these mobilising structures could be categorised as extensions of the regime apparatus that managed through this to control its citizens abroad. Given that for many, these organisations did not function as independent representations of the diaspora, the actual lack of opportunities to engage led to disengagement with the homeland. Hence, 
suspicion towards the other along with a fragmented solidarity among Syrians in Germany limited the ability to generate and maintain a common identity and can be seen as major stumbling blocks for diaspora mobilisation.

\subsection{The Syrian Revolution - Political mobilisation around a new diasporic consciousness}

In December 2010, the self-immolation of Mohamed Bouazizi in Tunisia led to protests, civil resistance, uprisings and upheavals in countries across the MENA region. Events happening in countries like Bahrain, Egypt, Libya, Morocco, Oman, Tunisia and Yemen, triggered calls for a Syrian 'Day of Rage' 4-5 February 2011, but given the fear of harsh government suppression, these did not result in major protests or demonstrations both inside and outside Syria. It was in this moment of change when hopes for a political transition in Syria and a renewed attachment to the country of origin became salient among Syrian diaspora entrepreneurs in Germany. The aspirations for change were not translated into real action, as for most a peaceful changeover of political power was hard to imagine under the enduring authoritarian ruling of the Assad government. It was only in March 2011, when the spirit of the 'Arab revolutions' caused widespread and large-scale resistance in Syria (Yassin-Kassab \& Al-Shami, 2016). Through the uprising inside Syria, a window of opportunity for Syrians abroad was created to raise their voice against long felt grievances. While the extra-territorial reach of state power historically prevented any form of political mobilisation in the diaspora space, the movement in Syria broke down the walls of fear and inspired segments of Syrians living abroad to engage in diverse means of collective action:

"At the beginning, before it started in Syria, it has started in Egypt and Tunisia, so in the other Arab countries [...] So, I was motivated and really hoped that it will start in Syria soon. But I also believed that it is impossible. The regime was very strict and everybody who is acting conspicuous, will be invited to an interrogation. One had the feeling that one is constantly under surveillance. And so, I thought it is impossible and when it started it was like a surprise to me. And it started in my city, the city in the South of Syria called Daara. And when I saw the demonstrators at the streets, which I know, so I directly recognised the places. Yes finally, I was positively surprised and happy that a change is coming and then I thought I finally have to do something as all the others. Everybody should search for a task to do something and not just listen to the news" (I55, representative of a humanitarian organisation, pre-conflict migration, phone, October 2016). 
The uprising can be seen as a transformative event that resulted in a favourable political opportunity for diaspora mobilisation in Germany, at least for those who positioned themselves against the regime. The resistance, in which protest quickly spread throughout Syria, shifted the centre of power from the state to the people. Seeing people demonstrating and risking their lives on the street in Syria, many respondents said they felt obliged to support the movement from the safe harbour of Europe. Hence, the transnational mobilisation of the Syrian diaspora emerged greatly as a response rather than causing the political transformations happening in the country of origin.

\subsubsection{Construction of identity and belonging}

For both the respondents who were residing in Syria at the outbreak of the conflict, and those living abroad, the revolution not only created a space for claiming rights and freedoms, but through this also a feeling of belonging and citizenship, something which for decades had been the privilege of the ruling elite. The following extracts by two respondents who were protagonists of the revolution inside Syria illustrate how the political change happening in the country enhanced their sense of belonging to Syria and motivated them to take part in the movement:
"Before I didn't feel Syrian. Before the revolution, you didn't feel like it is your country. I felt like a guest, the country belonged to one family. When the revolution started, I felt that we are part of the country and we have to fight for our rights" (I53, film maker and writer, conflict migration, Berlin, July 2016).
"Before I didn't see that I belong to this society, when the revolution started it was a chance to say we can make the country as we want" (I49, writer, conflict migration, Cologne, May 2016).

Very similar accounts were voiced by participants who lived in Germany during the outbreak of the conflict, showing that as a result of the revolution being Syrian became an important aspect of self-identification:

\footnotetext{
"Well there are many thoughts now of being a Kurd or being a Syrian and this double identity that everybody has. And if you have to choose one, to be Syrian it was very important" (I10, civil society activist, pre-conflict migration, Skype, October 2012).

"I was born in Damascus, I have fought with the Syrians, I have loved with Syrians and played football with them. And the Syrian revolution has just enabled these aspects of the Syrian identity. And
} 
now I am, I do not know whether I am more Syrian, Palestinian or German or all three" (I5, political activist, pre-conflict migration, Aachen, September 2012).

As such, the fire that the 'Children of Dara'a' inflamed was not constrained by geographical boundaries. It seems that even living abroad, being a Syrian for many respondents meant being part of the revolution, as one respondent explained:

"I haven't really thought about it. Because the revolution is of all Syrian people, I have to participate in it" (I12, representative of a humanitarian organisation, Skype, October 2012).

The uprising filled many respondents with pride and passion, and their longing for change finally came true, making them want to be part of the change happening in the country:

"Many Syrians are suddenly proud, we are proud that we are Syrians" (I1, academic, pre-conflict migration, Berlin September 2012).

While on the one hand the longing for change was something which inspired people to take action, the perceived grievance towards the regime-based violence resulted for those in the diaspora also in an obligation to become actively engaged in the homeland's political transformations. Following its earlier path of violent repression in the 1970s and 1980s, the regime opted for a military solution through the use of security forces and the army against civilian protesters to crackdown the rising resistance (Phillips, 2015; Yassin-Kassab \& Al-Shami, 2016). Seeing people suffering from regime violence, many felt obliged to support co-nationals from abroad. Personal experiences such as the death or disappearance of close family members and friends amplified a feeling of responsibility:

\section{"When the pictures from Dara'a came, bloody pictures, I consciously decided that I want to do everything to support the revolution" (I5, political activist, pre-conflict migration, Aachen, September 2012).}

At the same time, it has to be acknowledged that not all respondents perceived the changes happening in the country as something positive. Valuing order over liberty, these respondents felt that greater security and stability as well as the country's unity could only be achieved within the ruling system. For them, the political transformations were rather perceived as a threat to identity, based on a fear of losing the homeland: 
"So, you noticed Syria is our home and that is going to be problematic right now. No matter oppositional, pro-government, neutral, you still notice when something is lost. This is the first point. This fear of loss did not exist in the past, that is not that one was so happy, otherwise we would not all have been abroad all the Syrians. But you had the feeling ok that's my home you go in the summer, those who had children had taught their children in Arabic [...] You recognise the problems, you recognise the disease, you recognise the shortcomings in this country and so on. But you do not want to lose that, that's different" (I45, journalist, pre-conflict migration, Berlin, April 2016).

Hence it can be argued that the revolution reinforced a sense of belonging and selfidentification with the homeland among those who harboured long-felt grievances against the ruling regime of Assad. While emotional attachment to the culture and the people was present also before the revolution, the political transformations further heightened a sense of identification with the nation, as a shared feeling of belonging was created, and a national consciousness was reinforced.

\subsubsection{The emergence of a political consciousness - At home and abroad}

The violent response of the Syrian authorities towards the children of Dara'a was not an unusual event as such. There had been political detentions, torture, disappearances, and everyday acts of repressions throughout the ruling of the Assad regime. Yet, what made a difference was the continuation, dispersion and intensification of the protests across the country, engendering a moment of the 'political' and the formation of political subjects. Rancière (2010) understands the concept of subjectivation as the production through a series of actions of a body and a capacity for enunciation not previously identifiable within a given field of experience, whose identification is thus part of the reconfiguration of the field of experience' (p.35). While some of the respondents had been involved in earlier oppositional movements or individual acts of resistance to the regime, for most who were still in Syria at the start of the revolution, the uprising was experienced as a transformative event, which triggered the emergence of political subjectivities that divided their lives into a 'normal life' before the revolution and a 'political life' since:

"I am from Raqqa city. My life was a normal life. I came from a rich family. I didn't need anything, we had more than one car, so I didn't need anything. So, I joined school. Before the revolution there was nothing special, I didn't know anything about politics or I wasn't a journalist, I was just foolish [...] when the revolution started, I started because some people in another city wrote something about the 
government on the walls. So, they got them and tortured them. So, we were asking for freedom, they didn't deal with civilians the right way, they dealt with civilians with weapons. So, the protests and demonstration started to be big. So, that time there was no freedom you can't say anything against the government. So, we started for freedom to change the regime to take it down. And the first time I joined, it was first time to see some children and no one did anything, so it was solidarity" (I47, media activist, conflict migration, Berlin, May 2016).

The revolution was perceived as a moment of enlightenment, in which the everyday experiences of injustice and repression became connected to the general political system and the autocracies committed by the regime. Participation in acts of resistance and solidarity led to the formation of a collective subject 'the people', $a l$-sha'b, which acted in solidarity to transform the social and political order (Bamyeh, 2013). Similarly, when Syrians in Germany met at the first demonstrations, they came together, discussed and shared their opinions with each other, often for the first time in their lives. Interestingly, the process of bonding was not due to ethnic or religious similarities, but it was 'the Uprising which united the people' (I10, Syrian-Kurdish activist, pre-conflict migration, Skype, October 2012). A sense of 'we-ness' was created, in which the people became a signifier able to encompass a diverse range of individuals, leading to a politicised consciousness that marked the boundaries of the transnational imagined community. As the conflict escalated, religious belonging as well as ethnic and linguistic distinctiveness not only arose as an important aspect of self-identification, but also became more salient and politicised. Yet, the uprising can be perceived as a moment of unification that initially fostered a construction of a diasporic consciousness transcending ethnic or religious boundaries, at least for those who positioned themselves in opposition to the Syrian government. One respondent illustrates it as follows:

\section{"I think the revolution had a chance for the people to get more involved with each other so right here in the diaspora where it's really very, very colourful and where I say the political opinion unites the people. So, if you are for the opposition, it doesn't matter if I am a Christian, a Muslim, a Kurd or something else" (I25, representative a diaspora network, Berlin, January 2016).}

As the quote indicates, the sense of 'we-ness' and community was mainly constructed based on boundary maintenance along political lines, leading to a political consciousness among those who positioned themselves against the Assad regime. At the same time, as the respondent further reflects, the revolution also led 
to conflicts and fragmentations in particular with groups and individuals who continued to show loyalty to the regime:

\begin{abstract}
"You can't just say ok through the revolution, many are now united, many are also separated. So, I have to say that politics didn't play a big role in the circle of friends and family before, that we hardly ever talked about it. Because this revolution started, you had to position yourself somewhere. You then have an opinion on it and then it quickly diverged. And family ties have broken down, friendships have broken down" (I25, representative a diaspora network, Berlin, January 2016).
\end{abstract}

Hence, the uprising did not unify the diaspora as a whole, but rather created fragmentation along political lines, namely between those opposing and those favouring the ruling Assad regime. There were very little, if any, relationships between anti- and pro-regime diaspora members, highlighting a real break between these two categories. The latter group however, remained less visible in Germany and also less organised in the public sphere, as those who opposed the oppositional movement in Syria experienced their positionality in the destination country as rather weak. It seems that the political opportunity structures vary also within a single nation context, where the same opportunities might enable mobilisation among one group and at the same time constrain or repressing mobilisation among another.

\title{
6.2.3. Transnationalism from below
}

As a transformative event, the revolution reinforced a feeling of belonging and renewed the aspiration to influence the political process inside Syria from afar, at least among those who positioned themselves against the ruling regime. Among them, the changes happening in the country engendered a sense a community and an oppositional political consciousness that unified the initially scattered individuals into an imagined transnational community based on a common fate and future. Whereas independent diaspora networks were lacking prior to the revolution, the political transformation in Syria caused a spontaneous bottom-up mobilisation, in which several new diaspora initiatives emerged to support the movement from abroad:

"Things have changed after the revolution started. Most of the Syrians here realised that one needs to do something and that this would not work without cooperation. These events have brought them closer together. The events in Syria where people are right in the middle in danger and are not afraid. And we outside of Syria have to 
break down the wall of fear and help the people there together" (I6, representative of an advocacy organisation, pre-conflict migration, Skype, October 2012).

These initiatives were mainly politically motivated and aimed to show solidarity with the people inside Syria and to promote democratic change in Syria from abroad. Similarly to the movement inside Syria, the diaspora political entrepreneurs framed their action based on notions of non-violence, freedom, democracy and human rights. Frequently, protests, demonstrations, and other types of contentious actions in major German cities as well as dialogue and information events were organised to show solidarity with the non-violent movement in Syria and to raise awareness on the Syrian cause among the broader German public. As from the onset of uprising, the Syrian regime banned foreign media in order to prevent coverage of the protests, social media networks were perceived as crucial to connect the voices of the protesters inside Syria with a broader international public. Hence, diaspora activists used Facebook, Twitter and blogs to provide alternative background information and coverage in the form of print material, photographs and videos. By reaching out to German media outlets their aim was to spread the information beyond the realm of social media platforms and to enable local television channels, radio stations, and newspapers in Germany to report critically about the situation in Syria. In addition, Syrian diaspora actors established contacts with German politicians to lobby for a political solution to the conflict. In meetings with the German authorities, representatives of the diaspora demanded the government to take a clear position from against the Syrian regime, to introduce sanctions and to expel the Syrian ambassador from the German territory.

What began in Syria in 2011 as an initial peaceful movement of people demanding freedom, justice and democracy, has escalated into one of the world's most dramatic humanitarian and displacement crisis, caused deeply entrenched societal division and became a battlefield of several regional and international actors who fight for power and control over the country. Indeed, the conflict had a devastating impact on the lives of Syrian people, who became marked by experiences of suffering, loss and dislocation. At the same time, the Syrian revolution gave birth to a vibrant civil society, both inside Syria and abroad, engaging in political struggles for rights and against government repression, challenging the increasing sectarian dimension of the conflict and acting in solidarity to support those suffering from the consequences of the conflict. It is this micro-realm of individual experience of activism, that the more long-lasting consequence of the revolution was engendered, as a personal transformation in which changing worldviews and lives have been unfolded: 
"I was there from the beginning and we saw what happened and I was a part of it. So, I cannot believe that what happened will end up for nothing. Because everything changed, a lot of Syrian people were involved in things, they never used to do. They were asking for rights they never thought of asking for publicly. A lot of things happened" (I78, gender activist, conflict migration, Berlin, June 2017).

As Abourahme and Jayyusi (2011) argue, this was 'the most enduring aspect of the Arab revolts: the sense that people, ordinary people - through this novel relationship between politics and experience - were remaking themselves, shedding off years of conditioning and inertia to emerge as political subjects' (p.626).

\subsection{Conclusion - From transnationalism from above to transnationalism from below}

Historically, the Syrian regime through its 'transnationalism from above' was able to create geographies in which human and political spaces transcended territorial boundaries but which also served to repress the construction of alternative imaginations of the transnational community. For the respondents of this study, the Syrian revolution led to shifting configurations of power and as such to a redefined relationship between the government and the people, thus paving the way for alternative imaginations of the nation, citizenship and what it means to belong to Syria, both at home and abroad. As a transformative event, the Syrian revolution, hence, marked the emergence of Syrian diaspora mobilisation in Germany, since, as a moment of unification, it sparked collective action based on a shared diaspora consciousness among those who positioned themselves in opposition to the government. Through 'transnationalism from below' Syrian diaspora groups were also able to produce, transform and challenges political spaces across borders.

Given that diaspora mobilisation is a dynamic process, the next chapters will analyse the trajectories and evolution of Syrian diaspora mobilisation in Germany. Each of the chapters is dedicated to one of the three dimensions of diaspora mobilisation elaborated in Chapter 2. Examining both direct and indirect mechanisms, the chapters analyse how both political opportunities in the destination and origin country contexts influenced the construction and reconstruction of a diasporic consciousness (Chapter 7), shaped diasporic mobilising structures (Chapter 8) and practices (Chapter 9) and how diaspora actors enacted their agency in response to the structural constraints and opportunities at different stages of the diaspora mobilisation process. 



\section{Chapter 7: De-construction and Re-construction of the Diasporic Consciousness}

As discussed in the previous chapter, the early period of the Syrian conflict was marked by a strong feeling of shared and collective diaspora consciousness, a sense of community, as well as frequent interactions, exchange, and cooperation, at least among those who positioned themselves in opposition to the government. As such a transnational imagined community was constructed, which not only transcended the physical borders of the nation, but was also able to manifest itself based on the dichotomy of 'us' and 'them', 'us' the people and 'them' the members of the Assad regime, promoting salience of the Syrian collective identity abroad. However, the revolution in 2011 as a unifying event was, for many, perceived as a short-lived moment and as the conflict escalated, conflicting imaginations of the transnational community evolved.

If diaspora mobilisation is understood as a process, in which a heterogeneous group of diaspora actors engage in the construction of community and political projects, it becomes necessary to explore the internal social, cultural and political dynamics of mobilisation (Sökefeld, 2006). It is by now well accepted that diaspora groups are seldom or almost never homogeneous, but instead that lines of division, differences and contestations unfold along various axes, whether they are cultural, religious and ethnic, or based on social, economic, and political hierarchies (Baser, 2014; Koinova, 2011; Smith \& Stares, 2007; Walton, 2014).

While the previous chapter has shown that through the Syrian uprising, a national identity transcending ethnic or religious boundaries became salient and politicised, this identity in many cases can be better characterised as fluid and ephemeral, rather than stable and enduring. Focusing on the first dimension of the process of diaspora mobilisation outlined in the conceptual framework (Chapter 2.3.1.), this chapter aims to shed light on the processes of re-construction and de-construction of the Syrian diasporic consciousness over the course of the current conflict. The chapter is, therefore, guided by the following research questions:

- How is the transnational community discursively constructed and imagined? What are sites of contestations and resistance? Are there competing imaginations of community proposed?

- How did these change over time?

- What are the factors that influence a change in the collective consciousness? 
The first section aims to shed light on the process of how fragmentations and divisions among Syrian diaspora groups in Germany emerged and unfolded, what their nature was and how these groups were contested and performed. By analysing both, the contextual factors present in Syria and in Germany, the analysis seeks to provide a broader understanding of how the processes of collective consciousness building and collective identity formation are embedded in multiple sites and layers of the transnational space. What can be observed is that the conflict dynamics were also reproduced in the diaspora mobilisation, as arising fragmentations to certain degree mirrored the social, cultural and political divisions present in the homeland. In addition, internal power struggles present in the process of diaspora political mobilisation, as well as destination country developments and policies also to a certain extent exacerbated the dynamics of fragmentation and divisions within the process of Syrian diaspora mobilisation in Germany. Yet, as will be shown in the second section, most participants of the study frequently voiced a strong desire for unity and took several actions to tackle the societal divisions and fragmentations present in the process of diaspora mobilisation.

The third section of this chapter focuses on the de-construction of the collective consciousness. As will be shown, a considerable number of diaspora political entrepreneurs showed a long-term commitment and continued their involvement in the process of diaspora mobilisation throughout the conflict, in addition to numerous new actors entering the diasporic space. Yet, there are also several stories of de-diasporisation, which can be defined as a demobilisation of a diasporic consciousness, as the identity on which this consciousness is based becomes latent and depoliticised. So, the question becomes how and why diasporic identities become deconstructed and what factors may influence the process of dediasporisation. Given that communities are made up of individuals, it is crucial to not only focus on the meso-level processes of mobilisation but also how individual aspirations, desires and the willingness to become engaged in the diaspora project change over time. By focusing on the process of de-diasporisation this chapter seeks to shed light on the dynamic processes which are inherent in diaspora mobilisations and to contribute to a deeper understanding of diversity and heterogeneity.

\subsection{From unification to fragmented solidarities}

\subsubsection{Home country influences - The reproduction of conflict dynamics}

While earlier accounts on the Syrian diasporic consciousness emphasised a sense of unity, trust, and community, with the escalation of the conflict the notion of 
fragmented solidarity gained more and more importance. Although the organised diaspora was united on a common ground, namely being in opposition to the regime of Assad, conflicting ideas, narratives and visions for a peaceful Syria led to fragmentation among members of the Syrian diaspora in Germany. As the conflict escalated, the civil society, both inside and outside Syria, became increasingly fragmented and divided, mirroring to a certain extent the cultural, economic, social and political divisions present in the Syrian context. It is therefore not surprising that fragmentations, divisions and differences were mainly perceived as a result of the conflict trajectories and often amplified by external actors, instead of viewed as a historical fixed and essentialist element of the Syrian society. These were not only a result of the reproduction of the conflict dynamics and trajectories within the diaspora, but also arose from internal power struggles present in the process of diaspora political mobilisation.

With the escalation of the conflict, the opposition to Assad's regime became increasingly divided based on political, ideological and sectarian grounds, a fragmentation which was also reflected in the diaspora. Whereas the first six months of the revolution were marked by peaceful forms of resistance, from August 2011 onwards an armed component of the movement evolved gradually. One of the first moments in which divisions were manifested was when the oppositional movement inside Syria became militarised, and the Free Syrian Army and other armed groups increasingly dominated the resistance. Contestations were commonly centred on the militarisation, which for many was not only seen as a result of sharp government repression but also as a necessary consequence to defend the ordinary people and the peaceful demonstrations from regime violence:

"I'm more of a pacifist by nature, so I fought violence for a long time.
It has to be emphasised that this is unfortunately neglected these days,
that peaceful demonstrations are still taking place every day
throughout Syria. It is also understandable, however, that people are
not simply watching and allowing themselves to be shot, but that
resistance is being built up to combat this violence" (I7,
representative of an advocacy organisation, pre-conflict migration,
Skype, October 2012).

At the same time, the quote highlights an ambivalence among most of the diaspora actors involved in this study, as many emphasised their non-violent position in the conflict, though simultaneously also advocated for a stronger support of the armed component of the oppositional movement. As a result, diaspora actors called upon the international community to provide financial and material support for the armed insurgency, whereas in their practices they opted for tackling the consequences of militarisation by delivering humanitarian aid to the victims of the 
conflict. Others showed more resistance towards the armed component of the political struggle and were concerned that militarisation would eventually lead to an unending spiral of violence and further unpredicted escalation of the conflict. They felt that their voices were being increasingly excluded from the diasporic discourse:
"This was also a different polarisation in the opposition, one is for the military solution or not. And that had, I believe, in any case a strong impact on the whole organisation also here in Germany, also in Syria, but also abroad. In principle, always comes the first question, are you with us or against us? And the military side of the revolution was simply more dominant. And this was also difficult for the people, who have made this decision that they are for a peaceful solution, you have felt simply excluded" (I20, peace activist, pre-conflict migration, Skype January 2016).

In addition to the militarisation, the political opposition, in particular the National Coalition for Syrian Revolutionary and Opposition Forces, which was recognised by several international states as the legitimate government operating in exile, became increasingly fragmented. Internal divisions and power struggles, the lack of influence inside Syria as well as accusations of corruption and Muslim Brotherhood domination, profoundly weakened the position and influence of the Coalition, internationally, among the diaspora and inside Syria (Yassin-Kassab \& Al-Shami, 2016). The struggles among the different political actors involved in the oppositional movement, were commonly reproduced in the diaspora, in which the various actors competed for the legitimation of their discourses. Hence, although the organised diaspora seemed united on common ground, namely being in opposition to the Assad regime, different ideas, strategies and divergent solutions to the conflict became manifest throughout the conflict.

The sectarianisation of the Syrian conflict, in which the political 'others' were increasingly constructed and mobilised along ethnic and religious lines added another layer to the existing diasporic divides due to the transnational diffusion of sectarianism. In the early phase of diasporic mobilisation, the collective goal of regime change initially united different sections of society, cross-cutting gendered, class, ethnic or religious hierarchies, based on notions of justice, democracy and freedom. A dominant narrative on Syria featured the country as a model for the peaceful coexistence of different religious and ethnic groups in West Asia and in which 'tolerance was anchored in the foundations of Syrian society' (I15, representative of a humanitarian organisation, pre-conflict migration, Phone November 2013). However, as the conflict escalated, religious belonging, as well as 
ethnic and linguistic distinctiveness, became an essential aspect of selfidentification, consequently fragmenting the collective national identity due to religious and ethnic boundary creation and preservation. Hence, as the nation-state was failing and fragmenting, increasingly sub-national identifications became the available points of reference and belonging:

\section{"The opposition itself started to fragment. The line of interpersonal relations and political stances was taking the line of ethno-religious divisions within the framework of any Syrian group. The polarisation was very high" (I77, representative of a civil society organisation, conflict migration, Skype, July 2017).}

Acts of ethnic-based violence committed by the different actors engaged in the Syrian conflict held the sectarian discourse alive, which was transmitted transnationally through social media and the contacts with friends and family members inside Syria. In addition to this, the conflict also engendered the manifestation of different geographies inside Syria each having distinct historical conditions, which along with different economic, social, cultural and political circumstances as well as varying levels of exposure to the conflict shaped the lived experience of societies that inhabited the space. As transnational networks and connection of Syrian diaspora actors seldom spread across the entire origin country, but were instead rather trans-local in nature, different interpretations of reality as well as competing conflict narratives were present among the range of diaspora actors.

The Kurdish region in northern Syrian can serve as a valuable example in this regard. While there exist diverse opinions and stances among different Kurdish groups when it comes to their vision of the future inside Syria, the emergence of a de facto autonomous region in northern Syria reinforced the desire for selfdetermination among the Kurds. After decades of accumulation of historical grievances due to the cultural and economic marginalisation of Kurdish people under the Assad regime, the local self-administration enabled the flourishing of Kurdish culture and identity and empowered Kurdish groups to mobilise around the idea of decentralisation and a federalised Syria, both inside Syria and abroad:

\footnotetext{
"The Kurds, for example, are now more self-confident, so more nationally self-confident. They now speak more openly and more about themselves, about a system. In the past, before the conflict, they talked about minority rights, cultural rights and political rights. But now they are talking about Syria in general, the political system, they are talking about a federal state where the Kurds also have their own
} 
territory" (I40, representative of a human rights-based organisation, pre-conflict migration, Bonn April 2016).

Whereas the conflict allowed Kurdish groups to develop new and alternative imaginations of their future inside Syria, these received limited acceptance among other Syrian diaspora actors, who saw the autonomy of the Kurdish region as a threat to the country's unity. These different ideologies and seemingly incompatible positions concerning a solution of the Syrian conflict were also mirrored in the process of diaspora mobilisation. While collective action of Syrian diaspora groups was initially based on unity in the fight against the regime of Assad, mobilisation increasingly focused on the activation of sub-national identities:

"The Kurds try to cooperate only with the Kurds, even in the Kurdish
organisations. The Syrian organisations, those that were relatively
religiously oriented or had connections to the Muslim Brotherhood,
they also try to [organise] themselves as their own group [...]. At the
beginning of 2012 the flags of revolution and Kurdistan could be seen
everywhere. That means there was a lot of participation of Kurdish
activists or at least of the Kurdish population in Aachen. For two or
three years now, nobody has come to a demonstration and we are not
informed about what they are doing. That's a pity" (I21, political
activist, pre-conflict migration, Aachen January 2016).

In addition to divergent political positions, fragmentations also emerged due to internal organisational struggles for leadership, which were often not based on deeply entrenched ideologies, but rather on very practical issues, such as the potential names of organisations, logos and focus of activities. Autocratic leadership, using a top-down approach, with unilateral, hierarchical and centralised decision-making power, made the diaspora movement increasingly divided:

"There are very different interests. One wants to work with refugees
here in Germany, the other doesn't. One prefers to work with
children, the third would much rather distribute relief supplies in
Syria and each individual association also has individual connections
to Syria, also individual ties, and that is why there are very big
differences" (I43, representative of humanitarian and an advocacy
organisation, pre-conflict migration, Phone, April 2016).

Even though the internal struggle for leadership was not a direct result of the conflict trajectories, respondents attributed the lack of collaboration and dialogue to the political socialisation in the Syrian context. As such the legacy of 
dictatorship, which only allowed one opinion, one ideology and one belief, resulted in a lack of experience with democracy and civic engagement when it came to the Syrian question:

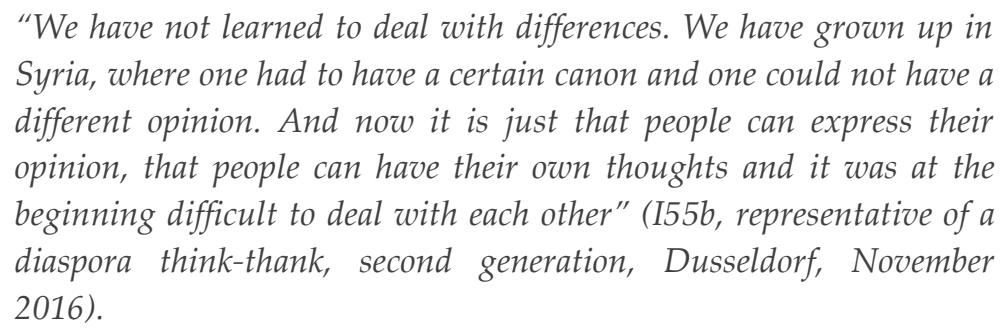

The fragmentation along ideological, sectarian and political lines in the Syrian diaspora and within and between diaspora initiatives prevented a necessary open discussion among civil society and a constructive approach in dealing with diversity.

\subsubsection{Destination country influences - Quest for resources, power and influence}

In addition to the reproduction of conflict lines present in the home country, destination country developments and policies also to a certain extent exacerbated the dynamics of fragmentation and divisions within the process of Syrian diaspora mobilisation in Germany. In the early years of mobilisation, most associations had minimal access to public funding and had to cope with limited and small budgets originating from fundraising events and other donations. The rising sectarianisation of the conflict shifted the discourse towards a security narrative in which Syria became not only a harbour of terrorism but also a threat to international security, in particular after ISIS-linked terror attacks in Paris, Brussels and Berlin (Orsini, 2016). Many of the diaspora actors perceived that the securitisation of the conflict resulted in a 'compassion fatigue' characterised by waning sympathy and willingness to donate for the Syrian cause among the general German public. Besides, after years of conflict and increasing displacement to Europe, some felt that personal financial resources as well as the possibility to mobilise funds within the broader Syrian community were exhausted. With insufficient donors, diminishing public support and exhaustion of private and community resources, Syrian diaspora political entrepreneurs found themselves confronted with a highly constrained financial environment which increased competition for the limited funds available:

"Between the groups as I know I got some information that
unfortunately at least in Germany there is big competition, there is no
cooperation. Every organisation fights for financial support, who gets 
what from the federal government. And unfortunately, that doesn't create a nice cooperative atmosphere, yes" (I21, political activist, preconflict migration, Aachen, January 2016).

As the quote indicates, the straining resources initially led to the creation of an environment of competition rather than cooperation, factoring into the already existing divides. What added to this was the quest for power to influence German decision-making on the Syrian cause, and a struggle over the legitimacy to speak on behalf of Syrian people:

"Unfortunately, as a result of these fragmentations, we were no
longer such a strong movement. So, at the beginning of 2011 we were
much more homogeneous. And then it was all about who is going to
the Foreign Office. Then the people tried to outdo each other" (I18,
media activist, pre-conflict migration, Skype June 2015).

The unity of Syrian diaspora mobilisation was, hence, subverted by the strife of representation, power and influence in which different diaspora actors struggled for sovereignty of the interpretation of the diasporic voice. The large-scale Syrian displacement to Germany further amplified these socio-political power dynamics within the diaspora mobilisation process in Germany, as it profoundly changed the nature, practices, positions and set of actors engaged in diasporic collective action.

Well before the media, public and political debate captured the Europeanisation of the refugee crisis, Syrian diaspora political entrepreneurs, as will be shown in Chapter 9, responded to the increasing numbers of Syrians seeking protection in Germany by engaging in countless acts of individual and collective solidarity. Yet, next to the strong feeling of co-responsibility and hospitality, some respondents also articulated reluctance and resentment towards those seeking protection in Germany. Their discourse rendered a socio-economic stratification within the Syrian immigrant population, in which the different trajectories of migration and displacement produced distinct socio-economic positions. As such, Syrian oldcomers often framed themselves and their generation as highly educated and well-integrated into the German society, whereas newcomers were rather perceived to occupy the lower socio-economic strata. Hence, the influx of Syrians seeking protection was in some cases also seen as a threat to the social status acquired in the host country:

"To be honest, I am against the Syrians coming to Germany and Europe, yes. So, of course, I understand that people come here, I understand that they are not well. [...] Well, I don't support them, first of all most people have a wrong idea of Europe and especially of 
Germany yes. [...] I am of the opinion that of the many hundreds of thousands if not 1 million refugees who are here, only a fraction of those will make it here in Germany [...] I say, people who come who are 20, 25, not married, no children have nothing yet and so on. Then I say, what are you doing here? Go, go to your country, fight for freedom, yes and don't come here and finally ask for alms" (I26 representative of humanitarian organisation, pre-conflict migration, Skype, January 2016).

The German public and media representations, which depicted refugees increasingly as either objects of pity in need of protection, or as a threat to the social, cultural, economic and political order, further amplified the process of distinction among the different representatives of the Syrian diaspora and among the wider immigrant population. As a result, self-representations of Syrian diaspora political entrepreneurs in Germany in some cases were also shaped by the broader representations of the categories of refugees and immigrants and the process of labelling present in the German context:

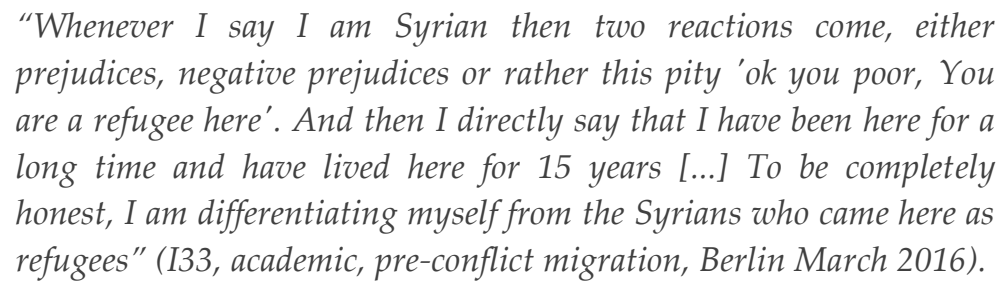

As such, destination country discourses to a certain degree reinforced the manifestation of social boundaries within the diaspora, engendering generational and social hierarchies among the different cohorts of the Syrian immigrant population in Germany. These social structures and processes produced not only distinct social positions and identities within the wider Syrian immigrant population but also specific imbalances of power within the process of diaspora mobilisation:

"The very old generation aged 65 wants to dominate. But they have had actually little to do with Syria, little with the new generation. But they have the power, as always, they have money, are people who are established, often doctors with contacts, they wanted to be on the board, they had to be always in front. On the other side, there was also the young generation, the students and so on, who actually started the revolution that naturally felt pressured by them" (I18, media activist, pre-conflict migration, Skype June 2015). 
The dominance of the older generation was, however, frequently challenged by newly exiled activists for whom the revolution inside Syria also came as a question of generations. Many had been involved in the non-violent and civil society movement in Syria, and accumulated knowledge and experiences through their work with local and international organisations. As the following quote indicates, members of the new migrant generation felt that the older generations had a different view on the conflict and on the situation in Syria that might not reflect the actual reality on the ground:

"So, the purpose of the organisations is to develop the current
generation, because we disagree with the 80 generation. You know,
they only do politics. [...] And they don't actually understand the
current generation. So, the current generation, I believe we
understand each other, we are on one level [......]. The current world,
it is an intelligent and smart world, democracy, values, liberties, you
cannot shut people up and you cannot play the father, you look at
your son or daughter as an individual" (I65, representative of
development organisation, conflict-migration, Leipzig November
2016).

Unlike generations of Syrians who migrated in the 1970s and 1980s, the younger generation perceived a different kind of ownership of the conflict, due to the fact that they had been actively involved in the Syrian revolution and had experienced recent trajectories of the conflict in Syria. Rather than a 'mere' overthrow of Assad's regime, many saw the need for a more complex social change that would break down the traditional patriarchal structures, which continue to exist within the Syrian society, both at home and abroad.

\subsubsection{Searching for a common ground - The desires for unity and solidarity among diaspora actors}

Though conflicting ideas, aspirations and positions were present among the diaspora political entrepreneurs, a strong desire for unity was frequently expressed, as many perceived the fragmentation not only as a significant stumbling block for collective political mobilisation but also as a factor that profoundly weakened their strength and power vis-à-vis the homeland government. Indeed, Shain and Barth (2003) argue that the capacity of diaspora groups to influence the homelands' foreign policies is shaped by the degree of cohesiveness, that is to say the ability to mobilise and sustain a collective identity and to create strong institutional networks. With increasing needs on the one hand and decreasing resources on the other, many diaspora actors saw the need to overcome the divisions and to bundle resources. In order to "unify" the 
(politically) divided landscape of diaspora organisations, the VDSH (Verband Deutsch-Syrischer Hilfsvereine, association of German Syrian humanitarian organisatiosn) was established in 2014 as a neutral coordination and capacity building mechanism. Putting the focus of the umbrella organisation and its member organisations on the provision of humanitarian aid in Syria and the neighbouring countries made it possible for many to find a common and less conflicting ground for action:

"Even this was a task, these diaspora meetings in Berlin, as Syrian
representatives from different backgrounds; more Islamic, other
regions [...] to come together, get some discussions. Why are we
judging each other on geographical backgrounds? It was to come close
to each other. And this has happened with humanitarian
organisations. And some of them human rights or civil society, so it's
happening now. That was also a chance after the coordination, to
trust each other" (I65, representative of civil society organisation,
conflict migration, Leipzig November 2016).

Even though the representation and legitimation of the umbrella organisation continued to be contested, its creation and work was perceived by many diaspora humanitarian actors as a very important step, which helped to coordinate the work and promoted dialogue among the diaspora organisations. What the last extract also implies is a process of civic and democratic learning within the mobilisation of the Syrian diaspora in Germany. In the beginning, the different positions and ideologies often led to heavy disputes, to split of organisations and conflict among the different actors engaged in the mobilisation process. As mentioned above, the historical lack of a culture of civil society and experience with democratic processes in Syria created a condition in which conflict and contestations were often dealt with in a destructive manner. Over the course of the conflict, there were increasingly encounters in which a range of Syrian diaspora actors could voice their different and sometimes opposing position in a peaceful and constructive way. These encounters were either facilitated by diaspora actors themselves, or by different stakeholders such as the German Development cooperation (GIZ), the Berghof Foundation, or the Danish Refugee Council, who increasingly implemented programmes to strengthen Syrian diaspora engagement in Germany and in other destination country contexts. As such, involvement in the process of diaspora mobilisation enabled the actors to accumulate experiences with political and civic engagement, in which diversity could be more and more understood as an opportunity that, if constructively approached through dialogue, could promote social transformation and development both in Syria and Germany. 
Besides the political need for unity and solidarity, diaspora political entrepreneurs might employ the construction of a 'fictive unity' to create a stable space of belonging, in a diasporic condition which is marked by exile, displacement, instability and insecurity (Mavroudi, 2007). In the end, every respondent said they wanted peace and what most narratives on a peaceful Syria had in common, was the desire for a democratic country in which the different segments of the Syrian society would enjoy the same rights and duties and could live in peaceful coexistence. Even though the ways on how to achieve this version of Syria were heavily disputed, there was a strong desire for finding new ways of meaningful dialogue to connect the different diaspora groups and the wider Syrian society, to overcome the profound disconnection that had torn apart the diverse segments of the Syrian society. Some respondents also argued that the destination country could provide a safe and neutral space for rapprochement, reflection and dialogue among the diverse range of Syrian diaspora actors, highlighting the potential role of diaspora groups as agents of change and peace. Indeed, as will be shown in Chapter 9, there are great examples of diaspora actions that tackle the division by promoting a process of peacebuilding, dialogue, community building and reconciliation among actors of the Syrian diaspora and the wider immigrant population in Germany. The actions taken by Syrian civil society organisations in Germany that address social, political, ethnic and religious divisions can be seen as important contributions in building a basis for sustainable peace in the future.

\subsection{The Process of de-diasporisation - The fall of diaspora structure}

This section explores the conditions and reasons why active members of the Syrian diaspora in Germany became demobilised. It has to be acknowledged that throughout the research process it was particularly difficult to follow-up with people who disengaged, as some did not respond, while others refused to participate. As the following stories highlight, the process of de-diasporisation may be a result of traumatic experiences and painful memories, disillusioning and resignation, a consequence of detachment and estrangement with the origin country, or as in other cases re-identification with other socio-cultural categories. It can also be a result of changing life courses, which may lead to new and sometimes conflicting responsibilities.

Overall, what many stories of de-diasporisation had in common was a feeling of resignation, despair, and exhaustion. When the revolution took to the streets in 2011, many respondents said they were filled were filled with the hope that political and social transformations would soon lead to considerable changes in the country of origin. Inspired by a sense of co-responsibility, a feeling of being part of 
the nation, diaspora actors felt empowered to take action in order to shape the home country's future. As the conflict escalated into a protracted crisis, in which both internal as well as external factors added to its complexity, there was increasingly the realisation, that one can do little to influence the conflict trajectories. Internal religious, social and political divisions had been largely propelled by a geopolitical quest for power, in which international actors such as the US and Russia, as well as regional actors including Saudi Arabia, Qatar, Turkey and Iran scrambled for dominance and power to establish their influence in the region:

\begin{abstract}
"Well, I think at the beginning of the revolution, yes, we had a great deal, we had worked together very intensively, and we had really tried very hard and we had achieved a lot, yes. But I think people have come to a limit or to a point where they realise we humans have done a lot and we believe that the situation is much more powerful than all our efforts. We are not significant at all as individuals, but they are the global players, especially the powerful of this world. So, whether it is the US, Israel, certain Arab countries, Iran and so on. And what we do is just a drop in the bucket. There has been some despair in many of us. And a certain resignation so we retired a bit, maybe it has just become too much" (I28, representative of advocacy organisation, preconflict migration, Hannover, March 2016).
\end{abstract}

As the extract shows, the growing international dimension of the conflict reinforced the perception that the solution was increasingly no longer in the hand of Syrians, highly limiting the feeling of self-efficacy, which is the belief that one's action can influence the political process and contribute to social change. As political self-efficacy is among the crucial aspects driving mobilisation (Brinkerhoff, 2008; van Stekelenburg, 2013), a protracted crisis may indeed lead to decreasing diasporic action over time. Another aspect that added to the perceived reduction of self-efficacy was the experiences of trauma resulting from the constant exposure to death, destruction, suffering and loss. Given their safe life at a distance in the destination countries, some scholars argue that diaspora actors do not have to bear the direct consequences of their action, and hence may take up a more radical stance (Anderson, 1998; Conversi, 2012; Demmers, 2007). In contrast, many of the interviews of this study revealed that despite the physical distance, members of diasporas are emotionally involved and influenced by events happening in the country of origin especially in times of ongoing conflicts. Often, a crisis leads to intensified contact with the beloved ones back home, where fear, suffering and threats to life are also felt very present in the diaspora. In addition, being active in the conflict even from at the distance, means also being exposed to the cruel reality 
of the war, often on a daily basis as images, videos, and stories are received unfiltered via social media, or direct contact with the family via phone and Skype. It seems hard to imagine that the suffering of co-nationals, co-nationals and beloved ones back home does not also have an effect on those living in the diaspora:

"I would say that I've also experienced a lot, a lot of bad things in
recent years. So alone in images [published at social media outlets].
That I can no longer look at and hear certain [things]. I temporarily
deleted my profile on Facebook. Because I did not want to hear or see
anything at all because it was just too much for me. I was feeling sick,
I was depressed [...]. Well, it was a psychological burden, so it's one of
many traumatic experiences we directly or indirectly live through,
directly from relatives, from people we know or even indirectly
through the media about Syria" (I28, representative of advocacy
organisation, pre-conflict migration, Hannover, March 2016)

Indeed, many interviewees expressed emotional distress, depression and other forms of psychological discomfort, due to the constant exposure to the conflict. When these emotions become overwhelming, this may cause feelings of paralysis, disillusionment and apathy, leading to a perceived inability to act. Van Hear and Cohen (2017) rightly argue that members of diasporas tend to be confronted with a 'portfolio of obligations', in which demands, needs, responsibilities and obligations to their own life and family and the desire to show commitment to the struggles of the broader imagined community have to be balanced and negotiated:

"At the beginning was the euphoria, I believed, that there can be a
quick change and at some point we had to realise that it is hopeless
after all, this peaceful change. What added to this are the financial
worries that you also had, so you put a lot of time into these actions at
the beginning. Neglected one's studies, neglected one's work. And
then reality caught up with you. [... I wouldn't say I'm a coward or
something, but I also have an entire family to lose, so to speak. I am
the only one in my family who is abroad and makes money and my
family depends on this money. So, for them, for them to live on in
dignity, I have a great responsibility" (I24, media activist, pre-conflict
migration, Bremen, March 2016).

Given that active members of diasporas dedicated not only their passion and time, but often also financial resources to the collective struggle for freedom and democracy, many sacrificed their financial security, well-being and pleasant life. While hope for regime change quickly disappeared, the enormous humanitarian 
challenges and the constant moral obligation resulting from this may have further exacerbated a sense of powerlessness and mental and physical exhaustion:

\begin{abstract}
"So, the signs of fatigue are with everyone, including me. It is difficult to continue on a voluntary basis in the long run. We have been busy for 5 years, not even a vacation. Every holiday we have we want to do this volunteer work, in Turkey, in Jordan, everywhere we can, and here too. It's exhausting and we hoped that it would stop at some point but unfortunately the escalations in the world and in Syria are such that we no longer know where it's going. Also, here the mood, which is slowly tilting, so at the beginning the welcome culture. Of course, it has taken a completely different turn: Fear of Islamisation and Muslims" (I64, representative of civil society organisation, pre-conflict migration, phone, November 2016).
\end{abstract}

As the last sentence indicates, it was not only the changing circumstances inside Syria but also shifting discourses and opportunities in the destination country which influenced the process of disengagement. Already by late 2015, the so-called summer of welcoming turned into winter, with increasing resistance to immigration and right-wing movements and parties such as the Patriotic Europeans against the Islamisation of the Occident and the Alternative for Germany (AFD) gaining public support (Geddes \& Scholten, 2016). The portrayal of newcomers in the mainstream media and the public discourse as either passive victims in need of assistance or a threat to German society, identity and culture tended to reinforce the Western gendered stereotypes of the 'Muslim Other' resulting for many in an additional front, which demanded constant struggles against collective condemnation. At the same time, when the home country is burning, seems lost and hopes and dreams of return are shattered, the destination country may serve as an alternative place of belonging, identification and security:

\begin{abstract}
"Well, I've always had such an identity crisis. Now I don't know what I am or where I belong. I recently applied for German citizenship and also received it. So, that I can at least find a place where I say this is my home or my Heimat. I have given up on that in the case of Syria, for example [...] So one of the motives why I applied for citizenship is the security I needed. When my country, my real country, my homeland burns then I have at least such a substitute home, I am not so completely lost in this world, that was a motive" (I24, media activist, pre-conflict migration, Bremen, March 2016).
\end{abstract}

In general, the process of de-diasporisation does not mean that individuals have disengaged and detached themselves from the homeland completely. As Mavroudi 
(2017) observed by analysing Palestinian and Greek diaspora mobilisation in times of crisis, there can be a strong emotional feeling of belonging and attachment to homeland, despite the absence of large-scale diaspora mobilisation. In one way or another, many participants felt a continuous connection to the homeland and a moral obligation to support those suffering from the consequences of the conflict, either in the country of origin or in Germany. However, as the following quotes indicates, involvement shifted from the imagined community, to the know community and as the conflict continued, to the household and extended family sphere (Van Hear \& Cohen, 2017):

"The commitment of the Syrian diaspora has shifted virtually from
the political level to the humanitarian level. Within the humanitarian
level from the collective humanitarian level to the family level. I used
to donate to these organisations, but now I think that my aunts, my
cousin and so on need the help" (I33, academic, pre-conflict
migration, Berlin, March 2016).

What seems relevant, is that it is often not one reason, but the accumulation of feelings, and convoluted, multidimensional and interlinked factors that drives the process of demobilisation. Hence, stories of demobilisation are complex, but often left untold, as these may cause pain or shame, or troubled identities in crisis.

\subsection{Conclusion}

As shown in this chapter, different and sometimes competing interests, aspirations and divergent opinions related to the settlement of the conflict among Syrians abroad emerged during the process of mobilisation, which tended to reflect the societal divisions and conflict lines on the ground in Syria. Yet, the different social, cultural and political divides were not necessarily based on deeply entrenched and radicalised ideologies. Instead, a strong desire for peace and reconciliation was present among the different actors involved in the mobilisation process, who countered the process of fragmentation with a diverse range of collective action. Both origin and destination country factors have been shown to have contradictory effects. For instance, while the escalation of the Syrian conflict led to the reproduction of conflict lines within the mobilisation process, the increasing humanitarian needs inside Syria, along with declining resources, fostered a desire for coordination and cooperation. In the context of destination, unequal access to resources and political influence offered by host country actors exacerbated tensions, competition and power imbalances between the different actors involved in the diaspora mobilisation process. At the same time, the destination country context also provided a safe space for reflection, among others through policies 
targeting the diaspora that facilitated encounters for dialogue, networking and cooperation.

Next to the emergence of competing imaginations of the transnational community, the chapter has also explored the process of de-diasporisation, in which the identity on which the diaspora consciousness is based became latent and demobilised. The findings indicate that the process of de-diasporisation was caused by a multiple set of factors, in which the loss of perceived self-efficacy can be considered as a central aspect.

After exploring the de-construction and re-construction of the diaspora consciousness, the following chapter examines in detailed how the alternative imaginations of the transnational community are mobilised and negotiated by the different agents of diaspora mobilisations. As such, it will shed light on the trajectories of the organisational framework and mobilising structure over the course of the conflict, how the set of actors engaged in the mobilisation process changes overtime, and what are their main characteristics in terms of the profile of the founders, the main organisational aims, activities and geographical focus, as well as on the capacity and degree of formalisation. 



\section{Chapter 8: The Evolution of Mobilising Structures}

The last chapter has explored how the internal social and political dynamics present in the mobilisation process produced a diverse range of alternative imaginations of the transnational community based on sometimes competing interpretations of the diasporic consciousness. Given that the diaspora consciousness is not objectively created but a result of boundary work and consciousness-raising by diaspora political entrepreneurs, this chapter focuses on the second dimension of the process of diaspora mobilisation (Chapter 2.3.2) and analyses the evolution of diasporic mobilising structures and the actors engaging in the construction of the imagined community. These diaspora political entrepreneurs may mobilise or are mobilised through different structures such as networks, institutions or organisations ranging from hometown associations, religious and cultural clubs, development, humanitarian and human rights organisations to political parties and activists, academic networks and media outlets that engage in the construction of the discourse of community (Kleist, 2015; Sinatti \& Horst, 2015). Yet, diaspora mobilising structures and the set of actors should not be perceived as fixed and static, but rather as highly dynamic and continuously changing. First, there might be changes in the organisational field, as some organisations which were set up at the beginning of the mobilisation process may no longer be functioning a few years later, while new agents may enter the field, leading to a high degree of dynamic change and fluctuation within the diaspora organisational structures. Next to the size of the organisational landscape, one can also analyse evolution of mobilising structures based on changing degrees of formalisation, institutionalisation and professionalisation of diaspora civil society organisations. For instance, mobilising structures may consist of informal ties and networks at the start of the mobilisation process, but eventually become highly institutionalised and professionalised over time.

This chapter aims to explore the mobilising structures, their nature and trajectories, as well as the conditions and factors that shape their evolution. This chapter is therefore guided by the following research questions:

- What are the different networks, institutions or organisations that engage in the discursive construction of community and how do they change over time?

- What is their degree of institutionalisation, professionalisation and formalisation and how has this change over time?

- Which factors influenced the trajectories of mobilising structures? 
As the following sections will show, the trajectories of mobilising structures might be a product of internal dynamics, rendering on the micro-realm of personal experiences, aspirations or desires, or externally driven as a result of changing opportunities and constraints in the host or home country settings. In general, it can be argued that different factors and events, both in the home and destination country, such as the outbreak of the revolution, the violent escalation of the conflict, as well as increased displacement to Germany, triggered the establishment of mobilising structures at different points of the mobilising process. Hence, while diaspora initiatives initially had a political nature aimed at supporting the movement in the homeland from abroad, the escalation of the conflict led to the establishment of humanitarian organisations that sought to alleviate the suffering of the Syrian population. Displacement engendered a change in the set of diaspora actors, as new agents entered the diaspora mobilisation process. In response to the large-scale displacement, new organisations were established to facilitate the arrival and integration of newcomers and to provide a safe place to safeguard a sense of belonging and community for Syrians in Germany. As a result, the mobilising structures are characterised by a diverse set of actors, who are sometimes aligned and sometimes compete in the discursive production of the transnational community.

\subsection{Conflict and displacement - Transformation of mobilising structures}

In contrast to other diaspora groups, such as the Kurdish and Tamil diasporas, which established strong transnational networks and mobilising structures connected to the secessionist movement in the homeland (Baser, 2017; Fair, 2007), the political opposition in Syria was not able to provide an ideologically unified framework to encompass the different societal and confessional groups of the Syrian society. As has been shown, the internal power struggles, and other sociopolitical dynamics, were reproduced in the diaspora mobilisation process, and hence, in spite of sharing a common oppositional stance to the ruling regime, the different positions to the settlement of the conflict prevented the establishment of a unified body that would be able to mobilise the Syrian diaspora for a common cause:

\footnotetext{
"Yeah, it's hard to create a homogenous group. There are so many different groups it is not easy to bring them all together under one roof. But at least about the general principles, they could agree, but that's also difficult, I think it's hard to bring Islamists and secular ones together. How could they agree on something? It is not easy. And this opposition with different political ideas and as I said, so
} 
controlled from outside it is not easy to bring them together" (I40, representative of human rights-based organisation, pre-conflict migration, Bonn, April 2016).

In addition, although the National Coalition, which was recognised by several international states as the legitimate representative of the Syrian people, mainly operated in exile, it not only lacked influence and legitimation inside Syria (YassinKassab \& Al-Shami, 2016), but as the following quote illustrates, it was not able to connect with Syrian diaspora civil society actors on the ground:

\begin{abstract}
"There are considerable external influences. I don't see a representative function [of the opposition] at the moment. Yes, they represent Syria in principle at events in Geneva, but there is hardly any presence on the ground in Syria. And here in Germany, I feel here as an activist or whatever not represented by the coalition in any way. Although the coalition in Berlin represents and observes human rights [...] So resignation, especially with the opposition. Because you can see we have this representative office of the National Coalition in Berlin, but it doesn't reach the activists. There is no coordination, no information, no formalities and no communications. And these are all topics that make it impossible to organise or do anything here" (I43, representative of a humanitarian and an advocacy organisation, preconflict migration, phone, April 2016).
\end{abstract}

Hence, although the revolution can be perceived as a transformative event that sparked collective action of those in opposition to the regime, the formal and organised political opposition was not able to offer a clear and sustainable framework for establishing mobilising structures in the Syrian diaspora in Germany. Instead, transformative events as well as conditions inside Syria and Germany, not only triggered Syrian diaspora mobilisation at different points in time, but as will be shown also influenced the nature and trajectories of the mobilising structures.

As Figure 15 indicates, the number of Syrian diaspora organisations in Germany has increased significantly since 2011, whereby the emergence of the peaceful movement, the violent escalation of the conflict as well as the increasing numbers of Syrians seeking protection in Germany can be seen as important transformative events that triggered diaspora mobilisation and the establishment of mobilising structures. 
Figure 15: Stock of Syrian diaspora organisations, 1979-June 2019

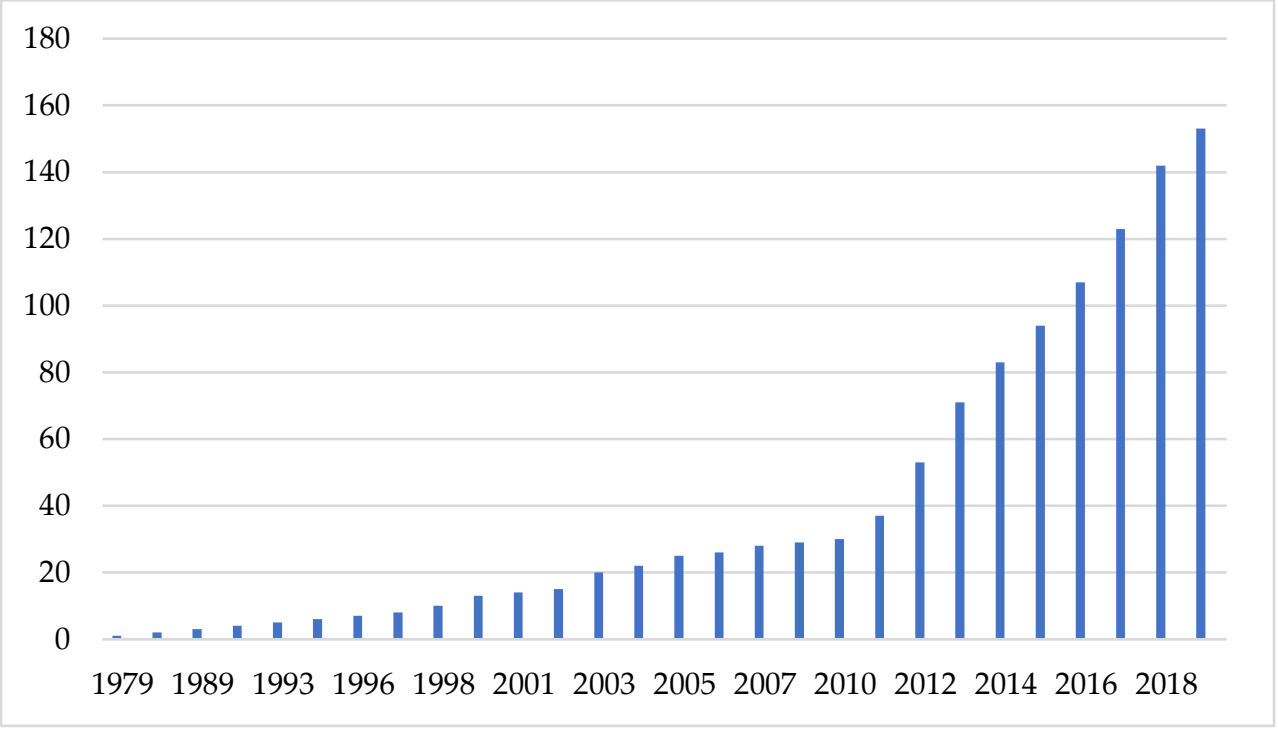

Major drivers for the evolution of diasporic mobilising structures can be seen in the increasing needs resulting from the Syrian conflict. As shown, the revolution can be considered as a transformative event that triggered diaspora mobilisation in Germany, as many initiatives emerged in solidarity to support the political struggles in the country of origin from abroad. Due to the militarisation and escalation of the conflict, which resulted in a devastating humanitarian crisis, many saw the need to alleviate the suffering of the Syrian people, both in Syria and in the neighbouring countries. As such, providing relief and humanitarian aid became a major focus of many initiatives. For some diaspora political entrepreneurs who could not fully identify with the political struggle and hesitated to get engaged in the early days of the uprising, the increasing humanitarian needs suffered by the population in Syria, resulted in a feeling of responsibility and obligation to act:

"When you see the suffering, the killing and the violence through the regime, you can't just stay calm and say 'yes that's okay that people are suffering', no we have to do something [...] I am a doctor. And my job is to help people. And I am a person who always offers help to people. That is also what I taught my children. Because if you can do something good - then do it! That is the only thing. I have no political interests, I have never been politically active, neither in Syria nor here in Germany. I wasn't interested in that at all. It's only about helping the people who are in need. That is the only reason for me" (I70, 
representative of a humanitarian organisation, pre-conflict migration, phone November 2016).

What added to the increasing numbers of diaspora organisations and initiatives in the first years was not necessarily that more people became active or mobilised, but that some organisations split up due to internal disputes over the associational work or leadership. One respondent described the evolution of diasporic mobilising structures as the big bang which led to the emergence of many stars which drifted apart over time, but eventually re-assembled to form a diasporic universe:
"So, in 2011 it was like that, that many associations have been founded. And then it's always like that when people come together with a certain idea then there are also always different ideas and then some isolate themselves and split off. So, there was a slight tendency towards fragmentation. Yes, more and more associations were formed that were independent and then said ok we don't want to do orphanages we do something different, or we are not in Northern Syria we are active in Southern Syria or otherwise" (I26, representative a diaspora network, Berlin, January 2016).

Hence, the formation of diasporic mobilising structures took place in the space of contestation, in which differences and similarities were negotiated, and antagonisms, as well as alliances, were forged.

In addition, displacement not only contributed to a rise and the heterogeneity of the Syrian immigrant population in Germany, but also to a rise and a diversification of diasporic mobilising structures. Even though this thesis argues that diasporas are not a direct product of migration, displacement nevertheless highly influenced the process of diaspora mobilisation, as with migrating people, identities, ideas as well as cultural, social, economic and political projects and practices circulated transnationally. As Koopmans and Statham (2003) argue that conflict may force especially political active people into exile. As a result,
"migrant communities from countries with a high level of internal political strife or oppression often harbour a disproportionate number of ideologically, ethnically or religiously 'conscious' members, who hold a diasporic identity and wish to remain involved in the homeland 'struggle' from a (safer) distance" (p.205).

The Syrian conflict not only caused displacement of people, but also of civil society structures, which had their origins inside Syria but became diasporic due to displacement of the founders. Hence, for the participants of this study, their cause 
did not stop with crossing the borders. As such migration and displacement did not lead to an interruption of activism, but rather changed the aspirations, nature, repertoires and channels of resistance. By making use of their networks within Syria, their aim was to continue being part of the movement by showing solidarity with the cause from abroad:

"It's hard to say what motivates me because the moment I ignore what is going on it will be bad because I have a lot of people there. This is my case, my revolution even with all these mistakes they should adopt. It's not to say now am in peace the other should suffer, I don't care. That's not my case (I59, writer, conflict migration, Cologne, May 2016).

In addition, displacement led in some cases to feelings of guilt and obligation to act. Leaving the country for a safe place in Europe, and those who continued to fight for their struggles behind in Syria was another crucial motivation for many to continue their resistance from abroad:

"It's the people who gave their lives for this war. When I think about them and about our colleagues still inside, they gave their lives and they are living in bad conditions and they could be killed by ISIS or an air strike. What about them, they are suffering. They have the ability to leave the city anytime, if they want and we asked them if they wanted to leave. But they decided to stay and to report with bad conditions. And so that's what makes me not to stop" (I47, media activist, conflict migration, Berlin, May 2016).

The favourable political opportunity structures present in Germany, such as the freedom of speech and to establish an organisation, especially when compared to the Syrian neighbouring country, was for some a major driver in their migration decision:
"The situation worsened in Syria and the NGOs came to Turkey and prepared for response to crisis, like the youth groups and civil society which never existed before 2011. Those formed after 2011 they were not registered so they were not recognised by the UN agencies as partners. To be partners we had to register our agency in Europe or the US. That's how I came to Europe to register the organisation in Germany" (I52, representative of a development organisation, conflict migration, Leipzig, July 2016).

Hence, with increasing numbers of Syrians seeking protection in Germany, one can also observe an increase in diaspora actors and mobilising structures. As will be 
shown in the following section, some organisations and initiatives have their origins in the local civil society inside Syria and became transnational in nature due to displacement of their founders, who continued their engagement in form of long-distance resistance from abroad.

As the conflict and displacement endured, the last years also saw the rise of integration and cultural organisations established by both those displaced by the conflict as well as the older generation, and driven by the need to foster the sense of belonging and community, at a time marked by insecurity, loss and instability. It can be argued that the formation of the Syrian diaspora in Germany is continuously in the making, not only shaped by contextual factors and developments in the host and origin country, but also by the duration of conflict and displacement.

\subsection{A typology of diaspora organisations}

Due to the recent emergence of Syrian organisations in Germany and the dynamic and multi-layered nature of the Syrian conflict, it is difficult to draw a clear-cut categorisation of the organisations. Many organisations try to address the various aspects of the Syrian crisis, becoming engaged in various fields of action in Syria, in the neighbouring countries and in Germany. Many organisations responded to an urgent need, be it to originally support the non-violent movement inside Syria, to alleviate suffering through humanitarian aid as the conflict escalated, or to support those who recently arrived in Germany. The complex nature of the conflict that is playing out in Syria, in its neighbouring countries and in destination countries such as Germany seems like a multi-layered crisis, which members of the Syrian diaspora try to address in as many aspects as possible, becoming engaged in various conflict fields at once.

As a result, the developed typology should not be seen as exclusive, since there is often an overlap in activities between the different groups, as well as a great diversity among the actors within each category. Taking into account the internal heterogeneity within each type of diaspora organisation, categories have been assigned based on the main focus/characteristics of each organisation in order to provide an analytical framework of the diasporic mobilising structures. The following section provides an overview of the main characteristics of each category, showing the profile of the founders, the main organisational aims, activities and geographical focus, as well as on the capacity and degree of formalisation. 


\subsubsection{Humanitarian organisations}

Origins of the organisations and profile of the founders

Most of the humanitarian diaspora organisations were set up by the 'generation of doctors', who were Syrians who migrated in the 1970s and 1980s mostly for educational reasons. They account for at least 80 per cent of the member organisations of the German umbrella organisations. For many of these Syrians, the motivation to get involved in the diaspora mobilisation process was not only driven by a feeling of co-responsibility but also by a professional ethos of helping those injured, by using the resources, skills and networks the diaspora political entrepreneurs had acquired in their professional life. Contacts with hospitals and pharmaceutical companies in Germany, for example, provided access to mobilise donations in the form of medicine and medical equipment, ambulances and medical devices. In addition, huge humanitarian demands inside Syria and the neighbouring countries matched the expertise of diasporic doctors, who therefore not only contributed to the humanitarian system through the provision of material aid but also through the transnational transfer of experiences, skills and knowledge. Given their trans-local connections, Syrian diaspora actors also benefited from greater access to otherwise inaccessible areas, when compared to more conventional humanitarian actors:

\section{"I think we have good networks within Syria and can really do a lot more than what the big organisations can do. Of course, the big ones might have more manpower, more money, but they don't have the networks we have" (I12, representative of humanitarian organisation, pre-conflict migration, Skype, October 2012).}

\section{Aim, activities and geographical focus}

With the increasing escalation of the Syrian conflict, many diaspora actors saw the need to support the victims of the crisis in Syria and in the neighbouring countries by providing humanitarian assistance to those affected by the consequences of the conflict. Hence, the main aim of the humanitarian diaspora organisations was to alleviate the suffering of the Syrian people and to provide aid to the victims of the Syrian conflict in order to improve their livelihoods. Relief aid ranged from clothes, baby milk, and medicine to medical equipment like ambulances and medical devices. As the conflict became increasingly protracted in nature, many of the humanitarian actors perceived the need to move beyond pure humanitarian aid, by implementing more sustainable development-oriented projects to alleviate peoples' dependency in favour of a more self-determined life. Initiatives ranged from promoting education, employment opportunities and livelihoods support to 
psychosocial support, as well as the maintenance and development of the medical sector in Syria. The geographical focus of humanitarian organisations initially targeted the Syrian population either inside Syria or in the neighbouring countries. Whereas the more professionalised organisations implemented activities in various regions of the country, most organisations focused on specific cities or regions mainly in opposition-controlled areas, whereby access was mainly facilitated through pre-existing personal contacts and ties. Due to the increasing numbers of Syrians seeking protection in Germany, some of the humanitarian organisations also started to implement initiatives aiming at promoting the integration of Syrian refugees into the German society.

\section{Capacity and degree of formalisation}

Looking at the degree of formalisation, one can observe that the majority of organisations started at the 'kitchen table' and have since tried to professionalise and institutionalise their efforts. With the escalation of the conflict, many Syrians both inside and outside Syria saw the need to formalise their involvement and to support the victims of the crisis in Syria and in the neighbouring countries. Responding to the increasing humanitarian needs, diaspora contributions shifted from an ad-hoc response, towards a more institutionalised action. Many organisations were formally registered in order to broaden their scale of activities and to increase their organisational capacity through the acquisition of donations and public funds. In general, the diaspora humanitarian organisations operated on a low capacity, mainly relying on voluntary work and donations to perform their activities. Interestingly, some organisations such as the German-Syrian Association for the Promotion of Freedoms and Human Rights (Deutsch-Syrische Verein zur Förderung der Freiheiten und Menschenrechte, DSV), and the Union of Medical Supply and Aid Organisations (Union der medizinischen Versorgung- und Hilfsorganisationen, UOSSOM), successfully mastered the path towards professionalisation and emerged as key players within the humanitarian and development response in Syria. The main success factors for professionalisation were identified as cooperation with more established German or international organisations, having a field office in Turkey and as such benefiting from higher proximity to international donors, as well as having a strong commitment from the founders, who at an early stage started to work full-time for the organisation. In addition, destination country policies, such as the capacity development programme of GIZ promoted some degree of professionalisation. While the diaspora engagement programmes by GIZ and BMZ (see. Chapter 6.3) presented an important step towards supporting the capacity development and professionalisation of Syrian diaspora organisations in Germany, its sustainability might be hampered by its project-based nature. 


\section{Networks and alliances}

The increasingly protracted nature of the Syrian conflict resulted in a need to engage in more long-term and coordinated action, to bundle resources and to become more effective, since for many respondents at this stage of the conflict, peace could only be achieved through collaboration and dialogue. Among the organisations active in humanitarian aid, the creation and work of an umbrella organisation was perceived as a very important step, which helped to coordinate the work and promoted dialogue among the members. Founded in 2014, the aim of the Federation of German-Syrian aid organisations (Verband Deutsch-Syrischer Hilfsvereine, VDSH) was to connect, unite and represent Syrian organisations in Germany that promoted humanitarian assistance in Syria and in the neighbouring countries. The establishment of the VDSH was initiated by different diaspora organisations and was further facilitated by the Berghof Foundation, which received funds from the German Federal Foreign Office to support the founding process. In order to work in a successful manner, in order to succeed, it was important for the VDSH to act strictly as a neutral coordination and capacity building mechanism in order to "unify" the (politically) divided landscape of diaspora organisations. The federation represented 23 member organisations active in the field of humanitarian aid. Activities included the promotion of communication, coordination and cooperation between the member organisations, the bundling of capacities through trainings and workshops, as well as the promotion of network opportunities with other German organisations and policymakers. So far, this umbrella organisation is the biggest body pooling the resources of Syrian diaspora organisations in Germany.

Beside this, other networks have evolved, revolving around specific professions, some being transnational in nature and involving members who are scattered across the world. For instance, the association of German-Syrian doctors for Humanitarian Aid (Deutsch-Syrische Ärzte für humanitäre Hilfe, DSÄ) was founded in August 2013 in order to bundle the expertise of doctors with a Syrian background in Germany and to leverage their respective contributions and technical knowledge. The association is part of the Union of Medical Care and Relief Organisations (UOSSM), a transnational network, which was founded in January 2012 in France and has become one of the most important actors in the humanitarian system in Syria. UOSSM is a coalition of humanitarian, nongovernmental, and medical diaspora organisations from the United States, Canada, United Kingdom, France, Germany, Netherlands, Switzerland, and Turkey. The main aim is to mobilise and pool resources of the member organisations and to coordinate their actions during weekly skype meetings, in order to increase the 
effectiveness of the humanitarian response and to provide independent and impartial relief and medical care to victims of war in Syria.

\subsubsection{Revolutionary civil society}

\section{Origins of the organisations and profile of the founders}

Most of these organisations and initiatives find their origins in the peaceful civil society movement inside Syria, but due to the displacement of active members became transnational in nature. For most of the founders of the organisations and initiatives, the revolution was experienced as transformative event that triggered the emergence of political subjectivities and created a space for claiming rights, freedoms, belonging and citizenship. As a result, the revolution gave birth to a vibrant civil society engaging in political struggles for rights and against government repression, challenging the increasing sectarian dimension of the conflict and acting in solidarity to support those suffering from the consequences of the conflict. As the conflict escalated, activists not only became a target of government repression, but also of other armed groups engaged in the conflict, forcing many to leave the country and to find refuge in exile. The Germany context which grants basic civil and political rights including the freedom of speech, association and assembly as well as legal mechanisms such as universal jurisdiction, was mentioned by some respondents not only as an enabling factor for their activism but also as an influencing factor for their migration choice. Looking at the profile of the founders, many initiatives were established by the younger generations who accumulated knowledge, skills and experiences in civil society work through their revolutionary grassroots activism inside Syrian or the neighbouring countries. Other organisations were established prior to the revolution by prominent oppositional figures of the Damascus Spring or the Damascus declaration, such as the human rights lawyers Anwar Bunni and Mazen Darwish, who engaged for years in underground activism to challenge regime repression.

\section{Aim, activities and geographical focus}

The activism's and organisational aims were based on the broader values of the revolution that call for justice, freedom, equality and respect for human rights and dignity. Under this umbrella there exist a variety of organisations that aim at building a strong basis for democratic change in Syria, which is realised through different kinds of activities. For instance, transnational activism in the form of protests, demonstrations, campaigns and lobbying aims to raise awareness and to influence policymaking in Germany as well as international decision-making on the Syrian conflict. In addition, artistic and cultural productions such as theatre, 
exhibitions, music and films are used as an alternative space for political expression. Some of the organisations implement activities that promote capacity development of Syrian civil society actors, in order to establish a basis for social and political transformation, while others tackle the more underlying causes of the crisis such as identity and conflict narratives, to promote a process of peacebuilding and reconciliation not only inside Syria, but often also among the broader displaced Syrian population either in the region or in Germany. Organisations that focus on the promotion of human rights often aim at strengthening the voice of marginalised groups such as women, youth or minorities and to foster their representation in international decision-making and peace processes. Finally, some organisations focus on the pursuit of justice and accountability, by documenting and reporting human rights violations committed by the various actors of the Syrian conflict, by providing support and legal assistance to victims of violations, and by processing and submitting files to competent jurisdictions. Given their origins in Syria or the region, most of the organisations and activist groups initially focused on the origin country context and made use of their Syrian branches and contacts to implement their activities and projects. In addition, some of the initiatives and organisations frequently used international decision-making processes, such as the Geneva talks, as a platform for advocacy where actors mobilised support and called for action and international recognition of their cause. In the case of organisations active in justice and accountability, legal mechanisms of international human rights regimes and the application of universal jurisdictions provide important channels for breaking the impunity for the atrocious crimes committed by all sides of the Syrian conflict, by enabling them to submit files to German courts. In addition, displacement for many led to new sites of contestations through which activism was not only targeted towards Syria but also increasingly towards to the destination country context. Initiatives in Germany aimed at contesting the dominant representations of refugees, claiming and enacting their rights in marches, occupations of public sites, and protests, and at fostering the political empowerment of newcomers through a diverse range of civil society initiatives.

\section{Capacity and degree of formalisation}

Within this type of diaspora organisations, the capacity and degree of formalisation vary significantly among the actors, mainly due to the nature of engagement. On the one hand, some organisations are formally registered in Germany and are often characterised by a higher level of organisational capacity, which is mainly a result of former experiences in working with the donor community inside Syria or the neighbouring countries. Destination country actors and international donors are a crucial source of funding, which nevertheless often 
tend to be project-based in nature. The lack of sustainable financial resources often presents a major challenge for ensuring organisational stability and for building a long-term strategy. On the other hand, this type of diaspora organisations includes a wide range of individual actors, such as political activists, musicians, artists and media workers who engage in transnational mobilisation via loose networks and ties and beyond institutionalised action. In most cases, their initiatives are not formally registered and are often realised through the mobilisation of financial resources within their own activist community and networks. The limited formalisation, institutionalisation and financial capacity are however, not a consequence of limited availability or lack of access to funds, but rather tend to be a conscious decision by the activists in order to ensure independence and to resist a potential depoliticisation of diasporic action.

\section{Networks and alliances}

In general, the mobilisation process especially of the younger generation of individual activists tends to be characterised by more non-hierarchical, loose mobilising structures and networks, which are often transnational in nature, connecting political activists in various destination countries and inside Syria. Social media provide not only a useful channel to connect $t$ political activists across the globe, but also a tool to mobilise people and to organise campaigns, protests and other acts of resistance transnationally. When it comes to activism targeting the destination country context, alliances are often forged with other migrant or refugee-led groups to mobilise people from diverse origins to collectively challenge discrimination and injustice present in the German refugee and asylum regime.

In addition to these loose mobilising structures and networks, some more formalised issue-based networks emerged, focusing on particular fields of action or specific target groups. For instance, the network We exist! was established in 2017 to build an advocacy alliance of over 25 Syrian civil society organisations with the aim to provide a platform to empower and strengthen the Syrian civil society through humanitarian efforts as well as long-term work promoting human rights, dignity, justice, accountability, peace and reconstruction. Through advocacy work, the network aims at challenging the dominant narratives on the Syrian conflict, by highlighting the values, work and efforts of the Syrian civil society and by shedding light on the complexity of the Syrian conflict. Collectively the network formulates public campaigns, participates in advocacy opportunities, works closely with the media, and coordinates lobbying that targets decision makers and policymakers in Europe in order to strengthen the voice of Syrian civil society in public debates and decision-making processes. 
The Syrian women's network (SWN) is a network of individuals and independent non-governmental democratic organisations working on issues of gender equality. It has around 30 member organisations and more than 100 individual activists. While originally, the largest share of members was comprised of organisations and activists that were based in Syria, the on-going crisis forced many partners in the network to leave the country. Yet, many continue their engagement from Germany and other destination countries. SWN implements projects in Syria, to challenge traditional norms and gender stereotypes and to promote political participation of Syrian women. At international level, members of SWN are part of the Syrian Women's Advisory Board, which was initiated by de Mistura, the UN special envoy for the Syrian crisis, to enable civil society participation in the Geneva peace talks. The main aim is to lobby for a commitment to gender-sensitive peacebuilding and reconstruction as well as for enshrining the rights of women in Syria's future constitution.

\subsubsection{Integration and cultural associations}

\section{Origins of the organisations and profile of the founders}

Prior to the outbreak of the conflict, there existed some Syrian-German friendship associations, which aimed to serve community interests. In particular, their goal was to support and strengthen the relationships between the Syrians living in Germany, promote their integration and strengthen the ties with the country of origin. Officially, these organisations distanced themselves from political or religious goals, but were seen by many as an extension of the Syrian state. Beside these, the vast majority of organisations under this type of diaspora organisations were established very recently in response to the increasing numbers of Syrians seeking protection in Germany. Interestingly, one can observe an increasing trend since the year 2015, with around 14 organisations (out of the 43) have been registered in the year 2018 alone. This can be partly explained by the distinct migration waves and patterns of Syrian displacement to Germany over the last years. While early waves were characterised by rather male dominated patterns, with men accounting for 67,5 per cent of the Syrian nationals in the year 2015, women made up almost 40 per cent in the year 2018. In addition, children under the age of 15 account for almost one third of the Syrian nationals residing in Germany (Statistisches Bundesamt, 2019b). With increasing numbers and more families migrating or being unified under family reunification schemes, new needs and motivations may evolve in the process of diaspora mobilisation. Instead of influencing homeland political processes from abroad, there might be a desire to create a stable space of belonging and community in the destination country due to a diasporic condition marked by exile, displacement, instability and insecurity. The 
profile of the founders of integration and cultural associations seems rather mixed. Some were established by Syrians who migrated prior to the conflict, in response to the increasing numbers of Syrians seeking protection in Germany and in order to facilitate their arrival and integration into the host society. Many others, however, were established by Syrians who migrated after the outbreak of the crisis, with the aim to support each other in settling down in Germany but also to strengthen a feeling of community and belonging.

\section{Aim, activities and geographical focus}

The main aim of the integration and cultural organisations is to promote community building within the Syrian diaspora, by providing a space for the expression of identities and the cultivation of heritage, traditions, customs and the culture of the origin country. While some organisations focus on specific ethnic or religious groups within the Syrian displaced population in Germany, others seek to create a politically, ethnically and denominationally neutral forum of encounter aiming to promote dialogue, exchange and understanding between the different segments of the Syrian displaced society. On a regular basis, religious or cultural events, family gatherings and meetings are organised to support and strengthen the relationships between newly arrived refugees from Syria. There is a particular desire to transmit a Syrian identity to future generations. In this regard, some organisations teach younger generations of Syrians in Germany about their origin and about Syrian history. Moreover, language classes are seen as crucial to foster their identity and sense of belonging, with different organisations providing courses either in Arabic or minority languages such as Kurdish and Aramaic. In addition, organisations often seek to foster social cohesion between Syrian immigrants and the local population and to contribute to intercultural dialogue and peaceful coexistence at a local level. Next to this, the aim is to provide orientation for Syrian newcomers in their new life environment and to support them in their integration process. Activities range from providing assistance with government agencies and doctors' visits, organising information events on asylum procedures, and providing legal advice or psycho-social support. Moreover, recognising that language plays an important part in the process of integration, some organisations offer German language and orientation courses. In general, most of the activities of integration and cultural organisations focus on the local context of the host country. In some cases, however, charity events or the collection of donations in religious festivals are organised occasionally to support victims of the conflict inside Syria through the provision of humanitarian aid. 


\section{Capacity and degree of formalisation}

The mapping of diaspora organisations indicates that there is an increase in formalisation, with almost half of the organisations active in culture and integration (20 out of 43) have been formally registered between 2018 and June 2019. However, 11 of the organisations do not have an online presence which makes it difficult to analyse the actual degree of activity. Given that many of the integration and cultural associations were established quite recently the organisational capacity in many cases is rather low. Often organisations rely on donations, membership fees and volunteers to realise their activities. Similarly to the humanitarian actors, it seems that some of the organisations, in particular those which were established at the early stage of Syrian displacement to Germany, were able to increase their organisational capacity through the cooperation with other more established German civil society actors and through the acquisition of government fonds or grants from international donors.

\section{Networks and alliances}

In contrast to the humanitarian organisations which are united under the umbrella of the VDSH, there is currently no network in place which connects the different integration and cultural associations in Germany. Some of the organisations such as Salam e.V. or Syrische Gemeinde in Schleswig-Holstein are, however, members of the VDSH. This is also partly a result of the broadening of focus and activities of the Dachverband, which increasingly seeks to address the needs of the Syrian population in Germany. In addition, forms of cooperation commonly exist with other external parties (e.g. local public authorities, government agencies and civil society actors) at a more informal level through joint events, projects, and collaborations. A few organisations are also part of more formalised consultative bodies at local level, such as foreign advisory, migration and integration councils (Ausländer-, Migrations-, Integrationsbeiräte), which have been established in various German cities and municipalities since the mid-1970s to ensure a political representation of migrants at the local level.

\subsection{Conclusion}

By shedding light on the trajectories of mobilising structures, one can observe not only a change in the set of actors, but also a process of institutionalisation over the course of the mobilisation process. Whereas mobilisation started ad-hoc, partly due to the lack of independent mobilising structures prior to the outbreak of the conflict, some organisations were able to formalise and professionalise their engagement over time and show a long-term commitment to their Syrian cause. 
The evolution of the mobilising structures suggests that the process of Syrian diaspora mobilisation is constantly in the making, and that various events and factors both in the home and host countries shaped the nature and characteristics of Syrian diaspora actors at different moments in time. However, the construction of mobilising structures not only emerged in relation to external factors but was also shape by internal factors of the mobilisation process. It has been shown that, next to the socio-political dynamics present in the mobilisation process, the characteristics and social locations of the agents engaging in the process of diaspora mobilisation also matter. For instance, although the escalation of the conflict drastically increased the humanitarian needs of the Syrian population, these also matched the resources, skills and networks of many diaspora political entrepreneurs among the older generation. As a result, the characteristics and social locations of the agents may also influence how the community is mobilised and which influences on the political process in the homeland are exerted. The following chapter will explore this aspect more in depth, by analysing the trajectories of mobilising practices, through which the community is mobilised, and political influence both in the context of origin and destination is wield.

Finally, limited attention has been paid so far on the way how forced displacement may influence the process of diaspora mobilisation, since most of the research focuses on the actors who were already established in the country of destination and their relation to actors engaging in the conflict in the country of origin. However, as has been shown, with the displacement of people, political ideas, projects and initiatives also travel with them, leading to a diversification of mobilising structures. As a result, a mobility lens that acknowledges the circularity of social, political and cultural processes can enable a more dynamic analysis that moves beyond a unidirectional understanding of flows from the destination to the origin context. The following chapter will add to this, by shedding light on the circularity of social, cultural, and political remittances. It argues that mobility not only influenced the process of diaspora mobilisation, but also led to a redefinition of the political spaces both at home and in the destination context, since boundaries of political communities were constantly shaped and negotiated. 



\section{Chapter 9: The Transformation of Diasporic Practices}

While the previous chapter explored the evolution of mobilising structures, this section is devoted to the third dimension of the diaspora mobilisation process, and analyses the trajectories of transnational practices, i.e. the actions through which the achievement of collective goals is pursued. The transnational mobilisation of diaspora groups tends to be a dynamic process as conflict developments have been shown to shape trajectories of transnational practices in various ways (Bercovitch, 2007). With a few exceptions (Baser, 2017; Giugni \& Passy, 2004; Hess \& Korf, 2014; Koopmans \& Statham, 2003; Koinova, 2016, 2014b), limited attention has been paid on how conditions and factors in the host country shape diaspora transnational practices over time. Further, it has been relatively unexplored how migrants' civic and political participation in the host and home countries happen simultaneously and how political opportunities of both contexts interplay and intersect. By analysing Syrian diaspora civil society contributions directed towards both the home and the host countries, this chapter sheds light on the embeddedness and interconnections of diaspora politics, how sending and receiving country dynamics may intersect and mutually affect each other and how mobility transforms political spaces in several places. By exploring the changes of diasporic action at different points in time, this chapter seeks to unpack the processes and mechanisms that explain the different pathways and trajectories of diasporic practices. The chapter is therefore guided by the following research questions:

- What are the practices through which the community is mobilised?

- What forms of engagement do different groups of the Syrian diaspora pursue, and how and why did these change over time?

As will be shown in the following sections, diasporic transnational practices are shaped by conflict dynamics in the country of origin, as well as the repercussions of the conflict in the destination country. Over the course of the conflict, Syrian diaspora political entrepreneurs responded to an urgent need, be it to originally support the non-violent movement inside Syria, to alleviate suffering through humanitarian aid as the conflict escalated, or to support those who recently arrived in Germany.

While initially diaspora mobilisation in Germany was political in nature, the escalation of the conflict resulted in an increasing humanitarian response to the crisis. However, the shift was not just a reaction to changing conditions inside Syria, but also driven by host country factors, as well as internal social political dynamics present in the process of diaspora mobilisation. At the same time, it also 
had strategic dimensions, as the shift towards humanitarian action had the potential to alter a feeling of self-efficacy, made it possible to find a common and less conflicting ground for action, and facilitated the generation of funding and support. Yet, the humanitarisation of diasporic practices, in which diasporic actions became embedded in apolitical parameters of relieving the suffering, has to a certain extent limited the transformative potential of diaspora political entrepreneurs to become actors of political change in the country of origin.

The changing set of diaspora actors resulting from displacement, however led to a re-politicisation of the space of diaspora mobilisation as some of the protagonists of the Syrian revolution who sought refuge in Germany continued their struggle for democracy and freedom from abroad. As their activism in many cases was not only directed towards the homeland, but also consisted of various acts of claiming rights, belonging and political participation Germany, diaspora mobilisation also transformed the political space in the destination country.

With increasing length of stay and progressing inclusion into the host society coupled with an increasing realisation that return would not be a feasible option in the near future, the experience of displacement for many shifted from a temporary phenomenon to a permanent condition. As a result, recent years also witnessed the emergence of cultural organisations that seek to maintain and cultivate a Syrian identity in order to provide a safe place of community and belonging to those forcibly displaced by the conflict. Shrinking access and space of influence in the origin country further amplified the shift from actions oriented towards the home country towards civic or political practices that address the context of destination.

\subsection{Conflict escalation and humanitarisation of the diasporic space}

The year 2012 witnessed an escalation of the Syrian conflict, driven by indiscriminate attacks by the regime on civilian populations and infrastructure and the rise of the armed component of the resistance movement. Heavy bombardments and sieges of opposition-controlled areas caused a drastic increase of casualties and the destruction of entire neighbourhoods and villages, especially in Homs, Hama and Idlib. Given the escalation and militarisation of the conflict, it became eventually later framed as one of the world's most dramatic humanitarian crisis. While initially the movement that took to the streets in 2011 to challenge the ruling regime was political in nature, the escalation of the conflict resulted in an increasing humanitarian response to the crisis. Inside the country, in particular in the then opposition-controlled areas, formal and informal organisations were established to coordinate and implement humanitarian assistance to alleviate the 
suffering of those affected by the conflict. The Syrian diaspora constituted not only the main source of funding for local NGOs, but also contributed to the humanitarian system by providing other forms of material aid, skills and knowledge. In particular in the early years of the conflict, diaspora and local organisations delivered the vast majority of humanitarian assistance in areas under opposition control, as international organisations and UN agencies were mainly operating in close coordination with the Syrian government and were therefore prevented from accessing areas beyond regime control (Svoboda \& Pantuliano, 2015).

\subsubsection{From activists to aid workers}

In response to the deteriorating humanitarian situation in Syria, diaspora actors organised campaigns and collected donations to provide humanitarian aid to those suffering from the consequences of the conflict. Relief aid ranged from clothes, baby milk, medicine and medical equipment to ambulances and medical devices. Other initiatives provided financial support for widows and orphans in order to ensure their livelihood. While humanitarian aid at an early stage of the escalation was characterised by an ad-hoc response, the closing of borders as well as bureaucratic procedures in the neighbouring countries made it increasingly difficult to deliver the aid to Syria and were frequently mentioned as major obstacles for a continued involvement.

As the conflict continued with no end in sight, many organisations also saw the need for more sustainable efforts, which would promote the well-being and development of the Syrian population beyond the pure delivery of aid. Increasingly, diaspora organisations became involved in more developmentoriented activities, in the areas of health, employment, education, gender and community development. Next to implementing activities inside Syria, some organisations also targeted Syrian refugees residing in the neighbouring countries, as this population was considered as particularly vulnerable due to scarce livelihood resources and limited access to public services such as healthcare and education.

To ensure the maintenance and development of the Syrian health sector, organisations like the German-Syrian Association for the Promotion of Freedoms and Human Rights (Deutsch-Syrische Verein zur Förderung der Freiheiten und Menschenrechte, DSV), the German- Syrian Doctors for Humanitarian Aid (Deutsch-Syrische Ärzte für Humanitäre Hilfe, DSÄ) and the Union of Medical Supply and Aid Organisations (Union der medizinischen Versorgung- und Hilfsorganisationen, UOSSOM), financed the construction and maintenance of 
hospitals, including the funding of medical staff and electricity. Another contribution consisted in the training, development, and support of human capital and medical practitioners to foster maintenance and development of the Syrian health sector. Professional training was provided in trainings centres in Turkey or directly in Syria. Next to human resource development, these initiatives sought to create new prospects for people in Syria, by countering extremism and addressing the root causes of forced displacement. Beside this, new media resources (e.g. WhatsApp, Skype) enabled knowledge transfer on a regular basis, so that doctors in Syria were able to consult with Syrian doctors abroad, discuss diagnosis or even receive assistance in surgeries.

After years of conflict, many diaspora entrepreneurs perceived an increasing risk for an entire generation of children to be deprived of their basic right to education. Therefore, many organisations saw the need to promote the education of children, through the establishment and financing of schools and educational centres both in Syria and in the neighbouring countries. Beside traditional subjects, such as languages and natural sciences, many organisations put emphasis on strengthening the awareness for and education on human rights, women's rights and principles of democracy and freedom. Moreover, an initiative of Homs League Abroad sought to promote the inclusion of Syrian refugees in higher education. In cooperation with six universities in Turkey, they provided scholarships to 60 university-qualified students in diverse fields of study to facilitate their skills development and to build a strong knowledge base for the reconstruction process.

As the conflict in Syria increasingly affected not just the physical health but also the emotional and social wellbeing of the Syrian population, both inside Syria and among those being forcibly displaced to the neighbouring countries, psychosocial support was seen as crucial to help the victims of the conflict to cope with the traumas of war, loss and displacement. In collaboration with local NGOs, DSV implemented a project financed by GIZ's 'Programme Migration for Development' (Programm Migration für Entwicklung, PME), in which social workers from three community centres and 10 schools in Aleppo were trained in psychosocial care for women and children. One member of the Syrian diaspora with a background in psychology frequently travelled to Turkey to provide supervision to the psychosocial personnel who works in refugee camps, widows' or orphans' centres, helping them to develop their professional skills. Another association, Homs League Abroad, established five widows and orphans' centres in Lebanon, Turkey and Jordan, which provide education, health care as well as social and psychological rehabilitation. Emphasis was placed not just on ensuring that the basic needs of refugees were met, but also on investing in more sustainable efforts that led women out of dependence towards a more self-determined life. 
In response to the severe socio-economic conditions faced by Syrian refugees in the neighbouring countries, some organisations implemented projects aiming at enhancing the access of Syrian refugees to employment opportunities and livelihoods support. For instance, the German-Syrian Forum (Deutsch-Syrisches Forum) implemented a project in Gaziantep, Turkey, in which Syrian refugee women received sewing training to enable them to become self-reliant and to live independently from aid. Another project aimed at providing micro finance to female refugee entrepreneurs in Turkey, in order to equip them with the resources necessary to realise their own business projects and ideas. The widows and orphans centres established by Homs League Abroad offered professional training in tailoring, healthcare and hairdressing. More than 700 orphans and widows have been supported so far, with women now being equipped with skills to earn their own livelihood.

\subsubsection{The humanitarisation of diaspora space - Between reaction and strategic choice}

The shift of the transnational practices from political action towards humanitarian work was not just a reaction to changing conditions inside Syria, but also driven by destination country factors as well as internal social political dynamics present in the process of diaspora mobilisation. On the one hand, shifting activities and practices can be considered as reactive, as diaspora groups responded to changing circumstances and factors both inside Syria and in Germany (and internationally). At the same time, the shift had also strategic dimensions, as engagement in humanitarian aid had the potential to alter a feeling of self-efficacy, made it possible to find a common and less conflicting ground for action, and facilitated the generation of funding and support.

When the revolution took to the streets in 2011, many of the respondents were filled with hope that political and social transformations would soon lead to considerable changes in their country of origin. Inspired by a sense coresponsibility, many respondents described the feeling of being part of the nation and acting in solidarity with the Syrian people at home as the main driver of the decisions to become part of the transnational resistance movement. Personal experience such as the death or disappearance of close family members and friends amplified the feeling of co-responsibility:

“The motivation was my family. Almost every week, somebody dies, or somebody disappears or gets arrested. Almost my whole history was destroyed. In your own inner cycles, you are affected. When you call there, they tell you your brother inlaw is dead, your uncle is dead, your brother disappeared. There's no traces of my 
brother and his family of five. This is the motivation" (I9, representative of a humanitarian organisation, pre-conflict migration, Skype, October 2012).

Already in September 2011, Al-Haj Saleh (2017) anticipated that the country was moving towards a situation of what he called 'the state of nature', which results in 'politics of subsistence, focused on survival and self-protection' (p.65). The need for survival, he argued, will shift the focus towards meeting the basic needs of protection and away from the more abstract and emancipatory demands of the revolution. Indeed, the escalation of the conflict has had a devastating impact on the lives of Syrian people, who became marked by experiences of suffering, loss and dislocation. The family and friends left behind, as well as the millions of Syrians suffering from the consequences of the war due to death, displacement and destruction shifted the motivation to engage in transnational activism from a choice to a necessity and obligation:

"I was a political activist in the uprising, the demonstration doing
these talks with the media. I was dreaming of democracy and liberty,
freedom, equality, fair election, social justice. Right now, these things
are to me quite ambitious if not impossible to happen. These days
right now what matters to me is ending this war, everyday hundreds
of Syrians are killed" (I51, representative of humanitarian
organisation, conflict migration, Skype, June 2016).

As the conflict escalated into a protracted crisis, in which both internal as well as external factors added to its complexity, there was increasingly the realisation that one can do little to influence the conflict trajectories. The international community's inability to put an end to the conflict by finding a political solution further amplified this feeling. The space allocated for civil society organisations during the international Syrian peace talks was perceived as a pure decoration rather than an opportunity to exert influence on international decision-making. As shown in Chapter 7.2., the growing international dimension of the conflict reinforced the increasing perception that the solution was no longer in the hand of Syrians, which highly limited the feeling of self-efficacy, i.e. the belief that one's action could influence the political process and contribute to social change. At the same time, the contact with the beloved ones back home, made the fear, suffering and threats to life feel very present to those in exile. Supporting the provision of humanitarian aid, education or healthcare in diasporic action represented for many an avenue to counter feelings of resignation, despair, and guilt and could help diaspora political entrepreneurs, as one gender activist puts it, 'to stay alive':

"All these people and the suffering. Also, there is a lot of pressure
from people asking what you are doing? Do you believe you can 
change something? Sometimes I say I will do nothing but that helps me be alive. If I do nothing it's like you say I will die. Maybe I can't change anything, I cannot provide anything but maybe I can help one child, one woman and one man in Syria. At least that helps me to stay alive and survive" (I38, human rights lawyer and gender activist, conflict migration, Berlin, April 2016).

Next to origin country factors, the destination country context also influenced the shift in practices of diaspora actors to a great extent. The public and media discourse in Germany, which initially framed the conflict in light of the wider Arab revolutions as a political struggle of ordinary people challenging the ruling of authoritarian regimes, was perceived by many diaspora political entrepreneurs as an enabling factor as it gave recognition to their cause, made it easier to gain public support, and through this to collect donations and exercise political influence. Yet, the escalation of the conflict and its repercussions increasingly unfolding in Europe were seen as crucially limiting the discursive space for diasporic political voices and action. With the rise of the so-called Islamic State in mid-2014, the media and public discourse shifted from framing the Syrian conflict as a democratic to a sectarian struggle. The rising sectarianisation of the conflict, shifted the discourse towards a security narrative in which Syria became not only a harbour of terrorism, but also a threat to international security, in particular after ISIS-linked terror attacks in Paris, Brussels and Berlin (Orsini, 2016). The discursive shift was perceived as an additional obstacle for a political mobilisation, as the following quote indicates:

\section{"Before, they called it the opposition, the freedom party, now they are called the rebels. Yes, before these were good people in their eyes and now, they became suddenly terrorists. This is something which annoys me, where you think why? This makes everything even more difficult" (I19a, youth activist, second generation, Cologne, July 2015).}

With the escalation of the conflict and the 'Europeanisation' of the Syrian displacement crisis with a sharp increase of Syrians seeking protection in Germany since the summer of 2015, a humanitarian narrative earned prominence, in which the conflict in Syria became framed as the world's most dramatic humanitarian crisis. Studies on the public and media representation of the 'refugee crisis' in Germany showed that the discourse mainly followed two dominant narratives, a humanitarian one which framed refugees as the embodiment of victimhood in need of protection and a security one which depicted refugees as a threat to the political, social and cultural order (Friese, 2017; Hinger, 2016; Holmes \& Castañeda, 2016; Holzberg et al., 2018; Vollmer \& Karakayali, 2018). As the following quote 
illustrates, the changing discursive context in Germany provided an increasingly limited space for political mobilisation:

"So of course, there are always, as I know, there are still organisations
that are still active at the political level. But most organisations I
know try to stay on the humanitarian level as much as possible. In
Germany there are no rules which say you are not allowed to do
politics, but the atmosphere in Germany has changed unfortunately
[...] the interest drastically reduced, in Germany they talk about
refugees and terrorism. [...] Under such an atmosphere it is very
difficult to do political work" (I21, political activist, pre-conflict
migration, Aachen, January 2016).

Given the highly complex nature of the conflict, with a great number of armed actors affiliated to different fractions and with complex and fluid relationships between the different rebel groups, the notions of 'the good' and 'evil' in the Syrian conflict became more and more difficult to identify. The weak political opposition was not able to establish itself as a trustful and publicly visible counterpart of the government of Assad, while at the same time ISIS propaganda was highly successful in gaining international attention (Orsini, 2016). Humanitarian engagement became a way for the diaspora civil society to mobilise public support, as it framed diasporic action in apolitical parameters of alleviating the suffering of the Syrian people. Social media outlets of different diaspora organisations started to post images of suffering women and children, aid workers distributing relief aid or doctors providing medical treatment to the injured. As one respondent critically reflected during an informal discussion, diasporic action may even have reinforced the representation of the Syrian conflict as a crisis in contrast to a political struggle but framing the Syrian conflict in line with the dominant German public discourse was seen as the only way to get attention and support. Being exposed to the cruel realities of the conflict often on a daily basis, sharing images and raising awareness on the cruelties committed in this war was not only seen as necessary to awaken the German public and regain their attention on their cause, but also to process the traumatic experience of the conflict from a distance.

Moreover, the framing of diasporic action as a humanitarian activity was also adopted in some cases as a strategy to generate not only public support but also external funding. The discussions on the adequate name of the umbrella organisation during a meeting in its establishment process highlights the way diaspora groups acted strategically to better position themselves in the transnational field. During a meeting a discussion arose around the choice of the name for the German umbrella (VDSH), in particular whether it should be called an umbrella of humanitarian organisations or if it should have a more general 
name. One of the main counter arguments was that the network not only united different organisations active in the humanitarian field but also political activist groups and organisations active in advocacy, which did not feel adequately represented by the name. Another point of discussion lied in how far the umbrella organisation should position itself politically in its vision and strategy. While most of the participants of the meeting positioned themselves clearly in opposition of the Syrian government, it was nevertheless decided at the end of the meeting that the political stance of the member organisations should not be included in the identity of the network, but that the network should present itself as politically neutral body. One of the justifications for this decision was the fact that one would be able to generate more funding as most of the big donors demand adherence to the humanitarian principles of independence, impartiality and neutrality.

Indeed, donors started to recognise the potential of Syrian diaspora organisations and their contributions within the Syrian humanitarian response, and designed programmes or funding streams to leverage the diasporic potential. These definitely led to the development of capacity and professionalisation of some of the organisations active in the humanitarian field. Yet, given that these programmes often demanded diaspora actors to comply with the humanitarian principles of neutrality, impartiality, and independence, host country policies also risked a depoliticisation of diasporic action in the name of neutrality:

"The humanitarian has actually killed everything else. We didn't
have a political voice, nobody organised anything anymore. Everyone
just rushed into the humanitarian one and then suddenly we had 40
humanitarian associations competing [...] Suddenly the
humanitarian had also got a bad taste. And the worst thing I found,
that's exactly what many donors said, we'll only give you money if
you stay absolutely politically neutral. This has led to activists who
were politically engaged suddenly acting neutrally just to get money.
And the money was not that much, 10 o00 euros or 5000 euros,
which can no nation keep alive. That means the price you paid was
very high" (I15, media activist, pre-conflict migration, June 2015).

As the last quote indicates, opportunities in the destination country further led to increasing competition for funds, power and influence and contributed to high discrepancies among the different diaspora organisations, in particular to the marginalisation of groups and initiatives that put emphasis on their political identity and action. The contributions of Syrian diaspora groups and other humanitarian actors to alleviate victims' hardships were certainly necessary efforts to tackle the inhumanity of war. At the same time, when the Syrian conflict was no longer framed as a political struggle of people against an authoritarian regime, but 
more and more as a security and humanitarian 'crisis', it drastically changed the civil society movement both inside Syria and in the diaspora. A Syrian activist recalls the changes in the Syrian civil society movement in a similar way:

"The civil society or community based in Syria most of them are
working on humanitarian because that's what's needed. Now looking
back, I think it wasn't the best. Political involvement shouldn't be
neglected. It was left for politicians who are old politicians, who form
coalitions and do nothing on the ground. I think it was one of the
reasons why the revolution lost its political youth power. I regret it, I
feel sorry that it turned, that we were driven by the escalation of
violence, by the need to help and support more than to try and do
something" (I78, gender activist, conflict migration, Berlin, June
2017).

Hence, through the narration of crisis an ahistorical and apolitical state of emergency was constructed, in which the focus of framing shifted from grievances to suffering, from rights to an obligation to care and from justice to survival, limiting the space for political diaspora mobilisation. Hence, some perceived that the humanitarisation of the diasporic space, in which diasporic actions became embedded in apolitical parameters of relieving the suffering, limited the transformative potential of diaspora political entrepreneurs to become actors of political change in their country of origin.

\subsection{Migrations - The transnationalisation of activism and the re- politicisation of the diasporic space}

As shown in Chapter 8, the escalation of the conflict in Syria not only caused massive displacement to its neighbouring countries and Europe but with this a transnationalisation of activism and resistance. From the beginning, the Syrian uprising was never a purely local struggle, but instead, as has been shown in the previous section, had always had a transnational dimension. Displacement amplified the transnational dimension of Syrian activism as many of those active in the movement inside the country had to seek refuge but continued their struggle for democracy and freedom from abroad, creating a transnational network of resistance. In contrast to the older generation, who more and more mobilised around a humanitarian narrative, the activism and organisational aims of many newcomers, were based on the broader values of the revolution that called for justice, freedom, equality and respect for human rights and dignity, and hence, for a re-politicisation of the space of diaspora mobilisation: 
"Our network had a very clear view and goals and identity. And we fight for that a lot, because the idea was that civil society should be neutral, totally neutral, which is silly, without any sense. We couldn't be neutral, we had a fight for that. We couldn't be neutral both inside and outside and that affected us in some way not to have support and funds from international organisation, because we are not neutral. But we insisted on that to concentrate on the member power, we can work voluntary just to keep, to protect our identity. We believe on the principles of the revolution freedom, dignity, equality" (I38, human rights lawyer and gender activist, conflict migration, Berlin, April 2016).

Displacement transformed the activism from locally lived experiences to long distant acts of resistance. Transnational activism aimed at creating:

1) a direct influence through cross-border diffusion of material and immaterial political resources, such as money, political tools, values or ideologies and initiatives seeking to promote empowerment of the local population inside Syria or,

2) indirect influence by raising awareness in the German public, by contesting the dominant representations of the figure of the refugee and the conflicts in the Middle East or by lobbying to influence German or international decision-making processes on the political cause.

At the same time, displacement also engendered new sites of contestation, as Syrian activists challenged the constructed figure of the refugee as embodiment of the other and agency-lessness by engaging in various acts of claiming rights, belonging and political participation in the destination country. Hence, the political lives of those forcibly displaced did not necessarily obey national boundaries. Instead, the struggle over the notion of belonging unfolded on multiple sites of contestation through which the boundaries of political communities were shaped and negotiated.

\subsubsection{Transnational activism}

Given that in the Syrian context, the political system left no-or at least very limited-room for formal participation, many respondents emphasised the importance of political empowerment of the Syrian population as well as the Syrian civil society and civic movements in bringing social and political change and transformation. Many initiatives aimed to support the peaceful movement inside Syria and to empower civil society actors on the ground by providing tools, 
knowledge and capacity-building initiatives. For instance, the organisation Impact, established in Germany by Syrian activists in 2013, aimed to build a broad base of social actors to raise awareness on the use of non-violence and to promote aspirations of freedom, dignity, civil participation and shared development. The organisation created a globally networked platform for civil society organisations, initiatives and activists to promote the development of an independent civil society in Syria and provides capacity development training for Syrian NGOs inside and outside the country. According to a member of this organisation:

"This can build responsibility, where we build political change
because these are the people on the ground and not just people from
the international community. Civil society even if it is not working
directly in the political system can build a base for society, can react,
act and criticise, can think and develop ideas and can participate and
get politically involved, if they have the skills" (I76, civil society
activist, conflict migration, Berlin, July 2017).

As another example, the organisation Doz was established in 2012 inside Syria but, due to the displacement of one of the founders, became transnational in nature. The main aim of Doz was to promote a peaceful and democratic transition of the country through the support of peace building and violence prevention activities, as well as the creation of social and political awareness. The organisation worked in four cities in Northern Syria and implemented activities in various sectors such as education, child protection and youth development, women protection and empowerment, bio-agriculture and food security as well as civil peace and awareness. DOZ is one of the first local CSO that initiated peace building campaigns since 2013, such as the annual week campaign 'Syria - Peace One Day'. Within the campaign public events were organised, bringing together various political parties, local CSOs and local communities to mitigate local intercommunal tensions in order to promote a culture of co-existence and tolerance among all Syrian community members and groups.

Another initiative by a loosely organised network of Syrian activists in Berlin, highlights the circularity of political remittance, in which political ideas and projects did not travel due to the migration of civil society actors but as a result of pre-established links with movements inside Syria. In response to the siege of cities that prevented the provision of food, local initiatives in Syria started to implement collective urban gardening projects in which vegetables were cultivated on rooftops, terraces and small fields in cobbled squares. The group in Berlin organised information campaigns and met with local farmers in Germany, to inform them about the situation of the people in besieged areas and the diverse acts of resistance by the civil society. The farmers where asked to donate seeds, 
which were then smuggled into the besieged areas and used in collective urban gardens. In the context of Syria, in which the starvation of civilians in besieged areas was used as a weapon of war, urban gardening not only ensured food sovereignty and self-reliance, but could be considered as important act of peaceful resistance. As local farmers in Germany became part of the network and continued to engage in acts of solidarity with the Syrian people, the direct diffusion of crossborder material support also had an indirect influence in mobilising the German public for the Syrian cause.

Besides exercising direct influence through the cross-border diffusion of material and immaterial political resources, Syrian activists sought to influence the political process indirectly by mobilising support among the broader German public and lobbying destination country and international actors to influence the decisionmaking process in the Syrian conflict. Every year vigils and demonstrations were organised at the anniversary of the Syrian revolution on $15^{\text {th }}$ of March in several German cities, to show solidarity with the Syrian people, to raise awareness on the existence of the peaceful resistance movement inside Syria and to call for international action to find a political solution to the conflict. For many, the protests also provided a space to express long-felt grievances and to relieve themselves collectively from feelings of suffering, despair and outrage. When in April 2016 the regime of Assad and its allies broke the ceasefire with indiscriminate bombardments of the city of Aleppo, Syrian activists launched a digital campaign that quickly spread via social media to stand in solidarity with Aleppo and the civilians still residing in the city. Individuals changed their Facebook profile pictures to a red box symbolising the bloodshed caused by the attacks and used the hashtag \#AleppoIsBurning on Twitter and Facebook posts to raise awareness on the atrocities that were afflicting the city. Eventually, the solidarity movement took to the streets in major cities across the globe, where activists organised demonstrations and protests to raise awareness on the destruction of the city and the killings and suffering of the civilians and to hold the international community accountable for its silence and inaction. According to the organisers around 3,000 people gathered in front of the Brandenburg Gate in Berlin, joining the international movement in solidarity with the civilians in Aleppo. The protests not only served as a form of resistance to oppression and persecution but also as a way to exert pressure on political decision-making by calling upon the international community to take action by stopping the air strikes and enforcing ceasefires across Syria.

Next to mobilisation that focused on raising awareness on the general grievances and injustices arising from the conflict among the broader German public, issuebased diaspora movements emerged that sought to connect individuals and 
transform their experience of suffering, trauma and despair into collective claims and action. For instance, Families for Freedom (www.syrianfamilies.org), a transnational women-led movement pleaded for the pursuit of justice and accountability for their family members who had become victims of enforced disappearance and arbitrary detention. The movement organised protests, vigils and campaigns to mobilise the public for their cause and lobbied destination country governments to put pressure on the Syrian regime, its allies and other armed groups responsible for the crimes. Among the main demands were calls for the release of detainees unlawfully kept in prison, the disclosure of the locations of the bodies of those executed or tortured to death and accountability of those who had committed the crimes. Next to exerting pressure on the destination country governments, the movement advocated at international political talks, such as the Geneva peace talks for putting the issues of enforced disappearance and arbitrary and unlawful detention on the agenda to ensure international recognition of its cause.

Similarly, some respondents had been engaged as civil society representatives in the Geneva peace talks to lobby at international level for an end to the conflict in Syria. For instance, members of the Syrian Women's Network were part of the Syrian Women's Advisory Board, which was initiated by Staffan de Mistura, the UN special envoy for the Syrian crisis, to allow civil society participation in the Geneva talks. The Syrian Women's Network aimed at lobbying for a commitment to ensure gender-sensitive peacebuilding and reconstruction as well as to enshrine the rights of women in Syria's future constitution. At the same time, many of the activists interviewed did not believe that the talks at international level would have a genuine political impact and saw the discussions as disconnected from the reality on the ground in Syria, evincing the limits of diaspora politics in influencing political processes.

To challenges the prevailing discourse in the German society and public debates, artistic and cultural productions such as theatre, exhibitions, music and films provided some respondents with an alternative space for political expression. For example, one respondent frequently organised art exhibitions and literature festivals to provide an opportunity for Syrian artists and writers in exile to present their work to a broader audience. These events gave artists a creative space to explore and express their identities, but also enabled them to provide alternative representations of the country of origin. Through their work, the artists often illustrated their troubling story of expulsion, flight and exile as well as their struggles for freedom, democracy and a better life in Syria. As such, arts and culture also provided a space and alternative channels for raising awareness on the situation and the suffering of the people inside Syria, as one respondent explains: 
"You feel responsibility. Because there are millions of people, they don't have a voice and you do make movies and you write, and you feel like you have audience to show these people and their voices. Because, these connections the links, you can't say I am over this country (I53, film maker and writer, conflict migration, Berlin July 2016).

In addition, media campaigns, lectures, demonstrations and protests, provided important tools and repertoires to re-contextualise the Syrian conflict and displacement and to embed them into the historical context. Through this, political activism also aimed to challenge the discourse of pity present in the current public debate about refugees, as well as the exclusion of European migration and refugee regimes:

"Our work could maybe give an input for people on changing the narrative on refugees. Many people saw refugees as people, who popped up in the Mediterranean. The story started to begin at the Mediterranean in boats, and that is how the whole story of refugees began. [...]. We started to dismantle that term refugee itself [...]. The majority of political movements, they see consciously or unconsciously that they have a moral responsibility towards what is happening. That's so messed up because morality doesn't count in the field of politics. Morality is nothings that you can talk about. Your responsibility is coming from your behaviour. The responsibly is the consequences of your individual behaviour. Because you all are taking the privileges of what your governments are doing. This is the kind of responsibility you have. It is the consequence. You get the burden of what is happening, because you get the privilege of it" (I73, musician and political activist, conflict migration, Berlin, June 2017).

By raising awareness on the globalised political contexts and root causes of the Syrian conflict and forced displacement, the political struggle for freedom, justice and democracy inside Syria became connected to the political struggle for human rights and against the marginalisation and discrimination of refugees in the destination country.

\subsubsection{Fostering spaces of civic and political empowerment}

Next to the transnationalisation of Syrian resistance to the continuous grievances in the home country, displacement also engendered new sites of contestation, as Syrian activists challenged the constructed figure of the refugee as embodiment of the other and agency-lessness through various acts of political participation, 
belonging and resistance in the destination country. Being involved socially, politically and culturally in German society was seen as an important aspect of inclusion and belonging, particularly since for many, a sustainable return in the near future or a cessation of conflict in their country of origin seemed unlikely. Respondents acknowledged and valued the freedom and space for political activism available in Germany as their host country:

\begin{abstract}
"You will not feel that you are really integrated or that you are powerful, unless you are involved in the local things happening here [...]. Being engaged here in Germany is very important because here are the tools, the freedoms to express yourself and freedoms of beliefs in general. This is an opportunity. I believe that being socially, politically active is very important. That was one of the main reasons for the revolution in Syria, and why I joined it" (I76, civil society activist, conflict migration, Berlin, June 2017).
\end{abstract}

Yet, many respondents also articulated a troubled relationship with the host country, in which the search for belonging was deeply interwoven with the search for acceptance. In that sense, belonging to the country of residence was not only influenced by one's identification with the place, but also by how far a person felt accepted by the broader society and context (Anthias, 2006). As Antonisch (2010) claims "every politics of belonging involves two opposite sides: the side that claims belonging and the side that has the power of 'granting' belonging'" (p. 650). For most, the dominant representations of 'the refugee' as well as the historical construction of migration and citizenship in Germany represented the major challenge for political participation and inclusion in the destination country, as these tend to produce the newcomers as voiceless, agency-less and non-legitimate part of society:

"Labelling someone as a refugee is a problem because whatever you do, you will not feel you belong in the society as a normal person" (I78, gender activist, conflict migration, Berlin, June 2017).

As El-Tayeb (2016) notes, the current discussions and policy responses around the so-called 'refugee crisis' are by no means a new phenomenon, but instead are deeply entrenched in the historical constructions of migration, race and nationality in Germany. She argues that the restrictiveness of Germany's citizenship regime, in which citizenship is historically granted on the basis of descent, tends to build on an ethno-cultural understanding of the nation-state which constructs the migrants as eternal strangers. Interestingly, the construction of the migrant and refugee as embodiment of the other results in a state in which identities were not only ascribed by the majority society but also became more salient and politicised: 
"In Germany for example they are trying to make these kinds of categories or stereotypes against the Arabs, and against the North Africans, and against the Middle East, against the Syrians, against all refugees. So, you will find yourself in many categories, so you find yourself as an immigrant, or refugee, and Arab, and Middle Eastern person, and Syrian and Palestinian - stateless. So, who are you? And if you want to do something, I should talk to all these people to create a big voice, a loud voice or big movement just to make the conditions better" (I49, writer, conflict migration, Cologne May 2016).

Participation in the destination country was therefore characterised by a situation of ambivalence in which the neglect of belonging that constructed the refugee or migrant as the eternal other and the enacting of belonging through active forms of resistance took place simultaneously. Herein, activism in the form of demonstrations, protests and other forms of collective action and contentious politics can be seen as important acts of claiming rights, citizenship and belonging. These political practices often sought to mobilise refugees and asylum seekers from diverse origins to collectively challenge discrimination and injustice present in the German refugee and asylum regime:

"The Syrian community is small and infant, they can give up and say let them do whatever. We are trying to tell them: you can demand your rights and trying to be active in changing the whole perspective on refugees and new arrivals. Not just show it as a question of pity, but as a question of people who still have rights [...] So we are trying to create something and integrate ourselves as Syrians into the already existence movements of refugees, immigrants and Germans who are anti racists. We are trying to connect it to the cause that made us refugees and the cause of our existence as refugees" (I73, musician and political activist, conflict migration, Berlin, June 2017).

For instance, for 54 days around 100 asylum seekers organised a protest camp in front of the BAMF building in Dortmund in 2015, demanding the repeal of the Dublin regulation, faster processing of asylum applications, facilitated conditions for family reunification, German language courses and facilitated access to work and higher education for all asylum seekers. According to an respondent, who was one of the organisers of the camp, the movement was an important way to put pressure on local authorities to improve the living conditions of asylum seekers and to raise awareness among the wider German public for their situation. Collective mobilisation and contentious action were often also trigged by critical events in the host country. For instance, in response to the mass sexual assaults on New Year's Eve in Cologne in 2015/2016, Syrians in Germany such as the group 
Syrians Against Sexism organised protests in various German cities, distributed flowers and initiated media campaigns to show solidarity with the victims of the incidents. By setting a clear sign against sexism and sexualised violence, the initiative sought to challenge the dominant media representation of the 'misogynistic refugee', which increasingly dominated the public and media debates.

In addition, initiatives emerged to promote the civic and political empowerment of Syrian newcomers and to ensure their political representation at the local, national or international levels to provide meaningful ways of expressing the challenges faced by refugees and asylum seekers and to make their voices heard in political decision-making. For instance, the Syrian-led initiative Diaspora Network Alliance (DNA), a network of 40 members based across Europe, aims at addressing the lack of avenues for political participation and representation of refugees in European democracies. By bringing together refugees, politicians from various levels of the decision-making processes, European experts and local populations, the project G100 seeks to create a participatory space for discussions, dialogue and exchange on the challenges and opportunities refugees face in their locations across Europe. Events have and continue to be held in different European cities, such as Amsterdam, Brussels and Berlin, in which topics selected by newcomers are discussed with other stakeholders to generate concrete solutions and recommendations to make the refugees' voices heard in decision-making processes. Their Global Summit of Refugees held in Geneva in June 2018 by refugee and migrant-led initiatives from diverse countries of origin aimed at creating a platform for influencing decision-making at global level.

Another example is the Young Leaders for Syria project, jointly implemented by Citizen Diplomats for Syria, Friedenskreis Syrien and the European Foundation for Democracy. Acknowledging the transnational experience, the project aims to build the capacity for political and social transformation in Syria by developing the individual capacity of young Syrians from diverse backgrounds who have come to Germany since 2011. In a range of workshops, participants discuss topics such as identity, sectarianism, conflict narratives and conflict resolution. The main goal of this project is to develop a basis for democratic and inclusive development among the population of young Syrians in Germany. In addition, the objective is to promote participation and integration into the local community in Germany through civic education and professional capacity building.

In the case of the respondents of this study, the Syrian revolution led to shifting configurations of power and as such to a redefined relationship between the government and the people, thus paving the way for alternative imaginations of the nation, citizenship and what it means to belong in Syria. Mobility led to a 
redefinition of the political space, which was no longer bounded to the territory of the state but instead unfolded in the transnational realm. Through displacement the initially local struggle for democracy and freedom inside Syria became transnational in nature, as activists continued their non-violent resistance to the Syrian regime and other actors of the conflict from various locations across the globe. In addition, grassroots activism also transformed the political space of the host country, since politically, culturally and socially constructed borders were contested through acts of claiming rights, political participation and belonging. By challenging the discourse of pity and exclusion present in the prevailing refugee debate, political activism served as a way to highlight the complexity and diversity of refugees' experiences. Thus, the experiences and conditions of displacement and exile led to several sites of contestations, in which the dominant construction of victimhood and passivity was challenged through various acts of participation and resistance, which connected the political struggle for human rights and against marginalisation and discrimination in the host country with the geopolitical root causes of their displacement.

\subsection{Displacement - A Syrian community in the making}

While Germany was already the main destination country for Syrian immigrants in Europe prior to the conflict, since the Europeanisation of the Syrian displacement crisis, the Federal Republic has developed into the most receptive country for Syrians seeking protection in Europe. Since 2014, Syria has ranked first among the 10 main countries of origin of asylum seekers and, the population of Syrians now at 770,000, represents the third largest group of people with foreign citizenship living in Germany in 2018 (Statistisches Bundesamt, 2019b). The large-scale Syrian displacement can be considered as a transformative event in the diaspora mobilisation process in Germany that not only engendered an increase and diversification of diasporic mobilising structures, but also shaped and transformed diasporic practices. While initially the actions of the organisations established by those who migrated prior to the outbreak of the conflict were oriented towards the homeland, the increasing numbers of Syrians arriving in Germany sparked a diaspora response by the older generation to assist the newcomers in their reception and integrational process. In addition, the last years have also witnessed self-organising of newcomers, since organisations have been established also by Syrians who migrated after the outbreak of the crisis, with the aim to support each other in settling down in Germany, to strengthen a feeling of community and belonging and to claims rights and political inclusion in Germany.

Next to fostering a space for civic and political empowerment, as outlined in the previous section, engagement in the destination country context aimed at offering 
a diverse range of services to facilitate the arrival of newcomers and their social and economic inclusion into the German society. Recent years also witnessed the emergence of cultural organisations that seek to maintain and cultivate the Syrian identity in order to provide a safe place of community and belonging to those forcibly displaced by the conflict.

\subsubsection{Fostering the inclusion of newcomers}

Realising the increasing needs of those seeking protection in Germany to secure their livelihood, to ensure their basic needs and to build a stable life in the new environment, Syrian diaspora political entrepreneurs responded with countless acts of individual and collective solidarity. As one respondent puts it:

\section{"It is not easy to plant a grown tree into a strange place, without support it doesn't work" (I62, representative of a humanitarian organisation, pre-conflict migration, Berlin November 2016).}

At an individual level, Syrian diaspora actors provided financial and practical support to close family members and friends. In the collective sphere, Syrian diaspora organisations served as a trusted point of contact for newcomers and facilitated their first orientation in the new 'home' and promoted their inclusion in the labour market, education and society through collective action and integration initiatives.

In the years 2015 and 2016 much of the support happened informally and ad-hoc, characterised by everyday acts of solidarity and organised via personal contacts and social media platforms such as Facebook and WhatsApp. Many initiatives started to offer advisory service for those newly arrived in Germany. Activities ranged from assistance with government agencies and doctors' visits, organisation of information events on asylum procedures, and provision of legal advice and psycho-social support. Moreover, some organisations offered German language and orientation courses. Next to the support for refugees in their daily life, some initiatives focused on the professional integration of Syrian refugees into the labour market. For instance, the organisation Alkawakibi advised around 450 Syrian doctors with a refugee background on questions regarding certifications and the recognition of diplomas. In their mentoring programme, doctors volunteered to provide support for Syrian doctors in building their career in Germany. Due to the success of this initiative, the focus of the project expanded to the professional integration of Syrian refugees with a background in engineering. The Union of Syrian Students and Academics (Union der Syrischen Studenten und Akademiker, USSA) advised Syrian students on questions regarding their studies and recognition of diplomas and established an extended network of professionals, 
students and academics with a Syrian background, to exchange their knowledge and experiences.

While initially support offered to the newcomers was more of an add-on to the activities directed towards the homeland, over the last years, practices implemented in the destination country became more formalised and institutionalised. For instance, in the project 'From Almanya to Germany (Von Almanya nach Deutschland)' financed by the German Federal Ministry of the Interior, Building and Community (BMI), selected member organisations of the VDSH organised intercultural seminars in Arabic for refugees in different federal states of Germany. Next to facilitating language acquisition, the initiative aimed to provide cultural and social orientation to assist the integrational process of those newly arrived in Germany. In seminars, newcomers were given information on various topics, ranging from political education about rights and duties of citizens in Germany, the German labour market and rights as an employee, to issues of child education and support services for parents. Another component was to strengthen the networks and position of member organisations to enable them to become an integral part of the integration scene in their local communities.

As another example, a project implemented by DSV in cooperation with the Office for Intercultural and International Affairs of the City of Darmstadt aimed at promoting the participation and visibility of Syrian refugees and migrants in the cultural, social, political and professional spheres of the host society. Besides, the project sought to strengthen the intercultural competences of citizens, in particular, public service workers, actors of health and education institutions and employees of refugee accommodation centres. To realise this, the project concentrated on four fields of action: health (especially psychological aspects of working with traumatised people), education, work and social integration, as well as awarenessraising on the conditions of refugees and asylum seekers among the broader German public. The main measures of the project were information events and the provision of migration-specific counselling services as well as the development of viable action concepts to promote the socio-political participation of migrants in the destination country.

The last two examples also illustrate how the shift of transnational practices was not only a response to the increasing numbers of Syrians seeking protection in Germany but also driven by financial opportunities arising from the changing realities in the destination country context. At an early stage of the diaspora mobilisation process, support for Syrian diaspora organisations was initially offered by German public authorities active in foreign relations and development cooperation, such as GIZ and the Foreign Office. However, with rising numbers of 
Syrian seeking protection other agents, such as the Ministry of Interior, the Federal Office for Migration and Refugees, as well as local authorities saw the potential to leverage the contribution of the diaspora to foster the inclusion of newcomers. Increasingly, these actors engaged with Syrian diaspora actors and offered financial resources to enhance the capacity of Syrian diaspora organisations in their integrational work. For instance, during a conference on Syrian diaspora mobilisation in Europe on November 2017, one representative of a Syrian diaspora organisation in Germany reflected critically on the findings presented. He argued that, it was true, that humanitarian aid took the most significant share regarding the fields of engagement of Syrian diaspora organisations in Germany at that time. Yet, he perceived that donors increasingly pulled his organisation towards action in the area of integration.

For others, the devastating situation inside Syria was a motivation to shift their action away from the home country contexts towards practices in the destination country. Realising that from a distance, one has limited influence on the situation inside Syria, supporting the newcomers in their integration into the new society was perceived as a much more valuable contribution, as the following quote illustrates:
"So, as I said this resignation that you can't achieve much locally [inside Syria] And I had the feeling that what I did for Syria from here was a drop in the ocean and the results you didn't see either. So, you worked, you worked, and then it went up in that endless net or something. You didn't exactly see the fruits of your voluntary work. And that's exactly what you can see here if you help on the spot. So, you see the change you achieve concretely in everyday life" (I24, media activist, pre-conflict migration, Bremen, January 2016).

The very feeling of achieving change through one's action, hence, motivated many to continue their engagement, even if it meant turning away from homeland issues, towards the support of co-nationals in the destination country. Yet, as Cho argues 'diasporic subjects emerge in turning, turning back upon those markers of the selfhomeland, memory, loss-even as they turn on or away from them' (p. 15). Shrinking access and space of influence in the origin country in the future may further amplify the shift.

\subsubsection{Impossibilities of return, lost homeland and the desire for a stable place of belonging and community}

The increasing length of stay and progressing inclusion into the host society coupled with an increasing realisation that return will not be a feasible option in 
the near future, the experience of displacement for many shifted from a temporary phenomenon to a permanent condition. As the conflict entered its eighth year in March 2019, many observers argued that Assad has effectively won the Syrian war and will most likely remain in power. The notion is increasingly present in the public and political discourse that the Syrian conflict is ending and that the Syrian regime presents itself as not only the victor of the conflict but also as the legitimate representative of the Syrian people and the force that will ensure security and stability in the country and the region (Hassan, 2018; Griffing, 2018; Behravesh, 2018).

In particular, Syrians who have been politically active in the oppositional movement find themselves in forced exile, with no possibility to return under the current regime because of the fear of persecution and defamation by the government and its security apparatus. But even in the cases in which displacement was not motivated by political persecution, the normalisation of the Assad regime in international relations poses crucial barriers for safe and sustainable return. The dynamics of the Syrian conflict have deepened the divisions in the society along religious, sectarian, and ethnic lines. Some Syrian refugees in Germany might fear collective punishment, due to the fact that they are ascribed to belong to a certain ethnic or religious group. Further, the regime discourse tends to categorise the refugees either in wanted or unwanted returnees, Assad sympathisers, who showed loyalty to the current regime, and those unwanted returnees who are either labelled as traitors, terrorists and security threats or as socially, culturally and economically posing a burden to the progress and reconstruction of the country of origin (Batrawi \& Uzelac, 2018). For instance, in a conference in Damascus in 2017 the Syrian president claimed that while the consequences of the conflict have been immense, the country now benefits from a 'healthier' and 'more homogeneous' society (SANA), 2017).

Next to safety and security, the limited prospects of ensuring a decent livelihood in Syria, due the challenging economic conditions, along with limited access to homes, infrastructure, basic services, education and health provision further limit the aspiration for return (Vignal, 2018). This might be particularly relevant in the case of families, who have sent their children to school and have established a more stable life in Germany. In this case, aspiration for return might be balanced by opportunities present in the host country, when compared to the challenging conditions in the country of origin. As a result, for many the notion of the homeland and belonging embraced multiple yet often conflicting meanings. In exile, the nostalgia for a mystic and romanticised, yet lost and distant place resulted in a feeling of homelessness and a deeply entrenched longing to belong: 
"I miss a lot of things in Syria, simple things, very simple. I miss the life, the wall of the old city. I used to live in a very special place, Damascus. It has very good historical feeling and atmosphere. I miss the way how to buy food, I miss my neighbour, my house with a lot of plants. But now I am staying in one room, it is hard, it completely changed. Even if I get rich here, I will not be happy, my heart is there, and my soul is there. But if you ask me, would you like to go back I'd say no I would not come back, even with my heart and my soul there. Because Syria is not like before anymore, this is the problem. It is not same soul, not the same atmosphere it's not the same people, completely everything changed" (I37, representative of a culturalsocial organisation, conflict migration, Berlin, April 2016).

Feelings of exclusion, discrimination and non-acceptance compounded by the assimilationist discourses felt present in the media and public debate, in some cases further reinforced the longing for the homeland:

"Now this is salvation somehow, going back to Syria is salvation. I can't live in this racist community forever, even if I speak German perfectly someone will ask me where am from because I look different" (I32, musician and political activist, conflict migration, Berlin, March 2016).

As a result, the need was increasingly perceived to establish a safe space for belonging and community for Syrians in Germany, in which identities could be expressed and the heritage, traditions, customs and the culture of the origin country could be cultivated. As mentioned earlier, the last years have witnessed the establishment of integration and cultural organisations that seek to promote community building. On a regular basis, religious or cultural events, family gatherings and meetings have been organised to support and strengthen the relationships between newly arrived refugees from Syria. There was a particular desire to transmit a Syrian identity to future generations. In this regard, significant efforts have been made to teach younger generations of Syrians in Germany about their origin and about the Syrian history. Many respondents saw integration as a two-way process meaning that it is as much about the way in which destination countries receive migrants and refugees as much as what migrants and refugees contribute to a new setting. Cultural events promoting dialogue between locals and refugees, as well as information events fostering an understanding about the root causes of forced displacement in the context of Syria were frequently organised. One important aim was also to change the perceptions of integration and to show that those who newly arrived in Germany were also bringing 
important resources with them and could successfully contribute to the German society.

While some organisations focused on specific ethnic or religious groups within the Syrian displaced population in Germany, others sought to create a politically, ethnically and denominationally neutral forum of encounter in order to promote dialogue, exchange and understanding between the different segments of the Syrian society. In that sense, building and mobilising around a unified collective Syrian identity, was not only seen as crucial to address the social and cultural divides present in the Syrian society, both at home and abroad, but also seen as necessary to promote collective action among the broader Syrian immigrant population:

\begin{abstract}
"Before we speak economic, education and political process we need to solve the problem, which is the identity. We don't know us and who we are anymore. We needed a safe place for discussion, we needed to define a positive identity based on participation and democratic values. We need to learn the democratic process in a systematic way. We need to learn what civil society is" (I71, representative of a civil society organisation, conflict migration, Skype, July 2017).
\end{abstract}

For instance, the project 'Young leaders for Syria', jointly implemented by Citizens Diplomats for Syria, Friedenskreis Syrien and The European Foundation for Democracy, aims at building capacity for political and social transformation in Syria. The project targets young Syrians with diverse backgrounds who came to Germany since 2011. In a range of workshops, participants discuss topics such as identities, sectarianism, conflict narratives and conflict resolution. The main aim of this project is to develop capacities for a democratic and inclusive development basis within the young Syrian population in Germany. In addition, the objective is to promote participation and integration into the local community through civil education and professional/capacity building.

Alkawakibi organises monthly dialogue forums and panel discussions, in which topics such as democratic transitions in the Arab world, cohabitation of Muslims and Christians, or islamophobia are discussed, with the broader aim to promote democratic education and the dissemination of respect for human rights. Moreover, the organisation created a WhatsApp group, which has around 170 members with diverse backgrounds, like atheists, Christians, Muslims, Alawites and Kurds, to encourage dialogue on a more regular basis. In Hannover, a member of the Syrian Women's Network organises meetings for Syrian refugees with different backgrounds, creating a place of encounter for people to meet and exchange experiences and ideas. While initially, the aim was to bring Syrian 
refugees together on a social basis, the initiative now also discuss more sensitive political issues. Being in Germany far away from the conflict may also enable more critical reflection of the conflict narratives, promote a free space for exchange and enable Syrians to overcome religious and ethnic divides.

The aim of the initiative Women for Common Spaces is to empower exiled women, by making them aware of their rights through sharing knowledge on the political system and laws in Germany. In addition, the focus lies on the creation of interactive opportunities for participation and dialogue, by building a common space on different levels: first between the exiled women themselves, then between them and their families, and finally between the women and the local population in Berlin. In workshops, women are provided with a safe space for free expression, in which they can articulate and share their stories and challenges to collectively find solutions. One of the results of the project are the collections of texts 'Female Voices in Exile', in which women share and voice the experiences of war, repression and displacement, marked by grief, anger and despair, as well as by stories of hope, desires, dreams and happiness. According to the initiator:

\section{"Female Voices in Exile is an attempt to put an end to the time of isolation that is wearing us down and to recover the ruins of collapsed humanity. An attempt to whisper stories into the ears of the world" (Women for Common Spaces, 201, p.4).}

Hence, it can be argued that the decreasing space of influence in the homeland and limited prospects for sustainable return, coupled with feelings of exclusion and marginalisation in the destination country, fostered the desire to engage in diaspora politics aimed at building safe spaces for belonging and community. Thus, if diaspora political entrepreneurs perceive themselves on the losing side, they are maybe less willing to engage in state-rebuilding and reconstruction and indeed might cultivate their own alternative imaginations of national community (Van Hear \& Cohen, 2017).

\subsection{Conclusion}

As has been shown, the trajectories of diaspora practices have been a product of internal dynamics, rendering on the micro-realm of personal experiences, aspirations or desires, or externally driven as a result of changing opportunities and constraints in the host or home country settings. As such, transnational political subjectivities, identities and practices are not given but emerge and evolve in a relational space, in which sending and receiving country dynamics intersect and mutually affect each other. For instance, Koopmans (2004) argued that if migrants face a restrictive space in the destination country due to limited access to 
citizenship and political institutions and/or an unfavourable public discourse, mobilisation efforts may turn towards political issues related to the origin country. The findings of this study indicates that the opposite might be true as well, as with vanishing hopes for sustainable return, coupled with decreasing access and space of influence present in the home country, diaspora actions turned towards practices that sought to influence their position and influence with regard to the destination country.

Next to these contextual insights, the findings also contribute to a deeper understanding of the temporal dimension of diaspora mobilisation by showing that diaspora mobilisation might be sparked by developments and transformative events in the country of origin and result in actions that seek to influence the political processes in the homeland. If diaspora mobilisation, as stated before, can be considered as a form of civic engagement in the country of destination, over time diaspora actors may become more embedded in the local civil society structures and networks which enable or motivate them to pursue political actions oriented towards the country of settlement (Quinsaat, 2019).

It can be argued that diaspora politics not only contribute to political processes in the country of origin but also transform the political space of the host country, since politically, culturally and socially constructed boundaries were contested through acts of claiming rights and belonging in the German context. As has been shown, when people migrate, political ideas, values, projects and practices travel with them. These are further shaped by migrants' encounters in their host society, which also influence what they re-remit back home. The circularity of social, political and cultural remittances puts emphasis on the dynamic process of transnational transfers and moves away from a unidirectional understanding of flows from destination to origin context (Levitt \& Lamba-Nieves, 2011). 



\section{Chapter 10: Conclusion}

The last decades have witnessed a rising interest in studying the nexus between diasporas and conflict, since diaspora groups are increasingly recognised as important agents in the international political arena. By now, it is well established that diaspora mobilisation can have both intended and unintended as well as negative and positive impacts on conflict and the origin country's development. Recent research on the diaspora conflict nexus has moved away from an impactoriented analysis towards dealing with diaspora mobilisation as a process. Rather than treating diaspora as the independent variable, it is approached as the dependent variable, by investigating how the process of diaspora mobilisation is influenced by the transnational political opportunity structure, i.e. factors in the destination, origin and transnational context. It is therefore necessary to understand the various configurations in place that shape the nexus between diaspora mobilisation and conflicts both in the origin and destination countries. This dissertation seeks to shed light on the underlying factors and their intersections that shape the trajectories of the complex process of diaspora mobilisation in conflict-settings. This final chapter will provide a summary of the main findings of the study and elaborate on the contribution to the debate, by testing the developed conceptual framework. It will then derive some policy recommendations for a conflict- and context-sensitive as well as for a participatory approach in engaging with diaspora groups. The chapter will conclude by highlighting some avenues for further research.

\subsection{Summary of the thesis}

The objective of this dissertation is to unpack the diverse processes and mechanisms that shaped the emergence and trajectories of Syrian diaspora mobilisation in Germany over the course of the Syrian conflict. In doing so, this study seeks to contribute to a gap in research, as it sheds light on the temporal dimensions of the mobilisation process. In addition, by putting the emphasis on the opportunity structures both in the country of origin as well as in the country destination, the study explores the relational space of mobilisation, in which sending and receiving country dynamics intersect and mutually affect each other, as well as the strategic choices of diaspora political entrepreneurs made in response to them. As a result, the primary research question guiding the study is: How does the interplay of individual characteristics, group dynamics and the transnational political opportunity structure shape the trajectories of Syrian diaspora mobilisation in Germany? 
The central argument of this dissertation is that diaspora mobilisation should be understood as a dynamic process in which structures and diaspora agents coconstruct each other. While political opportunity structures do provide opportunities and constraints in the process of mobilisation, diaspora actors show considerable agency in shaping the transnational political reality, by transforming political spaces both in the contexts of origin and destination. This dissertation, therefore, not only investigates the structural conditions of mobilisation, but also sheds light on the diverse contributions of Syrian diaspora actors to the transformation of conflicts in different locations, be they in the country of origin, the places they live in, or within the broader diasporic space.

As developed in Chapter 2, this research understands diaspora mobilisation as a process in which collective action and practices can be either homeland-oriented to influence political processes in the country of origin, hostland-oriented in which civic or political practices address the context of destination or hybrid in which these actions may intersect and happen simultaneously. These include collective actions that do not constitute political action in a narrow sense, but nevertheless influence political processes more indirectly, such as activities related to humanitarian aid and the development of the country of origin. Hence, by analysing diaspora contributions directed towards both the home and the host countries, the research sheds light on the embeddedness and interlinkages of diaspora politics, how sending and receiving country dynamics may intersect and mutually affect each other and how mobility transforms political spaces in several places.

Further, the research makes use of multi-level analysis to examine the interconnectivity and interaction of different factors at the micro and macro levels and to investigate how these shapes the trajectories of the diaspora mobilisation process (mesolevel analysis). The micro level analysis explores the process of how conflict might lead to the emergence of diaspora mobilisation, by focusing on the micro-realm of identity constructions, and the process and politics of belonging through which collective identities become politicised in conflict-settings. The macro level analysis examines the role of transnational political opportunities and the transnational structural embeddedness of human experiences, and how factors in the homeland, destination country and international sphere can provide opportunities and constraints for the mobilisation process. The meso-level of diaspora mobilisation has been structured along three dimensions:

1) the construction of diasporic consciousness which forms the basis for mobilisation based on a shared imagined community, 
2) the organisational framework and mobilising structures, through which the community is constructed and mobilised, and

3) the transnational actions and practices through which diaspora groups seek to pursue the achievement of collective goals.

Acknowledging the agency of diaspora actors, the study puts emphasis on the process of how diaspora actors actively negotiate the transnational political opportunity structures at individual and collective levels.

Given that diaspora mobilisation is considered as a process of social construction and as contextual, an explorative qualitative case study approach was best suited for this research. Selecting the Syrian diaspora as a case for the use of the conceptual framework enabled an investigation of the dynamics and trajectories of diaspora mobilisation in real time. In order to contextualise the analysis and to explore the socio-political space of Syrian diaspora mobilisation in Germany, a detailed mapping of the origin country and destination country context was conducted. The study then moved to the empirical analysis of the mechanisms shaping Syrian diaspora mobilisation in Germany over the course of the conflict. As such, it explored the events and developments that triggered Syrian transnational mobilisation in Germany, as well as the evolution and trajectories of the construction and reconstruction of a diasporic consciousness, the mobilising structures and the transnational practices.

Exploring the historical origins of Syrian state-diaspora relations, the study highlighted how repressive long-distance policies of the Syrian regime directly prevented any form of transnational political mobilisation of Syrian diaspora groups in Germany, by forcibly oppressing any attempts that challenged the regime from abroad. In addition, various measures of long-distance surveillance engendered mistrust and fear among the Syrian society at home and abroad. This limited the ability to generate and maintain a collective identity and formed one of the major stumbling blocks for collective mobilisation. As the long-distance policies influenced the individual sense of belonging and dis-belonging among members of the Syrian diaspora, these also acted indirectly towards Syrian diaspora mobilisation in Germany. As a result, the lack of national belonging negatively influenced the willingness to engage in a diasporic project. Yet, the Syrian revolution led to shifting configurations of power and as such to a redefined relationship between the government and the people, thus paving the way for alternative imaginations of the nation, citizenship and what it means to belong to Syria, both at home and abroad. As a transformative event, the Syrian revolution, hence, marked the emergence of Syrian diaspora mobilisation in Germany, since, as a moment of unification, it sparked collective action based on a shared diaspora 
consciousness among those who positioned themselves in opposition to the government. As such a transnational imagined community was constructed, which not only transcended the physical borders of the nation, but was also able to manifest itself based on the dichotomy of 'us' and 'them', 'us' the people and 'them' the members of the Assad regime, promoting salience of the Syrian collective identity abroad. Through 'transnationalism from below' Syrian diaspora groups were also able to produce, transform and challenges political spaces across borders.

However, the revolution in 2011 as a unifying event was, for many, perceived as a short-lived moment and with the escalation of the conflict, competing and sometimes conflicting imaginations of the transnational community evolved. Hence, while earlier accounts on the Syrian diasporic consciousness emphasised a sense of unity, trust, and community, with the escalation of the conflict the notion of fragmented solidarity gained more and more importance. The findings indicate that the conflict dynamics were also reproduced in the diaspora mobilisation, as arising fragmentations to certain degree mirrored the economic, social, cultural and political divisions present in the homeland. In addition, internal power struggles present in the process of diaspora political mobilisation, as well as destination country developments and policies to a certain extent also exacerbated the dynamics of fragmentation and divisions within the process of Syrian diaspora mobilisation in Germany. Yet, the different social, cultural and political divides were not necessarily based on deeply entrenched and radicalised ideologies. Instead, a strong desire for peace and reconciliation was present among the different actors involved in the mobilisation process, who countered the process of fragmentation with a diverse range of collective action.

The fragmentations present in the oppositional political movement prevented the establishment of an ideologically unified body, able to encompass the different political, societal and confessional groups of the Syrian diaspora. Instead, the evolution of the mobilising structures suggests that the process of Syrian diaspora mobilisation is constantly in the making. Different events and factors both in the home and host countries, such as the outbreak of the revolution, the violent escalation of the conflict, as well as increased displacement to Germany, shaped the nature and characteristics of Syrian diaspora actors at different points in time. As a result, the mobilising structures were characterised by a diverse set of actors, who sometimes aligned and sometimes competed in the discursive production of the transnational community. In addition, it has been shown that with migrating people, also political ideas, projects and initiatives travel with them, leading to a diversification of mobilising structures. As a result, a mobility lens that acknowledges the circularity of social, political and cultural processes can enable a 
more dynamic analysis that moves beyond a unidirectional understanding of flows from the destination to the origin context.

The evolution of mobilising structures is also reflected in the trajectories of transnational practices. Over the course of the conflict, Syrian diaspora political entrepreneurs responded to an urgent need, be it to originally support the nonviolent movement inside Syria, to alleviate suffering through humanitarian aid as the conflict escalated, or to support those who recently arrived in Germany. While initially diaspora mobilisation was political in nature, the escalation of the conflict resulted in an increasing humanitarian response to the crisis. The humanitarisation of diasporic practices, in which diasporic actions became embedded in apolitical parameters of relieving the suffering, to a certain extent, has limited the transformative potential of diaspora political entrepreneurs to become actors of political change in the country of origin. The changing set of diaspora actors resulting from displacement, however led to a re-politicisation of the space of diaspora mobilisation as some of the protagonists of the Syrian revolution who sought refuge in Germany continued their struggle for democracy and freedom from abroad. As their activism, in many cases, was not only directed towards the homeland, but also consisted of various acts of claiming rights, belonging and political participation Germany, diaspora mobilisation also transformed the political space in in the destination country. With increasing length of stay and progressing inclusion into the host society coupled with an increasing realisation that return would not be a feasible option in the near future, the experience of displacement for many shifted from a temporary phenomenon to a permanent condition. As a result, recent years also witnessed the emergence of cultural organisations that seek to maintain and cultivate the Syrian identity in order to provide a safe place of community and belonging to those forcibly displaced by the conflict. Shrinking access and space of influence in the origin country further amplified the shift from actions oriented towards the home countries towards civic or political practices that address the context of destination.

It can be argued that the trajectories and pathways of Syrian diaspora mobilisation are shaped by the transnational political opportunity structures, as well as the internal social political dynamics present in the mobilisation process. Acknowledging the agency of diaspora actors, the study showed how the effects of the transnational political opportunity structure are individually and collectively challenged and negotiated. In addition, it shed light on the diverse contributions of Syrian diaspora actors to the transformation of conflicts in different locations, whether in the country of origin, the places they live in, or within the broader diaspora space. 


\subsection{Contribution to the debate}

After summarising the main academic findings of this dissertation, the following section outlines some of the most relevant implications with regard to the developed theoretical framework and as such highlights the different contribution of this study to the academic debate on the nexus of diaspora mobilisation and conflicts.

\section{Figure 16: Conceptual framework revised}

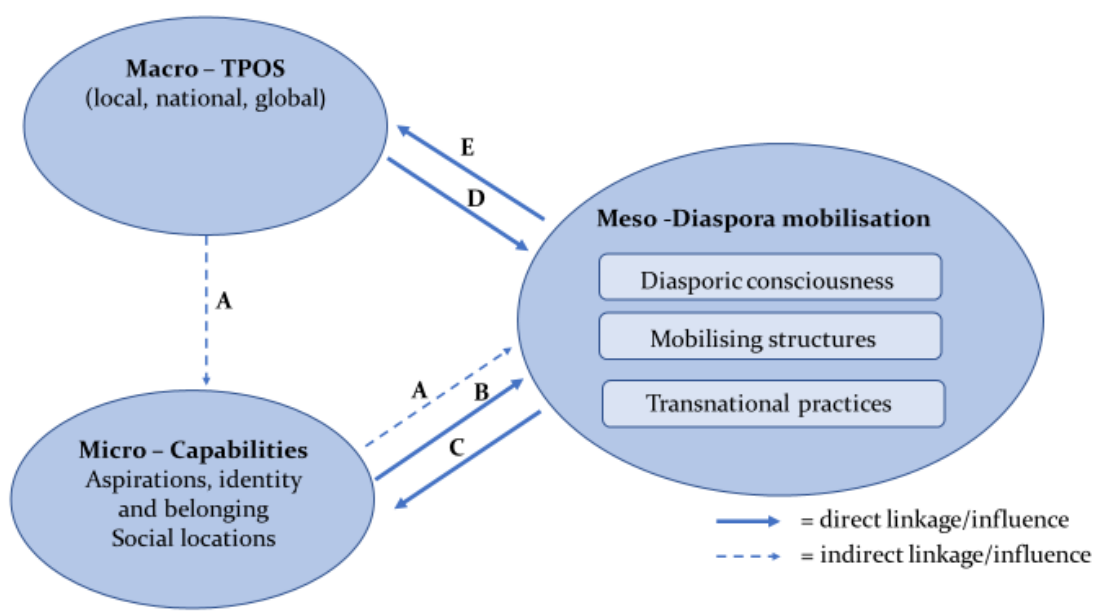

As has been shown throughout the study, transnational political opportunities structures influence the process of diaspora mobilisation not only directly, but also through indirect linkages (A), as these shape the micro-realm of interpretations, negotiation of meanings and construction of identities. In general, negotiations of home and belonging tend to be complex and fluid, influenced by factors, conditions and events in the home and destination country contexts. Conflicts and crisis can lead to a politicisation of identities, reinforce belonging and activate people to take action to shape the origin country's future. In addition, the escalation of a conflict and the resulting suffering of co-nationals in the home country may further reinforce a moral obligation and feelings of a political responsibility to act. At the same time, a protracted nature of conflicts may lead to despair, frustration, resignation and in action, and can result in a demobilisation of the diasporic consciousness, in which the initially politicised identity becomes latent and depoliticised. In this regard, the feeling of self-efficacy, the belief that one can make a change through his or her action, has been identified as another 
crucial aspect influencing diaspora mobilisation at the individual level. Individuals may counter and negotiate negative feelings, such as resignation and despair, through a deliberated change in their engagement that enables them to regain a feeling of empowerment and self-effectiveness.

Conflict dynamics might shape the process of diaspora mobilisation indirectly, as they can influence which aspect of an individual's social location or identity marker becomes politicised. For instance, the Syrian revolution initially sparked the construction of a national Syrian diaspora consciousness that transcended ethnic or religious boundaries. Yet, as the conflict escalated, religious belonging as well as ethnic and linguistic distinctiveness not only arose as important aspects of self-identification, but also became more salient and politicised. These also influenced the socio-political dynamics of the diaspora mobilisation process, engendering fragmentations that to a certain extent mirrored the cultural, economic, social and political divisions present in the Syrian context.

Further, political opportunity structures of the destination country may manifest uneven patterns of transnational engagement, since members of diasporas face different social, economic and political circumstances and conditions in the destination country that influence the capacity of individuals to get involved. For instance, whereas permanent residence status enables migrants to enjoy similar social, economic and political rights as citizens, temporary or undocumented migrants often suffer from restriction or even exclusion of rights, leading to a stratified system of socio-legal entitlement for the migrant population (Ruhs, 2010). This study, however, has shown that Syrian diaspora mobilisation was not only undertaken by members of the older generation, most of whom had secured a legal status, but also by those newly arrived in Germany. This underlines the increasing recognition of the agency of forcibly displaced persons and acknowledges the political life of those seeking refuge. As such, Banki (2013) argues that refugees, despite often being excluded from formal channels of political engagement, may make use of alternative forms and tools to influence decision-making processes and to alter representation in the political system. It can be argued that Syrian diaspora politics not only contributed to political processes in the country of origin but also transformed the political space of the host country, since legally, politically, culturally and socially constructed borders were contested through acts of claiming rights and belonging in the German context (E).

With regard to the direct linkages of the micro-level capabilities $(B)$, the findings of the dissertation suggest that next to the politicised identity, other markers such as professional background, age and the migration experience also influence the process of diaspora mobilisation. For, instance among the older generation, some 
mentioned the professional ethos of helping the injured to be the major driver for engaging in the provision of humanitarian aid. Indeed, diaspora political entrepreneurs may engage in transnational practices in which they can make the best use of their personal skills and knowledge as this might also alter the feeling of self-efficacy. Similarly, many of the young activists who were involved in the non-violent and civil society movement in Syria accumulated knowledge and experiences through their work with local and international organisations. Given their engagement in the revolution, they also perceived a different kind of ownership towards the conflict and engaged in political activism based on the broader values of the revolution. Hence, the characteristics and social locations of the agents may also influence how the community is mobilised and which influences on the political process in the homeland are exerted.

From an intersectional approach, social structures and processes produce social positions and identities that influence the capacity and desire of individuals and as a result also the composition of diaspora groups. As mentioned before, it is the intersection of class, professional, ethnic and gendered hierarchies that create fragmentation, power relations and competition among and within groups (Baser, 2014; Koinova, 2011; Walton, 2014). These processes might also influence who is included and excluded from diaspora mobilisation. Given that the study only focused on those engaged in the diaspora mobilisation process, the question of how social locations may facilitate or constrain involvement in diaspora mobilisation can be less explored. However, some of the findings indicate how the intersection of factors such as age, sexuality, gender, class, generation and sociopolitical status plays out in the mobilisation process. First, regardless of the reason for migration, those who engage in the mobilisation process tend to be highly educated and socio-economically better-off, indicating that diaspora mobilisation is a product of a small but rather powerful elite. In addition, this study has shown that Syrian diaspora mobilisation in Germany has been to certain extent maledominated. Yet, more recent observations indicate that these hierarchies are becoming increasingly contested. For instance, new Syrian women-led movements in Germany, such as the New Empowered Society for Women Activism (NESWA) or the Syrian Feminist Lobby, both which were established recently in 2019, point to this direction and indicate that socio-political hierarchies can also be challenged and contested through the mobilisation process (C).

With respect to the macro level, the findings of this study indicate that both origin and destination country opportunity structures matter (D), but that their influence is different at distinct junctures and stages of the diaspora mobilisation process. This is particularly relevant in the case of ongoing and highly dynamic conflicts, as these potentially lead to a great volatility of the opportunity structures in the origin 
country. In addition, as conflicts are seldom spatially isolated and their repercussions may unfold transnationally, conflict dynamics have the potential to also change the opportunities and constraints present in the destination country.

For instance, while Germany, as a democratic and liberal country, generally provided the freedom and space for diaspora activism, the long-distance policies and instruments of the Syrian regime were still able to historically repress political diaspora mobilisation, thereby counteracting the favourable conditions present in the destination country. It was only when shifting configurations of power emerged in the country of origin, that a window for bottom-up Syrian diaspora mobilisation was opened, and that Syrian diaspora political entrepreneurs in Germany felt empowered to engage in collective action to shape the home country's future. The destination country opportunity structure mattered, however, in so far as it influenced who mobilised based on a Syrian diasporic consciousness. Given Germany's political stance against the Syrian regime, the access to political institutions and to the discursive space was much more open and favourable for those groups who positioned themselves in opposition to the regime.

With regard to the trajectories of the diaspora mobilisation process, both origin and destination country factors have been shown to have somehow contradictory effects. For instance, while the escalation of the Syrian conflict led to the reproduction of conflict lines within the mobilisation process, the increasing humanitarian needs inside Syria, along with declining resources, fostered a desire for coordination and cooperation. In the context of the destination country, unequal access to resources and political influence offered by host country actors exacerbated tensions, competition and power imbalances between the different actors involved in the diaspora mobilisation process. At the same time, the destination country context also provided a safe space for reflection, among others through policies targeting the diaspora that facilitated encounters for dialogue, networking and cooperation. In addition, a strong desire for peace and reconciliation was present among the different actors involved in the mobilisation process, who countered the process of fragmentation with a diverse range of collective action.

In addition, transnational political subjectivities, identities and practices are not given but emerge and evolve in a relational space, in which sending and receiving country dynamics intersect and mutually affect each other. For instance, Koopmans (2004) argued that if migrants face a restrictive space due to limited access to citizenship and political institutions and/or an unfavourable public discourse, mobilisation efforts may turn towards political issues related to the 
origin country. The findings of this study indicate that the opposite might be true as well, as with vanishing hopes for sustainable return, coupled with limited access and space of influence present in the home country, diaspora actions turned towards practices that sought to influence their position and influence with regard to the destination country. Moreover, if diaspora mobilisation, as stated before, can be considered as a form of civic engagement in the country of destination, over time diaspora actors may become more embedded in the local civil society structures and networks, which enables or motivates them to pursue also political actions oriented towards the country of settlement (Quinsaat, 2019).

\subsection{Policy recommendation}

The findings of this dissertation yield a range of practical considerations relevant to stakeholders who seek to engage with Syrian diaspora actors. Based on this, the following sections will discuss recommendations for a conflict- and contextsensitive as well as participatory approach in engaging with diaspora groups.

\subsubsection{Conflict- and context-sensitive approach in engaging with diaspora groups}

As shown throughout the study, there exist different and sometimes competing interests, aspirations and divergent opinions related to the settlement of the conflict among Syrian diaspora actors in Germany and a diverse range of sociopolitical dynamics present within the mobilisation process. Hence, a sophisticated understanding of the conflict dynamics, including knowledge about the different actors (local and transnational) is needed in the design of policies and the selection of different diaspora groups as partners. When collaborating with diaspora groups, attention should also be paid to fragmentations, power relations and competition based on class, professional, ethnic, generational and gendered hierarchies to avoid unintended intensification of the conflict and tensions between groups.

Given this heterogeneity, the main challenge for policymakers is to identify and select 'legitimate' diaspora groups with whom to engage, taking into account the potential conflict and power-dynamics among these groups. A conflict- and context-sensitive approach in engaging with diaspora groups requires an awareness of the potential risks and limitations as well as of the socio-political dynamics present in the process of diaspora mobilisation. Including diaspora political entrepreneurs of different (political, socio-economic, demographic and cultural) backgrounds helps to gather different perceptions, experiences, and aspirations and provides a space for potentially marginalised sections of the diaspora to express their voices and foster their actions. On the other hand, underlying conflict lines might hamper effective and constructive programme 
implementation and may, in the worst case, contribute to further entrenchment of societal divisions among diaspora groups.

When choosing an inclusive approach, engagement should allow time and space for trust and confidence building, and not only be results-driven. Hence, long-term efforts by international organisations/NGOs and governments who want to involve the Syrian diaspora groups, are needed to build a trustful and lasting relationship. Projects, in which different groups and members of the Syrian diaspora are involved, need to create a space for reflecting on strategies and joint future actions (rather than reactions), to generate sustainable impacts. This also means that stakeholders should not search for a unified voice and representation among Syrian diaspora actors but rather create a space for discussion and debates, in which diversity (instead of uniformity) leads to future ways of cooperation and action. An inclusive approach, with participation of diaspora groups with diverse backgrounds and interests can encourage dialogue between the different fractions, which is an important step towards societal reconciliation and a peaceful solution of the conflict within the diaspora.

\subsubsection{Participatory approach in engaging with diaspora groups}

Collaborating with diaspora groups can yield a variety of advantages for stakeholders, not least due to their long-term commitment, context-specific knowledge, and access to communities based on personal transnational networks. Diaspora actors may benefit by gaining access to resources and know-how, which may enable them to develop their capacity further. Increasingly, the development potential of diaspora groups is being recognised, and diverse actors ranging from government institutions to international organisations and other civil society actors develop and implement policies in order to promote the participation of diaspora actors in development processes.

However, numerous measures that consider themselves as participatory, in reality tend to be deliberative in nature, since they do not offer any possibility of influencing decision-making processes. In some cases, actors may even instrumentalise diaspora groups for their own interest, and as a result, participation becomes pure decoration because participation in a 'real' sense grants target groups a formal, binding role in decision-making. For stakeholders this would demand that they allow for co-determination and at least a partial transfer decision-making authority. A bottom-up mobilisation of cooperation through the development of common strategies, as well as joint design and implementation of measures between diaspora actors and stakeholders, can help to establish a sustainable cooperation structure. Next to providing a clear definition of 
responsibilities and tasks, ensuring transparency of activities, work processes and decision paths are crucial steps to build commitment and trust among the actors involved. Actors engaging with diaspora groups should therefore not only clearly communicate which level of participation they intend to offer, but also show transparency on how the views and perceptions of diaspora actors have been taken into account in decision-making processes.

Next to granting decision-making power, a participatory approach should also recognise the political nature of diaspora mobilisation and provide a space for contestation and debate. The level of politicisation is commonly a key concern for policymakers when cooperating with diaspora groups in conflict settings, since a potential lack in compliance with the humanitarian principles of humanity, neutrality, and impartiality can undermine the fundamental foundations for peacebuilding, development cooperation, and humanitarian action. However, this study has shown that politicised collective identities are a crucial driver of diaspora mobilisation and that a plurality of positions, aspirations and interested is not necessarily something negative, but that if constructively approached, they can lead to social change and transformation. Instead of aiming at depoliticising diaspora action, Horst (2013) argues that development cooperation should acknowledge the political nature of such engagement and understand diaspora involvement as a form of civic participation in the host country, which is characterised by diversity, differences, and contestations:

\section{"Civic participation always takes place from a particular position, and it is in the debate between different positions and in contestations of the status quo in which societal change occurs" (Horst, 2013, p. 243).}

Finally, programmes targeting diaspora groups should not just focus on the elite or the most visible and outspoken persons, but rather seek to empower people and communities on the ground, by enabling them to formulate and represent their interests. Instead of selecting leaders using a top-down approach, programmes can provide a space and platform for people to participate in choosing legitimate representations through a democratic process. Promoting empowerment, dialogue and the strengthening of social capital can be seen as crucial to prevent the reproduction of a disconnected political elite.

\subsection{Avenues for future research}

There are several areas for further research to be explored from this study, and the following section will highlight three fields of potential further investigation. 
A first area for further research is to investigate the nexus of diasporas and conflicts beyond elite mobilisation. While it is crucial to shed light on the collective level of diaspora mobilisation, its structures, agents and practices, this involves the risk of limiting the analysis to the voice of a small but powerful elite, whose legitimation might potentially be highly contested. Exploring the perceptions and aspirations of co-nationals who are not involved in diasporic projects would have the potential to offer several further insights. One the hand, it would shed light on the diversity of aspirations, perceptions and voices and allow for a comparison of how these might differ among those who actively mobilise and those who do not become politically involved. In addition, it could contribute to answering the question why some people become involved in diaspora mobilisation, while others do not. This would contribute to a deeper understanding of how social locations, i.e. the intersection of factors such as age, sexuality, gender, class, generation and socio-political status, may facilitate or constrain involvement in diaspora mobilisation (Fiddian-Qasmiyeh, 2013).

A more in-depth examination of the intersectionality present in the diaspora mobilisation process offers the second area for potential further research. While intersections produce social locations that influence who is included and excluded in the mobilisation process, these hierarchies and power imbalances can be nevertheless also highly contested. While this research has illuminated the influences of social location, in particular those based on ethnicity, age and migration experiences, on the mobilisation process, the scope of the study did not allow for a detailed analysis of other markers of identity such as gender or sexuality. Analysing diaspora mobilisation through the lens of intersectionality would allow to shed light on the internal socio-political dynamics of diaspora mobilisation, and to examine how power relations are being manifested or contested (Al-Ali, 2007, 2010; Godin, 2019). As such, further research could focus for example more in-depth on the gendered dimension of Syrian diaspora mobilisation.

Finally, research on diaspora mobilisation in conflict settings tends to investigate the contributions by diaspora groups from the sending side without assessing how those contributions are actually presumed and used in the origin country context. As a result, there seems to be a limited understanding of how diasporic practices translate into on-the-ground impacts. Besides, focusing on the sending side only runs the risk of neglecting the circularity of transnational transfers and the potential of reverse social, cultural, political and economic remittances sent from the origin to the destination countries, as well as the influence these have on the process of diaspora mobilisation. Analysing diaspora mobilisation with a multisited approach helps to discover transnational connectivities and activities, thus 
cross-cutting dichotomies of 'local' and 'global' (Marcus, 1995). Through this, attention can be given to the dynamics of resource flows, by analysing connectivities, activities and potential impacts not just from destination to origin countries, but also vice versa. 


\section{References}

Abourahme, N., \& Jayyusi, M. (2011). The will to revolt and the spectre of the Real: Reflections on the Arab moment. City, 15(6), 625-630.

Abramson, Y. (2017). Making a homeland, constructing a diaspora: The case of Taglit-Birthright Israel. Political Geography, 58, 14-23.

Adamson, F. B. (2008). Constructing the diaspora: Diaspora identity politics and transnational social movements. Annual Meeting of the ISA's 49 Annual Convention., San Francisco, CA.

Adamson, F. B. (2012). Constructing the Diaspora- Diaspora Identity Politics and Transnational Social Movement. In T. Lyons \& P. G. Mandaville (Eds.), Politics from afar (pp. 25-42). Columbia: Columbia University Press.

Adamson, F. B. (2013). Mechanisms of diaspora mobilization and the transnationalization of civil war. In J. T. Checkel (Ed.), Transnational Dynamics of Civil War (pp. 63-88). New York: Cambridge University Press.

Adamson, F. B. (2016). Spaces of global security: Beyond methodological nationalism. Journal of Global Security Studies, 1(1), 19-35.

Adamson, F. B., \& Demetriou, M. (2007). Remapping the Boundaries of 'State' and 'National Identity': Incorporating Diasporas into IR Theorizing. European Journal of International Relations, 13(4), 489-526.

al-Sabbagh, H. (2016). Expatriates delegation calls for holding general conference of Syrian expatriates in Damascus before end of 2016. Retrieved 8 October 2019, from SANA Syrian Arab News Agency. https://www.sana.sy/en/?p=86095

Al-Ali, N. (2007). Iraqi Women in Diasporic Spaces: Political Mobilization, Gender \& Citizenship. Revue Des Mondes Musulmans et de La Méditerranée, 117-118, 137154.

Al-Ali, N. (2010). Diasporas and gender. In K. Knott \& S. MacLoughlin (Eds.), Diasporas: Concepts, intersections, identities (pp. 118-122). London, New York: Zed Books. 
Al-Ali, N., Black, R., \& Koser, K. (2001). The limits to 'transnationalism': Bosnian and Eritrean refugees in Europe as emerging transnational communities. Ethnic and Racial Studies, 24(4), 578-600.

al-Haj Saleh, Y. (2017). Impossible revolution: Making sense of the Syrian tragedy. London: Hurst \& Company.

Anderson, B. (1992). The New World Disorder. New Left Review, (193).

Ang, I. (2003). Together-in-difference: Beyond diaspora, into hybridity. Asian Studies Review, 27(2), 141-154.

Anthias, F. (1998). Evaluating 'diaspora': Beyond ethnicity. Sociology, 32(3), 557580 .

Anthias, F. (2006). Belongings in a Globalising and Unequal World: Rethinking Translocations. In N. Yuval-Davis, Kalpana. Kannabirān, \& Ulrike. Vieten (Eds.), The situated politics of belonging (Vol. 1-1), pp. 17-31). London: SAGE.

Antonsich, M. (2010). Searching for Belonging - An Analytical Framework. Geography Compass, 4(6), 644-659.

Antwi-Boateng, O. (2012). After War then Peace: The US-based Liberian Diaspora as Peace-building Norm Entrepreneurs. Journal of Refugee Studies, 25(1), 93-112.

Auswärtiges Amt. (2011). Außenminister Westerwelle: Politischer Neuanfang in Syrien notwendig [Press release 18.08.2011]. Retrieved 25 September 2019, from Auswärtiges Amt website: https://www.auswaertigesamt.de/de/newsroom/110818-syrien/246580

Auswärtiges Amt. (2012). Deutschland weist syrischen Botschafter aus [Press release 29.05.2012]. Retrieved 25 September 2019, from Auswärtiges Amt website: https://www.auswaertiges-amt.de/de/newsroom/120529-ausweisung-syrbotschafter $/ 250256$

Baeza, C., \& Pinto, P. (2016). Building Support for the Asad Regime: The Syrian Diaspora in Argentina and Brazil and the Syrian Uprising. Journal of Immigrant E Refugee Studies, 14(3), 334-352.

Balanche, F. (2007). Les travailleurs syriens au Liban ou la complémentarité de deux systèmes d'oppression - Editions Arabe (Le Monde Diplomatique). 
BAMF. (2016). BAMF - Bundesamt für Migration und Flüchtlinge-Strukturförderung von Migrantenorganisationen. Retrieved 1 May 2017: http://www.bamf.de/DE/Infothek/Projekttraeger/Strukturfoerderung$\mathrm{MO} /$ strukturfoerderung-mo-node.html

BAMF. (2019). Bundesamt in Zahlen 2018. Asyl, Migration und Integration. Bundesamt für Migration und Flüchtlinge (BAMF). Nürnberg.

Bamyeh, M. A. (2007). The Palestinian Diaspora. In H. Smith \& P. B. Stares (Eds.), Diasporas in Conflict: Peace-Makers or Peace-Wreckers? Tokyo, New York: United Nations University Press.

Bamyeh, M. A. (2013). Anarchist Method, Liberal Intention, Authoritarian Lesson: The Arab Spring between Three Enlightenments*. Constellations, 20(2), 188-202.

Banki, S. (2013). R The Paradoxical Power of Precarity: Refugees and Homeland Activism. Refugee Review: Social Movements.

Barnard, A. (2018, January 30). Syrian Peace Talks in Russia: 1,500 Delegates, Mostly Pro-Assad. The New York Times. Retrieved 25 February 2020 from New York Times website:

https://www.nytimes.com/2018/01/30/world/middleeast/syria-russia-sochitalks.html

Baser, B. (2013). Diasporas and Imported Conflicts: Turkish and Kurdish SecondGeneration Diasporas in Sweden. Journal of Conflict Transformation \& Security, $3(2), 104-125$.

Baser, B. (2014). The Awakening of a Latent Diaspora: The Political Mobilization of First and Second Generation Turkish Migrants in Sweden. Ethnopolitics, 13(4), 355-376.

Baser, B. (2017). Diasporas and Homeland Conflicts: A Comparative Perspective. London, New York: Routledge Taylor and Francis Group.

Baser, B., \& Swain, A. (2010). Stateless Diaspora Groups and their Repertoires of Nationalist Activism in Host Countries. Journal of International Relations, 8(1), 3760.

Baser, B., \& Toivanen, M. (2017). Politicized and depoliticized ethnicities, power relations and temporality: Insights to outsider research from comparative and transnational fieldwork. Ethnic and Racial Studies, 0(0), 1-18. 
Batrawi, S., \& Uzelac, A. (2018). Four ways in which the Syrian regime controls refugee return (September 2018; CRU Policy Brief). Clingendael - the Netherlands Institute of International Relations.

BBC. (2014). Syria election: Refugees vote in Lebanon and Jordan. BBC News. Retrieved 6 August 2018, from http:// www.bbc.com/news/world-middle-east27599868

BBC. (2017). Syria war: Army retakes last IS urban stronghold-BBC News Retrieved 6 August 2019 from http://www.bbc.com/news/world-middle-east-41918913

Beauftragte der Bundesregierung für Migration, Flüchtlinge und Integration. (2018). Die deutsche Staatsbürgerschaft-Alles was Sie darüber wissen sollten. Beauftragte der Bundesregierung für Migration, Flüchtlinge und Integration.

Beck, C. T. (2005). Benefits of Participating in Internet Interviews: Women Helping Women. Qualitative Health Research, 15(3), 411-422.

Bekaj, A., \& Antara, L. (2018). Political participation of refugees: Bridging the gaps. Stockholm: International IDEA.

Bengo. (2019). Über uns-Bengo. Retrieved 12 November 2017 from https://bengo.engagement-global.de/ueber-uns.html

Bercovitch, J. (2007). A neglected relationship: Diasporas and conflict resolution. In H. Smith \& P. B. Stares (Eds.), Diasporas in Conflict: Peace-Makers or PeaceWreckers? (pp. 17-38). Tokyo, New York: United Nations University Press.

Bernard, H. R., Ryan, G. W., \& Wutich, A. (2016). Analyzing qualitative data: Systematic approaches. Los Angeles: SAGE.

Bernstein, M. (2008). The Analytic Dimensions of Identity A Political Identity Framework. In J. Reger, D. J. Myers, \& R. L. Einwohner (Eds.), Identity work in social movements (pp. 277-301). Minneapolis: University of Minnesota Press.

Bhabha, H. K. (2004). The location of culture. London, New York: Routledge.

Binaisa, N. (2013). Nigeria @ 50: Policies and Practices for Diaspora Engagement. In M. Collyer (Ed.), Emigration Nations (pp. 226-251). London: Palgrave Macmillan.

Birman, D. (2006). Ethical Issues in Research With Immigrants and Refugees. In J. E. Trimble \& C. B. Fisher (Eds.), The Handbook of Ethical Research with 
Ethnocultural Populations and Communities (pp. 155-178). Thousand Oaks, London, New Delhi: SAGE.

BMI. (2018). Erwerb der deutschen Staats-angehörigkeit durch Geburt in Deutschland. Bundesministerium des Innern, für Bau und Heimat. Retrieved 26 August 2019 from:

http://www.bmi.bund.de/DE/themen/verfassung/staatsangehoerigkeit/optionsp flicht/optionspflicht.html;jsessionid=DF2D77F688DBA5B686415555FC2CBC48.2 _cid373?nn=9394292

BMZ. (2019). Syrien. Bundesministerium für wirtschaftliche Zusammenarbeit und Entwicklung. Retrieved 25 October 2019 from:

http://www.bmz.de/de/laender_regionen/naher_osten_nordafrika/syrien/index. html

Boccagni, P., Lafleur, J.-M., \& Levitt, P. (2016). Transnational Politics as Cultural Circulation: Toward a Conceptual Understanding of Migrant Political Participation on the Move. Mobilities, 11(3), 444-463.

Boyatzis, R. E. (1998). Transforming qualitative information: Thematic analysis and code development. Thousand Oaks, London, New Delhi: Sage Publications, Inc.

Brand, L. A. (2006). Citizens Abroad: Emigration and the State in the Middle East and North Africa. New York: Cambridge University Press.

Braun, V., \& Clarke, V. (2006). Using thematic analysis in psychology. Qualitative Research in Psychology, 3(2), 77-101.

Brinkerhoff, J. M. (2008). Diaspora identity and the potential for violence: Toward an identity-mobilization framework. Identity: An International Journal of Theory and Research, 8(1), 67-88.

Brinkerhoff, J. M. (2011). Diasporas and conflict societies: Conflict entrepreneurs, competing interests or contributors to stability and development? Conflict, Security \& Development, 11(02), 115-143.

Brubaker, R. (2005). The 'diaspora' diaspora. Ethnic and Racial Studies, 28(1), 1-19.

Brubaker, R. (2006). Ethnicity without groups (1. Harvard Univ. Press paperback ed). Harvard Univ. Press. 
Brubaker, R. (2017). Grounds for difference. Cambridge, Massachusetts, London: Harvard University Press.

Burgess, K. (2014). Unpacking the Diaspora Channel in New Democracies: When Do Migrants Act Politically Back Home? Studies in Comparative International Development, 49(1), 13-43.

Bush, K. (2008). Diaspora Engagement in Peacebuilding. Empirical and Theoretical Challenges. In M. C. Pugh, N. Cooper, \& M. Turner (Eds.), Whose peace?: Critical perspectives on the political economy of peacebuilding (pp. 191-205). Basingstoke [England], New York: Palgrave Macmillan.

Byman, D., Chalk, P., Hoffman, B., Rosenau, W., \& Brannan, D. (2001). Trends in Outside Support for Insurgent Movements. RAND Corporation.

Carling, J., Erdal, M. B., \& Ezzati, R. (2014). Beyond the insider-outsider divide in migration research. Migration Studies, 2(1), 36-54. 022

Castells, M. (2011). The power of identity: The information age: Economy, society, and culture (Vol. 2). West Sussex: John Wiley \& Sons.

Castles, S. (2011). Bringing Human Rights into the Migration and Development Debate. Global Policy, 2(3), 248-258.

Cederman, L.-E., Gleditsch, K. S., \& Buhaug, H. (2013). Inequality, grievances, and civil war. New York: Cambridge University Press.

Chaudhary, A. R., \& Guarnizo, L. E. (2014). Determinants of transnational political engagement among Dominican and Colombian migrants in Southern Europe (No. 82; Working Paper). International Migration Institute, University of Oxford.

Chaudhary, A. R., \& Moss, D. M. (2016). Triadic political opportunity structures: Reconceptualising immigrant transnational politics (Paper 129; IMI Working Papers). International Migration Institute (IMI), Oxford Department of International Development (QEH), University of Oxford.

Chaudhary, A. R., \& Moss, D. M. (2019). Suppressing transnationalism: Bringing constraints into the study of transnational political action. Comparative Migration Studies, 7(1).

Chenoweth, E., \& Cunningham, K. G. (2013). Understanding nonviolent resistance An introduction. Journal of Peace Research, 50(3), 271-276. 
Cinalli, M., \& Giugni, M. (2011). Institutional Opportunities, Discursive Opportunities and the Political Participation of Migrants in European. In L. Morales \& M. Giugni (Eds.), Social Capital, Political Participation and Migration in Europe (pp. 43-62). London: Palgrave Macmillan UK.

Clifford, J. (1994). Diasporas. Cultural Anthropology, 9(3), 302-338.

Cochrane, F., Baser, B., \& Swain, A. (2009). Home Thoughts from Abroad: Diasporas and Peace-Building in Northern Ireland and Sri Lanka. Studies in Conflict $\mathcal{E}$ Terrorism, 32(8), 681-704.

Cohen, R. (2008). Global Diasporas: An Introduction (2 edition). London: Routledge.

Cohen, R., \& Kennedy, P. M. (2013). Global sociology (Third Edition). New York: NYU Press.

Collier, P., \& Hoeffler, A. (2004). Greed and grievance in civil war. Oxford Economic Papers, 56(4), 563-595.

Crabtree, B. F., \& Miller, W. L. (Eds.). (1999). Doing qualitative research (2nd ed). Thousand Oaks, Calif: Sage Publications.

Dahi, O. S., \& Munif, Y. (2012). Revolts in Syria: Tracking the Convergence Between Authoritarianism and Neoliberalism. Journal of Asian and African Studies, 47(4), 323-332.

Darke, D. (2014). The choice in Syria's election: Vote for Assad or else. The Guardian. Retrieved 6 August 2018 from:

https://www.theguardian.com/commentisfree/2014/jun/02/syria-electionvotefor- assad-or-else

Davis, J. E. (2002). Narrative and Social Movements. The Power of Stories. In J. E. Davis (Ed.), Stories of change: Narrative and social movements (pp. 4-29). Albany: State University of New York Press.

Dawisha, A. I. (1978). Syria under Asad, 1970-78: The Centres of Power. Government and Opposition, 13(3), 341-354.

De Bel-Air, F. (2016). Migration profile: Syria. Migration Policy Centre, Policy Briefs, 2016/02. 
de Haas, H. (2007). Between courting and controlling: The Moroccan state and 'its' emigrants (Working Paper No. 54). COMPAS Centre on Migration, Policy and Society.

Délano, A., \& Gamlen, A. (2014). Comparing and theorizing state-diaspora relations. Political Geography, 41, 43-53.

DEMAC. (2016). About DEMAC. Retrieved 15 October 2018 from: http://www.demac.org/about-demac

Demmers, J. (2007). New wars and diasporas: Suggestions for research and policy. Journal of Peace Conflict \& Development, 11, 1-26.

Di Bartolomeo, A., Jaulin, T., \& Perrin, D. (2012). CARIM- Migration Profile Syria. CARIM-Consortium for Applied Research on International Migration.

Doorn, M. van, Prins, J., \& Welschen, S. (2013). "Protest against Whom?": The Role of Collective Meaning Making in Politicization. In J. van Stekelenburg, C. Roggeband, \& B. Klandermans (Eds.), The Future of Social Movement Research (pp. 59-78). Minneapolis: University of Minnesota Press.

DRC. (2018). Durable Solutions I DRC. Retrieved 15 October 2018 from: https://drc.ngo/relief-work/diaspora-programme/what-we-do/durable-solutions

Dufoix, S., \& Waldinger, R. (2008). Diasporas (W. Rodamor, Trans.; 1 edition). Berkeley: University of California Press.

El-Tayeb, F. (2016). Undeutsch: Die Konstruktion des Anderen in der postmigrantischen Gesellschaft. Bielefeld: Transcript.

Fair, C. C. (2007). The Sri Lankan Tamil Diaspora. Sustaining conflict and pushing for peace. In H. Smith \& P. B. Stares (Eds.), Diasporas in Conflict: Peace-Makers or Peace-Wreckers? (pp. 172-195). Tokyo, New York: United Nations University Press.

Faist, T. (2004). Staatsbürgerschaft und Integration in Deutschland: Assimilation, kultureller Pluralismus und Transstaatlichkeit. In Y. Bizeul (Ed.), Integration von Migranten: Französische und deutsche Konzepte im Vergleich (2004th ed., pp. 77104). Wiesbaden: Deutscher Universitätsverlag. 
Fereday, J., \& Muir-Cochrane, E. (2006). Demonstrating Rigor Using Thematic Analysis: A Hybrid Approach of Inductive and Deductive Coding and Theme Development. International Journal of Qualitative Methods, 5(1), 80-92.

Féron, É., \& Lefort, B. (2019). Diasporas and conflicts - understanding the nexus. Diaspora Studies, 12(1), 34-51.

Fiddian-Qasmiyeh, E. (2013). Transnational childhood and adolescence: Mobilizing Sahrawi identity and politics across time and space. Ethnic and Racial Studies, 36(5), 875-895.

Fleischmann, L., \& Steinhilper, E. (2017). The Myth of Apolitical Volunteering for Refugees: German Welcome Culture and a New Dispositif of Helping. Social Inclusion, 5(3), 17.

Friese, H. (2017). Flüchtlinge: Opfer - Bedrohung - Helden: zur politischen Imagination des Fremden. Bielefeld: Transcript.

Funk, N. C., \& Said, A. A. (2004). Islam and the West: Narratives of conflict and conflict transformation. International Journal of Peace Studies, 1-28.

Gabrielli, L., Gsir, S., \& Zapata-Barrero, R. (2017). Political and Civic Participation of Immigrants in Host Countries. An Interpretative Framework from the Perspective of the Origin Countries and Societies. In A. Weinar, A. Unterreiner, \& P. Fargues (Eds.), Migrant Integration Between Homeland and Host Society Volume 1 (Vol. 7, pp. 87-116). Cham: Springer International Publishing.

Gamlen, A. (2008). The emigration state and the modern geopolitical imagination. Political Geography, 27(8), 840-856.

Gamlen, A. (2019a). In R. Cohen \& C. Fischer (Eds.), Routledge handbook of diaspora studies (pp. 479-492). London, New York: Routledge Taylor \& Francis Group.

Gamlen, A. J. (2019b). Human geopolitics: States, emigrants, and the rise of diaspora institutions (First edition). Oxford: Oxford University Press.

Geddes, A., \& Scholten, P. (2016). The Politics of Migration and Immigration in Europe. Los Angeles, London, New Delhi, Singapore, Washington DC: SAGE.

Gesemann, F., \& Roth, R. (2014). Integration ist (auch) Ländersache: Schritte zur politischen Inklusion von Migrantinnen und Migranten in den Bundesländern. Berlin: Friedrich-Ebert-Stiftung, Forum Berlin. 
Gesemann, F., Roth, R., \& Aumüller, J. (2012). Stand der kommunalen Integrationspolitik in Deutschland. BMVBS / Bundesbeauftragte für Migration, Flüchtlinge und Integration.

Giugni, M., \& Passy, F. (2004). Migrant mobilization between political institutions and citizenship regimes: A comparison of France and Switzerland. European Journal of Political Research, 43(1), 51-82.

Gleditsch, K. S. (2007). Transnational Dimensions of Civil War. Journal of Peace Research, 44(3), 293-309.

Glick Schiller, N. (2013). Transnational Migration Paradigm: Global Perspectives on Migration Research. In D. Halm \& Z. Sezgin (Eds.), Migration and organized civil society: Rethinking national policy. London, New York: Routledge.

Godin, M. (2019). Intersectionalizing diaspora studies. In R. Cohen \& C. Fischer (Eds.), Routledge handbook of diaspora studies (Vol. 1-255-267). London, New York: Routledge Taylor \& Francis Group.

Gray, B. (2013). Towards the Neo-Institutionalisation of Irish State-Diaspora Relations in the Twenty-First Century. In Michael Collyer (Ed.), Emigration nations (pp. 100-125). London: Palgrave Macmillan.

Green, J., Willis, K., Hughes, E., Small, R., Welch, N., Gibbs, L., \& Daly, J. (2007). Generating best evidence from qualitative research: The role of data analysis. Australian and New Zealand Journal of Public Health, 31(6), 545-550.

Guarnizo, L. E., Portes, A., \& Haller, W. (2003). Assimilation and Transnationalism: Determinants of Transnational Political Action among Contemporary Migrants. American Journal of Sociology, 108(6), 1211-1248.

Gurr, T. R. (2011). Why men rebel (40. anniversary paperback ed). Boulder, Colo.: Paradigm Publ.

Hall, S. (2014). Cultural identity and diaspora. In Diaspora and visual culture (pp. 3547). London: Routledge.

Hammond, L. (2013). Somali Transnational Activism and Integration in the UK: Mutually Supporting Strategies. Journal of Ethnic and Migration Studies, 39(6), 1001-1017. 
Hammond, L., Awad, M., Ibrahim Dagane, A., Hansen, P., Horst, C., Menkhaus, K., \& Obare, L. (2011). Cash \& Compassion: The Somali Diaspora's Role in Relief, Development $\mathcal{E}$ Peacebuilding. UN Development Programme (UNDP).

Harris, M. (2012). International responses to the Syrian uprising: March 2011- June 2012 (Background Note). Parliament of Australia, Foreign Affairs, Defence and Security Section.

Hess, M., \& Korf, B. (2014). Tamil diaspora and the political spaces of secondgeneration activism in Switzerland. Global Networks, 14(4), 419-437.

Hinger, S. (2016). Asylum in Germany: The Making of the 'Crisis' and the Role of Civil Society. Human Geography, 9(2), 78-88.

Hinnebusch, R. A. (1995). The political economy of economic liberalization in Syria. International Journal of Middle East Studies, 27(3), 305-320.

Hinnebusch, R. A. (2002). Syria: Revolution from above. London, New York: Routledge.

Hinnebusch, R. A. (2008). Modern Syrian Politics. History Compass, 6(1), 263-285.

Hinnebusch, R. A. (2012). Syria: From 'authoritarian upgrading' to revolution? International Affairs, 88(1), 95-113.

Hinnebusch, R. A., \& Imady, O. (2017). Syria's Reconciliation Agreements. Syria Studies, 9(2), 1-14.

Hinnebusch, R., \& Zintl, T. (2015). The Syrian Uprising and Bashar al-Asad's First Decade in Power. In R. A. Hinnebusch \& T. Zintl (Eds.), Syria from reform to revolt (First edition, pp. 285-310). Syracuse, New York: Syracuse University Press.

Holmes, S. M., \& Castañeda, H. (2016). Representing the "European refugee crisis" in Germany and beyond: Deservingness and difference, life and death: Representing the "European refugee crisis". American Ethnologist, 43(1), 12-24.

Holzberg, B., Kolbe, K., \& Zaborowski, R. (2018). Figures of Crisis: The Delineation of (Un)Deserving Refugees in the German Media. Sociology, 52(3), 534-550.

Horst, C. (2013). The Depoliticisation of Diasporas from the Horn of Africa: From Refugees to Transnational Aid Workers. African Studies, 72(2), 228-245. 
Horst, C. (2018). Making a difference in Mogadishu? Experiences of multi-sited embeddedness among diaspora youth. Journal of Ethnic and Migration Studies, 44(8), 1341-1356.

Horst, C., Ezzati, R., Guglielmo, M., Mezzeti, P., Pirkkalainen, P., Saggiomo, V., \& Warnecke, A. (2010). Participation of Diasporas in Peacebuilding and Development. Oslo: PRIO.

Howard, J. A. (2000). Social Psychology of Identities. Annual Review of Sociology, 26, 367-393.

Human Rights Watch. (2019). World report 2019: Events of 2018.

Hund, S. A., \& Benford, R. A. (2004). In David A. Snow, S. A. Soule, \& H. Kriesi (Eds.), The Blackwell companion to social movements (pp. 433-458). Blackwell Pub.

Hunger, U., \& Candan, M. (2009). Politische Partizipation der Migranten in der Bundesrepublik Deutschland und über die deutschen Grenzen hinweg (Expertise Im Auftrag des Bundesamts Für Migration Und Flüchtlinge (BAMF)). Universität Münster, FB Erziehungswissenschaft und Sozialwissenschaften, Institut für Politikwissenschaft.

Hutchinson, S. A., Wilson, M. E., \& Wilson, H. S. (1994). Benefits of Participating in Research Interviews. Image: The Journal of Nursing Scholarship, 26(2), 161-166.

ICMPD, \& ECDPM. (2013). Migration and development policies and practices: A mapping study of eleven European countries and the European Commission. International Centre for Migration Policy Development (ICMPD) \& European Centre for Development Policy Management.

ICMPD, \& IOM. (2010). Linking Emigrant Communities for More Development. Inventory of Institutional Capacities and Practices (MTM: A Dialogue in Action). International Centre for Migration Policy Development (ICMPD) \& International Organization for Migration (IOM).

Ismail, A. A. (2011). Diaspora and Post-War Political Leadership in Somalia. Nordic Journal of African Studies, 20(1), 28-47.

Jacobsen, K., \& Landau, L. B. (2003). The dual imperative in refugee research: Some methodological and ethical considerations in social science research on forced migration. Disasters, 27(3), 185-206. 
Jörum, E. L. (2015). Repression across borders: Homeland response to anti-regime mobilization among Syrians in Sweden. Diaspora Studies, 8(2), 104-119.

Kadhum, O. (2014). Diaspora Mobilisation and Belonging in the UK: The Case of the Iraqi Diaspora in the Aftermath of the 2003 Intervention. In Dialogue Society (Ed.), Workshop Proceedings: Sense of Belonging in a Diverse Britain (pp. 105-128). London.

Khalaf, R. (2015). Governance without Government in Syria: Civil Society and State Building during Conflict. Syria Studies, 7(3), 37-72.

Khayati, K. (2012). Diaspora as an instance of global governance: The case of Kurds in Sweden (pp. 181-185). Uppsala Centre for Sustainable Development, Uppsala University.

Khoury, D. (2014). Syria-Organising for the future: Grassroots governance and national peace. In A. Ramsbotham \& A. Wennmann (Eds.), Legitimacy and peace processes: From coercion to consent (pp. 78-81). London: Conciliation Resources.

King, R. (2002). Towards a new map of European migration. International Journal of Population Geography, 8(2), 89-106.

Kitschelt, H. P. (1986). Political Opportunity Structures and Political Protest: AntiNuclear Movements in Four Democracies. British Journal of Political Science, 16(01), 57-85.

Kleist, N. (2015). Diaspora organisations as development actors. The New Europeans, 5 .

Koinova, M. (2011). Diasporas and secessionist conflicts: The mobilization of the Armenian, Albanian and Chechen diasporas. Ethnic and Racial Studies, 34(2), 333-356.

Koinova, M. (2012a). Autonomy and Positionality in Diaspora Politics. International Political Sociology, 6(1), 99-103.

Koinova, M. (2012b). Four Types of Diaspora Mobilization: Albanian Diaspora Activism For Kosovo Independence in the US and the UK. Foreign Policy Analysis, 9(4), pp. 433-453. 
Koinova, M. (2014a). Diasporas and Contextualized Transnationalism. In D. Abazović \& M. Velikonja (Eds.), Post-Yugoslavia: New Cultural and Political Perspectives (pp. 133-161). London: Palgrave Macmillan UK.

Koinova, M. (2014b). Why do conflict-generated diasporas pursue sovereigntybased claims through state-based or transnational channels? Armenian, Albanian and Palestinian diasporas in the UK compared. European Journal of International Relations, 20(4), 1043-1071.

Koinova, M. (2016). Sustained vs episodic mobilization among conflict-generated diasporas. International Political Science Review, 37(4), 500-516.

Koinova, M. (2017). Diaspora mobilisation for conflict and post-conflict reconstruction: Contextual and comparative dimensions. Journal of Ethnic and Migration Studies, 44(8), 1-19.

Koinova, M. (2018). Critical junctures and transformative events in diaspora mobilisation for Kosovo and Palestinian statehood. Journal of Ethnic and Migration Studies, 44(8), 1289-1308.

Koopmans, R. (2004). Migrant mobilisation and political opportunities: Variation among German cities and a comparison with the United Kingdom and the Netherlands. Journal of Ethnic and Migration Studies, 30(3), 449-470.

Koopmans, R., \& Statham, P. (2003). How National Citizenship Shapes Transnationalism: Migrant and Minority Claims-making in Germany, Great Britain and the Netherlands. In C. Joppke \& E. Morawska (Eds.), Toward Assimilation and Citizenship: Immigrants in Liberal Nation-States (pp. 195-238). London: Palgrave Macmillan.

Koser, K. (2007). African diasporas and post-conflict reconstruction: An Eritrean case study. In H. Smith \& P. B. Stares (Eds.), Diasporas in Conflict: Peace-Makers or Peace-Wreckers? (pp. 239-252). Tokyo, New York: United Nations University Press.

Kriesberg, L. (2014). Constructive Conflict Approach to World Struggles. Brown Journal of World Affairs 21, 23(1).

Kriesberg, L., \& Dayton, B. W. (2011). Constructive Conflicts: From Escalation to Resolution. Lanham: Rowman \& Littlefield Publishers. 
Lake, D. A., \& Rothchild, D. S. (1998). The International Spread of Ethnic Conflict: Fear, Diffusion, and Escalation. Princeton: Princeton University Press.

Levitt, P., \& Glick Schiller, N. (2004). Conceptualizing Simultaneity: A Transnational Social Field Perspective on Society1. International Migration Review, 38(3), 1002-1039.

Levitt, P., \& Lamba-Nieves, D. (2011). Social Remittances Revisited. Journal of Ethnic and Migration Studies, 37(1), 1-22.

Lewis, J. (2011). Design Issues. In J. Ritchie \& J. Lewis (Eds.), Qualitative research practice: A guide for social science students and researchers (pp. 47-76) Los Angeles: SAGE.

Luckham, R., Moncrieffe, J., \& Harris, C. (2006). Understanding the routes in and out of political violence: An assessment of the linkages between identity politics, exclusion, inequality and political violence in EMAD countries. Governance and Social Development Resource Centre, Birmingham.

Lum, B., Nikolko, M., Samy, Y., \& Carment, D. (2013). Diasporas, Remittances and State Fragility: Assessing the Linkages. Ethnopolitics, 12(2), 201-219.

Lundgren, M. (2016). Mediation in Syria: Initiatives, strategies, and obstacles, 20112016. Contemporary Security Policy, 37(2), 273-288.

Lyons, T. (2004). Engaging diasporas to promote conflict resolution: Transforming hawks into doves. Working Paper (Washington, DC: Institute of Conflict Analysis and Resolution, George Mason University).

Lyons, T., \& Mandaville, P. (2010). Think Locally, Act Globally: Toward a Transnational Comparative Politics. International Political Sociology, 4, 121-141.

Mack, N., Woodsong, C., MacQueen, K. M., Guest, G., \& Namey, E. (2005). Qualitative research methods: A data collectors field guide. Retrieved 21 February 2017. Research Triangle Park, North Carolina: Family Health International.

Mackenzie, C., McDowell, C., \& Pittaway, E. (2007). Beyond 'Do No Harm': The Challenge of Constructing Ethical Relationships in Refugee Research. Journal of Refugee Studies, 20(2), 299-319. 
MAIS NRW. (2017). Migrantenselbstorganisationen I Arbeit.Integration.Soziales. $\begin{array}{lllll}\text { Retrieved } & 1 & \text { May } & 2017 & \text { from: }\end{array}$ https://www.mais.nrw/migrantenselbsthilfeorganisationen

Mansfield, E. D., \& Snyder, J. (2007). Turbulent Transitions: Why Emerging Democracies Go to War. In C. A. Crocker, F. O. Hampson, \& P. R. Aall (Eds.), Leashing the Dogs of War: Conflict Management in a Divided World (pp. 161-177). US Institute of Peace Press.

Marcus, G. E. (1995). Ethnography in/of the World System: The Emergence of Multi-Sited Ethnography. Annual Review of Anthropology, 24(1), 95-117.

Martiniello, M. (2006). Political participation, mobilisation andrepresentation of immigrants and their offspring in Europe. In R. Bauböck \& K. Kraal (Eds.), Migration and citizenship: Legal status, rights and political participation (pp. 83-105). Amsterdam:Amsterdam University Press.

Martiniello, M., \& Lafleur, J.-M. (2008). Ethnic Minorities' Cultural and Artistic Practices as Forms of Political Expression: A Review of the Literature and a Theoretical Discussion on Music. Journal of Ethnic and Migration Studies, 34(8), 1191-1215.

Mason, J. (2002). Qualitative researching (2nd ed). London,Thousand Oaks, Calif: Sage Publications.

Mavroudi, E. (2007). Diaspora as Process: (De)Constructing Boundaries. Geography Compass, 1(3), 467-479.

Mavroudi, E. (2017). Deconstructing diasporic mobilisation at a time of crisis: Perspectives from the Palestinian and Greek diasporas. Journal of Ethnic and Migration Studies, 44(8), 1309-1324.

Mazzucato, V. (2008). The Double Engagement: Transnationalism and Integration. Ghanaian Migrants' Lives Between Ghana and The Netherlands. Journal of Ethnic and Migration Studies, 34(2), 199-216.

Mehchy, Z., \& Doko, A. M. (2011). General Overview of Migration into, through and from Syria. [Migration Policy Centre], [CARIM-South], CARIM Analytic and Synthetic Notes, 2011/41, Mediterranean and Sub-Saharan Migration: Recent Developments Series. 
Melucci, A. (2003). The Process of Collective Identity. In Social Movements and Culture. University of Minnesota Press.

Mey, E. (2008). Cambodian Diaspora Communities in Transitional Justice: Briefing Paper (March 2008; Briefing Paper). International Center for Transitional Justice (ICTJ).

Meyer, D. S., \& Minkoff, D. C. (2003). Conceptualizing Political Opportunity. Social Forces, 82, 1457.

Ministry of Foreign Affairs and Emigrants. (2019). Ministry of Foreign Affairs and Emigrants-Syrian Arab Republic. Retrieved 23 August 2019 from: http://www.mofa.gov.sy/

Minority Rights Group. (2018). Directory, Countries, Syria. Retrieved 23 February 2020 from Minority Rights Group website: https://minorityrights.org/country/syria/

Morales, L., \& Giugni, M. (Eds.). (2011). Social Capital, Political Participation and Migration in Europe. London: Palgrave Macmillan UK.

Morris, A., \& Braine, N. (2001). Social movements and oppositional consciousness. In J. Mansbridge \& A. Morris (Eds.), Oppositional Consciousness- The Subjective Roots of Social Protest (pp. 20-37). Chicago: University of Chicago Press.

Moss, D. M. (2016a). Diaspora Mobilization for Western Military Intervention During the Arab Spring. Journal of Immigrant E Refugee Studies, 14(3), 277-297.

Moss, D. M. (2016b). Transnational Repression, Diaspora Mobilization, and the Case of The Arab Spring. Social Problems, 63(4), 480-498.

MPC Team. (2013). MPC - Migration Profile Syria. Florence: Migration Policy Centre (MPC).

Müller-Funk, L. (2016). Diaspora Mobilizations in the Egyptian (Post)Revolutionary Process: Comparing Transnational Political Participation in Paris and Vienna. Journal of Immigrant E Refugee Studies, 14(3), 353-370.

Müller-Funk, L. (2019). Diaspora politics and political remittances: A conceptual reflection. In R. Cohen \& C. Fischer (Eds.), Routledge handbook of diaspora studies (pp. 402-414). London, New York: Routledge Taylor \& Francis Group. 
Nicholson, M. (1992). Rationality and the Analysis of International Conflict. Cambridge: Cambridge University Press.

Nielsen, T. M., \& Riddle, L. (2010). Investing in Peace: The Motivational Dynamics of Diaspora Investment in Post-Conflict Economies. Journal of Business Ethics, 89(4), 435-448.

Nijenhuis, G., \& Zoomers, A. (2015). Transnational activities of immigrants in the Netherlands: Do Ghanaian, Moroccan, And Surinamese diaspora organizations enhance development? In A. Portes \& M. P. Fernández-Kelly (Eds.), The state and the grassroots: Immigrant transnational organizations in four continents. New York: Berghahn Books.

Nowicka, M., \& Cieslik, A. (2014). Beyond methodological nationalism in insider research with migrants. Migration Studies, 2(1), 1-15.

OCHA. (2012). Syrian Arab Republic: Humanitarian Dashboard-17 December 2012. United Nations Office for the Coordination of Humanitarian Affairs (OCHA).

OCHA. (2019). Humanitarian Needs Overview-Syrian Arab Republic (March 2019; Humanitarian Needs Overview). United Nations Office for the Coordination of Humanitarian Affairs (OCHA).

OECD. (2001). Database on Immigrants in OECD and non-OECD Countries: DIOC OECD. Retrieved 23 November 2016, from: http://www.oecd.org/els/mig/dioc.htm

OECD. (2015). Syria. In Connecting with Emigrants (pp. 350-351). OECD Publishing. Retrieved 23 November 2016, from: http://www.oecd-ilibrary.org/social-issuesmigration-health/connecting-with-emigrants/syria_9789264239845-117-en

Omran, R. (2014). The Sect as Homeland. Critical Muslim, 11.1 Syria.

Orb, A., Eisenhauer, L., \& Wynaden, D. (2001). Ethics in Qualitative Research. Journal of Nursing Scholarship, 33(1), 93-96.

Orjuela, C. (2008). Distant warriors, distant peace workers? Multiple diaspora roles in Sri Lanka's violent conflict. Global Networks, 8(4), 436-452.

Orjuela, C. (2012). Diaspora Identities and Homeland Politics: Lessons from the Sri Lanka/Tamil Eelam Case. In T. Lyons \& P. G. Mandaville (Eds.), Politics from afar (pp. 91-116). New York: Columbia University Press. 
Orsini, C. (2016). Narratives of (non)intervention: Syria from the humanitarian to the terror lens. Paris School of International Affairs. Paris: Sciences Po.

Østergaard-Nielsen, E. (2003a). Transnational politics: Turks and Kurds in Germany. London: Routledge.

Østergaard-Nielsen, E. (2003b). The Politics of Migrants' Transnational Political Practices. International Migration Review, 37(3), 760-786.

Patton, M. Q. (2002). Qualitative research and evaluation methods (3 ed). Thousand Oaks, Calif: Sage Publications.

Però, D., \& Solomos, J. (2010). Introduction: Migrant Politics and Mobilization: Exclusion, Engagements, Incorporation. Ethnic and Racial Studies, 33(1), 1-18.

Pettersson, T., \& Wallensteen, P. (2015). Armed conflicts, 1946-2014. Journal of Peace Research, 52(4), 536-550.

Phillips, C. (2015). Sectarianism and conflict in Syria. Third World Quarterly, 36(2), 357-376.

Phillips, C., \& Valbjørn, M. (2018). 'What is in a Name?': The Role of (Different) Identities in the Multiple Proxy Wars in Syria. Small Wars \& Insurgencies, 29(3),

Pinto, P. G. (2017). The Shattered Nation: The Sectarianization of the Syrian Conflict. In N. Hashemi \& D. Postel (Eds.), Sectarianization: Mapping the new politics of the Middle East. Oxford, New York: Oxford University Press.

Polletta, F., \& Jasper, J. M. (2001). Collective Identity and Social Movements. Annual Review of Sociology, 27, 283-305.

Portes, A. (2015). Immigration, Transnationalism and, Development-The State of the Question. In A. Portes \& M. P. Fernández-Kelly (Eds.), The state and the grassroots: Immigrant transnational organizations in four continents (pp. 1-24). New York: Berghahn Books.

Portes, A., Escobar, C., \& Arana, R. (2008). Bridging the gap: Transnational and ethnic organizations in the political incorporation of immigrants in the United States. Ethnic and Racial Studies, 31(6), 1056-1090.

Portes, A., Escobar, C., \& Radford, A. W. (2007). Immigrant Transnational Organizations and Development: A Comparative Study. International Migration Review, 41(1), 242-281. 
Pries, L., \& Sezgin, Z. (2012). Migration, Organizations and transnational Ties. In Cross border migrant organizations in comparative perspective (pp. 1-36). Houndmills, Basingstoke; New York: Palgrave Macmillan.

Qayyum, M. (2011). Syrian Diaspora: Cultivating a New Public Space Consciousness. Washington: Middle East Institute.

Quinsaat, S. M. (2019). Diasporas as social movements? In R. Cohen \& C. Fischer (Eds.), Routledge handbook of diaspora studies (pp. 93-104). London, New York: Routledge Taylor \& Francis Group.

Ragab, N. J., Rahmeier, L., \& Siegel, M. (2017). Mapping the Syrian diaspora in Germany-Contributions to peace, reconstruction and potentials for collaboration with German Development Cooperation (Commissioned by Deutsche Gesellschaft Für Internationale Zusammenarbeit (GIZ). Maastricht Graduate School of Governance/UNU merit.

Rancière, J., \& Corcoran, S. (2010). Dissensus: On politics and aesthetics. London, New York: Continuum.

Reuters. (2014, May 28). Tens of thousands of Syrians abroad vote in early poll. Reuters. Retrieved 6 August 2018, from: http:// www.reuters.com/article/ussyria-crisis-election-idUSKBNOE815R20140528

Riaño-Alcalá, P., \& Goldring, L. (2014). Unpacking Refugee Community Transnational Organizing: The Challenges and Diverse Experiences of Colombians in Canada. Refugee Survey Quarterly, 33(2), 84-111.

Roth, R. (2017). Politische Partizipation von Migrantinnen und Migranten. In T. Groß, S. Huth, B. Jagusch, A. Klein, \& S. Naumann (Eds.), Engagierte Migranten: Teilhabe in der Bürgergesellschaft (pp. 61-74). Schwalbach/Ts: WochenschauVerlag.

Ruhs, M. (2010). Migrant Rights, Immigration Policy and Human Development. Journal of Human Development and Capabilities, 11(2), 259-279.

Ryan, L. (2015). 'Inside' and 'Outside' of What or Where? Researching Migration Through Multi-Positionalities. Forum Qualitative Sozialforschung / Forum: Qualitative Social Research, Vol 16, No 2 (2015).

Safran, W. (1991). Diasporas in Modern Societies: Myths of Homeland and Return. Diaspora: A Journal of Transnational Studies, 1(1), 83-99. 
Saideman, S. M., Jenne, E., \& Cunningham, K. G. (2011). Diagnosing Diasporas: Understanding the Conditions Fostering or Blocking Mobilization (SSRN Scholarly Paper ID 1900448). Social Science Research Network.

Saldaña, J. (2013). The coding manual for qualitative researchers (2nd ed). Los Angeles: SAGE.

Sauer, M. (2016). Politische und zivilgesellschaftliche Partizipation von Migranten. In Einwanderungsgesellschaft Deutschland (pp. 255-279). Springer VS, Wiesbaden.

Schmitz Stiftung. (2016). EZ-Kleinprojektefonds. Schmitz Stiftungen. Retrieved 19 November 2016, from Schmitz Stiftungen website: http:/www.schmitzstiftungen.de/de/ez-kleinprojektefonds/

Schweitzer, C., Ronnefeldt, C., Grobe-Hagel, K., \& Buro, A. (2012). Syrien zwischen gewaltfreiem Aufstand und Bürgerkrieg (Dossier V). Monitoring-Projekt, Zivile Konfliktbearbeitung, Gewalt- und Kriegsprävention.

Shain, Y., \& Barth, A. (2003). Diasporas and International Relations Theory. International Organization, 57(03), 449-479. https://doi.org/10.1017/S0020818303573015

Sheffer, Gabriel. (2006). Diaspora politics: At home abroad. New York Cambridge University Press.

Simon, B., \& Klandermans, B. (2001). Politicized collective identity: A social psychological analysis. American Psychologist, 56(4), 319.

Sinatti, G., \& Horst, C. (2015). Migrants as agents of development: Diaspora engagement discourse and practice in Europe. Ethnicities, 15(1), 134-152.

Skrbis, Z. (2007). The mobilized Croatian diaspora: Its role in homeland politics and war. In H. Smith \& P. B. Stares (Eds.), Diasporas in Conflict: Peace-Makers or Peace-Wreckers? (pp. 218-238). Tokyo, New York: United Nations University Press.

Smith, H. (2007). Diasporas in international conflict. In H. Smith \& P. B. Stares (Eds.), Diasporas in Conflict: Peace-Makers or Peace-Wreckers? (pp. 3-16). Tokyo, New York: United Nations University Press.

Smith, H., \& Stares, P. B. (Eds.). (2007). Diasporas in Conflict: Peace-Makers or PeaceWreckers? Tokyo, New York: United Nations University Press. 
Snow, D.A. (2001). Collective Identity and Expressive Forms. In International Encyclopedia of the Social \& Behavioral Sciences (pp. 2212-2219). Elsevier.

Sökefeld, M. (2006). Mobilizing in transnational space: A social movement approach to the formation of diaspora. Global Networks, 6(3), 265-284.

Soysal, Y. N. (2000). Citizenship and identity: Living in diasporas in post-war Europe? Ethnic and Racial Studies, 23(1), 1-15.

Stadt Wuppertal. (2016). Die Initiative 'Syrien von Morgen' stellt sich vor. Retrieved 27 March 2018, from: https://www.wuppertal.de/pressearchiv/meldungen2016/september/102370100000721548.php

Statistisches Bundesamt. (2016). Statistische Daten zu Flüchtlingen-Statistisches Bundesamt (Destatis). Retrieved 19 December 2016, from:

https://www.destatis.de/DE/ZahlenFakten/_Querschnitt/Fluechtlinge/Fluechtlin ge.html

Statistisches Bundesamt. (2018). Bevölkerung und Erwerbstätigkeit. Ausländische Bevölkerung- Ergebnisse des Ausländerzentralregisters 2017 (Fachserie 1 Reihe 2). Wiesbaden: Statistisches Bundesamt.

Statistisches Bundesamt. (2019a). Bevölkerung und Erwerbstätigkeit - Bevölkerung mit Migrationshintergrund - Ergebnisse des Mikrozensus 2018 (Fachserie 1 Reihe 2.2). Wiesbaden: Statistisches Bundesamt.

Statistisches Bundesamt. (2019b). Bevölkerung und Erwerbstätigkeit. Ausländische Bevölkerung- Ergebnisse des Ausländerzentralregisters 2018 (Fachserie 1 Reihe 2). Wiesbaden: Statistisches Bundesamt.

Stiftung Nord-Süd-Brücken. (2016). Stiftung Nord-Süd-Brücken | Fördermöglichkeiten. Retrieved 19 November 2016, from:

http://www.nord-sued-bruecken.de/foerderinstrumente/

Stokke, E., \& Wiebelhaus-Brahm, E. (2019). Syrian diaspora mobilization: Vertical coordination, patronage relations, and the challenges of fragmentation in the pursuit of transitional justice. Ethnic and Racial Studies, 1-20.

Svoboda, E., \& Pantuliano, S. (2015). International and local/diaspora actors in the Syria response. A diverging set of systems? London: Overseas Development Institute. 
Syrian Arab News Agency (SANA). (2017, August 20). President al-Assad: Everything related to the destiny and future of Syria is a $100 \%$ Syrian issue, unity of Syrian territory is self-evident and not up for debate. Syrian Arab News Agency. Retrieved 15 July 2019, from https://sana.sy/en/?p=112238

Tarrow, S. (1988). National Politics and Collective Action: Recent Theory and Research in Western Europe and the United States. Annual Review of Sociology, 14(1), 421-440.

Tarrow, S. (2011). Power in Movement: Social Movements and Contentious Politics. New York: Cambridge University Press.

Taylor, V. (2013). Social Movement Participation in the Global Society: Identity, Networks and Emotions. In J. van Stekelenburg, C. Roggeband, \& B. Klandermans (Eds.), The future of social movement research: Dynamics, mechanisms, and processes. Minneapolis: University of Minnesota Press.

Taylor, V., \& Whittier, N. E. (1992). Collective identity in social movement communities: Lesbian feminist mobilization. In A. D. Morris \& C. M. Mueller (Eds.), Frontiers in Social Movement Theory (pp. 104-130). New Haven, London: Yale University Press.

Trimble, J. E., \& Fisher, C. B. (Eds.). (2006). The Handbook of Ethical Research with Ethnocultural Populations and Communities. Thousand Oaks, London, New Delhi: SAGE.

Turcu, A., \& Urbatsch, R. (2015). Diffusion of Diaspora Enfranchisement Norms: A Multinational Study. Comparative Political Studies, 48(4), 407-437.

Turner, M. (2008). Three Discourses on Diasporas and Peacebuilding. In M. C. Pugh, N. Cooper, \& Mandy Turner (Eds.), Whose Peace? Critical Perspectives on the Political Economy of Peacebuilding - (pp. 132-190). Basingstoke [England], New York: Palgrave Macmillan.

Turner, S. (2013). Staging the Rwandan Diaspora: The Politics of Performance. African Studies, 72(2), 265-284.

Ulutas, U. (2011). The Syrian Opposition in the Making: Capabilities and Limits. Insight Turkey, 13(3), 87-105.

UNHCR. (2019). Global Trends-Forced Displacement in 2018. UNHCR (United Nations High Commissioner for Refugees). 
United Nations, Department of Economic and Social Affairs, Population Division. (2019). International Migrant Stock 2019 (United Nations Database, POP/DB/MIG/Stock/Rev.2019).

United Nations Secretary-General. (2016, April 22). Note to Correspondents: Transcript of press stakeout by United Nations Special Envoy for Syria, Mr. Staffan de Mistura. Retrieved 7 October 2019, from United Nations Secretary-General website:

https://www.un.org/sg/en/content/sg/note-correspondents/2016-04-22/notecorrespondents-transcript-press-stakeout-united

Van Hear, N., \& Cohen, R. (2017). Diasporas and conflict: Distance, contiguity and spheres of engagement. Oxford Development Studies, 45(2), 171-184.

van Stekelenburg, J. (2013). Collective Identity. In David A. Snow, D. Della Porta, B. Klandermans, \& D. McAdam (Eds.), The Wiley-Blackwell Encyclopedia of Social and Political Movement. Malden, MA: Blackwell Publishing Ltd.

Van Veen, E. (2019). The Geopolitics Of Syria's Reconstruction: A Case Of Matryoshka. Syria Studies, 11(1), 33-56.

Vertovec, S. (2005). The political importance of diasporas. (Working Paper No. 13) Oxford: Centre on Migration, Policy and Society, University of Oxford.

Vertovec, S. (2007). Super-diversity and its implications. Ethnic and Racial Studies, 30(6), 1024-1054.

Vertovec, S., \& Kraal, K. (2016). Citizenship in European cities: Immigrants, local politics, and integration policies. London, New York: Routledge Taylor and Francis Group.

Vicente, M. (2011). Die Arbeit der Integrationsbeiräte in Deutschland. Forschungsjournal Soziale Bewegungen, 24(2), 38-43.

Vignal, L. (2018). Perspectives on the return of Syrian refugees (FMR 57; Forced Migration Review, pp. 69-71). University of Oxford.

Vollmer, B., \& Karakayali, S. (2018). The Volatility of the Discourse on Refugees in Germany. Journal of Immigrant \& Refugee Studies, 16(1-2), 118-139.

Wallensteen, P. (2018). Understanding Conflict Resolution. London, Thousand Oaks, New Delhi, Singapore: SAGE. 
Walton, O. (2014). Framing disputes and organizational legitimation: UK-based Sri Lankan Tamil diaspora groups' use of the 'genocide' frame since 2009. Ethnic and Racial Studies, 1-17.

Ward, J., Silberman, M., \& Till, K. E. (2012). Walls, Borders, Boundaries: Spatial and Cultural Practices in Europe. New York: Berghahn Books.

Warnecke, A. (2010). Diaspora and peace: A comparative assessment of Somali and Ethiopian communities in Europe (BICC brief 42). Bonn: Bonn International Center for Conversion (BICC).

Wayland, S. (2004). Ethnonationalist networks and transnational opportunities: The Sri Lankan Tamil diaspora. Review of International Studies, 30(03), 405-426.

Weerakkody, N. (2006). Where else have you been? The effects of diaspora consciousness and transcultural mixtures on ethnic identity. Journal of Issues: Proceedings of the Informing Science+ Information Technology Conference (InSITE), 3, 709-720.

Werbner, P. (2002). The place which is diaspora: Citizenship, religion and gender in the making of chaordic transnationalism. Journal of Ethnic and Migration Studies, 28(1), 119-133.

Women For Common Spaces (2017). Female Voices in Exile, No. 1. Berlin. Retrieved 11 July 2018, from https://issuu.com/sashawaltz/docs/voices_1b_10.

White, B. (2007). The Nation-State Form and the Emergence of 'Minorities" in Syria'. Studies in Ethnicity and Nationalism, 7(1), 64-85.

Wieland, C. (2012). Syria- A decade of lost chances: Repression and revolution from Damascus Spring to Arab Spring. Seattle: Cune Press.

Wüst, A. M. (2014). Immigration into Politics: Immigrant-origin Candidates and Their Success in the 2013 Bundestag Election. German Politics and Society, 32(3),

Wüst, A. M. (2016). Incorporation beyond Cleavages? Parties, Candidates and Germany's Immigrant-Origin Electorate. German Politics, 25(3), 414-432.

Yassin-Kassab, R., \& Al-Shami, L. (2016). Burning country: Syrians in revolution and war. London: Pluto Press.

Yuval-Davis, N. (2006). Belonging and the politics of belonging. Patterns of Prejudice, 40(3), 197-214. 
Yuval-Davis, N., Kannabirān, Kalpana., \& Vieten, Ulrike. (2006). The situated politics of belonging. London: SAGE.

Zunzer, W. (2004). Diaspora communities and civil conflict transformation (Berghof Occasional Paper Nr. 26). Berlin: Berghof Research Center for Constructive Conflict Management. 


\section{Appendix I: Interview guide}

\section{A. Introductory question}

First, I would like to start with a more personal question

1. Can you tell me a bit more about your migration experience?
a. How was your live before you left Syria?
b. What year did you migrate to Germany?
c. What were the reasons for your migration?

\section{B. Syrian community and diaspora mobilisation}

Now, I would like to ask you some questions on the Syrian diaspora.

1. Can you tell me some details about the Syrian diaspora in Germany?

a. Is it homogeneous or heterogeneous? [In terms of socio-economic factors, ethnicity, political aspirations and religion].

b. Are there strong ties/networks within the Syrian diaspora in Germany, and in other countries? [What is the role of ethnicity and religion, political ideologies if any?]

c. What is the relationship to Syria? [Are there strong connections? What is the relationship to the state?]

d. How do you perceive the "evolution" of the Syrian diaspora since you've lived in Germany?

\section{Perception on peace and conflict}

Now, I would like to ask you some questions on the Syrian conflict.

1. In your opinion, how would a peaceful Syria look like and how could peace be achieved?

2. How do you perceive the role of the Syrian diaspora?

3. Have your perceptions changed over time?

\section{Basic organisational information}

Now, I would like to ask some basic information about your organisation - about how it started, why and what the main characteristics are.

1. What motivated you to become engaged?

1. In what year was this organisation established? Why was the organisation established, and why at that time?

2. What would you say is the goal or the "core mission" of the organisation? [Has it changed over time?]

3. What is the size of your organisation's membership? [Does this include both active and inactive members? (What is the size of both groups?]

4. Do you have paid staff? Or is it run on voluntary basis? 
5. Is the size of your membership consistent, or does it fluctuate?

6. What is the composition of your membership? [What is the distribution in terms of gender, age, generation (e.g., first, second, etc.), ethnic group, educational level, newcomers?]

4) How is your organisation financed?

Is the organisation part of any larger network of organisations, like an umbrella organisation for all Syrian diaspora organisations, or a transnational migrant platform, or something similar? [Why or why not?]

\section{E. Current organisation activities in conflict}

Now, let's talk about what your organisation does, about what kinds of activities or events your organisation organises or takes part in. I'm also interested in your view on the conflict.

1. What kind of activities and projects does your organisation implement both Syrian and in Germany? [Please, describe all activities in detail]

2. Have these core activities changed over time? [If so, why]?

3. Where do these activities take place? [Are some activities run exclusively from Germany while others take place in Syria or in the refugee camps?]

4. Why have these activities become the focus of your organisation? What inspired these activities?

\section{F. Cooperation}

1. Are any of your organisation's activities run in cooperation with other organisations or institutions, either in country of destination or in Syria? If so, which ones and how? [In other words: does your organisation cooperate with others to execute certain activities?]

a. Do you corporate with other Syrian diaspora organisations in Germany or other countries of residence? [Why or why not? If yes: Could you give me the names of the organisations?]

2. How does your organisation interact with stakeholders in Syria/neighbouring countries?

a. What kind of stakeholders are these?

b. Does your organisation support any specific group in Syria?

3. Does the government in Germany have programs in place to facilitate cooperation with stakeholders in Syria/neighbouring countries?

\section{G. Main Challenges and future Plans}

Finally, I would like to talk about the future of your organisation-about what is on your agenda for the coming months and years. 
1. What is the key driver that motivates you to continue your engagement? What would you like to see the organisation achieve in the future? [For instance, what are its short/medium/long-term goals?]

2. What are its key challenges/obstacles now and in the future?

Is there any other important information, you think I should know? 


\section{Appendix II: Template field notes}

Event:

Date:

Place:

Descriptive information:

- What was the nature of the event (e.g. protest, discussion round, information event, exhibition, concert)?

- By whom was it organised (e.g. diaspora organisation, activists, stakeholder)?

- Who were participating in the event (e.g. only diaspora political entrepreneurs or also other stakeholder and groups) and what was their role (e.g. actively participating or passive)?

- How did the participants interact with each other (e.g. collaborative or conflictual, non-violent or violent)?

- Have there been patterns or specific events that sparked a change in behaviour or emotions of the participants (e.g. specific points raised which caused a dispute)?

\section{Reflective information:}

- What kind of ideas, impressions, thoughts, and/or any criticisms are sparked by the observed situation?

- Are there any unanswered questions or concerns that have arisen from analysing the observation data?

- What are potential thoughts regarding any future observations?

- What was my potential impact on the observed situation?

\section{Emerging questions/analysis:}

- How does the collected data relate to the research question?

- What does the observed information add to other parts of data (e.g. supplementing or contradicting)? 


\section{Appendix III: Participant list}

\begin{tabular}{|c|c|c|c|c|c|}
\hline Code & $\begin{array}{l}\text { Type of } \\
\text { Engagement }\end{array}$ & Gender & $\begin{array}{l}\text { Reasons for } \\
\text { migration }\end{array}$ & $\begin{array}{l}\text { Year of } \\
\text { arrival }\end{array}$ & $\begin{array}{l}\text { Interview Place } \\
\text { and Date }\end{array}$ \\
\hline I1 & Academic & Female & Education & 2002 & $\begin{array}{l}\text { Berlin, } \\
\text { September } 2012\end{array}$ \\
\hline $\mathrm{I} 2$ & $\begin{array}{l}\text { Advocacy } \\
\text { organisation }\end{array}$ & Male & Education & 1999 & $\begin{array}{l}\text { Berlin, } \\
\text { September } 2012\end{array}$ \\
\hline $\mathrm{I} 3 \mathrm{a}$ & $\begin{array}{l}\text { Advocacy } \\
\text { organisation }\end{array}$ & Female & Education & 1981 & $\begin{array}{l}\text { Berlin, } \\
\text { September } 2012\end{array}$ \\
\hline $\mathrm{I} 3 \mathrm{~b}$ & $\begin{array}{l}\text { Advocacy } \\
\text { organisation }\end{array}$ & Male & Education & 1999 & $\begin{array}{l}\text { Berlin, } \\
\text { September } 2012\end{array}$ \\
\hline $\mathrm{I} 3 \mathrm{c}$ & $\begin{array}{l}\text { Advocacy } \\
\text { organisation }\end{array}$ & Male & Education & 2009 & $\begin{array}{l}\text { Berlin, } \\
\text { September } 2012\end{array}$ \\
\hline $\mathrm{I} 3 \mathrm{~d}$ & $\begin{array}{l}\text { Advocacy } \\
\text { organisation }\end{array}$ & Male & Education & 2007 & $\begin{array}{l}\text { Berlin, } \\
\text { September } 2012\end{array}$ \\
\hline $\mathrm{I} 4$ & $\begin{array}{l}\text { Human rights-based } \\
\text { organisation }\end{array}$ & Male & $\begin{array}{l}\text { Political } \\
\text { persecution }\end{array}$ & 1999 & $\begin{array}{l}\text { Bonn, September } \\
2012\end{array}$ \\
\hline I5 & Political activist & Male & Education & 2001 & $\begin{array}{l}\text { Aachen, } \\
\text { September } 2012\end{array}$ \\
\hline I6 & $\begin{array}{l}\text { Advocacy } \\
\text { organisation }\end{array}$ & Male & Education & 2003 & $\begin{array}{l}\text { Skype, October } \\
2012\end{array}$ \\
\hline I7 & $\begin{array}{l}\text { Advocacy } \\
\text { organisation }\end{array}$ & Female & $\begin{array}{l}\text { Second } \\
\text { generation }\end{array}$ & n.a. & $\begin{array}{l}\text { Skype, October } \\
2012\end{array}$ \\
\hline I8 & Media activist & Male & Education & 2005 & $\begin{array}{l}\text { Skype, October } \\
2012\end{array}$ \\
\hline I9 & $\begin{array}{l}\text { Humanitarian } \\
\text { organisation }\end{array}$ & Male & Education & 2000 & $\begin{array}{l}\text { Skype, October } \\
2012\end{array}$ \\
\hline $\mathrm{I} 10$ & Civil society activist & Male & $\begin{array}{l}\text { Political } \\
\text { persecution }\end{array}$ & 2011 & $\begin{array}{l}\text { Skype, October } \\
2012\end{array}$ \\
\hline I11 & $\begin{array}{l}\text { Humanitarian } \\
\text { organisation }\end{array}$ & Male & $\begin{array}{l}\text { Second } \\
\text { generation }\end{array}$ & n.a. & $\begin{array}{l}\text { Skype, October } \\
2012\end{array}$ \\
\hline $\mathrm{I} 12$ & Student organisation & Male & Education & 2009 & $\begin{array}{l}\text { Skype, October } \\
2012\end{array}$ \\
\hline I13 & Humanitarian & Male & Education & 1990 & Skype, October \\
\hline
\end{tabular}




\begin{tabular}{|c|c|c|c|c|c|}
\hline Code & $\begin{array}{l}\text { Type of } \\
\text { Engagement }\end{array}$ & Gender & $\begin{array}{l}\text { Reasons for } \\
\text { migration }\end{array}$ & $\begin{array}{l}\text { Year of } \\
\text { arrival }\end{array}$ & $\begin{array}{l}\text { Interview Place } \\
\text { and Date }\end{array}$ \\
\hline & organisation & & & & 2012 \\
\hline I14 & $\begin{array}{l}\text { Humanitarian } \\
\text { organisation }\end{array}$ & Male & Education & 1976 & $\begin{array}{l}\text { Phone, October } \\
2013\end{array}$ \\
\hline I15 & $\begin{array}{l}\text { Humanitarian } \\
\text { organisation }\end{array}$ & Male & Education & 1990 & $\begin{array}{l}\text { Phone, } \\
\text { November } 2013\end{array}$ \\
\hline I16 & Diaspora network & Male & $\begin{array}{l}\text { Second } \\
\text { generation }\end{array}$ & n.a. & $\begin{array}{l}\text { Phone, January } \\
2014\end{array}$ \\
\hline I17 & $\begin{array}{l}\text { Humanitarian } \\
\text { organisation }\end{array}$ & Male & Education & 1992 & $\begin{array}{l}\text { Skype, June } \\
2015,\end{array}$ \\
\hline I18 & Media activist & Male & Education & 1986 & $\begin{array}{l}\text { Cologne, July } \\
2015\end{array}$ \\
\hline I19a & Youth activist & Female & $\begin{array}{l}\text { Family } \\
\text { migration }\end{array}$ & 1993 & $\begin{array}{l}\text { Cologne, July } \\
2015\end{array}$ \\
\hline $\mathrm{I} 19 \mathrm{~b}$ & Youth activist & Female & $\begin{array}{l}\text { Family } \\
\text { migration }\end{array}$ & 1993 & $\begin{array}{l}\text { Cologne, July } \\
2015\end{array}$ \\
\hline $\mathrm{I} 20$ & Peace activist & Male & Education & 2011 & $\begin{array}{l}\text { Skype, January } \\
2016\end{array}$ \\
\hline $\mathrm{I} 21$ & $\begin{array}{l}\text { Political activist, } \\
\text { round } 2\end{array}$ & Male & Education & 2001 & $\begin{array}{l}\text { Aachen, January } \\
2016\end{array}$ \\
\hline $\mathrm{I} 22$ & $\begin{array}{l}\text { Diaspora think- } \\
\text { thank }\end{array}$ & Male & Education & 2005 & $\begin{array}{l}\text { Krefeld, January } \\
2016\end{array}$ \\
\hline $\mathrm{I} 23 \mathrm{a}$ & $\begin{array}{l}\text { Humanitarian } \\
\text { organisation }\end{array}$ & Male & $\begin{array}{l}\text { Political } \\
\text { persecution }\end{array}$ & 1986 & $\begin{array}{l}\text { Hannover, } \\
\text { January } 2016\end{array}$ \\
\hline $\mathrm{I} 23 \mathrm{~b}$ & $\begin{array}{l}\text { Humanitarian } \\
\text { organisation }\end{array}$ & Male & Work & 1963 & $\begin{array}{l}\text { Hannover, } \\
\text { January } 2016\end{array}$ \\
\hline $\mathrm{I} 24$ & $\begin{array}{l}\text { Media activist, } \\
\text { round } 2\end{array}$ & Male & Education & 2005 & $\begin{array}{l}\text { Bremen, January } \\
2016\end{array}$ \\
\hline $\mathrm{I} 25$ & Diaspora network & Female & n.a. & n.a. & $\begin{array}{l}\text { Berlin, January } \\
2016\end{array}$ \\
\hline $\mathrm{I} 26$ & $\begin{array}{l}\text { Humanitarian } \\
\text { organisation, round } \\
2\end{array}$ & Male & $\begin{array}{l}\text { Second } \\
\text { generation }\end{array}$ & n.a. & $\begin{array}{l}\text { Skype, January } \\
2016\end{array}$ \\
\hline $\mathrm{I} 27$ & $\begin{array}{l}\text { Humanitarian } \\
\text { organisation }\end{array}$ & Male & $\begin{array}{l}\text { Family } \\
\text { migration }\end{array}$ & 1970 & $\begin{array}{l}\text { Braunschweig, } \\
\text { March } 2016\end{array}$ \\
\hline
\end{tabular}




\begin{tabular}{|c|c|c|c|c|c|}
\hline Code & $\begin{array}{l}\text { Type of } \\
\text { Engagement }\end{array}$ & Gender & $\begin{array}{l}\text { Reasons for } \\
\text { migration }\end{array}$ & $\begin{array}{l}\text { Year of } \\
\text { arrival }\end{array}$ & $\begin{array}{l}\text { Interview Place } \\
\text { and Date }\end{array}$ \\
\hline $\mathrm{I} 28$ & $\begin{array}{l}\text { Advocacy } \\
\text { organisation }\end{array}$ & Male & $\begin{array}{l}\text { Political } \\
\text { persecution }\end{array}$ & 1983 & $\begin{array}{l}\text { Hannover, } \\
\text { March } 2016\end{array}$ \\
\hline I29 & $\begin{array}{l}\text { Humanitarian } \\
\text { organisation }\end{array}$ & Male & Education & 1970 & $\begin{array}{l}\text { Hannover, } \\
\text { March } 2016\end{array}$ \\
\hline $\mathrm{I} 30$ & $\begin{array}{l}\text { Humanitarian } \\
\text { organisation, round } \\
2\end{array}$ & Male & Education & 1979 & $\begin{array}{l}\text { Hamburg, } \\
\text { March } 2016\end{array}$ \\
\hline I31 & Charity organisation & Male & $\begin{array}{l}\text { Political } \\
\text { persecution }\end{array}$ & 2015 & $\begin{array}{l}\text { Berlin, March } \\
2016\end{array}$ \\
\hline $\mathrm{I} 32$ & $\begin{array}{l}\text { Musician and } \\
\text { political activist }\end{array}$ & Male & $\begin{array}{l}\text { Political } \\
\text { persecution }\end{array}$ & 2014 & $\begin{array}{l}\text { Berlin, March } \\
2016\end{array}$ \\
\hline $\mathrm{I} 33$ & Academic, round 2 & Female & Education & 2002 & $\begin{array}{l}\text { Berlin, March } \\
2016\end{array}$ \\
\hline $\mathrm{I} 34$ & Stakeholder & Male & n.a. & n.a. & $\begin{array}{l}\text { Berlin, March } \\
2016\end{array}$ \\
\hline $\mathrm{I} 35$ & $\begin{array}{l}\text { Civil society } \\
\text { organisation }\end{array}$ & Male & Education & 1990 & $\begin{array}{l}\text { Phone, April } \\
2016\end{array}$ \\
\hline $\mathrm{I} 36$ & $\begin{array}{l}\text { Cultural-social } \\
\text { organisation }\end{array}$ & Male & Education & 2005 & $\begin{array}{l}\text { Berlin, April } \\
2016\end{array}$ \\
\hline I37 & $\begin{array}{l}\text { Cultural-social } \\
\text { organisation }\end{array}$ & Male & $\begin{array}{l}\text { Political } \\
\text { persecution }\end{array}$ & 2013 & $\begin{array}{l}\text { Berlin, April } \\
2016\end{array}$ \\
\hline $\mathrm{I} 38$ & $\begin{array}{l}\text { Human rights } \\
\text { lawyer and gender } \\
\text { activist }\end{array}$ & Female & $\begin{array}{l}\text { Political } \\
\text { persecution }\end{array}$ & 2013 & $\begin{array}{l}\text { Berlin, April } \\
2016\end{array}$ \\
\hline I39 & $\begin{array}{l}\text { Civil society activist, } \\
\text { round } 2\end{array}$ & Male & $\begin{array}{l}\text { Political } \\
\text { persecution }\end{array}$ & 2012 & $\begin{array}{l}\text { Berlin, April } \\
2016\end{array}$ \\
\hline $\mathrm{I} 40$ & $\begin{array}{l}\text { Human rights-based } \\
\text { organisation, round } \\
2\end{array}$ & Male & $\begin{array}{l}\text { Political } \\
\text { persecution }\end{array}$ & 1999 & Bonn, April 2016 \\
\hline I41 & $\begin{array}{l}\text { Humanitarian } \\
\text { organisation }\end{array}$ & Male & Education & 1999 & $\begin{array}{l}\text { Cologne, April } \\
2016\end{array}$ \\
\hline $\mathrm{I} 42$ & Artist & Male & Education & 1971 & $\begin{array}{l}\text { Aachen, April } \\
2016\end{array}$ \\
\hline I43 & $\begin{array}{l}\text { Humanitarian and } \\
\text { advocacy }\end{array}$ & Male & Second & n.a. & Phone, April \\
\hline
\end{tabular}




\begin{tabular}{|c|c|c|c|c|c|}
\hline Code & $\begin{array}{l}\text { Type of } \\
\text { Engagement }\end{array}$ & Gender & $\begin{array}{l}\text { Reasons for } \\
\text { migration }\end{array}$ & $\begin{array}{l}\text { Year of } \\
\text { arrival }\end{array}$ & $\begin{array}{l}\text { Interview Place } \\
\text { and Date }\end{array}$ \\
\hline & organisation & & generation & & 2016 \\
\hline $\mathrm{I} 44$ & $\begin{array}{l}\text { Student } \\
\text { organization }\end{array}$ & Male & Education & 2012 & Bonn, April 2016 \\
\hline $\mathrm{I} 45$ & Journalist & Male & Education & 1990 & $\begin{array}{l}\text { Berlin, April } \\
2016\end{array}$ \\
\hline I46 & Media activist & Female & $\begin{array}{l}\text { Political } \\
\text { persecution }\end{array}$ & 2014 & $\begin{array}{l}\text { Berlin, April } \\
2016\end{array}$ \\
\hline $\mathrm{I} 47$ & Media activist & Male & $\begin{array}{l}\text { Political } \\
\text { persecution }\end{array}$ & 2014 & Berlin, May 2016 \\
\hline $\mathrm{I} 48$ & $\begin{array}{l}\text { Cultural and } \\
\text { political activist }\end{array}$ & Male & $\begin{array}{l}\text { Political } \\
\text { persecution }\end{array}$ & 2014 & $\begin{array}{l}\text { Cologne, May } \\
2016\end{array}$ \\
\hline I49 & Writer & Male & $\begin{array}{l}\text { Political } \\
\text { persecution }\end{array}$ & 2014 & $\begin{array}{l}\text { Cologne, May } \\
2016\end{array}$ \\
\hline $\mathrm{I} 50$ & Artist & Female & Conflict & 2014 & $\begin{array}{l}\text { Aachen, May } \\
2016\end{array}$ \\
\hline I51 & $\begin{array}{l}\text { Humanitarian } \\
\text { organisation }\end{array}$ & Male & $\begin{array}{l}\text { Political } \\
\text { persecution }\end{array}$ & 2013 & Skype, June 2016 \\
\hline I52 & $\begin{array}{l}\text { Development } \\
\text { organisation }\end{array}$ & Male & $\begin{array}{l}\text { Political } \\
\text { persecution }\end{array}$ & 2012 & $\begin{array}{l}\text { Leipzig, July } \\
2016\end{array}$ \\
\hline I53 & $\begin{array}{l}\text { Film maker and } \\
\text { writer }\end{array}$ & Male & $\begin{array}{l}\text { Political } \\
\text { persecution }\end{array}$ & 2012 & Berlin, July 2016 \\
\hline I54 & $\begin{array}{l}\text { Humanitarian } \\
\text { organisation }\end{array}$ & Male & Education & 2003 & $\begin{array}{l}\text { Phone, Octobre } \\
2016\end{array}$ \\
\hline I55a & $\begin{array}{l}\text { Diaspora think- } \\
\text { thank }\end{array}$ & Male & Education & 2001 & $\begin{array}{l}\text { Dusseldorf, } \\
\text { November } 2016\end{array}$ \\
\hline $\mathrm{I} 55 \mathrm{~b}$ & $\begin{array}{l}\text { Diaspora think- } \\
\text { thank }\end{array}$ & Female & $\begin{array}{l}\text { Second } \\
\text { generation }\end{array}$ & n.a. & $\begin{array}{l}\text { Dusseldorf, } \\
\text { November } 2016\end{array}$ \\
\hline I56 & $\begin{array}{l}\text { Humanitarian } \\
\text { organisation, round } \\
3\end{array}$ & Male & $\begin{array}{l}\text { Second } \\
\text { generation }\end{array}$ & n.a. & $\begin{array}{l}\text { Skype, } \\
\text { November } 2016\end{array}$ \\
\hline I57 & $\begin{array}{l}\text { Diaspora network, } \\
\text { round } 2\end{array}$ & Male & n.a. & n.a. & $\begin{array}{l}\text { Berlin, } \\
\text { November } 2016\end{array}$ \\
\hline I58 & $\begin{array}{l}\text { Diaspora network, } \\
\text { round } 2\end{array}$ & Male & $\begin{array}{l}\text { Second } \\
\text { generation }\end{array}$ & n.a. & $\begin{array}{l}\text { Berlin, } \\
\text { November } 2016\end{array}$ \\
\hline
\end{tabular}




\begin{tabular}{|c|c|c|c|c|c|}
\hline Code & $\begin{array}{l}\text { Type of } \\
\text { Engagement }\end{array}$ & Gender & $\begin{array}{l}\text { Reasons for } \\
\text { migration }\end{array}$ & $\begin{array}{l}\text { Year of } \\
\text { arrival }\end{array}$ & $\begin{array}{l}\text { Interview Place } \\
\text { and Date }\end{array}$ \\
\hline I59a & $\begin{array}{l}\text { Civil society activist, } \\
\text { round } 2\end{array}$ & Male & $\begin{array}{l}\text { Political } \\
\text { persecution }\end{array}$ & 2011 & $\begin{array}{l}\text { Berlin, } \\
\text { November } 2016\end{array}$ \\
\hline $\mathrm{I} 59 \mathrm{~b}$ & $\begin{array}{l}\text { Civil society } \\
\text { organisation }\end{array}$ & Male & $\begin{array}{l}\text { Political } \\
\text { persecution }\end{array}$ & 2014 & $\begin{array}{l}\text { Berlin, } \\
\text { November } 2016\end{array}$ \\
\hline $\mathrm{I} 60$ & $\begin{array}{l}\text { Human rights } \\
\text { lawyer and gender } \\
\text { activist, round } 2\end{array}$ & Female & $\begin{array}{l}\text { Political } \\
\text { persecution }\end{array}$ & 2013 & $\begin{array}{l}\text { Berlin, } \\
\text { November } 2016\end{array}$ \\
\hline I61 & $\begin{array}{l}\text { Humanitarian } \\
\text { organisation }\end{array}$ & Male & Education & 2000 & $\begin{array}{l}\text { Berlin, } \\
\text { November } 2016\end{array}$ \\
\hline $\mathrm{I} 62$ & $\begin{array}{l}\text { Humanitarian } \\
\text { organisation }\end{array}$ & Male & Education & 1987 & $\begin{array}{l}\text { Berlin, } \\
\text { November } 2016\end{array}$ \\
\hline I63 & $\begin{array}{l}\text { Peace activist, round } \\
2\end{array}$ & Male & Education & 2011 & $\begin{array}{l}\text { Berlin, } \\
\text { November } 2016\end{array}$ \\
\hline $\mathrm{I} 64$ & $\begin{array}{l}\text { Civil society } \\
\text { organisation, round } \\
2\end{array}$ & Male & Education & 1990 & $\begin{array}{l}\text { Phone, } \\
\text { November } 2016\end{array}$ \\
\hline $\mathrm{I} 65$ & $\begin{array}{l}\text { Development } \\
\text { organisation, round } \\
2\end{array}$ & Male & $\begin{array}{l}\text { Political } \\
\text { persecution }\end{array}$ & 2012 & $\begin{array}{l}\text { Leipzig, } \\
\text { November } 2016\end{array}$ \\
\hline I66 & $\begin{array}{l}\text { Cultural-social } \\
\text { organisation }\end{array}$ & Male & $\begin{array}{l}\text { Political } \\
\text { persecution }\end{array}$ & 1994 & $\begin{array}{l}\text { Löhne, } \\
\text { November } 2016\end{array}$ \\
\hline I67 & $\begin{array}{l}\text { Humanitarian } \\
\text { organisation }\end{array}$ & Male & Education & 1991 & $\begin{array}{l}\text { Darmstadt, } \\
\text { November2016 }\end{array}$ \\
\hline I68 & $\begin{array}{l}\text { Cultural-social } \\
\text { organisation }\end{array}$ & Male & $\begin{array}{l}\text { Political } \\
\text { persecution }\end{array}$ & 1978 & $\begin{array}{l}\text { Frankfurt, } \\
\text { November } 2016\end{array}$ \\
\hline I69 & $\begin{array}{l}\text { Humanitarian } \\
\text { organisation }\end{array}$ & Male & $\begin{array}{l}\text { Political } \\
\text { persecution }\end{array}$ & 1976 & $\begin{array}{l}\text { Phone, } \\
\text { November } 2016\end{array}$ \\
\hline I70 & $\begin{array}{l}\text { Humanitarian } \\
\text { organisation }\end{array}$ & Male & Education & 1975 & $\begin{array}{l}\text { Phone, } \\
\text { November } 2016\end{array}$ \\
\hline I71 & $\begin{array}{l}\text { Civil society } \\
\text { organisation, round } \\
2\end{array}$ & Male & $\begin{array}{l}\text { Political } \\
\text { persecution }\end{array}$ & 2013 & $\begin{array}{l}\text { Hannover, } \\
\text { December } 2016\end{array}$ \\
\hline I72 & $\begin{array}{l}\text { Diaspora network, } \\
\text { round } 3\end{array}$ & Male & $\begin{array}{l}\text { Second } \\
\text { generation }\end{array}$ & n.a. & Berlin, June 2017 \\
\hline
\end{tabular}




\begin{tabular}{|c|c|c|c|c|c|}
\hline Code & $\begin{array}{l}\text { Type of } \\
\text { Engagement }\end{array}$ & Gender & $\begin{array}{l}\text { Reasons for } \\
\text { migration }\end{array}$ & $\begin{array}{l}\text { Year of } \\
\text { arrival }\end{array}$ & $\begin{array}{l}\text { Interview Place } \\
\text { and Date }\end{array}$ \\
\hline I73 & $\begin{array}{l}\text { Musician and } \\
\text { political activist, } \\
\text { round } 2\end{array}$ & Male & $\begin{array}{l}\text { Political } \\
\text { persecution }\end{array}$ & 2014 & Berlin, June 2017 \\
\hline $\mathrm{I} 74$ & $\begin{array}{l}\text { Human rights } \\
\text { lawyer and gender } \\
\text { activist, round } 3\end{array}$ & Female & $\begin{array}{l}\text { Political } \\
\text { persecution }\end{array}$ & 2013 & Berlin, June 2017 \\
\hline $\mathrm{I} 75$ & $\begin{array}{l}\text { Cultural and } \\
\text { political activist, } \\
\text { round } 2\end{array}$ & Male & $\begin{array}{l}\text { Political } \\
\text { persecution }\end{array}$ & 2014 & $\begin{array}{l}\text { Cologne, June } \\
2017\end{array}$ \\
\hline I76 & $\begin{array}{l}\text { Civil society } \\
\text { organisation }\end{array}$ & Female & $\begin{array}{l}\text { Political } \\
\text { persecution }\end{array}$ & 2015 & Berlin June 2017 \\
\hline I77 & $\begin{array}{l}\text { Civil society } \\
\text { organisation }\end{array}$ & Male & $\begin{array}{l}\text { Political } \\
\text { persecution }\end{array}$ & 2013 & Skype, June 2017 \\
\hline $\mathrm{I} 78$ & Gender activist & Female & $\begin{array}{l}\text { Political } \\
\text { persecution }\end{array}$ & 2016 & Berlin, June 2017 \\
\hline I79 & Political activist & Male & $\begin{array}{l}\text { Political } \\
\text { persecution }\end{array}$ & 2013 & Berlin, June 2017 \\
\hline $\mathrm{I} 80$ & Political activist & Male & $\begin{array}{l}\text { Political } \\
\text { persecution }\end{array}$ & 2014 & $\begin{array}{l}\text { Cologne, July } \\
2017\end{array}$ \\
\hline
\end{tabular}




\section{Appendix IV: List of selected participant observations}

\begin{tabular}{|c|c|c|c|}
\hline Event & Short description & Location & Date \\
\hline $\begin{array}{l}\text { Founding meeting of } \\
\text { the VDSH (Verband } \\
\text { Deutsch-Syrischer } \\
\text { Hilfsvereine) }\end{array}$ & $\begin{array}{l}\text { Meeting of different Syrian } \\
\text { diaspora organisations in } \\
\text { Germany to discuss the } \\
\text { establishment of an umbrella } \\
\text { organisation. The association } \\
\text { pursues the goals of providing } \\
\text { help for politically, racially and } \\
\text { religiously persecuted people, } \\
\text { refugees and victims of war and } \\
\text { of promoting development } \\
\text { cooperation and international } \\
\text { understanding. }\end{array}$ & Berlin & 14-Dec-13 \\
\hline $\begin{array}{l}\text { Protest in Memory on } \\
\text { poison gas attack in } \\
\text { Ghouta }\end{array}$ & $\begin{array}{l}\text { Protest organised in memory of } \\
\text { the poison gas attacks in Ghouta } \\
2013 \text { which killed around } 1.500 \\
\text { people and is perceived as one of } \\
\text { the most catastrophic events in } \\
\text { the Syrian conflicts. The } \\
\text { demonstrators came from Aachen, } \\
\text { Dortmund and other cities in } \\
\text { North Rheine Westphalia to show } \\
\text { their solidarity with the Syrian } \\
\text { people. }\end{array}$ & Cologne & 23-Aug-15 \\
\hline $\begin{array}{l}\text { Solidarity event for } \\
\text { the 5th anniversary of } \\
\text { the Syrian Revolution } \\
\text { in Germany }\end{array}$ & $\begin{array}{l}\text { The event was organised by a } \\
\text { Syrian diaspora organisation to } \\
\text { raise awareness on the } \\
\text { revolution's 5th year anniversary } \\
\text { and to show solidarity with the } \\
\text { Syrian people from abroad }\end{array}$ & Hamburg & 19-Mar-16 \\
\hline $\begin{array}{l}\text { Panel discussion: } \\
\text { Traces from Syria - } \\
\text { literature, culture, } \\
\text { politics and society }\end{array}$ & $\begin{array}{l}\text { Organised by the Syrian artist and } \\
\text { a Syrian journalist in cooperation } \\
\text { with the municipality, the event } \\
\text { aimed at shedding light on the } \\
\text { Syrian conflict and its } \\
\text { developments as well as on the }\end{array}$ & Aachen & 14-Apr-16 \\
\hline
\end{tabular}




\begin{tabular}{|c|c|c|c|}
\hline Event & Short description & Location & Date \\
\hline & $\begin{array}{l}\text { Syrian refugees who are seeking } \\
\text { protection in Germany. }\end{array}$ & & \\
\hline $\begin{array}{l}\text { Movie Streaming } \\
\text { Melody's escape }\end{array}$ & $\begin{array}{l}\text { The movie pictured the stories of } \\
\text { musicians who had to flee Syria } \\
\text { often taking the Balkan route or } \\
\text { the Mediterranean Sea towards } \\
\text { Germany and who ended up in } \\
\text { Berlin continuing with spreading } \\
\text { their music but also the protests of } \\
\text { the revolution. It is also a story } \\
\text { about the potential of music and } \\
\text { arts to connect people from } \\
\text { diverse backgrounds creating a } \\
\text { vibrant mixture of cultures and } \\
\text { innovative forms of music }\end{array}$ & Berlin & $24-A p r-16$ \\
\hline $\begin{array}{l}\text { Aleppo is Burning } \\
\text { Protests }\end{array}$ & $\begin{array}{l}\text { Protest organised by Syrian } \\
\text { activists protests to raise } \\
\text { awareness on the destruction of } \\
\text { the city of Aleppo and the killings } \\
\text { and suffering of the civilians and } \\
\text { to hold the international } \\
\text { community accountable for its } \\
\text { silence and inaction. }\end{array}$ & Berlin & 02-May-16 \\
\hline $\begin{array}{l}\text { Exhibition "Syria, Art } \\
\text { and Flight" }\end{array}$ & $\begin{array}{l}\text { Organised by a Syrian activists, to } \\
\text { exhibit Syrian artwork by artists } \\
\text { who have been displaced by the } \\
\text { conflict. }\end{array}$ & Cologne & 05-May-16 \\
\hline
\end{tabular}




\begin{tabular}{|c|c|c|c|}
\hline Event & Short description & Location & Date \\
\hline $\begin{array}{l}\text { DEMAC } \\
\text { Humanitarian } \\
\text { Workshop Series }\end{array}$ & $\begin{array}{l}\text { Hosted by Berghof foundation, } \\
\text { the workshop discussed } \\
\text { challenges and opportunities } \\
\text { related to humanitarian access in } \\
\text { crisis and conflict environments. } \\
\text { Presentations from UN agencies, } \\
\text { international NGOs and diaspora } \\
\text { organisations dealt with ways and } \\
\text { tools of security management, } \\
\text { dialogue/negotiations with actors } \\
\text { to the conflicts, accountability, } \\
\text { and the formation of sustainable } \\
\text { partnerships in high-risk } \\
\text { environments among others. }\end{array}$ & Berlin & 2-4 Jun-16 \\
\hline $\begin{array}{l}\text { GIZ Event: Small } \\
\text { associations big } \\
\text { impact }\end{array}$ & $\begin{array}{l}\text { Organised by GIZ, the event } \\
\text { brought together representatives } \\
\text { of ministries and of major German } \\
\text { aid organisations, as well as } \\
\text { Syrian diaspora organisations to } \\
\text { discuss the opportunities and } \\
\text { challenges related to their } \\
\text { engagement }\end{array}$ & Berlin & 15-Jul-16 \\
\hline $\begin{array}{l}\text { Syrian diaspora } \\
\text { business Forum }\end{array}$ & $\begin{array}{l}\text { Event hosted by the World Bank } \\
\text { in cooperation with CMI and } \\
\text { other development partners, } \\
\text { convened more than } 100 \text { regional } \\
\text { and global stakeholders that } \\
\text { represent Syrian diaspora } \\
\text { community, policy makers, } \\
\text { academic experts, businesspeople } \\
\text { and representatives of NGOs and } \\
\text { think tanks. }\end{array}$ & Eschborn & $\begin{array}{l}27-28 \mathrm{Feb}- \\
17\end{array}$ \\
\hline $\begin{array}{l}\text { Festival "Literature } \\
\text { from Syria - } \\
\text { Encounters in a new } \\
\text { society" }\end{array}$ & $\begin{array}{l}\text { Organised by Syrian activists to } \\
\text { to offer Syrian writers living in the } \\
\text { diaspora the opportunity to } \\
\text { present themselves and their } \\
\text { works, to get in touch with other }\end{array}$ & Cologne & 8- 9 Apr-17 \\
\hline
\end{tabular}




\begin{tabular}{|c|c|c|c|}
\hline Event & Short description & Location & Date \\
\hline & writers and to form networks. & & \\
\hline $\begin{array}{l}\text { The Role of Diaspora } \\
\text { organisations in } \\
\text { supporting durable } \\
\text { solutions for Syrians } \\
\text { displaced' conference }\end{array}$ & $\begin{array}{l}\text { Organised by the Danish Refugee } \\
\text { Council's Diaspora Programme } \\
\text { (DRC) and the Durable Solutions } \\
\text { Platform (DSP), the conference } \\
\text { brought together representatives } \\
\text { of diaspora organisations in } \\
\text { Europe, humanitarian and } \\
\text { development practitioners, as well } \\
\text { as a government representative to } \\
\text { discuss durable solutions to } \\
\text { Syrian displacement. }\end{array}$ & Berlin & 04-Nov-17 \\
\hline $\begin{array}{l}\text { Sounding Board } \\
\text { Meeting for Syrian } \\
\text { Leadership } \\
\text { Programme in QICS }\end{array}$ & $\begin{array}{l}\text { The informal meeting was } \\
\text { organised by GIZ, to discuss their } \\
\text { programming }\end{array}$ & Berlin & 30-Jan-18 \\
\hline $\begin{array}{l}\text { The Syrian Diaspora } \\
\text { in the Aftermath of } \\
2011\end{array}$ & $\begin{array}{l}\text { Organised by the Arab Reform } \\
\text { Initiative in collaboration with the } \\
\text { Chair of History of the } \\
\text { Contemporary Arab World at } \\
\text { College de France, the workshop } \\
\text { brought together researchers from } \\
\text { various backgrounds, who } \\
\text { presented the outcomes of field- } \\
\text { informed studies on the economic } \\
\text { and social dynamics of the Syrian } \\
\text { diaspora in different host country } \\
\text { contexts. }\end{array}$ & Paris & 12-Apr-18 \\
\hline
\end{tabular}




\section{About the Author}

Nora Jasmin Ragab holds a master's degree in Public Policy and Human Development, with a specialisation in Migration Studies, from the Maastricht Graduate School of Governance of UNU-MERIT. Prior to that, she obtained a B.Sc. in Business, Economics and Social Sciences from Vienna University of Economics and Business in Austria.

Since joining UNU-MERIT, she has gained extensive teaching experiences at Bachelor and Master level and supervised numerous Master theses. She has conducted studies on Syrian, Palestinian, Jordanian and Tunisian diaspora mobilisation in various locations such as Germany, Europe and West Asia, investigating how social and political transformations in the country of origin, as well as factors and developments in destinations countries influence transnational mobilisation of diaspora actors.

Beside this research experience, Nora works as a freelance transcultural consultant, focusing on the development of methods and concepts to promote selforganisation, political and social participation as well as empowerment of migrant and refugee communities in Germany. Currently, Nora is a Post-Doctoral Researcher at the Maastricht Graduate School of Governance of UNU-MERIT, focusing on diaspora mobilisation, conflicts, as well as socio-political dynamics of forced displacement, including civic and political participation of refugees and migrants in the destination country. 


\section{Valorisation}

The Global Compact on Refugees, together with the Global Compact for Safe, Orderly and Regular Migration (GCM) can be considered as important milestones in the history of global migration governance, for making important contributions to enhanced cooperation and dialogue on international migration. Both frameworks are based on a people-centred and whole-of-society approach, which represents two of the main guiding principles. Placing individuals at the core, the people-centred approach seeks to promote the well-being of migrants and the members of communities in countries of origin, transit and destination and, therefore, puts a strong emphasis on the human dimension inherent to the migration experience. As such, refugees, migrants and diaspora groups are not perceived only as objects of protection, but as important stakeholders in their own right, who should be included in key forum and decision-making processes.

Increasingly, the development potential of diaspora groups is being recognised, and diverse actors ranging from government institutions to international organisations and other civil society actors develop and implement policies in order to promote the participation of diaspora actors in development processes. For instance, objective number 19 of the GCM aims to create conditions for migrants and diaspora groups to fully contribute to sustainable development in all countries. Recognising that migration is of relevance to the sustainable development of countries of origin, transit and destination, the objective is to empower migrants and diaspora groups to catalyse their development contributions in different spheres and contexts. This objective stresses the importance of research to investigate the impact of non-financial contributions of migrants and diaspora groups, including social and civic engagement, to develop evidence-based policies and to strengthen global policy discussions. Attention is also given to the promotion of political participation and engagement of migrants in their countries of origin, including in peace and reconciliation processes, in elections and political reforms.

As such, the findings of this dissertation yield a range of practical considerations relevant to policymakers and stakeholders who seek to engage with diaspora actors. From a scientific point of view, the objective of this dissertation is to unpack the diverse processes and mechanisms that shaped the emergence and trajectories of Syrian diaspora mobilisation in Germany over the course of the Syrian conflict. In doing so, this study contributed to a gap in research, as it sheds light on the temporal dimensions of the mobilisation process. In addition, by laying the emphasis on the opportunity structures both in the country of origin as well as in the destination country, the study explored the relational space of mobilisation, in 
which sending and receiving country dynamics intersect and mutually affect each other, as well as the strategic choices of diaspora political entrepreneurs made in response to them. The research highlights that diasporic actors are not passive prisoners of the transnational political opportunity structures, but individually and collectively negotiate the opportunities and constraints present in the transnational space. The dissertation therefore highlights the co-constitutive nature of diaspora mobilisation, through which diaspora groups and conflicts co-construct each other.

The findings of the dissertation suggest that a conflict- and context-sensitive approach in engaging with diaspora groups requires an awareness of the potential risks and limitations as well as of the socio-political dynamics present in the process of diaspora mobilisation. This includes not only a sophisticated understanding of the conflict dynamics, including knowledge about the different actors (local and transnational), but also an investment of time and the creation of a space for trust and confidence building. An inclusive approach, with participation of diaspora groups with diverse backgrounds and interests can encourage dialogue between the different fractions, which is an important step towards societal reconciliation and a peaceful solution of the conflict within the diaspora. On the other hand, underlying conflict lines might hamper effective and constructive programme implementation and may, in the worst case, contribute to further entrenchment of societal divisions among diaspora groups.

Projects, in which different groups and members of the Syrian diaspora are involved, need to create a space for reflecting on strategies and joint future actions (rather than reactions), to generate sustainable impacts. This also means that stakeholders should not search for a unified voice and representation among Syrian diaspora actors but rather create a space for discussion and debates, in which diversity (instead of uniformity) leads to future ways of cooperation and action. A participatory approach should also recognise the political nature of diaspora mobilisation and provide a space for contestation and debate. The level of politicisation is commonly a key concern for policymakers when cooperating with diaspora groups in conflict settings, since a potential lack in compliance with the humanitarian principles of humanity, neutrality, and impartiality can undermine the fundamental foundations for peacebuilding, development cooperation, and humanitarian action. However, this study has shown that politicised collective identities are a crucial driver of diaspora mobilisation and that a plurality of positions, aspirations and interests is not necessarily something negative, but that if constructively approached, can lead to social change and transformation.

In principle, legal frameworks should be created that guarantee the right to political participation and representation of diaspora groups both in the contexts of 
origin and destination. Programmes and policies promoting engagement with diaspora groups, should further create opportunities for 'real' participation, by enabling diaspora actors to (co-)determine and influence decision-making processes. Numerous measures that consider themselves as participatory, in reality tend to be deliberative in nature, since they do not offer any possibility of influencing decision-making processes. In some cases, actors may even instrumentalise diaspora groups for their own interest, and as a result, participation becomes pure decoration. Because participation in a 'real' sense grants target groups a formal, binding role in the decision-making process. For stakeholders this would demand that they allow for co-determination and at least a partial transfer of the decision-making authority.

Throughout the years of my doctoral research, various occasions arose which gave me the opportunity to share these important points with a larger and non-scientific audience. The research findings of this dissertation have been disseminated to the academic community as well as to policymakers on various occasions. I presented papers based on the different chapters of this dissertation at academic conferences, including the International Studies Association 60th Annual Convention in Toronto (2019), the "Democratizing Displacement" conference of the Refugee Studies Centre of the University of Oxford (2019), the "Path of resistance in the Middle East and North Africa" 14th SeSaMO Conference of the University of Turin (2019) and the "Dislocations and Cultural Conflicts: Migrations, Diaspora, Terrorism, Borders" conference of the Centre for Culture and Cultural Studies, Skopje (2016).

In addition, during my research journey, several opportunities for cooperation and dialogue with policymakers and other stakeholders arose, which enabled the dissemination of findings to a broader non-scientific audience. These contributions include inputs given at the "Sounding Board Meeting for Syrian Leadership Program in QICS" organised by GIZ, which discussed the role of Syrian diaspora groups in strengthening local leadership in Syria. Further, I presented findings of this dissertation at the GIZ Expert Forum "Return and Reintegration in the Migration Context", hosted by GIZ in Eschborn (2017), at the "Syrian diaspora business Forum" hosted by the World Bank group, GIZ, IOM and CMI in Eschborn, Germany (2017), as well as at the "Federal Conference on Local Development Cooperation" hosted by the Service Agency Communities in One World (2018). The dialogue event on the UN Global Compact for Migration (GCM) and the UN Global Compact on Refugees (GCR) hosted by the Bertelsmann Foundation and the Robert Bosch Foundation in Berlin in 2018, provided me with the opportunity to share some insights of this dissertation not only with high-level policymakers, but also with migrant and refugee-led civil society actors in 
Germany. In addition, continuous cooperation with policymakers and other stakeholders, including the German development cooperation (GIZ), the Danish Refugee Council and the Swiss Development Cooperation, enabled me to develop evidence-based policy recommendations to inform their programming of diaspora engagement strategies.

The findings of this research are not only relevant to actors who seek to engage with Syrian diaspora groups, but also to the Syrian diaspora civil society itself. Given the focus on the socio-political dynamics of diaspora mobilisation, the dissertation investigates the processes of how fragmentations and divides emerge and unfold, what their nature is and how they are contested and performed by the various diaspora actors. Understanding the process and nature of fragmentations may help to transform diaspora struggles into a constructive way of dealing with diversity, which would enable diaspora groups to create common spaces, based on a collective and coordinated vision. A joint action by the diaspora civil society and a strong collective voice can lead to the advancement of political goals and thus promote empowerment through solidarity. The findings of the dissertation suggest that it is crucial to support the creation of online and offline platforms and spaces to ensure sustainable and effective interaction and exchange among different stakeholders involved in the Syrian issue.

Hence, another extremely important societal achievement of my research was to engage actively not only with political actors and the public, but also with Syrian diaspora groups themselves as well as with other migrant organisations. As part of the two research projects on Syrian diaspora mobilisation commissioned by the Danish Refugee Council, I participated in two conferences to share my findings and recommendations with Syrian civil society actors and other stakeholders based in different countries across Europe and the United States as well as from Turkey, Lebanon, Jordan and Syria. These events presented important spaces for mutual exchange and knowledge-sharing on the topic of Syrian diaspora mobilisation. By discussing lessons learnt, challenges and best practices in supporting the Syrian civil society, the conferences provided a space for Syrian-led organisations to reflect on future scenarios, joint strategies and plans for collective action rather than reactions. In addition, the discussions on the findings and recommendations of the studies offered a crucial opportunity for dialogue between researchers and diaspora actors and not only generated further insights and knowledge but also provided a space for the validation of my research results. 